\title{
Self-management support for outpatients with cancer pain
}

Citation for published version (APA):

Hochstenbach, L. M. J. (2017). Self-management support for outpatients with cancer pain: development, feasibility and impact of an eHealth intervention. [Doctoral Thesis, Maastricht University]. Datawyse / Universitaire Pers Maastricht. https://doi.org/10.26481/dis.20170630lh

Document status and date:

Published: 01/01/2017

DOI:

10.26481/dis.20170630lh

Document Version:

Publisher's PDF, also known as Version of record

\section{Please check the document version of this publication:}

- A submitted manuscript is the version of the article upon submission and before peer-review. There can be important differences between the submitted version and the official published version of record.

People interested in the research are advised to contact the author for the final version of the publication, or visit the DOI to the publisher's website.

- The final author version and the galley proof are versions of the publication after peer review.

- The final published version features the final layout of the paper including the volume, issue and page numbers.

Link to publication

\footnotetext{
General rights rights.

- You may freely distribute the URL identifying the publication in the public portal. please follow below link for the End User Agreement:

www.umlib.nl/taverne-license

Take down policy

If you believe that this document breaches copyright please contact us at:

repository@maastrichtuniversity.nl

providing details and we will investigate your claim.
}

Copyright and moral rights for the publications made accessible in the public portal are retained by the authors and/or other copyright owners and it is a condition of accessing publications that users recognise and abide by the legal requirements associated with these

- Users may download and print one copy of any publication from the public portal for the purpose of private study or research.

- You may not further distribute the material or use it for any profit-making activity or commercial gain

If the publication is distributed under the terms of Article $25 \mathrm{fa}$ of the Dutch Copyright Act, indicated by the "Taverne" license above, 
The research presented in this thesis was conducted at CAPHRI Care and Public Health Research Institute, Department of Health Services Research, of Maastricht University. CAPHRI participates in the Netherlands School of Primary Care Research CaRe. This research was funded by the Dutch Cancer Society (UM2011-5079).

The two companies involved in the development of the eHealth intervention were:

IDEE Maastricht UMC+

Universiteitssingel 50, 6229 ER Maastricht, the Netherlands

www.idee-mumc.nl

\title{
Sananet Care
}

Rijksweg Zuid 37, 6131 AL Sittard, the Netherlands

www.sananet.nl

\author{
Lay-out: Tiny Wouters \\ Cover: Gaston Vogel \\ Printing: Datawyse, Maastricht \\ ISBN: $\quad$ 978-94-6159-714-4 \\ (c) Laura Hochstenbach, Maastricht 2017
}

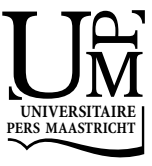

All rights reserved. No part of this thesis may be reproduced or transmitted in any form or by any means, electronic or mechanical, including photocopying, recording or any information storage or retrieval system, without prior permission in writing by the author, or when appropriate, by the publishers of the publication. 


\title{
Self-management support for outpatients with cancer pain
}

\author{
Development, feasibility, and impact \\ of an eHealth intervention
}

\begin{abstract}
PROEFSCHRIFT
ter verkrijging van de graad van doctor aan de Universiteit Maastricht, op gezag van de Rector Magnificus, Prof. dr. Rianne M. Letschert volgens het besluit van het College van Decanen, in het openbaar te verdedigen op vrijdag 30 juni 2017 om 12.00 uur

door
\end{abstract}

Laura Maria Josephina Hochstenbach 


\section{Promotor}

Prof. dr. L.P. de Witte

\section{Copromotores}

Dr. S.M.G. Zwakhalen

Dr. M.H.J. van den Beuken - van Everdingen

\section{Beoordelingscommissie}

Prof. dr. G.D.E.M. van der Weijden (voorzitter)

Prof. dr. L.J. Boersma

Dr. W.H. Oldenmenger (Erasmus MC Rotterdam)

Prof. dr. S. Mawson (Sheffield University, United Kingdom)

Prof. dr. D. Ruwaard 


\section{Contents}

Chapter $1 \quad$ General introduction 7

Chapter $2 \quad$ Update on prevalence of pain in patients with cancer: 23

systematic review and meta-analysis

Chapter 3 Co-creative development of an eHealth nursing intervention:

69

self-management support for outpatients with cancer pain

Chapter $4 \quad$ Feasibility of a mobile and web-based intervention to support

self-management in outpatients with cancer pain

Chapter 5 Self-management support intervention to control cancer pain in

in the outpatient setting: a randomised controlled trial study

protocol

Chapter 6 Impact evaluation of an eHealth intervention to support

self-management in outpatients with cancer pain

Chapter $7 \quad$ General discussion

Summary

Samenvatting

171

Valorisation

177

Dankwoord

About the author

List of publications 



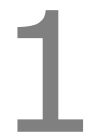

General introduction 

"Ineke, aged 62 years, is married and has three children. She was diagnosed with breast cancer two years ago for which she was treated with surgery, chemotherapy and adjuvant radiotherapy. Now she receives hormone therapy. Recently, during an outpatient consultation, she indicated to experience an increase in pain. She talked about pain in her rib bow that got worse while breathing. Based on extensive additional diagnostics, bone and liver metastasis were found. I suggested to start with second line chemotherapy and radiotherapy. I also prescribed low dose, long and short acting opioids." Obviously, Ineke was shocked about the bad news. The palliative care team was contacted and a nurse consultant visited Ineke at home.

Perspective of the oncologist

\section{Cancer pain}

\section{Cancer}

The incidence of cancer is on the rise. Recent figures of the Dutch cancer registry show 108,400 new cases of cancer in 2016 (Figure 1.1)[1,2]. Due to advancements in early detection and more effective treatments, the chances of survival are increasing as well. As a consequence of these more effective and more invasive treatments, patients experience adverse side effects that have an enormous impact on daily functioning and quality of life [3]. Side effects can be physical (e.g. hair loss), psychological (e.g. anxiety) or social (e.g. inability to work). In addition, these effects can be characterised as short-term effects that often disappear after treatment (e.g. nausea), long-term effects that are persistent (e.g. fatigue), or late effects that occur months or even years after the end of treatment (e.g. heart disease) [4-6]. The assessment and management of these symptoms receive more and more attention.

\section{Pain}

Cancer is associated with pain and for many patients an important source of concern. Although not all patients necessarily experience pain, pain is frequently reported. Pain prevalence rates are $39.3 \%$ after curative treatment; $55.0 \%$ during anti-cancer treatment; and $66.4 \%$ in advanced disease. Of all patients $38.0 \%$ reports moderate to severe pain [7]. Cancer pain is classified as nociceptive or neuropathic pain. Nociceptive pain is caused by tissue damage. Neuropathic pain results from damage to the peripheral or central nervous system. Pain is nociceptive in $50 \%$, neuropathic in less than $10 \%$, and both nociceptive and neuropathic in $40-50 \%$ of patients with cancer [8]. Pain is caused by direct growth of the tumour or metastases $(70 \%)$, by treatment $(20 \%)$ or by other factors $(10 \%)$ [8]. About one-third of patients in pain experience pain at a single site, one-third at two sites, and one-third at three or more 
sites [9]. Cancer pain is characterised by variations in pain intensity. Patients usually experience a continuous and average level of pain that is alternated with breakthrough pain, both spontaneously, unrelated to anything, and predictably related to moving, washing, or wound care [10].

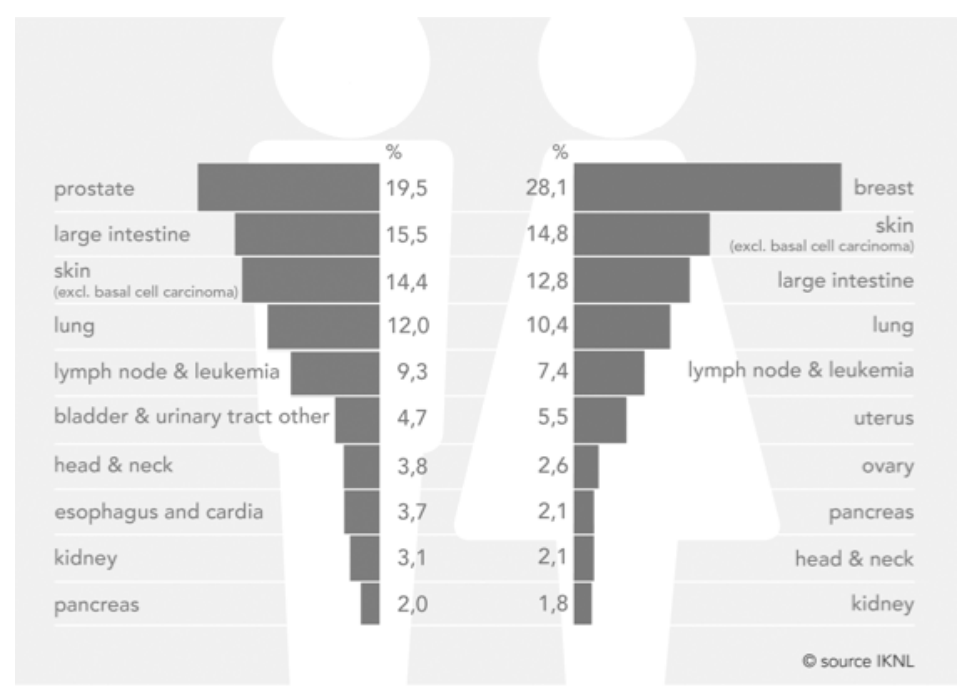

Figure 1.1 Most common cancer localisations in 2016 [1]

\section{Care as usual for patients with cancer pain}

\section{Concept of pain}

The International Association for the Study of Pain (IASP) defines pain as 'an unpleasant sensory and emotional experience associated with actual or potential damage, or described in terms of such damage' [11]. 'Pain is what the person experiencing it says that it is, and is present when he says that it is present' is a more pragmatic definition [12]. In this regard pain is more than a physical disorder and emphasises the subjective experience of patients. Pain influences psychological and social functioning. Conversely, psychological and social functioning affect pain. In this context, the model of Loeser includes four dimensions of pain (Figure 1.2) [13]. Nociception relates to the tissue or nerve damage. Pain corresponds to the perception or the sensation of pain. Suffering concerns the unpleasant emotional response. Pain behaviour occurs in the social context. In line with this model, the model of Saunders 
differentiates between four dimensions of pain (Figure 1.3) [14]. Physically, the cancer or its treatment causes pain. Psychologically, pain is the result of feelings of frustration, anxiety, and hopelessness. Socially, losing work, family, societal, and social roles generates pain. Spiritually, pain is due to not finding meaning and fear for the unknown. All these dimensions influence one another and together constitute the 'total pain' as experienced by patients. In the end, the most important question is what pain means to the individual patient. Obviously, thorough pain assessment is crucial in determining the appropriate diagnosis and formulating a proper treatment plan.

\section{Assessment of pain}

A differentiation is made between unidimensional and multidimensional pain assessments [15]. A unidimensional pain assessment focuses only on pain severity [16]. Pain severity is the primary factor determining the impact of pain on the patient and the urgency of the treatment process. Simple pain scales, like a numerical rating scale (NRS), a Visual Analogue Scale (VAS) or a Verbal Rating Scale (VRS), make it possible to assess pain on each outpatient consultation [17]. Patients, for instance, can score their pain on an NRS 0-10, 0 indicating no pain and 10 representing the worst pain imaginable. Although general consensus about specific cut-off points is lacking, mild (NRS 1-3), moderate (NRS 4-6) and severe (NRS 7-10) pain are often discriminated [18]. A multidimensional pain assessment also takes other aspects into account in order to cover the full spectrum of the pain construct, including pain characteristics and pain impact [16]. Pain characteristics involves information about aspects of cancer pain other than its severity that will help refine treatment plans. Information needs to be gathered about pain location (areas of pain, pain during movement or position), temporal patterns of pain (continuous pain, breakthrough pain), pain quality (nociceptive pain, neuropathic pain) and pain history (response to prior treatment, patient beliefs, patient adherence). Pain impact measures the degree to which pain interferes with areas of the patient's life, and the degree to which other symptoms or problems interact with pain: quality of life, function, mood, social interaction, and concurrent symptoms. Body drawings, word lists, questionnaires and checklists are available and might help during the assessment of pain. A multidimensional pain assessment can be performed by additional questions, or the use of questionnaires, such as the Brief Pain Inventory (BPI) [19], the McGill Pain Questionnaire (MPQ) [20], or the Dutch national nurse pain assessment [21]. 


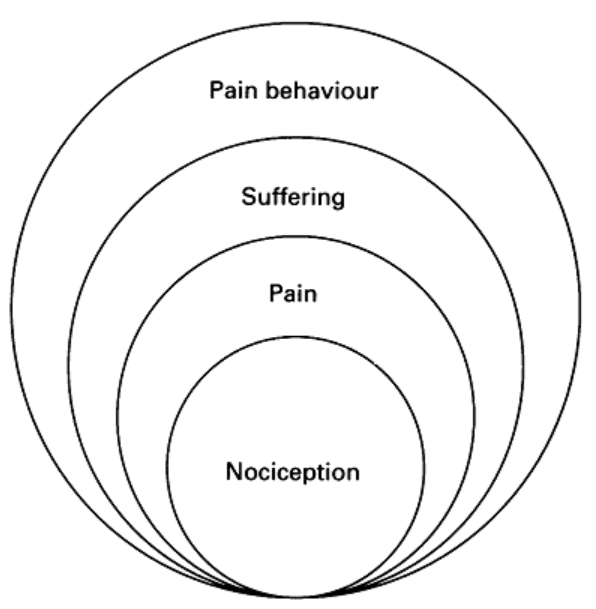

Figure 1.2 Model of Loeser [13]

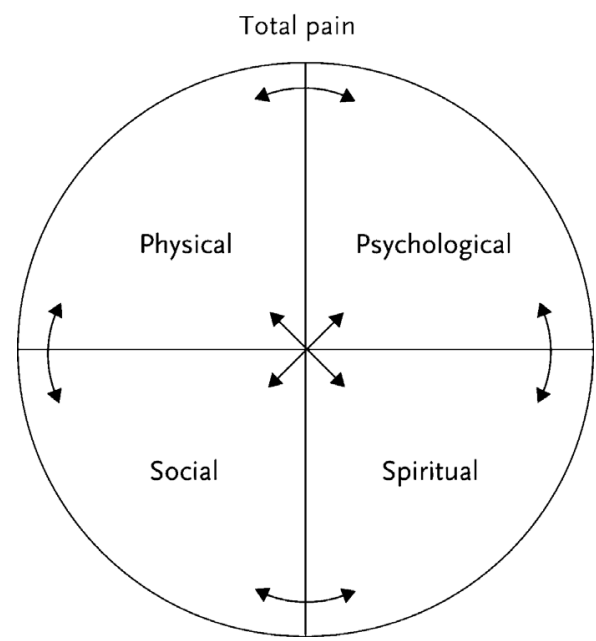

Figure 1.3 Model of Saunders [14]

\section{Treatment of pain}

Pain treatment aims to minimise pain to acceptable levels with minimal side effects [8]. Cancer pain can be controlled with pharmacological and non-pharmacological treatments. Pharmacological treatment is based on the WHO three step analgesic ladder that advises to control nociceptive pain with step 1 (paracetamol and nonsteroidal anti-inflammatory drugs), step 2 (weak opioids as tramadol), and step 3 (strong opioids as morphine and fentanyl) [22]. When opioids are prescribed, patients receive long-acting 'around the clock' medication for continuous and average pain and short-acting 'as needed' medication for breakthrough pain. Neuropathic pain often better responds to medication that is originally not indicated for pain such as antidepressants and anti-epileptics. Non-pharmacological treatment includes rest, heat and cold, massage, relaxation, exercises, and distraction. As a result of pain treatment, a pain reduction of $30 \%$ or a decrease with 2 on the NRS (0-10) is aimed for and considered clinically relevant [23]. Moreover, an NRS of 4 is regarded as the point from which pain significantly impacts daily functioning and guidelines require follow-up. According to national and international guidelines, adequate pain relief should be accomplished in $70-90 \%$ of patients with cancer $[8,22]$. At present though, adequate pain control is not being realised in $30 \%$ of the patients [24]. 
"The home visit was informative. Ineke revealed to experience continuous pain that sometimes got worse without reason. She admitted to take not all pain medication as prescribed, because all those pills can't be good. Ineke has sleeping difficulties; she appears to be anxious and worried about what is going to be next. Her husband added that the pain prevents her from going out and living her life. I provided Ineke with information about pain and the effect of pain medication. Some practical tips can help her to keep track of her pain, to take medication properly and to search for distraction and relaxation." The nurse shared these findings with the physician consultant palliative care and advised the oncologist about the follow-up.

Perspective of the nurse consultant

\section{Situation of outpatients with cancer pain at home}

\section{Barriers that prevent adequate pain control}

Inadequate cancer pain management in the outpatient setting can be attributed to barriers related to the organisation, the health professional and the patient. First, the organisation makes coordination and continuity of pain management challenging. Different health professionals in different healthcare settings are involved and close monitoring and follow-up of pain is difficult once patients are at home [25]. Second, the subjective experience of pain is difficult to measure objectively by health professionals [26]. Yet, pain is not structurally and thoroughly discussed and assessed during consultations [27], probably due to a lack of time, knowledge, and attention. Health professionals are careful to prescribe opioids and reluctant to refer patients to pain or palliative care services [28]. Third, patients struggle with misconceptions about analgesic use (e.g. fear of addiction, tolerance, and side effects), concerns about pain communication (e.g. keep the focus on disease cure, be a good patient, and present to others as strong and in control), and a belief that pain is inevitable and uncontrollable [29]. These misconceptions, concerns, and beliefs influence adherence and prevent patients from taking their pain medication as prescribed [30]. At the same time, outpatients face more practical day-to-day challenges at home, such as tailoring prescriptions to meet individual needs, coping with adverse effects, and managing new or unusual pain [31].

\section{Existing interventions}

Various valuable interventions have been developed and evaluated in order to improve pain control [32-36]. Interventions directed at patients commonly address knowledge by sharing information about pain, pain medication, side effects, alternative methods to control pain, and when to get help. Some of the interventions also target problem- 
solving skills by providing instructions on how to assess pain, how to take medication, how to manage side effects, how to apply alternative methods, and how to communicate with health professionals. Because interventions are diverse and did not achieve desired effects so far, questions remain about the optimal format as well as content and combination of intervention components $[37,38]$.

\section{Recommendations related to existing barriers}

Recommendations to overcome barriers include a multidisciplinary approach that promotes collaboration between different health professionals and ongoing assessment of pain with regular follow-up appointments [39]. Moreover, patient education as well as pain and medication diaries are suggested to ensure realistic expectations and appropriate medication use [40]. In order to address these recommendations, active patient involvement seems a prerequisite. Comparable to many prevalent chronic conditions, patients with cancer pain are more and more encouraged to contribute actively to their own pain management and practice self-management [41]. Patients themselves do want to be more active in pain management [42].

\section{Self-management}

\section{Concept of self-management}

Self-management is frequently defined as 'a person's ability to manage the symptoms and the consequences of living with a chronic condition, including treatment, physical, social, and lifestyle changes' [43]. Patients have to manage their chronic condition on a day-to-day basis. Therefore, it is not so much the question whether they perform self-management, but rather how they implement self-management [41]. Basically, patients have three self-management tasks: medical management, behavioural management; and emotional management [44]. To accomplish these tasks, patients need core self-management skills: problem solving, decision-making, resource utilisation, forming partnerships with health professionals, and taking action [45]. Self-management is similar to and different from concepts as self-care, selfmonitoring, symptom monitoring, and self-efficacy; concepts that are often used interchangeably (Figure 1.4)[46]. Self-care is a broad concept and refers to the individual responsibilities for healthy life style behaviour in general [47]. Selfmanagement has been conceptualised as a subset of self-care and focuses on managing the consequences of a chronic condition [43]. Self-monitoring, that includes the monitoring of physiologic parameters or symptoms, is related to improved selfmanagement and symptom management [48]. Symptom management extends 
beyond self-care and includes activities from health professionals too. Self-efficacy can mediate or moderate the other concepts [49].

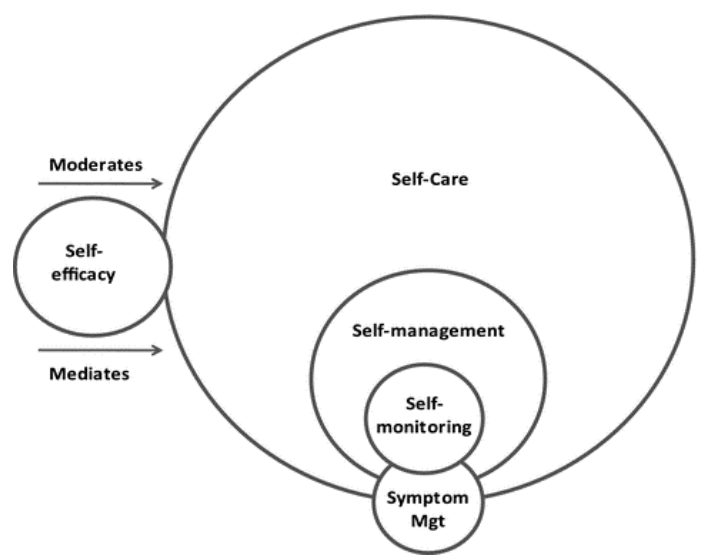

Figure 1.4 Delineation of self-management and related concepts [50]

\section{Self-management support}

Self-management challenges health professionals in a shift of focus away from clinical outcomes and towards providing help with the day-to-day problems of living with a chronic condition [50]. Self-management support has been defined as 'the systematic provision of education and supportive interventions by health professionals to increase patients' skills and confidence in managing their health problems, including regular assessment of progress and problems, goal setting, and problem-solving support [51]. Self-management education, focusing on the implementation of skills, results in more self-efficacy and improved clinical outcomes. In contrast, traditional patient education, referring to the provision of information, leads to behaviour change and improved clinical outcomes [40]. Supportive interventions become available more and more, also for patients with cancer during treatment, post-treatment, and end of life [41]. Self-management means something different to different patients and sometimes even something different at different times to the same patients $[52,53]$. For this reason, multi-component interventions are proposed. 
"Because I thought pain was inevitable and didn't want to complain, I doubted a long time before I admitted that my pain was unbearable. The pain took a lot of energy and I just didn't know what to do anymore. The home visit was nice and really appreciated. The nurse took the time and extensively asked questions about the pain, the way I took pain medication, the presence of side effects, and the impact of pain on my daily activities. By means of a graph, the nurse showed me how pain typically evolves and how medication needs to be adjusted to adequately control the pain. We also made a schedule with all pain medication that needs to be taken on fixed times. Now I better understand why; it all makes more sense." Hopefully pain relief will be adequate and Ineke will feel less anxious and worried.

Perspective of the patient

\section{eHealth for self-management support}

\section{Concept of eHealth}

eHealth is the use of new information- and communication technologies, particularly internet technologies, to support or improve health and healthcare [54,55]. This broad definition gives further room to classify eHealth into 1) when applications are used in the care process, including e-public health, e-care and e-care support; 2) whom makes use of these applications, such as patients or health professionals themselves, patients with health professionals, or health professionals with other health professionals; and 3) on which technologies these applications are based, for example portals, mobile applications, electronic patient health records, sensors and wearable devices [56]. eHealth provides an excellent means for complex self-management interventions, as it allows the integration of different self-management components that can be tailored to the individual patient and to the situation for which support is required. Moreover, eHealth is convenient in connecting patients at home with health professionals in care organisations [57]. By means of eHealth, the availability of accurate and timely data facilitates feedback and communication, which advances follow-up and accommodates subsequent consultations or referrals [58].

\section{Match between eHealth and patients}

For interventions in general and for eHealth interventions in particular, the match with patients is key [59]. All too often interventions are unsuccessful among others because patients were not or not enough involved. As a consequence, usability issues may occur and dropout rates may be considerable. Patients simply stop using eHealth applications that do not fit their daily lives, habits, or rituals: 'high tech, low impact' interventions [60]. Intervention development needs to focus on the patient, from 
acquiring input to evaluating output. As regards the input, insight is needed into 'a day in the life of' a patient. What does a day look like? How do symptoms and treatment influence daily activities? What health professionals are involved? What problems are faced? What goes well and what needs to be improved? With concern to the output, feedback is warranted for the intervention, it's usability, and feasibility in daily life. The same applies for the involvement of health professionals. Principles of user centred design give direction to do so: a multidisciplinary development team; an iterative and incremental process; involvement of health professionals and patients; an early and continuous focus on context, tasks, goals and needs; easy-to-understand language and prototypes; organisation of care processes in parallel; and evaluations in real life [61].

\section{Integration of eHealth in care as usual}

eHealth is more than technology. A part of the eHealth definition 'to support or improve health or healthcare' will not occur based only on the implementation of technology, though requires careful integration into the existing care process [62]. The uptake of eHealth requires changes regarding tasks, roles, responsibilities and expectations $[63,64]$. Appropriate coaching of patients and health professionals during implementation is critical. Careful coordination and clear communication with everybody involved is needed. As conditional to successful eHealth implementation, health professionals indicate that quality of eHealth interventions needs improvement in terms of technological functioning and usability; attention must be directed towards all end users; time, education and experience should be available within the organisation; ambassadors need to be involved and results must be made visible; and arrangements should be made regarding finance, best practices and effectiveness [62].

\section{Aims and outline}

The main objective of this thesis is to develop and evaluate an eHealth intervention for outpatient with moderate to severe cancer pain. The aim of the intervention is to support self-management in order to improve pain control and quality of life. Underlying objectives are:

- To provide an update on the prevalence and severity of cancer pain

- To iteratively and collaboratively develop an eHealth intervention

- To evaluate feasibility of the eHealth intervention in everyday practice

- To evaluate the eHealth intervention on effect, process, and cost outcomes 
Findings will reveal the state of affairs with concern to the prevalence and severity of cancer pain. Moreover, studies will contribute to the knowledge about interventions directed at patients to better control cancer pain. In addition, findings will lead to more insights into methodologies appropriate for the development and evaluation of eHealth interventions.

Chapter 2 presents an update on the prevalence and severity of cancer pain based on articles published in approximately the last 10 years. Pooled outcomes are reported per group based on disease characteristics: patients after finishing curative treatment; patients receiving anti-cancer treatment; patients with advanced, metastatic or terminal disease; or all patients. Determinants of pain prevalence related to patient, disease and study characteristics are explored. Chapter 3 describes the iterative and co-creative development process and content of an eHealth intervention to support self-management in outpatients with moderate to severe cancer pain. Researchers and technical experts collaborate in different phases and steps; health professionals and patients are consulted to provide input and evaluate output. As a result, the intervention consists of a home visit, a mobile application for patients, a web application for nurses, and follow-up activities. Chapter 4 informs about the feasibility of the eHealth intervention in everyday practice as indicated by outpatients with moderate to severe cancer pain and registered nurses specialised in pain and palliative care. Learnability, usability, and desirability are assessed, adherence is measured, and experiences are explored. Chapter 5 describes the protocol of the intended multicentre randomised controlled trial with an effect, process, and cost evaluation. Information is provided on the design, recruitment, randomisation, intervention, data collection, outcomes measures, and data analyses. Chapter 6 reports on the evaluation that started as a randomised controlled trial, had to be redesigned twice, and was finalised as a non-randomised intervention study. Process outcomes related to the study (recruitment and reach) and the intervention (dose delivered, exposure and satisfaction) are extensively described; effect outcomes (pain and quality of life) are of descriptive nature and provide an indication of possible effects. Chapter 7 summarises the main findings and discusses some methodological and theoretical considerations in relation to the interpretation of results, followed by implications for future research, clinical practice, and policymaking. 


\section{References}

1. The Dutch Cancer Registry (IKNL) (2017) [Gestage groei aantal patiënten met kanker in Nederland]. Available from https://www.iknl.nl/cijfers/nieuws/nieuws-detail/2017/02/03/ gestage-groei-aantal-patiënten-met-kanker-in-nederland. Accessed February 4, 2017.

2. The Dutch Cancer Registry (IKNL) (2016) [Meest voorkomende localisaties van kanker in 2016]. Available from http://www.cijfersoverkanker.nl. Accessed February 4, 2017.

3. Hewitt M, Greenfield S, Stovall E, eds Institute of Medicine (2006) From Cancer Patient to Cancer Survivor: Lost in Transition. Washington DC: The National Academies Press.

4. Ganz PA (2009) Survivorship: Adult cancer survivors. Prim Care 36(4):721-741.

5. Stein KD, Syrjala KL, Andrykowski MA (2008) Physical and psychological long-term and late effects of cancer. CA Suppl 112(11):2577-2592.

6. Porter LS, Keefe FJ (2011) Psychosocial issues in cancer pain. Curr Pain Headache Rep 15(4):263-270.

7. Van den Beuken-van Everdingen MH, Hochstenbach LM, Joosten EA, Tjan-Heijnen VC, Janssen DJ (2016) Update on prevalence of pain in patients with cancer: Systematic review and meta-analysis. J Pain Symptom Manage 51(6):1070-1090.

8. Netherlands Comprehensive Cancer Organisation (IKNL) (2016) Pain: National guideline, version 2.1.

9. Grond S, Zech D, Diefenbach C, Radbruch L, Lehmann KA (1996) Assessment of cancer pain: a prospective evaluation in 2266 cancer patients referred to a pain service. Pain $64(1)$ : 107-114.

10. Davies AN, Dickman A, Reid C, Stevens AM, Zeppetella G; Science Committee of the Association for Palliative Medicine of Great Britain and Ireland (2009) The management of cancer-related breakthrough pain: Recommendations of a task group of the Science Committee of the Association for Palliative Medicine of Great Britain and Ireland. Eur J Pain 13(4):331-318.

11. International Association for the Study of Pain (IASP) (2012) IASP Taxonomy. Available from http://www.iasp-pain.org/Taxonomy. Accessed: December 20, 2016.

12. McCaffery M, Beebe A (1989) Pain: Clinical Manual for Nursing Practice. St. Louis: CV Mosby Company.

13. Loeser JDA (1980) Definitions of pain. Washington: Medicine.

14. Saunders C, Sykes N (1993) The management of terminal malignant disease. London: Oxford University Press.

15. Caraceni A, Cherny N, Fainsinger R, Kaasa S, Poulain P, Radbruch L, De Conno F (2002) Pain Measurement Tools and Methods in Clinical Research in Palliative Care: Recommendations of an Expert Working Group of the European Association of Palliative Care. J Pain Symp Manage 23(3):239-255.

16. Jensen MP (2003) The validity and reliability of pain measures in adults with cancer. J Pain $4(1): 2-21$.

17. Hjermstad MJ, Fayers PM, Haugen DF, Caraceni A, Hanks GW, Loge JH, Fainsinger R, Aass N, Kaasa S, European Palliative Care Research Collaborative (2011) Studies comparing Numerical Rating Scales, Verbal Rating Scales, and Visual Analogue Scales for assessment of pain intensity in adults: a systematic literature review. J Pain Symptom Manage 41:10731093.

18. Serlin RC, Mendoza TR, Nakamura Y, Edwards KR, Cleeland CS (1995) When is cancer pain mild, moderate or severe? Grading pain intensity by its interference with function. Pain 61 : 277-284.

19. Cleeland CS (1989) Measurement of pain by subjective report. In: Chapman CR, Loeser JD, eds. Advances in pain research and management. Issues in pain management. New York: Raven Press.

20. Melzack R (1975) The McGill pain questionnaire: major properties and scoring methods. Pain $1: 277-299$ 
21. Oldenmenger WH, Stronks DL, Terwiel CT, Verhage S, Gootjes JR, Klomp M, de Wit R (2006) Naar een landelijke, uniforme, verpleegkundige pijnanamnese: Psychometrische kwaliteiten. Nederlands Tijdschrift voor Pijn en Pijnbestrijding 25:10-12.

22. World Health Organization (WHO)(1996) Cancer pain relief, 2nd edition, with a guide to opioid availability. Geneva.

23. Farrar JT, Young JP Jr, LaMoreaux L, Werth JL, Poole RM (2001) Clinical importance of changes in chronic pain intensity measured on an 11 -point numerical pain rating scale. Pain 94(2):149-158.

24. Greco MT, Roberto A, Corli O, Deandrea S, Bandieri E, Cavuto S, Apolone G (2014) Quality of cancer pain management: an update of a systematic review of undertreatment of patients with cancer. J Clin Oncol 32:4149-4154.

25. Schumacher KL, Clark VL, West CM, Dodd MJ, Rabow MW, Miaskowski C (2014) Pain medication management processes used by oncology outpatients and family caregivers part ii: home and lifestyle contexts. J Pain Symptom Manage 48:784-796.

26. Butow $P$, Sharpe $L$ (2013) The impact of communication on adherence in pain management. Pain 154(1):101-107.

27. Berry DL, Wilkie DJ, Thomas CR Jr, Fortner P (2003) Clinicians communicating with patients experiencing cancer pain. Cancer Invest 21:374-381.

28. Kwon JH (2014) Overcoming barriers in cancer pain management. J Clin Oncol 32: $1727-1733$.

29. Jacobsen R, Moldrup C, Christrup L, Sjogren P (2009) Patient-related barriers to cancer pain management: a systematic exploratory review. Scand J Caring Sci 23:190-208.

30. Miaskowski C, Dodd MJ, West C, Paul SM, Tripathy D, Koo P, Schumacher K (2001) Lack of adherence with the analgesic regimen: a significant barrier to effective cancer pain management. J Clin Oncol 19:4275-4279.

31. Schumacher KL, Koresawa S, West C, Hawkins C, Johnson C, Wais E, Dodd M, Paul SM, Tripathy D, Koo P, Miaskowski C (2002) Putting cancer pain management regimens into practice at home. J Pain Symptom Manage 23:369-382.

32. Bennett MI, Bagnall AM, Jose Closs S (2009) How effective are patient-based educational interventions in the management of cancer pain? Systematic review and meta-analysis. Pain 143:192-199.

33. Oldenmenger WH, Sillevis Smitt PA, van Dooren S, Stoter G, van der Rijt CC (2009) A systematic review on barriers hindering adequate cancer pain management and interventions to reduce them: a critical appraisal. Eur J Cancer 45:1370-1380.

34. Cummings GG, Olivo SA, Biondo PD, Stiles CR, Yurtseven O, Fainsinger RL, Hagen NA (2011) Effectiveness of knowledge translation interventions to improve cancer pain management. J Pain Symptom Manage 41:915-939.

35. Koller A, Miaskowski C, De Geest S, Opitz O, Spichiger E (2012) A systematic evaluation of content, structure, and efficacy of interventions to improve patients' self-management of cancer pain. J Pain Symptom Manage 44:264-284.

36. Jho HJ, Myung SK, Chang YJ, Kim DH, Ko DH (2013) Efficacy of pain education in cancer patients: a meta-analysis of randomized controlled trials. Support Care Cancer 21:19631971.

37. Marie N, Luckett T, Davidson PM, Lovell M, Lal S (2013) Optimal patient education for cancer pain: a systematic review and theory-based meta-analysis. Support Care Cancer 21: 3529-3537.

38. Adam R, Bond C, Murchie P (2014) Educational interventions for cancer pain. A systematic review of systematic reviews with nested narrative review of randomized controlled trials. Patient Educ Couns 98:269-282.

39. Brink-Huis A, van Achterberg T, Schoonhoven L (2008) Pain management: a review of organisation models with integrated processes for the management of pain in adult cancer patients. J Clin Nurs 17:1986-2000.

40. McCorkle R, Ercolano E, Lazenby M, Schulman-Green D, Schilling LS, Lorig K, Wagner EH (2011) Self-management: enabling and empowering patients living with cancer as a chronic illness. CA Cancer J Clin 61:50-62.

41. Bodenheimer T, Lorig K, Holman H, Grumbach K (2002) Patient self-management of chronic disease in primary care. JAMA 288:2469-2475. 
42. Kimberlin C, Brushwood D, Allen W, Radson E, Wilson D (2004) Cancer patient and caregiver experiences: communication and pain management issues. J Pain Symptom Manage 28: 566-578.

43. Barlow J, Wright C, Sheasby J, Turner A, Hainsworth J (2002) Self-management approaches for people with chronic conditions: a review. Patient Educ Couns 48:177-187.

44. Corbin JM, Strauss A (1988) Unending work and care: Managing chronic illness at home. San Francisco, CA: Jossey-Bass Publishers.

45. Lorig KR, Holman H (2003) Self-management education: history, definition, outcomes, and mechanisms. Ann Behav Med 26:1-7.

46. Richard AA, Shea K (2011) Delineation of self-care and associated concepts. J Nurs Scholarsh 43:255-264.

47. Wilkinson A, Whitehead $L$ (2009) Evolution of the concept of self-care and implications for nurses: a literature review. Int J Nurs Stud 46(8):1143-1147.

48. Wilde $\mathrm{MH}$, Garvin S (2007) A concept analysis of self-monitoring. J Adv Nurs 57:339-350.

49. Bandura A (1997) Self-efficacy: The exercise of control. New York, Freeman.

50. Coleman MT, Newton KS (2005) Supporting self-management in patients with chronic illness. Am Fam Physician 72(8):1503-1510.

51. Adams K, Corrigan JM, eds Institute of Medicine (2003) Priority areas for national action: Transforming healthcare quality. Washington DC: The National Academies Press.

52. McGowan P (2005) Self-Management: A Background Paper. University of Victoria, Centre on Aging.

53. van Houtum L, Rijken M, Heijmans M, Groenewegen P (2013) Self-management support needs of patients with chronic illness: Do needs for support differ according to the course of illness? Patient Educ Couns 93(3):626-632.

54. Pagliari C, Sloan D, Gregor P, Sullivan F, Detmer D, Kahan JP, Oortwijn W, MacGillivray S (2005) What is eHealth (4): a scoping exercise to map the field. J Med Internet Res 7(1):e9.

55. van Rijen AJ, de Lint MW, Ottes L (2002) [Inzicht in e-health. Achtergrondstudie uitgebracht door de Raad voor de Volksgezondheid en Zorg bij het advies E-health in zicht]. RVZ, Zoetermeer.

56. Krijgsman J, Klein Wolterink G (2012) [Ordening in de wereld van eHealth]. Nictiz, Den Haag.

57. Dickinson R, Hall S, Sinclair JE, Bond C, Murchie P (2014) Using technology to deliver cancer follow-up: a systematic review. BMC Cancer 14:311.

58. Meystre S (2005) The current state of telemonitoring: a comment on the literature. Telemed J E Health 11:63-69.

59. Shah SG, Robinson I (2007) Benefits of and barriers to involving users in medical device technology development and evaluation. Int J Technol Assess Health Care 23:131-137.

60. van Gemert-Pijnen JE, Nijland N, van Limburg M, Ossebaard HC, Kelders SM, Eysenbach G, Seydel ER (2011) A holistic framework to improve the uptake and impact of eHealth technologies. J Med Internet Res 13:e111.

61. Gulliksen J, Göransson B, Boivie I, Blomkvist S, Persson J, Cajander A (2003) Key principles for user-centered systems design. Behav Inform Technol 22:397-409.

62. Krijgsman J, Swinkels I, van Lettow B, de Jong J, Out K, Friele R, van Gennip L (2016) eHealth-monitor 2016. Meer dan techniek. Nictiz, Den Haag. Nivel, Utrecht.

63. Segar J, Rogers A, Salisbury C, Thomas C (2013) Roles and identities in transition: boundaries of work and inter-professional relationships at the interface between telehealth and primary care. Health Soc Care Community 21:606-613.

64. Taylor J, Coates E, Brewster L, Mountain G, Wessels B, Hawley MS (2014) Examining the use of telehealth in community nursing: identifying the factors affecting frontline staff acceptance and telehealth adoption. J Adv Nurs 71:326-337. 



\section{2 \\ Update on prevalence of pain in patients with cancer systematic review and meta-analysis}

This chapter was published as:

van den Beuken-van Everdingen $\mathrm{MH}$, Hochstenbach LM, Joosten EA, Tjan-Heijnen VC, Janssen DJ (2016)

J Pain Symptom Manage 51(6):1070-1090.e9

DOI: $10.1016 / j$.jpainsymman.2015.12.340 


\section{Abstract}

\section{Context}

Cancer pain has a severe impact on quality of life and is associated with numerous psychosocial responses. Recent studies suggest that treatment of cancer pain has improved during the last decade.

\section{Objectives}

The aim of this review was to examine the present status of pain prevalence and pain severity in patients with cancer.

\section{Methods}

A systematic search of the literature published between September 2005 and January 2014 was performed using the databases of Pubmed, Medline, Embase, Cinahl, and Cochrane. Articles in English or Dutch that reported on the prevalence of cancer pain in an adult cancer population were included. Titles and abstracts were screened by two authors independently, after which full texts were evaluated and assessed on methodological quality. Study details and pain characteristics were extracted from the articles with adequate study quality. Prevalence rates were pooled with meta-analysis; meta-regression was performed to explore determinants of pain prevalence.

\section{Results}

Out of 4117 titles, 122 studies were selected for the meta-analysis on pain (117 studies, $n=63533$ ) and pain severity (52 studies, $n=32261$ ). Pain prevalence rates were $39.3 \%$ after curative treatment; $55.0 \%$ during anti-cancer treatment; $66.4 \%$ in advanced, metastatic or terminal disease. Moderate to severe pain (NRS $\geq 5$ ) was reported by $38.0 \%$ of all patients.

\section{Conclusion}

Despite increased attention for the assessment and management, pain continues to be a prevalent symptom in patients with cancer. In the upcoming decade we need to overcome barriers towards effective pain treatment and develop and implement interventions to optimally manage pain in patients with cancer. 


\section{Introduction}

At the beginning of the global year against cancer in 2008, the International Association for the Study of Pain (IASP) stated: 'For the more than 10 million people worldwide who are diagnosed with some form of cancer each year, pain associated with their condition is a serious concern. Although pain is not necessarily inevitable for everyone with cancer, it is common. The consequences of unrelieved cancer pain are devastating' [1].

Pain has a severe impact on patients' quality of life [2] and numerous psychosocial responses are associated with cancer pain $[3,4]$. Patients report that pain prevents them from concentrating or thinking and that pain creates difficulty in performing normal daily activities [5]. Over one-third of patients describes pain related to cancer as distressing or even as an intolerable aspect of their cancer [5]. Evidence suggests that adequate pain treatment results in clinically relevant improvements in health related quality of life [6].

In 2007 a systematic review has been published on the prevalence of cancer pain over a time perspective of 40 years [7]. Based on the results, the authors concluded that no progress was made in the treatment of cancer pain within the four decades before.

Almost ten years have passed since this systematic review and attention for pain in cancer has greatly increased. A recent review of under-treatment of patients with cancer suggests that the adequacy of pharmacological pain management has improved [8]. Moreover, global opioid consumption has increased [9], new mechanistic insights for e.g. metastatic bone pain have been gained [10], and new therapeutic options including rapid onset opioids are available. In view of these recent improvements, this review aimed to study the present status of the prevalence of pain in patients with cancer and explore the determinants of pain prevalence. A priori, progress in cancer pain treatment during recent years was expected to result in lower prevalence rates of pain in patients with cancer compared to a decade ago.

\section{Methods}

\section{Search strategy}

A systematic search of the literature published between September 2005 and January 2014 was performed using the databases of Pubmed, Medline, Embase, Cinahl, and Cochrane (Appendix 2.1). Search terms comprised 'pain' and 'prevalence' or 'symptom' and 'prevalence' in combination with 'cancer', 'neoplasm', 'terminal', 'endstage', 'advanced', 'hospice', or 'palliative' in the title, abstract, or keywords. 


\section{Study selection}

After identification and exclusion of duplicates, two authors independently screened the titles (DJ, MvdB) and subsequently the abstracts ( $\mathrm{LH}, \mathrm{MvdB}$ ). Full texts of selected articles were examined with regard to the eligibility criteria ( $\mathrm{LH}, \mathrm{MvdB})$. Original articles that reported on the prevalence of cancer pain in an adult population and were written in English or Dutch were included. Exclusion of articles was based on design (editorials, letters, reviews, case studies, secondary analysis), setting (studies performed at pain clinics including only patients with pain) or population (studies reporting on pain without differentiating between patients with and without cancer, studies that focus on breakthrough pain, studies about pain in childhood cancer). When needed, authors were contacted by email for extra information on pain prevalence data.

\section{Methodological quality}

Methodological quality assessment was performed by using criteria developed for prevalence studies based on Leboeuf-Yde and Lauritsen [11]. Criteria relate to the representativeness of the sample ( 3 items); quality of the data ( 3 items); description of the methods and results ( 3 items); and definition of pain prevalence ( 1 item). Weighting factors were introduced for each criterion. In the previous review [7], criteria specifically for lower back pain were revised and replaced by criteria with an adequate description of the disease stage and/or condition for cancer. For this review, the quality assessment was further refined by upgrading studies that provided an adequate description of the stage of disease and downgrading studies that relied on either proxy reporting or retrospective medical records (Table 2.1). All articles were assessed independently by two authors ( $\mathrm{LH}, \mathrm{MvdB}$ ), resulting in a quality score that ranged from 0 to 20 points. Differences in quality assessments were resolved using a discussion and consensus approach. Articles with a predefined quality score of $\geq 15$ points, which equals $75 \%$ of the maximum 20 points [12], were accepted for inclusion in the meta-analysis.

\section{Data extraction}

\section{General characteristics}

General characteristics were recorded for each study and included: author(s), year of publication, continent of origin, aim of the study, setting (inpatient, outpatient, home, hospice or palliative care unit, referred to palliative care service), type of cancer (head and neck, lung, breast, gastro-intestinal, prostate, gynaecological, all other types of cancer), sex, age (40-49, 50-59, 60-69, 70-79 years), race (Caucasian, Mediterranean), Eastern Cooperative Oncology Group (ECOG) performance status (1, 
2 , 3) [13], sample size, and method of data collection (questionnaire completed by patient or proxy, interview with patient or proxy, medical record).

Table 2.1 Methodological quality criteria for prevalence studies representative of the target population

Quality of data

General description of method and results
The final sample should be

At least one of the following should apply for the study: an entire target population, randomly selected sample, or sample stated to represent the target population ( 2 points)

At least one of the following: reasons for non-response described, non-responders described, comparison of responders and nonresponders, or comparison of sample and target population ( 2 points)

Response rate $\geq 90 \%$ ( 2 points)

Response rate $70-90 \%$ (1 point)

Response rate $<70 \%$ ( 0 point)

Were the data primary from a prevalence study ( 2 points) or was it taken from a survey not specifically designed for that purpose (1 point)?

The same mode of data collection should be used for all subjects ( 2 points), if not 0 points

The data have been collected directly from the patient by means of a validated questionnaire/interview (3 points) No validated questionnaire/interview (2 points)

Data have been collected from proxies or retrospectively from medical record (0 points)

Description of the target population and setting where patients were found ( 2 points)

Description of stage of disease (1 point)

Description of type of cancer, sex and age: all (2 points), 2 of 3 (1 point), 1 of 3 (0 points)

Final sample size (1 point)

Definition of pain prevalence Prevalence recall periods should be stated (1 point)

\section{Pain prevalence and pain severity}

The following data were extracted: pain prevalence; pain severity; recall period for pain (point, week, month(s), year); and the scale or instrument used to measure pain (Visual Analogue Scale (VAS), Numerical Rating Scale (NRS), Verbal Rating Scale (VRS), pain 'yes/no'). When pain severity was reported as VAS or NRS, the rating of Serlin [14] was applied: none (0), mild (1-4), moderate (5-6), or severe ( $\geq 7)$. 


\section{Groups}

As in the previous systematic review [7], studies were categorised into groups based on the disease characteristics described in the methods and results sections. Group 1 studies that included patients after finishing curative treatment; group 2 - studies that included patients receiving anti-cancer treatment, with curative or palliative intention; group 3 - studies that included patients with advanced, metastatic and/or terminal disease; group 4 - studies including all groups.

\section{Data analyses}

Pooled prevalence rates, precision (95\% confidence interval) and statistical significance (defined as $p<0.05$ ) were determined for each group with concern to pain and pain severity. The reciprocal of the variance from individual studies was used as a weighting factor, which relates closely to the sample size. This weighting factor was chosen to reflect the amount of information that each study contained [12]. A test for homogeneity was carried out to investigate whether the variation in prevalence rates between studies was more than could be attributed to chance alone. In case this test would appear to be significant, the extra variation was to be incorporated into the analysis using a random effects model. To examine whether pooled prevalence rates for pain were significantly different between groups, meta-regression analysis was performed.

Meta-regression analysis was also used to explore the association of continent of origin; cancer type; age of the population; ECOG; race; recall period; and method of data collection with the outcome. All the analyses were performed using STATA Statistical Software: Release 12 (metan, metareg).

\section{Results}

\section{Selected articles}

The initial search yielded 4117 articles (Figure 2.1). After removing duplicates and screening titles, 871 abstracts were screened of which 483 articles were selected for evaluation on a full text base. In total 262 full texts were excluded based on predefined eligibility criteria, which resulted in 221 articles for the methodological quality assessment. The authors of 60 articles were e-mailed for extra information; nineteen of them provided the requested information in order to include their article in this review. All included articles were published in English. 


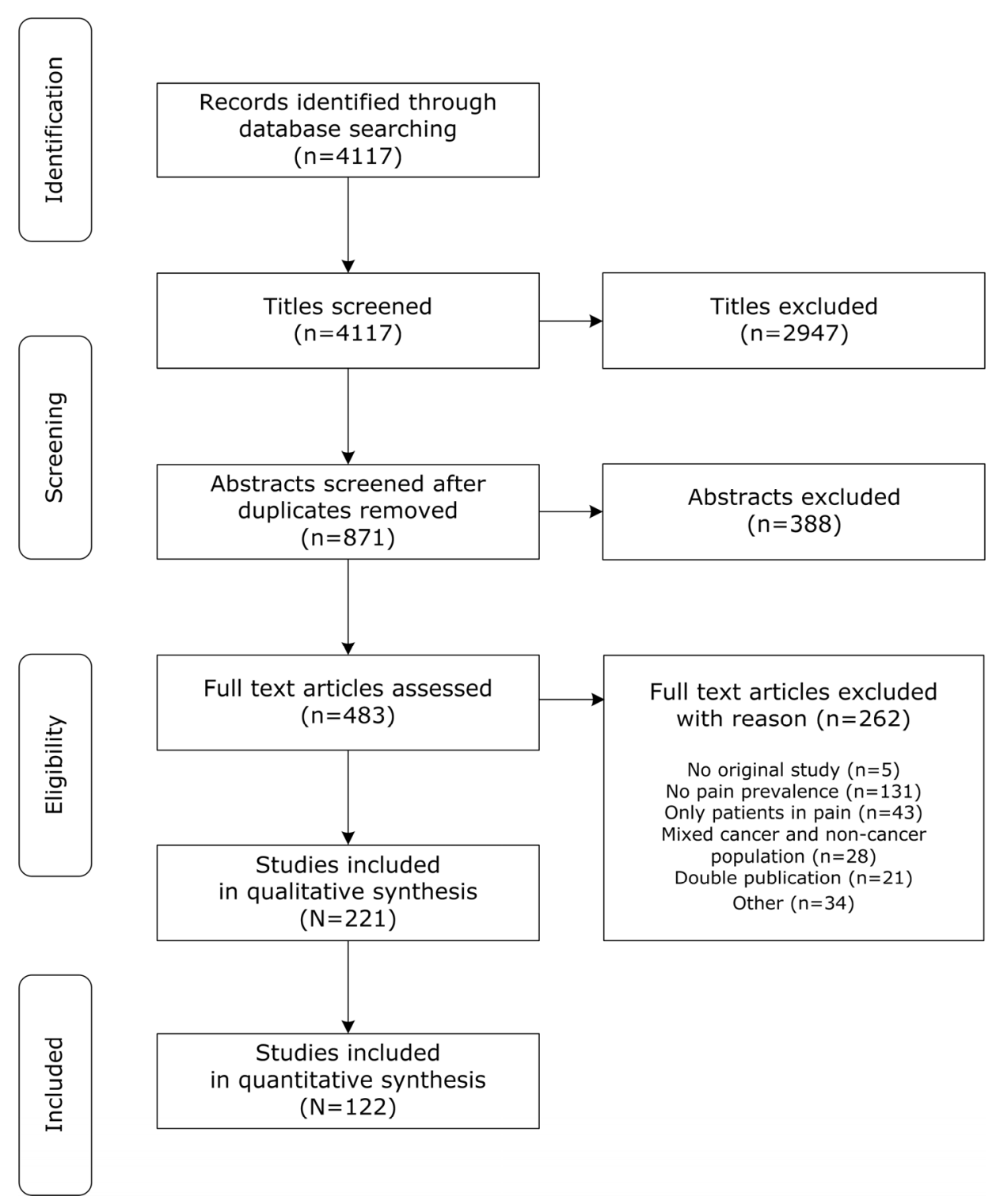

Figure 2.1 Flow diagram of study selection 
In total, $122(55.2 \%)$ of the remaining 221 articles reached the predefined methodological quality score of at least 15 points (Appendix 2.2). Articles that did not meet this threshold were excluded due to the following reasons: response rate of less than $70 \%$ or response rate not mentioned $(n=95)$; data retrieved from medical records $(n=52)$; lack of description of non-responders $(n=93)$; and sample not representative $(n=47)$ (Appendix 2.3). The methodological quality assessment is included in Appendix 2.4.

\section{General characteristics}

General characteristics of the 122 articles are listed in Tables 2.2 to 2.7. Some studies reported on two or more groups [15-18]. In 78 studies (64\%), (part of) the primary aim of the study was to determine the prevalence of pain in patients with cancer. In the other 44 studies, measuring of pain prevalence was not the primary aim of the study. Eight studies focused on quality of life [16, 19-25]; six studies described the effectiveness of an intervention [17, 26-30]; five studies focused on (predictors of) fatigue or sleeping problems [31-35]; five papers studied the concordance in symptom reporting between patients and (professional) caregivers [36-40]; three studies explored the prognostic significance of symptoms [41-43]; three studies reported the validation or effectiveness of a questionnaire [44-46]; and three studies described palliative care needs [47-49]; symptom clusters were the subject of two studies [50, $51]$; while the remaining nine studies concerned other topics such as mindfulness or oral health [52-60].

\section{Pain prevalence}

The results of the stratified meta-analysis on the prevalence of pain in different patient groups are shown in Figures 2.2 to 2.7. 117 studies described pain prevalence. Pooled pain prevalence rates were $39.3 \%(95 \%$ CI 33.3-45.3) after curative treatment (group 1: 29 studies, $\mathrm{n}=18832$ ); $55.0 \%$ (95\% CI 45.9-64.2) during anti-cancer treatment (Group 2: 29 studies, $\mathrm{n}=6904) ; 66.4 \%$ (95\% CI 58.1-74.7) in advanced, metastatic or terminal disease (group 3: 24 studies, $n=9653$ ); and 50.7\% (95\% CI 37.2-64.1) in studies that included all cancer stages (group 4: 18 studies, $n=17682$ ). Pain was reported by $52.2 \%(95 \%$ CI $32.2-72.3)$ in the patients after curative treatment or on anti-cancer treatment (group 1 and 2: 3 studies, $n=6840$ ) and $74.8 \%$ (95\% CI 61.5 88.0 ) of the patients on anti-cancer treatment or with advanced, metastatic treatment (groups 2 and 3: 14 studies, $n=3622$ ). The prevalence of pain was significantly higher in group 3 compared to group 2 and group $1(p=0.032, p=0.000)$ as well as in group 2 compared to group $1(p=0.002)$. 


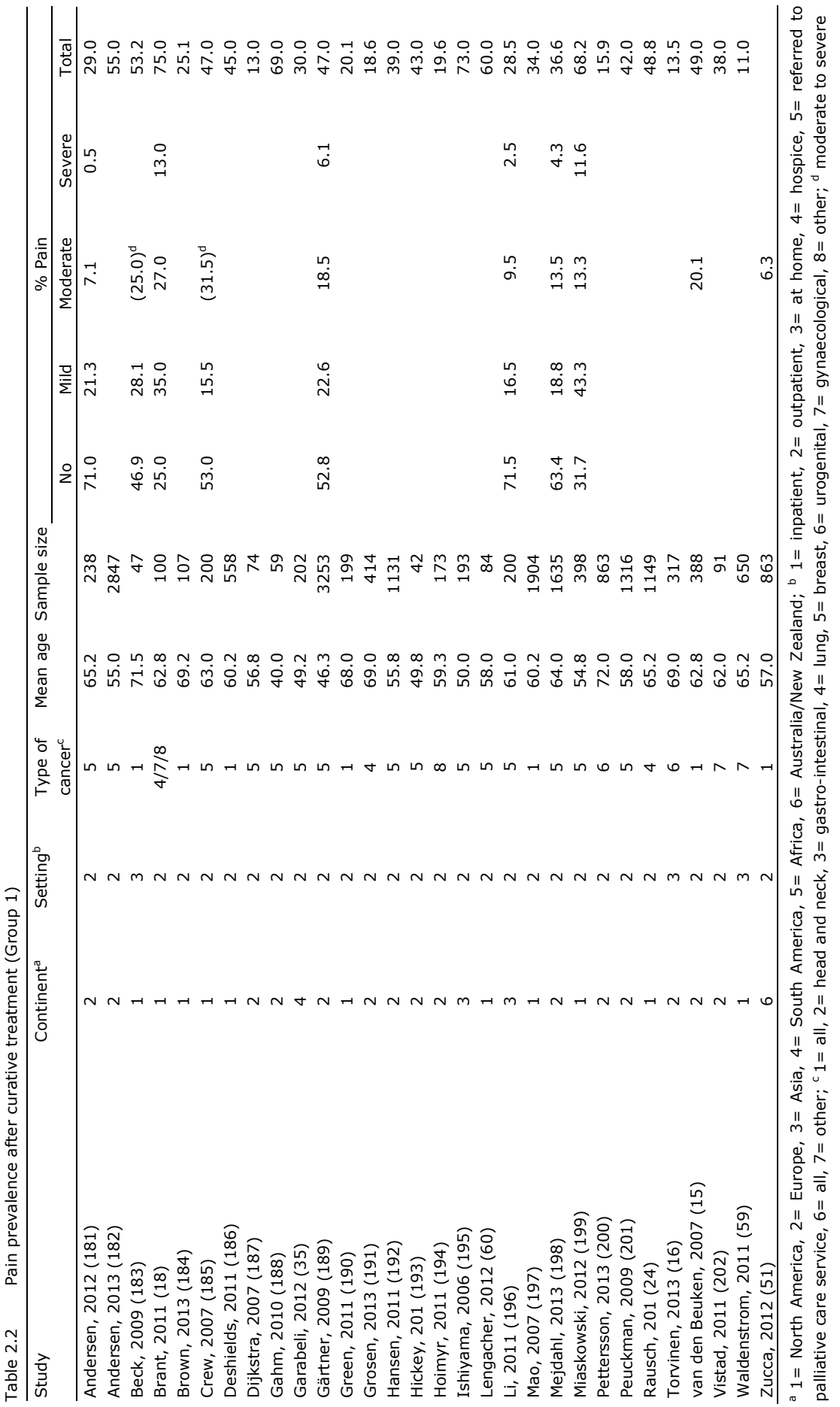




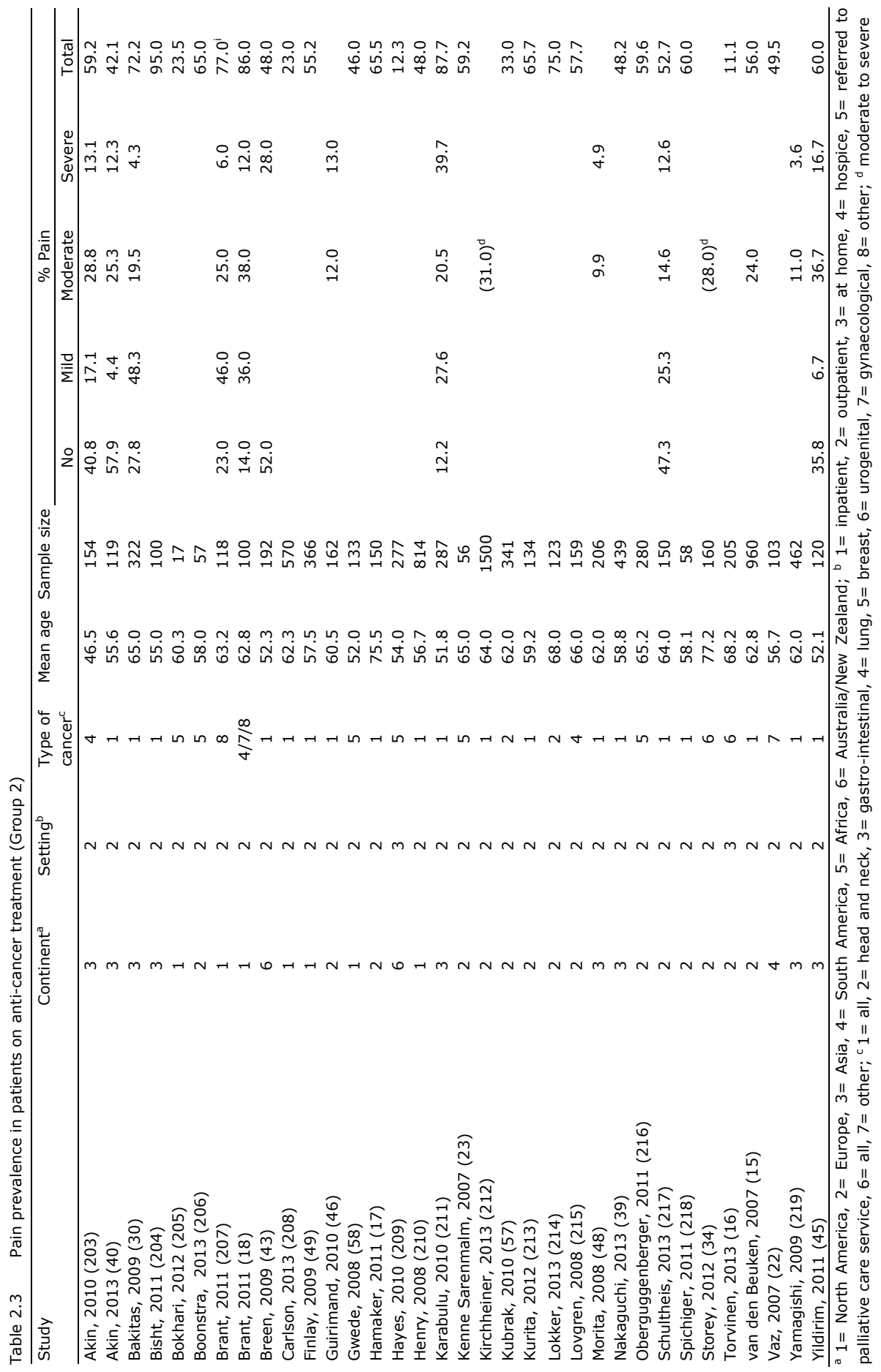




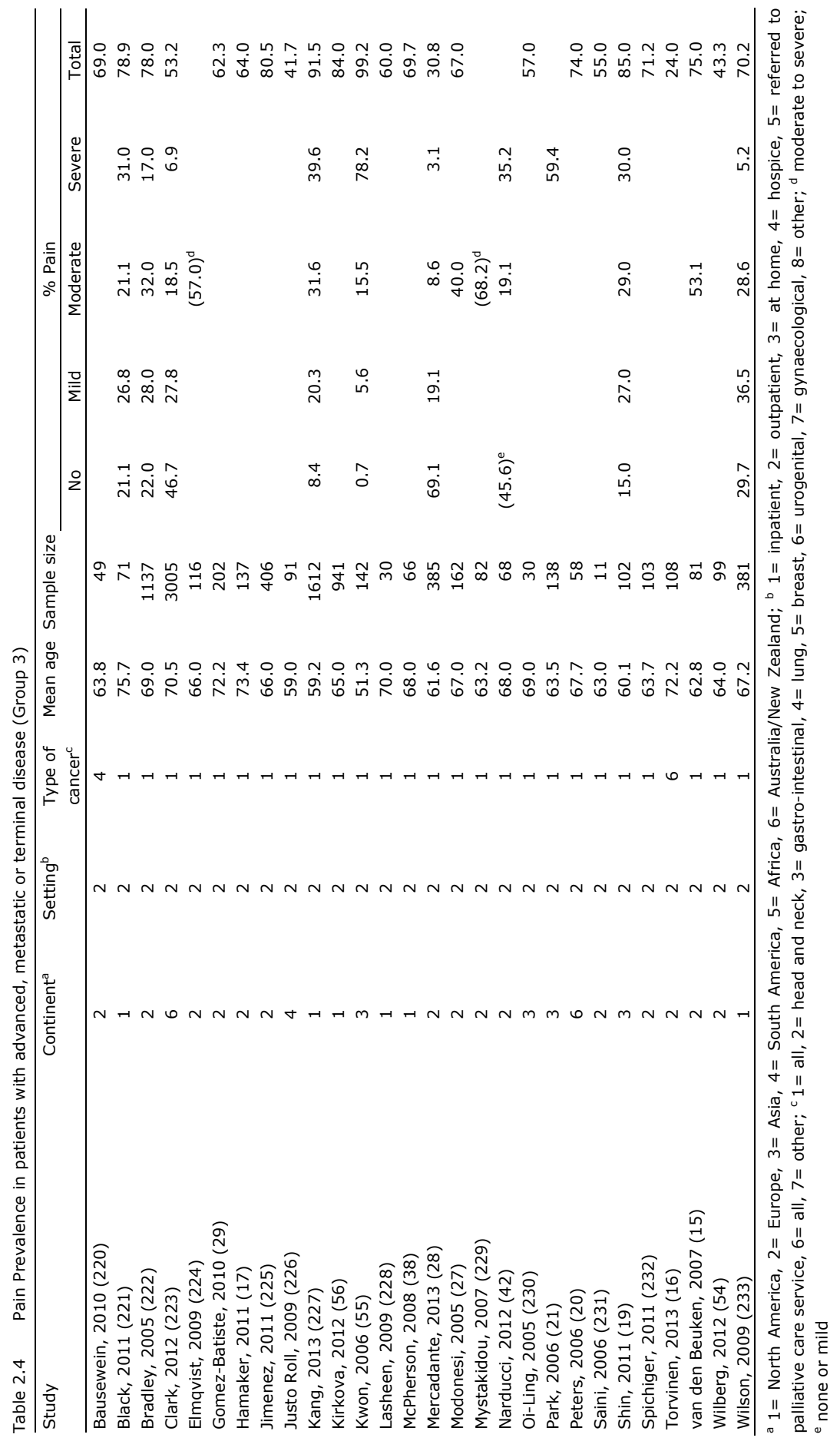




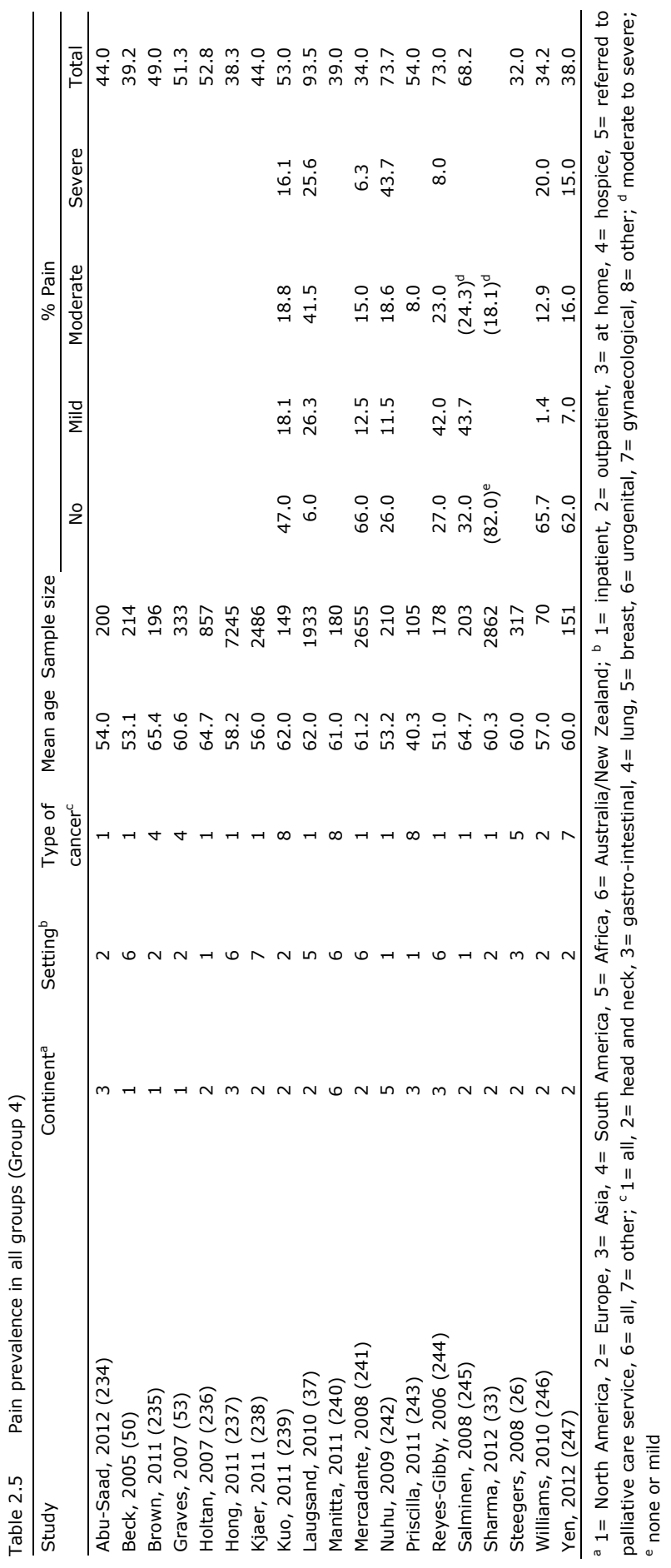




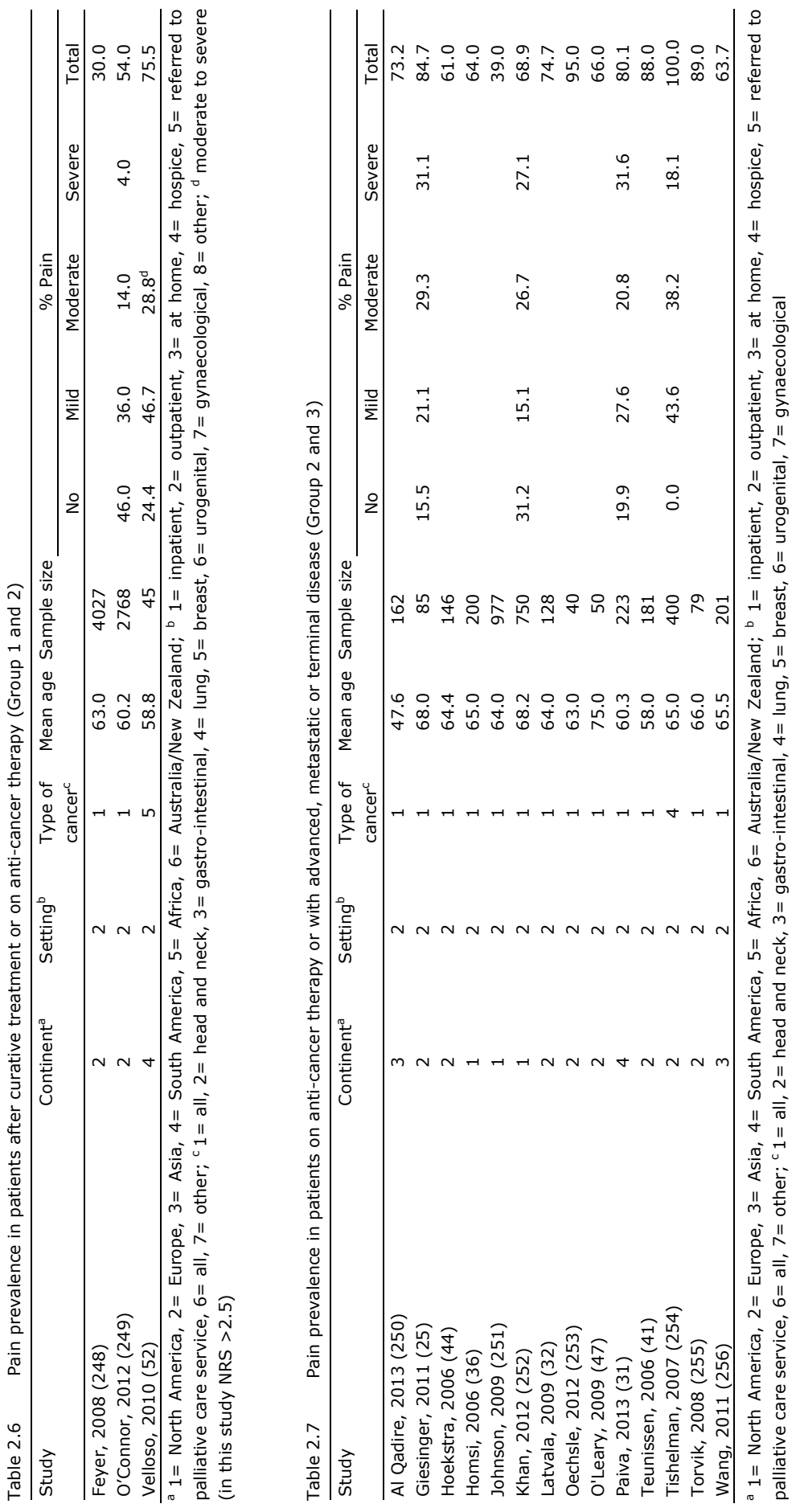


Author

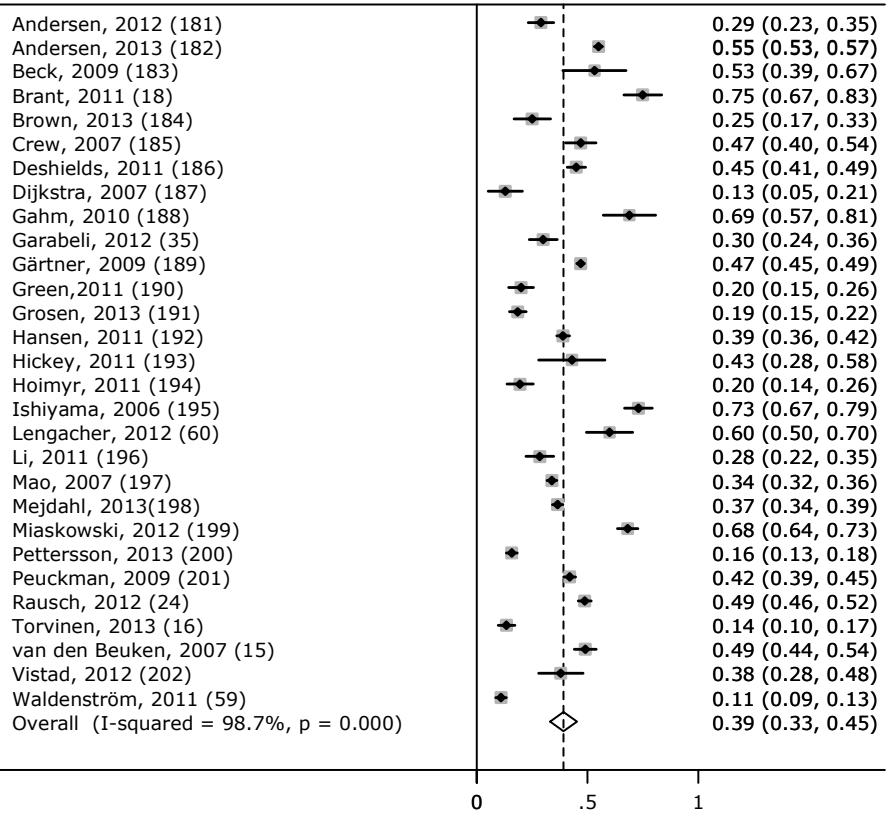

Figure 2.2 Forest plot of pain prevalence in patients after curative treatment (Group 1)
ES $(95 \% \mathrm{CI})$

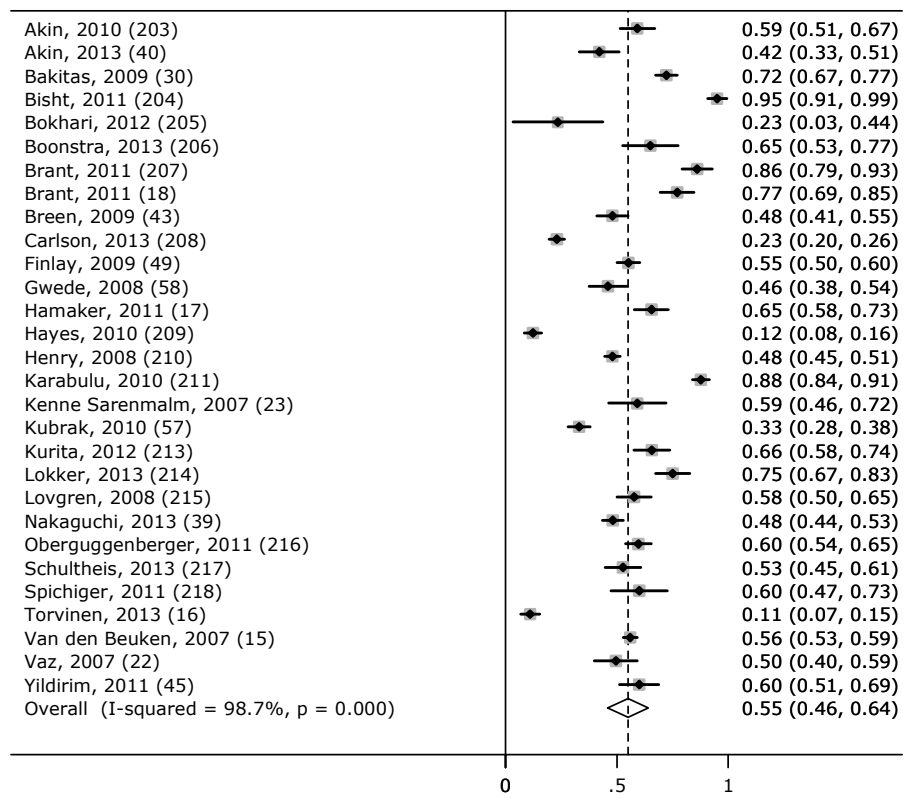

Figure 2.3 Forest plot of pain prevalence in patients on anti-cancer treatment (Group 2) 
Author

ES $(95 \% \mathrm{CI})$

Figure 2.4 Forest plot pain prevalence in patients with advanced, metastatic or terminal disease (Group 3)

Author

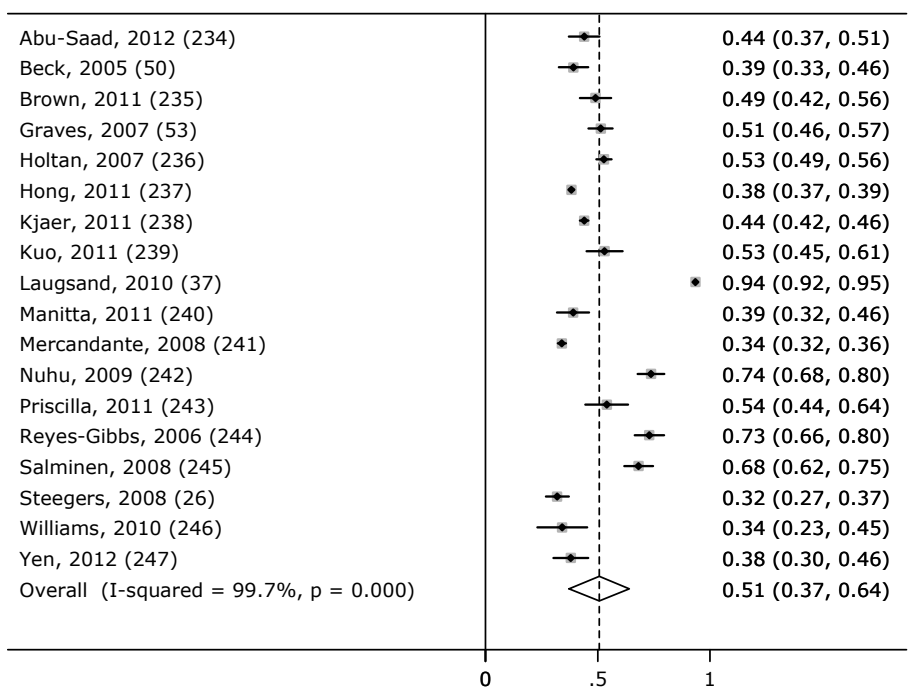

Figure 2.5 Forest plot of pain prevalence in all groups (Group 4) 


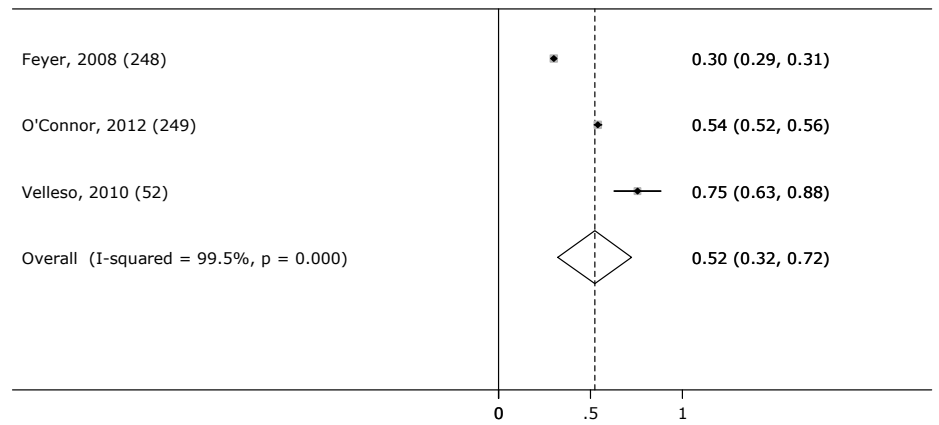

Figure 2.6 Forest plot of pain prevalence in patients after curative treatment or on anti-cancer therapy (Group 1 and 2)

\begin{tabular}{|c|c|c|}
\hline Author & & ES $(95 \% \mathrm{CI})$ \\
\hline Al Qadire, 2013 (250) & & $0.73(0.66,0.80)$ \\
\hline Giesinger, 2011 (25) & & $0.85(0.77,0.92)$ \\
\hline Hoekstra, 2006 (44) & $\rightarrow$ & $0.61(0.53,0.69)$ \\
\hline Homsi, 2006 (36) & $\rightarrow$ & $0.64(0.57,0.71)$ \\
\hline Johnson, 2009 (251) & $\bullet$ & $0.39(0.36,0.42)$ \\
\hline Khan, 2012 (252) & & $0.69(0.66,0.72)$ \\
\hline Latvala, 2009 (32) & & $0.75(0.67,0.82)$ \\
\hline Oechsle, 2012 (253) & $\rightarrow$ & $0.95(0.88,1.02)$ \\
\hline O'Leary, 2009 (47) & & $0.66(0.53,0.79)$ \\
\hline Paiva, 2013 (31) & & $0.80(0.75,0.85)$ \\
\hline Teunissen, 2006 (41) & $\rightarrow$ & $0.88(0.83,0.93)$ \\
\hline Tishelman, 2007 (254) & - & $0.99(0.98,1.00)$ \\
\hline Torvik, 2008 (255) & $\rightarrow$ & $0.89(0.82,0.96)$ \\
\hline Wang, $2011(256)$ & 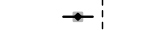 & $0.64(0.57,0.70)$ \\
\hline Overall (I-squared $=99.3 \%, p=0.000)$ & & $0.75(0.62,0.88)$ \\
\hline
\end{tabular}

Figure 2.7 Forest plot of pain prevalence in patients on anti-cancer therapy or with advanced, metastatic or terminal disease (Group 2 and 3)

\section{Pain severity}

Fifty-two studies (42.6\%) described pain severity. Overall, $38.0 \%$ (95\% CI 32.8-43.3) of the patients reported moderate to severe pain (NRS $\geq 5$ ). Pain was rated as moderate to severe by $27.6 \%$ (95\% CI 18.9-36.3) of the patients after curative treatment (group 1: 10 studies, $n=7322$ ); by $32.4 \%$ ( $95 \%$ CI $26.6-38.2$ ) of the patients on anti-cancer treatment (group 2: 15 studies, $n=4670)$; by $51.9 \%$ ( $95 \%$ CI 
37.7-66.1) of the patients with advanced, metastatic or terminal disease (group 3: 14 studies, $\mathrm{n}=7482)$; and $33.1 \%$ (95\% CI 19.2-47.0) of the patients with cancer in all different stages (group 4: 10 studies, $n=8516$ ). Moderate to severe pain was reported by $21.3 \%$ (95\% CI $11.6-31.1)$ in the patients after curative treatment or on anticancer treatment (group 1 and 2: 2 studies, $\mathrm{n}=2813$ ) and $55.1 \%(95 \%$ CI $52.0-58.2$ ) in the patients on anti-cancer treatment or with advanced, metastatic treatment (group 2 and 3: 4 studies, $n=1458$ ). The prevalence of moderate to severe pain was significantly higher in group 3 compared to group 2 and group $1(p=0.005, p=0.002$, respectively).

Table 2.8 Meta-regression to explore determinants of pain prevalence

\begin{tabular}{|c|c|c|c|}
\hline \multirow{2}{*}{$\frac{\text { Determinant }}{\text { Continent }}$} & \multicolumn{2}{|c|}{$\beta[95 \% \mathrm{CI}]$} & \multirow[t]{2}{*}{$\mathrm{P}$-value } \\
\hline & & & \\
\hline Europe & 0.52 & $(0.47-0.58)$ & - \\
\hline North-America & 0.03 & $(-0.07-0.12)$ & 0.564 \\
\hline South-America & 0.03 & $(-0.17-0.23)$ & 0.788 \\
\hline Asia & 0.12 & $(0.00-0.23)$ & 0.049 \\
\hline Africa & 0.21 & $(-0.22-0.64)$ & 0.334 \\
\hline Australia & -0.07 & $(-0.28-0.13)$ & 0.458 \\
\hline \multicolumn{4}{|l|}{ Type of cancer } \\
\hline Prostate & 0.16 & $(-0.30-0.35)$ & - \\
\hline Head and neck & 0.31 & $(0.02-0.61)$ & 0.036 \\
\hline Lung & 0.38 & $(0.15-0.62)$ & 0.002 \\
\hline Breast & 0.30 & $(0.09-0.50)$ & 0.006 \\
\hline Gastro-intestinal & 0.37 & $(-0.06-0.80)$ & 0.093 \\
\hline Gynaecological & 0.18 & $(-0.09-0.45)$ & 0.193 \\
\hline \multicolumn{4}{|l|}{ Age } \\
\hline 40-49 years & 0.51 & $(0.34-0.68)$ & - \\
\hline $50-59$ & 0.05 & $(-0.13-0.23)$ & 0.582 \\
\hline $60-69$ & 0.04 & $(-0.14-0.21)$ & 0.669 \\
\hline 70-79 & 0.03 & $(-0.19-0.25)$ & 0.794 \\
\hline \multicolumn{4}{|l|}{ Race } \\
\hline Caucasian & 0.40 & $(0.06-0.74)$ & - \\
\hline Mediterranean & 0.32 & $(-0.28-0.93)$ & 0.149 \\
\hline \multicolumn{4}{|l|}{ Performance status } \\
\hline ECOG 3 & 0.75 & $(0.62-0.89)$ & - \\
\hline ECOG 0 & -0.20 & $(-0.43-0.04)$ & 0.098 \\
\hline ECOG 1 & -0.24 & $(-0.41--0.07)$ & 0.006 \\
\hline ECOG 2 & -0.03 & $(-0.20-0.13)$ & 0.684 \\
\hline \multicolumn{4}{|l|}{ Data collection method } \\
\hline Questionnaire patient & 0.53 & $(0.49-0.58)$ & - \\
\hline Interview patient & 0.12 & $(-0.01-0.24)$ & 0.066 \\
\hline Medical record & 0.38 & $(-0.04-0.80)$ & 0.075 \\
\hline \multicolumn{4}{|l|}{ Recall period } \\
\hline Point & 0.60 & $(0.54-0.65)$ & - \\
\hline Week & -0.05 & $(-0.18-0.03)$ & 0.257 \\
\hline Month & -0.30 & $(-0.47--0.13)$ & 0.001 \\
\hline Year & -0.36 & $(-0.65--0.07)$ & 0.015 \\
\hline
\end{tabular}




\section{Determinants of pain prevalence}

In the meta-regression analysis (Table 2.8), the prevalence of pain in patients with prostate cancer was significantly lower than in patients with head and neck, lung and breast cancer, respectively $p=0.036, p=0.002$ and $p=0.006$. Breast cancer patients were subject of more than half of the studies that included specific cancers. More specifically, fifteen of these breast cancer studies $(n=11872)$ presented pain after curative treatment resulting in a prevalence rate of $45.1 \%$. Six of these studies also measured pain severity; moderate to severe pain was present in $19.5 \%$ (95\% CI 13.8-25.3) of the survivors of breast cancer.

Age and race as well as method of data collection were not associated with overall pain prevalence rates $(p>0.05)$. Studies from Asia (18 studies, $n=14221$ ) showed significantly higher pain rates than the studies from Europe (57 studies, $n=35361$ ) $(p=0.049)$. Patients with a worse performance status (ECOG 2 and 3 ) had significant higher prevalence rates than patients with an ECOG $1 \quad(p=0.004, p=0.006$, respectively). The use of recall periods of a month ( 6 studies, $n=3808$ ) or a year ( 2 studies, $n=1978$ ) resulted in lower pain rates than the use of point prevalence (54 studies, $n=26235)(p=0.001, p=0.015$, respectively) or week prevalence (48 studies, $n=24035)(p=0.005, p=0.034$, respectively $)$.

\section{Discussion}

The aim of this systematic review and meta-analysis was to study the present status of the pain prevalence and pain severity in patients with cancer and explore the determinants of pain prevalence. Based on the data of 122 articles, pain prevalence rates were $39.3 \%$ after curative treatment; $55.0 \%$ during anti-cancer treatment; $66.4 \%$ in advanced, metastatic or terminal disease and $50.7 \%$ in all cancer stages. The 52 studies that reported on pain severity resulted in a $38.0 \%$ prevalence of moderate to severe pain. With concern to types of cancer, lower pain prevalence rates were demonstrated in prostate cancer compared to head and neck, lung, and breast cancer. A possible explanation could be found in group assignment: 1180 out of 1493 included patients with prostate cancer belonged to the group after curative treatment. Higher prevalence rates were seen in studies from Asia compared to Europe, in studies that used point or week prevalence compared to recall periods of a month or a year, and in studies that included patients with an ECOG 2 and 3 compared to an ECOG 1. Age and race as well as method of data collection were not associated with overall pain prevalence rates. As opposed to a priori expectations, pain continues to be a prevalent symptom in patients with cancer. More attention for pain in patients with cancer; a better understanding of mechanisms underlying cancer pain; developments 
in pharmacological cancer pain management; and an increase of global opioid consumption: And nothing has changed during the last 10 years?

\section{More attention to cancer pain}

Considering the previous systematic review [7], the number of articles that addressed prevalence of cancer pain during the last 10 years has increased with $35 \%$ as compared to the 40 years before. The methodological quality of these papers improved (55\% of the articles reached the minimal quality score to be included in 2015 compared to $34 \%$ in 2005) and as a consequence the number of patients to be included in this review tripled (68,581 in 2015 compared to 20,613 in 2005). The global year against cancer pain of the IASP created a lot of awareness among health professionals as well as in the general public. A special interest group in cancer pain was installed, fact sheets were made available in many languages, and research was encouraged by grants. Cancer pain is present on Wikipedia, subject of twitter chats, and regularly addressed in the magazines of patients organisations. Yet, despite all these initiatives, a decrease in prevalence rates was not achieved and still many general misconceptions exist ranging from "you don't have to have pain anymore" to "opioids will kill you" [61].

\section{Developments in treatment according to the guidelines}

In a recent systematic review on the quality of cancer pain management, a $25 \%$ decrease in under-treatment of pain in patients with cancer was shown, based on the Pain Management Index (PMI) [8]. Nevertheless, still one third of the patients did not receive pain medication proportional to their pain intensity levels. Current curative treatment, non-advanced disease, the presence of comorbidities, a better performance status, and belonging to a minority were associated with under-treatment.

\section{Better understanding mechanisms underlying cancer pain}

Basic science facilitated better understanding of the mechanisms underlying cancer pain [62], which may have resulted in new clinical therapeutic options. For example, based on scientific findings, we know that a neuropathic component is present in metastatic bone cancer [62]. Another example is the introduction of the Rapid Onset Opioids (ROO's) for the treatment of breakthrough pain in cancer. These ROO's, which provide faster relief than immediate release preparations of other opioids with a shorter titration period, significantly lower the impact of pain on daily life and result in better satisfaction scores $[63,64]$. However, the prevalence of breakthrough pain is still 59\% [65]. 


\section{Increased opioid consumption}

Global opioid consumption increased from 28 to $42 \mathrm{mg}$ morphine equivalents per capita (ME) in the period from 2005 till 2012. At the same time, regional differences in opioid consumption are immense. To illustrate, in 2011 the ME with exception of methadone was 554 for the United States and 0.298 for Bangladesh [66]. In their systematic review on the quality of cancer pain management, Greco et al. [8] found that China, Russia and Nigeria accounted for more than $60 \%$ of the negative Pain Management Indexes whereas the opioid consumption rates in these countries are considerably low. The high Asian prevalence rates that were found in this study might be clarified against this background. Yet, studies from both Asia and North America revealed comparable prevalence rates, which imply that opioid availability alone is not an explanation for the high prevalence rates.

\section{Nothing has changed during the last 10 years?}

This conclusion might be too simple. Important to notice and inextricably linked with the prevalence of cancer pain is the idea that not only assessment and treatment have evolved, though also patients with cancer nowadays are quite different from patients half a century ago. Patients have become older and live longer. They are also often familiar with comorbidities and receive different treatments. Patients have become more assertive and are possibly more willing to mention their pain.

\section{Adequate therapeutic options}

According to the WHO three step analgesic ladder, in combination with appropriate dosage guidelines, pain relief should be adequate for $70-90 \%$ of patients [67-70]. A systematic review on pain relief based on the WHO ladder, 20 years after its introduction, demonstrated adequate pain relief in $45-100 \%$ of patients [71]. However, the evidence provided by the included studies was considered insufficient to grant the effectiveness of the WHO guidelines. Moreover, the European Association of Palliative Care (EAPC) confirms the importance of skilled use of opioid analgesics in the relief of cancer pain, but also acknowledges the lack of evidence to support clinical practice and guidelines. This in turn causes recommendations in practice guidelines to be based on expert consensus [72]. Among others, subject for debate include the benefit of paracetamol with step 3 opioids for which the evidence is 'weak if any' as well as the use of adjuvant analgesics for which outcomes are generally modest $[73,74]$. 


\section{More than medication}

Of course, medication is not the only approach. Already in her early work, summarised by David Clark [75], dame Cicely Saunders elaborated on the concept of 'Total pain', which holds its value up till today. Pain is not purely a physical experience, but involves various other components of human functioning including personality, mood, behavior, and social relations. A systematic review has identified an association between psychological distress, lack of social support, and cancer pain [76]. A variety of psychological and cognitive behavioral treatments can reduce pain severity and interference with function, as indicated in multiple meta-analysis and high quality randomised controlled trials [77]. It is widely accepted that a biopsychosocial approach in assessment and management is needed for treatment of pain in patients with cancer.

\section{Barriers}

Different barriers have been acknowledged in relation to adequate pain management in patients with cancer. Kwon [78] describes a lack of knowledge regarding the assessment and management of cancer pain. Health professionals are careful to prescribe opioids because of fear for adverse effects, tolerance, and addiction. Moreover, they may consider pain in specific patients as a result of emotional distress for which pain killers are not a solution. Patients struggle with misconceptions about analgesic use, concerns about pain communication, and a belief that pain is inevitable and uncontrollable [79]. Patients are known to be reluctant to take opioids [80]. Educational interventions for patients and professionals may improve the success of pain management [81]. These interventions will have to address all aspects of pain and pain management. Adam et al. [82] recently presented a multi-step process of optimal cancer pain management with respect to these barriers.

\section{Methodological considerations}

Our systematic review had some limitations that should be taken into consideration in interpreting the results. First, the application of eligibility criteria as well as methodological criteria resulted in a shortlist of studies; studies published in languages other than Dutch or English and studies with a quality score of 15 or less were not selected. Inclusion of these studies as well as the grey literature, that often present more recent findings and more negative or inconclusive data, could have impacted the results. Second, not every study made use of the criteria of Serlin [14] for defining mild, moderate or severe pain, and some studies did not give a pain definition at all. Further to this, the extent to which other pain conditions influenced the reported prevalence of pain in the different studies was unknown. Third, only three studies reported on pain prevalence in group 2 and 3 together and only four studies 
stratified pain prevalence for race, which actually did not allow us to formulate conclusions. Fourth, as mentioned previously, it is not clear whether the results of this review can be compared with the previous review due to many changes in the population of patients with cancer over time (age, co-morbidities, therapy, and patient empowerment).

\section{Conclusions}

This systematic review and meta-analysis shows that the prevalence of pain in patients with cancer still remains high and is unchanged over the last decade. Worldwide, over one-third of the patients after curative treatment, over half of the patients during anti-cancer treatment and two-third of the patients with advanced, metastatic or terminal disease have pain. Overall, more than one third of the patients graded their pain as moderate or severe. 


\section{References}

1. IASP (2008) 2008-2009 Global year against cancer Pain. Available from https://www.iasppain.org/GlobalYear/CancerPain. Accessed February 10, 2015.

2. Kroenke K, Theobald D, Wu J, Loza JK, Carpenter JS, Tu W (2010) The association of depression and pain with health-related quality of life, disability, and health care use in cancer patients. J Pain Symptom Manage 40:327-341.

3. Porter LS, Keefe FJ (2011) Psychosocial issues in cancer pain. Curr Pain Headache Rep 15:263-270.

4. Rief W, Bardwell WA, Dimsdale JE, Natarajan L, Flatt SW, Pierce JP (2011) Long-term course of pain in breast cancer survivors: a 4-year longitudinal study. Breast Cancer Res Treat 130:579-586.

5. Breivik H, Cherny N, Collett B, de Conno F, Filbet M, Foubert AJ, Cohen R, Dow L (2009) Cancer-related pain: a pan-European survey of prevalence, treatment, and patient attitudes. Ann Oncol 20:1420-1433.

6. Puetzler J, Feldmann RE, Jr., Brascher AK, Gerhardt A, Benrath J (2014) Improvements in health-related quality of life by comprehensive cancer pain therapy: a pilot study with breast cancer outpatients under palliative chemotherapy. Oncol Res Treat 37:456-462.

7. van den Beuken-van Everdingen $M H$, de Rijke JM, Kessels AG, Schouten HC, van Kleef M, Patijn J (2007) Prevalence of pain in patients with cancer: a systematic review of the past 40 years. Ann Oncol 18:1437-1449.

8. Greco MT, Roberto A, Corli O, Deandra S, Bandieri E, Cavuto S, Apolone G (2014) Quality of cancer pain management: an update of a systematic review of undertreatment of patients with cancer. J Clin Oncol 32:4149-4154.

9. Hastie BA, Gilson AM, Maurer MA, Cleary JF (2014) An examination of global and regional opioid consumption trends 1980-2011. J Pain Palliat Care Pharmacother 28:259-275.

10. Mantyh PW (2014) Bone cancer pain: from mechanism to therapy. Curr Opin Support Palliat Care 8:83-90.

11. Leboeuf-Yde C, Lauritsen JM (1995) The prevalence of low back pain in the literature. A structured review of 26 Nordic studies from 1954 to 1993. Spine 20:2112-2118.

12. Egger M (2001) Systematic Reviews. In: 2nd ed. London: BMJ Publishing Group.

13. Oken MM, Creech RH, Tormey DC, Horton J, Davis TE, McFadden ET, Carbone PP (1982) Toxicity and response criteria of the Eastern Cooperative Oncology Group. Am J Clin Oncol 5:649-55.

14. Serlin RC, Mendoza TR, Nakamura Y, Edwards KR, Cleeland CS (1995) When is cancer pain mild, moderate or severe? Grading pain severity by its interference with function. Pain 61:277-284.

15. van den Beuken-van Everdingen $M H$, de Rijke JM, Kessels AG, Schouten HC, van Kleef M, Patijn J (2007) High prevalence of pain in patients with cancer in a large population-based study in The Netherlands. Pain 132:312-320.

16. Torvinen S, Farkkila N, Sintonen H, Saarto T, Roine RP, Taari K (2013) Health-related quality of life in prostate cancer. Acta Oncol 52:1094-1101.

17. Hamaker ME, Buurman BM, van Munster BC, Kuper IM, Smorenburg CH, de Rooij SE (2011) The value of a comprehensive geriatric assessment for patient care in acutely hospitalized older patients with cancer. Oncologist 16:1403-1412.

18. Brant JM, Beck S, Dudley WN, Cobb P, Pepper G, Miaskowski C (2011) Symptom trajectories in posttreatment cancer survivors. Cancer Nurs 34:67-77.

19. Shin DW, Choi JE, Miyashita M, Choi JY, Kang J, Baik YJ, Mo HN, Park J. Kim HJ, Park EC (2011) Cross-cultural application of the Korean version of the European Organization for Research and Treatment of Cancer Quality of Life Questionnaire-Core 15-Palliative Care. J Pain Symptom Manage 41:478-484. 
20. Peters L, Sellick K (2006) Quality of life of cancer patients receiving inpatient and homebased palliative care. J Adv Nurs 53:524-533.

21. Park SM, Park MH, Won JH, Lee KO, Choe WS, Heo DS, Kim SY, Lee KS, Yun YH (2006) EuroQol and survival prediction in terminal cancer patients: a multicenter prospective study in hospice-palliative care units. Support Care Cancer 14:329-333.

22. Vaz AF, Pinto-Neto AM, Conde DM, Costa-Paiva L, Morais SS, Esteves SB (2007) Quality of life of women with gynecologic cancer: associated factors. Arch Gynecol Obstet 276: 583-589.

23. Kenne Sarenmalm E, Ohlen J, Jonsson T, Gaston-Johansson F (2007) Coping with recurrent breast cancer: predictors of distressing symptoms and health-related quality of life. J Pain Symptom Manage 34:24-39.

24. Rausch SM, Gonzalez BD, Clark MM, Patten C, Felten S, Liu H, Li Y, Sloan J, Yang (2012) SNPs in PTGS2 and LTA predict pain and quality of life in long term lung cancer survivors. Lung Cancer 77:217-223.

25. Giesinger JM, Wintner LM, Oberguggenberger AS, Gamper EM, Fiegl M, Denz H, Kemmler G, Zabernigg A, Holzner B (2011) Quality of life trajectory in patients with advanced cancer during the last year of life. J Palliat Med 14:904-912.

26. Steegers MA, Wolters B, Evers AW, Strobbe L, Wilder-Smith OH (2008) Effect of axillary lymph node dissection on prevalence and intensity of chronic and phantom pain after breast cancer surgery. J Pain 9:813-822.

27. Modonesi C, Scarpi E, Maltoni M, Derni S, Fabbri L, Martini F, Sansoni E, Amadori D (2005) Impact of palliative care unit admission on symptom control evaluated by the Edmonton Symptom Assessment System. J Pain Symptom Manage 30:367-373.

28. Mercadante S, Guccione C, Di Fatta S, Alaimo V, Prestia G, Bellingardo R, Gebbia V, Giarratano A, Casuccio A (2013) Cancer pain management in an oncological ward in a comprehensive cancer center with an established palliative care unit. Support Care Cancer 21:3287-3292.

29. Gomez-Batiste X, Porta-Sales J, Espinosa-Rojas J, Pascual-Lopez A, Tuca A, Rodriguez J (2010) Effectiveness of palliative care services in symptom control of patients with advanced terminal cancer: a spanish, multicenter, prospective, quasi-experimental, pre-post study. J Pain Symptom Manage 40:652-660.

30. Bakitas M, Lyons KD, Hegel MT, Balan S, Brokaw FC, Seville J, Hull JG, Li Z, Tosteson TD, Byock IR, Ahles TA (2009) Effects of a palliative care intervention on clinical outcomes in patients with advanced cancer: the project ENABLE II randomized controlled trial. JAMA 302:741-749.

31. Paiva CE, Paiva BS (2013) Prevalence, predictors, and prognostic impact of fatigue among Brazilian outpatients with advanced cancers. Support Care Cancer 21:1053-1060.

32. Latvala A, Syrjanen K, Salmenoja H, Salminen E (2009) Anaemia and other predictors of fatigue among patients on palliative therapy for advanced cancer. Anticancer Res 29: 2569-2575.

33. Sharma N, Hansen $\mathrm{CH}, \mathrm{O}^{\prime}$ Connor M, Thekkumpurath $\mathrm{P}$, Walker J, Kleiboer A, Murray G, Espie C, Storey D, Sharpe M, Fleming L (2012) Sleep problems in cancer patients: prevalence and association with distress and pain. Psychooncology 21:1003-1009.

34. Storey DJ, McLaren DB, Atkinson MA, Butcher I, Frew LC, Smyth JF, Sharpe M (2012) Clinically relevant fatigue in men with hormone-sensitive prostate cancer on long-term androgen deprivation therapy. Ann Oncol 23:1542-1549.

35. Garabeli Cavalli Kluthcovsky AC, Urbanetz AA, de Carvalho DS, Pereira Maluf EM, Schlickmann Sylvestre GC, Bonatto Hatschbach SB (2012) Fatigue after treatment in breast cancer survivors: prevalence, determinants and impact on health-related quality of life. Support Care Cancer 20:1901-1909.

36. Homsi J, Walsh D, Rivera N, Rybicki LA, Nelson KA, Legrand SB, Davis M, Naughton M, Gvozdjan D, Pham H (2006) Symptom evaluation in palliative medicine: patient report vs systematic assessment. Support Care Cancer 14:444-453. 
37. Laugsand EA, Sprangers MAG, Bjordal K, Skorpen F, Kaasa S, Klepstad P (2010) Health care providers underestimate symptom intensities of cancer patients: a multicenter European study. Health Qual Life Outcomes 8:104.

38. McPherson CJ, Wilson KG, Lobchuk MM, Brajtman S (2008) Family caregivers' assessment of symptoms in patients with advanced cancer: concordance with patients and factors affecting accuracy. J Pain Symptom Manage 35:70-82.

39. Nakaguchi T, Okuyama T, Uchida M, Ito Y, Komatsu H, Wada M, Akechi T (2013) Oncology nurses' recognition of supportive care needs and symptoms of their patients undergoing chemotherapy. Jpn J Clin Oncol 43:369-376.

40. Akin S, Durna Z (2013) A comparative descriptive study examining the perceptions of cancer patients, family caregivers, and nurses on patient symptom severity in Turkey. Eur J Oncol Nurs 17:30-37.

41. Teunissen SC, de Graeff A, de Haes HC, Voest EE (2006) Prognostic significance of symptoms of hospitalised advanced cancer patients. Eur J Cancer 42:2510-2516.

42. Narducci F, Grande R, Mentuccia L, Trapasso T, Sperduti I, Magnolfi E, Fariello AM, Gemma D, Gamucci T (2012) Symptom improvement as prognostic factor for survival in cancer patients undergoing palliative care: A pilot study. Support Care Cancer 20:1221-1226.

43. Breen SJ, Baravelli CM, Schofield PE, Jefford M, Yates PM, Aranda SK (2009) Is symptom burden a predictor of anxiety and depression in patients with cancer about to commence chemotherapy? Med J Aust 190:S99-104.

44. Hoekstra J, Vos R, Duijn NP, Schadé E, Bindels PJ (2006) Using the symptom monitor in a randomized controlled trial: the effect on symptom prevalence and severity. J Pain Symptom Manage 31(1):22-30.

45. Yildirim Y, Tokem Y, Bozkurt N, Fadiloglu C, Uyar M, Uslu R (2011) Reliability and validity of the Turkish version of the Memorial Symptom Assessment Scale in cancer patients. Asian Pac J Cancer Prev 12:3389-3396.

46. Guirimand F, Buyck JF, Lauwers-Allot E, Revnik J, Kerguen T, Aegerter P, Brasseur L, Cleeland CS (2010) Cancer-related symptom assessment in France: validation of the French M. D. Anderson Symptom Inventory. J Pain Symptom Manage 39:721-733.

47. O'Leary N, Murphy NF, O'Loughlin C, Tiernan E, McDonald K (2009) A comparative study of the palliative care needs of heart failure and cancer patients. Eur J Heart Fail 11:406-412.

48. Morita T, Fujimoto K, Namba M, Sasaki N, Ito T, Yamada C, Ohba A, Hiroyoshi M, Niwa H, Yamada T, Noda T (2008) Palliative care needs of cancer outpatients receiving chemotherapy: an audit of a clinical screening project. Supportive Care Cancer 16:101-107.

49. Finlay E, Lu HL, Henderson H, O'Dwyer PJ, Casarett DJ (2009) Do phase 1 patients have greater needs for palliative care compared with other cancer patients? Cancer 115:446-453.

50. Beck SL, Dudley WN, Barsevick A (2005) Pain, sleep disturbance, and fatigue in patients with cancer: using a mediation model to test a symptom cluster. Oncol Nurs Forum 32:542.

51. Zucca AC, Boyes AW, Linden W, Girgis A (2012) All's Well That Ends Well? Quality of life and physical symptom clusters in long-term cancer survivors across cancer types. J Pain Symptom Manage 43:720-731.

52. Velloso FS, Barra AA, Dias RC (2010) Functional performance of upper limb and quality of life after sentinel lymph node biopsy of breast cancer. Rev Bras Fisioter 15:146-153.

53. Graves KD, Arnold SM, Love CL, Kirsh KL, Moore PG, Passik SD (2007) Distress screening in a multidisciplinary lung cancer clinic: prevalence and predictors of clinically significant distress. Lung Cancer 55:215-224.

54. Wilberg P, Hjermstad MJ, Ottesen S, Herlofson BB (2012) Oral health is an important issue in end-of-life cancer care. Support Care Cancer 20:3115-3122.

55. Kwon YC, Yun YH, Lee KH, Son KY, Park SM, Chang YJ, Wang XS, Mendoza TR, Cleeland CS (2006) Symptoms in the lives of terminal cancer patients: which is the most important? Oncology 71:69-76.

56. Kirkova J, Rybicki L, Walsh D, Aktas A (2012) Symptom prevalence in advanced cancer: age, gender, and performance status interactions. Am J Hosp Palliat Care 29:139-145. 
57. Kubrak C, Olson K, Jha N, Jensen L, McCargar L, Seikaly H, Harris J, Scrimger R, Parliament M, Baracos VE (2010) Nutrition impact symptoms: key determinants of reduced dietary intake, weight loss, and reduced functional capacity of patients with head and neck cancer before treatment. Head Neck 32:290-300.

58. Gwede CK, Small BJ, Munster PN, Andrykowski MA, Jacobsen PB (2008) Exploring the differential experience of breast cancer treatment-related symptoms: a cluster analytic approach. Support Care Cancer 16:925-933.

59. Waldenström AC, Olsson C, Wilderang U, Dunberger G, Lind H, al-Abany M, Palm $\AA$, AvallLundqvist $E$, Johansson KA, Steineck G (2011) Pain and mean absorbed dose to the pubic bone after radiotherapy among gynecological cancer survivors. Int J Radiat Oncol Biol Phys 80:1171-1180.

60. Lengacher CA, Reich RR, Post-White J, Moscoso M, Shelton MM, Barta M, Le N, Budhrani P (2012) Mindfulness based stress reduction in post-treatment breast cancer patients: an examination of symptoms and symptom clusters. J Behav Med 35:86-94.

61. Schumacher KL, Plano Clark VL, West CM, Dodd MJ, Rabow MW, Miaskowski C (2014) Pain medication management processes used by oncology outpatients and family caregivers part II: home and lifestyle contexts. J Pain Symptom Manage 48:784-796.

62. Yoneda T, Hiasa M, Nagata Y, Okui T, White F (2015) Contribution of acidic extracellular microenvironment of cancer-colonized bone to bone pain. Biochim Biophys Acta 1848(10):2677-2684.

63. Rivera IV, Muñoz Garrido JC, García Velasco P, Ximénez de Enciso IE, Velázquez Clavarana L (2014) Efficacy of sublingual fentanyl vs. oral morphine for cancer-related breakthrough pain. Adv Ther 31:107-117.

64. Kongsgaard UE, Eeg M, Greisen $H$ (2014) The use of Instanyl in the treatment of breakthrough pain in cancer patients: a 3-month observational, prospective, cohort study. Support Care Cancer 22:1655-1662.

65. Deandrea S, Corli O, Consonni D, Villani W, Greco MT, Apolone G (2014) Prevalence of breakthrough cancer pain: a systematic review and a pooled analysis of published literature. J Pain Symptom Manage 47:57-76.

66. Pain \& Policy Studies Groups, University of Wisconsin-Madison (2015) Opioid Conumption Data. Available from http://www.painpolicy.wisc.edu/opioid-consumption-data. Accessed February 10, 2015.

67. Ventafridda V, Tamburini M, Caraceni A, De Conno F, Naldi F (1987) A validation study of the WHO method for cancer pain relief. Cancer 59:850-856.

68. Walker VA, Hoskin PJ, Hanks GW, White ID (1988) Evaluation of WHO analgesic guidelines for cancer pain in a hospital-based palliative care unit. J Pain Symptom Manage 3:145-149.

69. Zech DF, Grond S, Lynch J, Hertel D, Lehmann KA (1995) Validation of World Health Organization Guidelines for cancer pain relief: a 10-year prospective study. Pain 63:65-76.

70. Felleiter P, Gustorff B, Lierz P, Hornykewycz S, Kress HG (2005) [Use of the World Health Organization guidelines on cancer pain relief before referral to a specialized pain service]. Schmerz 19:265-271.

71. Azevedo Sao Leao Ferreira K, Kimura M, Jacobsen Teixeira M (2006) The WHO analgesic ladder for cancer pain control, twenty years of use. How much pain relief does one get from using it? Support Care Cancer 14:1086-1093.

72. Caraceni A, Hanks G, Kaasa S, Bennett MI, Brunelli C, Cherny N, Dale O, De Conno F, Fallon M, Hanna M, Haugen DF, Juhl G, King S, Klepstad P, Laugsand EA, Maltoni M, Mercadante S, Nabal M, Pigni A, Radbruch L, Reid C, Sjogren P, Stone PC, Tassinari D, Zeppetella G; European Palliative Care Research Collaborative (EPCRC); European Association for Palliative Care (EAPC) (2012) Use of opioid analgesics in the treatment of cancer pain: evidence-based recommendations from the EAPC. Lancet Oncol 13:e58-68. 
73. Nabal M, Librada S, Redondo MJ, Pigni A, Brunelli C, Caraceni A (2012) The role of paracetamol and nonsteroidal anti-inflammatory drugs in addition to WHO Step III opioids in the control of pain in advanced cancer. A systematic review of the literature. Palliat Med 26:305-312.

74. Finnerup NB, Attal N, Haroutounian S, McNicol E, Baron R, Dworkin RH, Gilron I, Haanpää M, Hansson P, Jensen TS, Kamerman PR, Lund K, Moore A, Raja SN, Rice AS, Rowbotham M, Sena E, Siddall P, Smith BH, Wallace M (2015) Pharmacotherapy for neuropathic pain in adults: a systematic review and meta-analysis. Lancet Neurol. 14(2):162-173.

75. Clark D (1999) 'Total pain', disciplinary power and the body in the work of Cicely Saunders, 1958-1967. Soc Sci Med 49:727-736.

76. Zaza C, Baine N (2002) Cancer pain and psychosocial factors: a critical review of the literature. J Pain Symptom Manage 24:526-542.

77. Syrjala KL, Jensen MP, Mendoza ME, Yi JC, Fisher HM, Keefe FJ (2014) Psychological and behavioral approaches to cancer pain management. J Clin Oncol 32:1703-1711.

78. Kwon JH (2014) Overcoming barriers in cancer pain management. J Clin Oncol 32: 1727-1733.

79. Jacobsen R, Moldrup C, Christrup L, Sjogren P (2009) Patient-related barriers to cancer pain management: a systematic exploratory review. Scand J Caring Sci 23:190-208.

80. Miaskowski C, Dodd MJ, West C, Paul SM, Tripathy D, Koo P, Schumacher K (2001) Lack of adherence with the analgesic regimen: a significant barrier to effective cancer pain management. J Clin Oncol 19:4275-4279.

81. Marie N, Luckett T, Davidson PM, Lovell M, Lal S (2013) Optimal patient education for cancer pain: a systematic review and theory-based meta-analysis. Support Care Cancer 21: 3529-3537.

82. Adam R, Bond C, Murchie P (2015) Educational interventions for cancer pain. A systematic review of systematic reviews with nested narrative review of randomized controlled trials. Patient Educ Couns 98:269-282.

83. Abela JE (2009) Symptom management by a community palliative care team. Malta Med J 21:12-18.

84. Abu-Saad Huijer H, Doumit M, Abboud S, Dimassi H (2012) Quality of palliative care. Perspective of Lebanese patients with cancer. J Med Liban 60:91-98.

85. Achterberg WP, Gambassi G, Finne-Soveri H, Liperoti R, Noro A, Frijters DH, Cherubini A, Dell'aquila G, Ribbe MW (2010) Pain in European long-term care facilities: cross-national study in Finland, Italy and the Netherlands. Pain 148:70-74.

86. Alshemmari S, Ezzat H, Samir Z, Sajnani K, Alsirafy S (2010) Symptom burden in hospitalized patients with cancer in kuwait and the need for palliative care. Am J Hosp Palliat Care 27:446-449.

87. Alsirafy SA, El Mesidy SM, Abou-Elela EN, Elfaramawy YI (2010) Pain prevalence in advanced cancer patients in Egypt. Eur J Palliat Care 17:303-305.

88. Aslan FE, Kayis A, Inanir I, Onturk ZK, Olgun N, Karabacak U (2011) Prevalence of cancer pain in outpatients registered to a cancer therapy center in Turkey. Asian Pac J Cancer Prev 12:1373-1375.

89. Barbera L, Seow H, Howell D, Sutradhar R, Earle C, Liu Y, Stitt A, Husain A, Sussman J, Dudgeon D (2010) Symptom burden and performance status in a population-based cohort of ambulatory cancer patients. Cancer 116:5767-1576.

90. Bekelman DB, Rumsfeld JS, Havranek EP, Yamashita TE, Hutt E, Gottlieb SH, Dy SM, Kutner JS (2009) Symptom burden, depression, and spiritual well-being: a comparison of heart failure and advanced cancer patients. J Gen Intern Med 24:592-598.

91. Bergmann A, Bourrus NS, de Carvalho CM, Dias Rde A, Fabro EA, Sales NS, de Aguiar SS (2011) Arm symptoms and overall survival in Brazilian patients with advanced breast cancer. Asian Pac J Cancer Prev 12:2939-2942. 
92. Borgsteede SD, Deliens L, Beentjes B, Schellevis F, Stalman WA, Van Eijk JT, Van der Wal G (2007) Symptoms in patients receiving palliative care: a study on patient-physician encounters in general practice. Palliat Med 21:417-423.

93. Butt Z, Wagner LI, Beaumont JL, Paice JA, Peterman AH, Shevrin D, Von Roenn JH, Carro G, Straus JL, Muir JC, Cella D (2008) Use of a single-item screening tool to detect clinically significant fatigue, pain, distress, and anorexia in ambulatory cancer practice. J Pain Symptom Manage 35:20-30.

94. Camps C, Caballero C, Blasco A, Safont MJ, Berrocal A, Garde J, Juarez A, Sirera R, Bremnes RM (2005) Weekly paclitaxel as second/third-line treatment in advanced non-small cell lung cancer patients: efficacy and tolerability. Anticancer Res 25:4611-4614.

95. Chen ML, Tseng HC (2006) Symptom clusters in cancer patients. Support Care Cancer 14:825-830.

96. Cheng KK, Wong EM, Ling WM, Chan CW, Thompson DR (2009) Measuring the symptom experience of Chinese cancer patients: a validation of the Chinese version of the Memorial Symptom Assessment Scale. J Pain Symptom Manage 37:44-57.

97. Cheng KK, Thompson DR, Ling MW, Chan CW (2005) Measuring symptom prevalence, severity and distress of cancer survivors. Clin Effect Nurs 9:154-160.

98. Cheung WY, Le LW, Zimmermann C (2009) Symptom clusters in patients with advanced cancers. Support Care Cancer 17:1223-1230.

99. Choi JY, Chang YJ, Song HY, Jho HJ, Lee MK (2013) Factors that affect quality of dying and death in terminal cancer patients on inpatient palliative care units: perspectives of bereaved family caregivers. J Pain Symptom Manage 45:735-745.

100. Chow E, Fan G, Hadi S, Wong J, Kirou-Mauro A, Filipczak L (2008) Symptom clusters in cancer patients with brain metastases. Clin Oncol 20:76-82.

101. Cohen MZ, Rozmus CL, Mendoza TR, Padhye NS, Neumann J, Gning I, Aleman A, Giralt S, Cleeland CS (2012) Symptoms and quality of life in diverse patients undergoing hematopoietic stem cell transplantation. J Pain Symptom Manage 44:168-180.

102. De Raaf PJ, De Klerk C, Timman R, Busschbach JJ, Oldenmenger WH, van der Rijt CC (2013) Systematic monitoring and treatment of physical symptoms to alleviate fatigue in patients with advanced cancer: a randomized controlled trial. J Clin Oncol 31:716-723.

103. de Santiago A, Portela MA, Ramos L, Larumbe A, Urdiroz J, Martínez M, García-Foncillas J, Centeno $C$ (2012) A new palliative care consultation team at the oncology department of a university hospital: an assessment of initial efficiency and effectiveness. Support Care Cancer 20:2199-2203.

104. Delgado-Guay MO, Parsons HA, Li Z, Palmer LJ, Bruera E (2009) Symptom distress, interventions, and outcomes of intensive care unit cancer patients referred to a palliative care consult team. Cancer 115:437-445.

105. Dumitrescu L, van den Heuvel-Olaroiu M, van den Heuvel WJ (2007) Changes in symptoms and pain intensity of cancer patients after enrollment in palliative care at home. J Pain Symptom Manage 34:488-496.

106. Elsayem A, Mori M, Parsons HA, Munsell MF, Hui D, Delgado-Guay MO, Paraskevopoulos T, Fadul NA, Bruera E (2010) Predictors of inpatient mortality in an acute palliative care unit at a comprehensive cancer center. Support Care Cancer 18:67-76.

107. Fadol A, Mendoza T, Gning I, Kernicki J, Symes L, Cleeland CS, Lenihan D (2008) Psychometric testing of the MDASI-HF: a symptom assessment instrument for patients with cancer and concurrent heart failure. J Card Fail 14:497-507.

108. Fainsinger RL, Nekolaichuk CL, Lawlor PG, Neumann CM, Hanson J, Vigano A (2005) A multicenter study of the revised Edmonton Staging System for classifying cancer pain in advanced cancer patients. J Pain Symptom Manage 29:224-237.

109. Fox SW, Lyon DE (2006) Symptom clusters and quality of life in survivors of lung cancer. Oncol Nurs Forum 33:931-936. 
110. Franceschini J, Jardim JR, Fernandes AL, Jamnik S, Santoro IL (2013) Relationship between the magnitude of symptoms and the quality of life: a cluster analysis of lung cancer patients in Brazil. J Bras Pneumol 39:23-31.

111. Garcia de Paredes ML, del Moral Gonzalez F, Martinez del Prado P, Martí Ciriquián JL, Enrech Francés S, Cobo Dols M, Esteban González E, Ortega Granados AL, Majem Tarruella M, Cumplido Burón JD, Gascó Hernández A, López Miranda E, Ciria Santos JP, de Castro Carpeño FJ (2011) First evidence of oncologic neuropathic pain prevalence after screening 8615 cancer patients. Results of the On study. Ann Oncol 22:924-930.

112. Georges JJ, Onwuteaka-Philipsen BD, van der Wal G, van der Heide A, van der Maas PJ (2005) Differences between terminally ill cancer patients who died after euthanasia had been performed and terminally ill cancer patients who did not request euthanasia. Palliat Med 19:578-586.

113. Gerbershagen HJ, Ozgür E, Straub K, Dagtekin O, Gerbershagen K, Petzke F, Heidenreich A, Lehmann KA, Sabatowski R (2008) Prevalence, severity, and chronicity of pain and general health-related quality of life in patients with localized prostate cancer. Eur J Pain 12: 339-350.

114. Ghosn M, Boutros C, Geara S, Kattan J, Nasr F, Chahine G (2011) Experience with palliative care in patients with advanced cancer at a tertiary care hospital in a developing country. Support Care Cancer 19:573-575.

115. Gooneratne NS, Dean GE, Rogers AE, Nkwuo JE, Coyne JC, Kaiser LR (2007) Sleep and quality of life in long-term lung cancer survivors. Lung Cancer 58:403-410.

116. Gough NJ, Smith C, Ross JR, Riley J, Judson I (2011) Symptom burden, survival and palliative care in advanced soft tissue sarcoma. Sarcoma: 2011.

117. Halawi R, Saad Aldin E, Baydoun A, Dbouk H, Nahleh Z, Nasser Z, Tfayli A (2012) Physical symptom profile for adult cancer inpatients at a Lebanese cancer unit. Eur J Intern Med 23:e185-e189.

118. Harding R, Selman L, Agupio G, Dinat N, Downing J, Gwyther L, Mashao T, Mmoledi K, Sebuyira LM, Ikin B, Higginson IJ (2011) The prevalence and burden of symptoms amongst cancer patients attending palliative care in two African countries. Eur J Cancer 47:51-56.

119. Helzlsouer KJ, Gallicchio L, MacDonald R, Wood B, Rushovich E (2012) A prospective study of aromatase inhibitor therapy, vitamin D, C-reactive protein and musculoskeletal symptoms. Breast Cancer Res Treat 131:277-285.

120. Hickey OT, Burke SM, Hafeez P, Mudrakouski AL, Hayes ID, Shorten GD (2010) Severity of acute pain after breast surgery is associated with the likelihood of subsequently developing persistent pain. Clin J Pain 26:556-560.

121. Hirakawa Y, Masuda Y, Kuzuya M, Iguchi A, Uemura K (2006) Symptoms and care of elderly patients dying at home of lung, gastric, colon, and liver cancer. Japan Med Assoc J 49: $140-145$.

122. Hoffman AJ, Given BA, von Eye A, Gift AG, Given CW (2007) Relationships among pain, fatigue, insomnia, and gender in persons with lung cancer. Oncol Nurs Forum 34:785-792.

123. Im EO, Chee W, Guevara E, Lim HJ, Liu Y, Shin H (2007) Gender and ethnic differences in cancer pain experience: a multiethnic survey in the United States. Nurs Res 56:296-306.

124. Inoue $T$, Segawa $T$, Kamba T, Yoshimura K, Nakamura E, Nishiyama H, Ito N, Kamoto T, Habuchi T, Ogawa O (2009) Prevalence of skeletal complications and their impact on survival of hormone refractory prostate cancer patients in Japan. Urology 73:1104-1109.

125. Iritani S, Tohgi M, Miyata H, Ohi G (2011) Impact of dementia on cancer discovery and pain. Psychogeriatrics 11:6-13.

126. Johnson VM, Teno JM, Bourbonniere M, Mor V (2005) Palliative care needs of cancer patients in U.S. nursing homes. J Palliat Med 8:273-279.

127. Kim JY, Jang WY, Hur MH, Lee KK, Do YR, Park KU, Hong YS, Song HS (2012) Prevalence and management of pain by different age groups of Korean cancer patients. Am J Hosp Palliat Care 30:393-398. 
128. Lal M, Raheja S, Kale S, Das N, Gogia AR, Bhowmik KT (2012) An experience with 156 patients attending a newly organized pain and palliative care clinic in a tertiary hospital. Indian J Cancer 49:293-297.

129. Lesperance RN, Kjorstadt RJ, Halligan JB, Steele SR (2008) Colorectal complications of external beam radiation versus brachytherapy for prostate cancer. Am J Surg 195:616-620.

130. Lin YL, Lin IC, Liou JC (2011) Symptom patterns of patients with head and neck cancer in a palliative care unit. J Palliat Med 14:556-559.

131. Liu Y, Xi QS, Xia S, Zhuang L, Zheng W, Yu S (2011) Association between symptoms and their severity with survival time in hospitalized patients with far advanced cancer. Palliat Med 25:682-690.

132. Liu Y, Zhang P-Y, Na J, Ma C, Huo WL, Han L, Yu Y, Xi QS (2013) Prevalence, intensity, and prognostic significance of common symptoms in terminally ill cancer patients. J Palliat Med 16:752-757.

133. Lukas A, Mayer B, Fialova D, Topinkova E, Gindin J, Onder G, Bernabei R, Nikolaus T, Denkinger MD (2013) Pain characteristics and pain control in European nursing homes: cross-sectional and longitudinal results from the Services and Health for Elderly in Long TERm care [SHELTER] study. J Am Med Dir Assoc 14:421-428.

134. Meeske K, Smith AW, Alfano CM, McGregor BA, McTiernan A, Baumgartner KB, Malone KE, Reeve BB, Ballard-Barbash R, Bernstein L (2007) Fatigue in breast cancer survivors two to five years post diagnosis: a HEAL Study report. Qual Life Res 16:947-960.

135. Mendoza TR, Wang XS, Lu C, Palos GR, Liao Z, Mobley GM, Kapoor S, Cleeland CS (2011) Measuring the symptom burden of lung cancer: the validity and utility of the lung cancer module of the M. D. Anderson Symptom Inventory. Oncologist 16:217-227.

136. Mercadante S, Valle A, Sabba S, Orlando A, Guolo F, Gulmini L, Ori S, Bellingardo R, Casuccio A (2013) Pattern and characteristics of advanced cancer patients admitted to hospices in Italy. Support Care Cancer 21:935-939.

137. Mercadante S, Zagonel V, Breda E, Arcara C, Gebbia V, Porzio G, Aielli F, David F, Gammucci T, Narducci F, Lanzetta G, Restuccia R, Lembo A, Passeri V, Virzì V, Casuccio A (2010) Breakthrough pain in oncology: a longitudinal study. J Pain Symptom Manage 40:183-190.

138. Mota DD, Pimenta CA, Caponero R (2012) Fatigue in colorectal cancer patients: prevalence and associated factors. Rev Lat Am Enfermagem 20:495-503.

139. Omran S, Saeed AM, Simpson J (2012) Symptom distress of Jordanian patients with cancer receiving chemotherapy. Int J Nurs Pract 18:125-132.

140. Pantilat SZ, O'Riordan DL, Dibble SL, Landefeld CS (2012) Longitudinal assessment of symptom severity among hospitalized elders diagnosed with cancer, heart failure, and chronic obstructive pulmonary disease. J Hosp Med 7:567-572.

141. Parsons HA, Delgado-Guay MO, El Osta B, Chacko R, Poulter V, Palmer JL, Bruera E (2008) Alcoholism screening in patients with advanced cancer: impact on symptom burden and opioid use. J Palliat Med 11:964-968.

142. Pelayo-Alvarez M, Perez-Hoyos S, Agra-Varela Y (2013) Reliability and concurrent validity of the Palliative Outcome Scale, the Rotterdam Symptom Checklist, and the Brief Pain Inventory. J Palliat Med 16:867-874.

143. Peng WL, Wu GJ, Sun WZ, Chen JC, Huang AT (2006) Multidisciplinary management of cancer pain: a longitudinal retrospective study on a cohort of end-stage cancer patients. J Pain Symptom Manage 32:444-452.

144. Porta-Sales J, Codorniu N, Gomez-Batiste X, Alburquerque E, Serrano-Bermúdez G, SánchezPosadas D, Pérez-Martin X, González-Barboteo J, Tuca-Rodríguez A (2005) Patient appointment process, symptom control and prediction of follow-up compliance in a palliative care outpatient clinic. J Pain Symptom Manage 30:145-153. 
145. Price MA, Bell ML, Sommeijer DW, Friedlander M, Stockler MR, Defazio A, Webb PM, Butow PN; Australian Ovarian Cancer Study Group; Australian Ovarian Cancer Study Quality of Life Study Investigators (2013) Physical symptoms, coping styles and quality of life in recurrent ovarian cancer: a prospective population-based study over the last year of life. Gynecol Oncol 130:162-168.

146. Puhse G, Wachsmuth JU, Kemper S, Husstedt IW, Evers S, Kliesch S (2012) Chronic pain has a negative impact on sexuality in testis cancer survivors. J Androl 33:886-893.

147. Rannestad T, Skjeldestad FE (2007) Pain and quality of life among long-term gynecological cancer survivors: a population-based case-control study. Acta Obstet Gynecol Scand 86:1510-1516.

148. Rayment C, Hjermstad MJ, Aass N, Kaasa S, Caraceni A, Strasser F, Heitzer E, Fainsinger R, Bennett MI; European Palliative Care Research Collaborative (EPCRC) (2013) Neuropathic cancer pain: Prevalence, severity, analgesics and impact from the European Palliative Care Research Collaborative-Computerised Symptom Assessment study. Palliat Med 27:714-721.

149. Reed E, Simmonds P, Haviland J, Corner J (2012) Quality of life and experience of care in women with metastatic breast cancer: a cross-sectional survey. J Pain Symptom Manage 43:747-758.

150. Reyes-Gibby CC, Anderson KO, Shete S, Bruera E, Yennurajalingam S (2012) Early referral to supportive care specialists for symptom burden in lung cancer patients: a comparison of non-Hispanic whites, Hispanics, and non-Hispanic blacks. Cancer 118:856-863.

151. Reyes-Gibby CC, Chan W, Abbruzzese JL, Xiong HQ, Ho L, Evans DB, Varadhachary G, Bhat S, Wolff RA, Crane C (2007) Patterns of self-reported symptoms in pancreatic cancer patients receiving chemoradiation. J Pain Symptom Manage 34:244-252.

152. Riechelmann RP, Krzyzanowska MK, O'Carroll A, Zimmermann C (2007) Symptom and medication profiles among cancer patients attending a palliative care clinic. Support Care Cancer 15:1407-1412.

153. Saidi HS, Karuri D, Nyaim EO (2008) Correlation of clinical data, anatomical site and disease stage in colorectal cancer. East Afr Med J 85:259-262.

154. Salamonde GL, Vercosa N, Barrucand L, Da Costa AF (2006) Clinical and therapeutic analysis of oncology patients treated at the pain and Palliative Care Program of the Hospital Universitario Clementino Fraga Filho in 2003. Braz J Anesthesiol 56:602-618.

155. Sandgren A, Fridlund B, Nyberg P, Strang P, Petersson K, Thulesius H (2010) Symptoms, care needs and diagnosis in palliative cancer patients in acute care hospitals: a 5-year follow-up survey. Acta Oncol 49:460-466.

156. Sarna L, Cooley ME, Brown JK, Chernecky C, Elashoff D, Kotlerman J (2008) Symptom severity 1 to 4 months after thoracotomy for lung cancer. Am J Crit Care 17:455-467.

157. Schrier M, Amital D, Arnson Y, Rubinow A, Altaman A, Nissenabaum B, Amital H (2012) Association of fibromyalgia characteristics in patients with non-metastatic breast cancer and the protective role of resilience. Rheumatol Int 32:3017-3023.

158. Semionov V, Singer $Y$, Shvartzman P (2012) Prevalence and management of symptoms during the last month of life. Isr Med Assoc J 14:96-99.

159. Sherman DW, Ye XY, Beyer McSherry C, Parkas V, Calabrese M, Gatto M (2007) Symptom assessment of patients with advanced cancer and AIDS and their family caregivers: the results of a quality-of-life pilot study. Am J Hosp Palliat Care 24:350-365.

160. Simone CB, 2nd, Vapiwala N, Hampshire MK, Metz JM (2012) Cancer patient attitudes toward analgesic usage and pain intervention. Clin J Pain 28:157-162.

161. Skaug K, Eide GE, Gulsvik A (2007) Prevalence and predictors of symptoms in the terminal stage of lung cancer: a community study. Chest 131:389-394.

162. Smith AK, Cenzer IS, Knight SJ, Puntillo KA, Widera E, Williams BA, Boscardin WJ, Covinsky KE (2010) The epidemiology of pain during the last 2 years of life. Ann Intern Med 153: 563-569.

163. Smith D, Ballal M, Hodder R, Soin G, Selvachandran SN, Cade D (2006) Symptomatic presentation of early colorectal cancer. Ann R Coll Surg Engl 88:185-190. 
164. Spoozak L, Seow H, Liu Y, Wright J, Barbera L (2013) Performance status and symptom scores of women with gynecologic cancer at the end of life. Int J Gynecol Cancer 23: 971-978.

165. Steel JL, Kim KH, Dew MA, Unruh ML, Antoni MH, Olek MC, Geller DA, Carr BI, Butterfield LH, Gamblin TC (2010) Cancer-related symptom clusters, eosinophils, and survival in hepatobiliary cancer: an exploratory study. J Pain Symptom Manage 39:859-871.

166. Stuver SO, Isaac T, Weeks JC, Block S, Berry DL, Davis RB, Weingart SN (2012) Factors associated with pain among ambulatory patients with cancer with advanced disease at a comprehensive cancer center. J Oncol Pract 8:e17-23.

167. Tsai JS, Wu CH, Chiu TY, Chen CY (2010) Significance of symptom clustering in palliative care of advanced cancer patients. J Pain Symptom Manage 39:655-662.

168. Tsoussis S, Ikonomidou F, Vourliotaki I, Papadaki A, Apostolakis S (2007) Clinical burden of terminal phase in cancer patients. J BUON 12:383-388.

169. Vergnenegre A, Hominal S, Tchalla AE, Berard H, Monnet I, Fraboulet G, Baize N, AudigierValette C, Robinet G, Oliviero G, Le Caer H, Thomas P, Geriniere L, Mastroianni B, Chouaid C; GFPC 0804 team (2013) Assessment of palliative care for advanced non-small-cell lung cancer in France: a prospective observational multicenter study (GFPC 0804 study). Lung Cancer 82:353-357.

170. Walsh D, Rybicki L (2006) Symptom clustering in advanced cancer. Support Care Cancer 14:831-836.

171. Wang XS, Cleeland CS, Mendoza TR, Yun YH, Wang Y, Okuyama T, Johnson VE (2010) Impact of cultural and linguistic factors on symptom reporting by patients with cancer. J Natl Cancer Inst 102:732-738.

172. Wang XS, Shi Q, Lu C, Basch EM, Johnson VE, Mendoza TR, Mobley GM, Cleeland C (2010) Prognostic value of symptom burden for overall survival in patients receiving chemotherapy for advanced nonsmall cell lung cancer. Cancer 116:137-145.

173. Watanabe SM, Nekolaichuk C, Beaumont C, Johnson L, Myers J, Strasser F (2011) A multicenter study comparing two numerical versions of the Edmonton Symptom Assessment System in palliative care patients. J Pain Symptom Manage 41:456-468.

174. Yalcin B, Buyukcelik A, Senler FC, Utkan G, Tek I, Dogan M, Doruk H, Demirkazik A, Akbulut A, Icli F (2005) Frequency of symptoms in patients with advanced cancer. Turk J Cancer 35:177-180.

175. Yan S, Kin-Fong C (2006) Quality of life of patients with terminal cancer receiving palliative home care. J Palliat Med 22:261-266.

176. Yennurajalingam S, Kang JH, Hui D, Kang DH, Kim SH, Bruera E (2012) Clinical response to an outpatient palliative care consultation in patients with advanced cancer and cancer pain. J Pain Symptom Manag 44:340-50.

177. Reyes-Gibby CC, Aday LA, Anderson KO, Mendoza TR, Cleeland CS (2006) Pain, depression, and fatigue in community-dwelling adults with and without a history of cancer. J Pain Symptom Manage 32:118-28.

178. Haisfield-Wolfe ME, McGuire DB, Soeken K, Geiger-Brown J, De Forge B, Suntharalingam M (2012) Prevalence and correlates of symptoms and uncertainty in illness among head and neck cancer patients receiving definitive radiation with or without chemotherapy. Support Care Cancer 20:1885-1893.

179. So WK, Marsh G, Ling WM, Leung FY, Lo JC, Yeung M, Li GK (2009) The symptom cluster of fatigue, pain, anxiety, and depression and the effect on the quality of life of women receiving treatment for breast cancer: a multicenter study. Oncol Nurs Forum 36:E205-214.

180. Henningsohn L, Wijkström H, Pedersen J, Ahlstrand C, Aus G, Bergmark K, Onelöv E, Steineck G (2003) Time after surgery, symptoms and well-being in survivors of urinary bladder cancer. BJU Int 91:325-330.

181. Andersen KG, Gartner R, Kroman N, Flyger H, Kehlet H (2012) Persistent pain after targeted intraoperative radiotherapy (TARGIT) or external breast radiotherapy for breast cancer: a randomized trial. Breast 21:46-49. 
182. Andersen KG, Jensen MB, Tvedskov TF, Kehlet H, Gärtner R, Kroman N (2013) Persistent pain, sensory disturbances and functional impairment after immediate or delayed axillary lymph node dissection. Eur J Surg Oncol 39:31-35.

183. Beck SL, Towsley GL, Caserta MS, Lindau K, Dudley WN (2009) Symptom experiences and quality of life of rural and urban older adult cancer survivors. Cancer Nurs 32:359-369.

184. Brown JC, Chu CS, Cheville AL, Schmitz KH (2013) The prevalence of lymphedema symptoms among survivors of long-term cancer with or at risk for lower limb lymphedema. Am J Phys Med Rehabil 92:223-231.

185. Crew KD, Greenlee H, Capodice J, Raptis G, Brafman L, Fuentes D, Sierra A, Hershman DL (2007) Prevalence of joint symptoms in postmenopausal women taking aromatase inhibitors for early-stage breast cancer. J Clin Oncol 25:3877-3883.

186. Deshields TL, Potter P, Olsen S, Liu J, Dye L (2011) Documenting the symptom experience of cancer patients. J Support Oncol 9:216-223.

187. Dijkstra PU, Rietman JS, Geertzen JH (2007) Phantom breast sensations and phantom breast pain: a 2-year prospective study and a methodological analysis of literature. Eur J Pain 11:99-108.

188. Gahm J, Wickman M, Brandberg Y (2010) Bilateral prophylactic mastectomy in women with inherited risk of breast cancer: prevalence of pain and discomfort, impact on sexuality, quality of life and feelings of regret two years after surgery. Breast 19:462-469.

189. Gartner R, Jensen MB, Nielsen J, Ewertz M, Kroman N, Kehlet H (2009) Prevalence of and factors associated with persistent pain following breast cancer surgery. JAMA 302:19851992.

190. Green CR, Hart-Johnson T, Loeffler DR (2011) Cancer-related chronic pain: examining quality of life in diverse cancer survivors. Cancer 117:1994-2003.

191. Grosen K, Laue Petersen G, Pfeiffer-Jensen M, Hoejsgaard A, Pilegaard HK (2013) Persistent post-surgical pain following anterior thoracotomy for lung cancer: a cross-sectional study of prevalence, characteristics and interference with functioning. Eur J Cardiothorac Surg 43: 95-103.

192. Hansen DM, Kehlet H, Gartner R (2011) Phantom breast sensations are frequent after mastectomy. Dan Med Bull 58:A4259.

193. Hickey OT, Nugent NF, Burke SM, Hafeez P, Mudrakouski AL, Shorten GD (2011) Persistent pain after mastectomy with reconstruction. J Clin Anesth 23:482-488.

194. Hoimyr H, Rokkones KA, von Sperling ML, Finnerup K, Jensen TS, Finnerup NB (2011) Persistent pain after lymph node excision in patients with malignant melanoma is neuropathic. Pain 152:2721-2728.

195. Ishiyama H, Niino K, Hosoya T, Hayakawa K (2006) Results of a questionnaire survey for symptom of late complications caused by radiotherapy in breast conserving therapy. Breast Cancer 13:197-201.

196. Li YY, Kong SK (2011) Persistent pain after breast cancer surgery in a Chinese population. Clin J Pain 27:481-485.

197. Mao JJ, Armstrong K, Bowman MA, Xie SX, Kadakia R, Farrar JT (2007) Symptom burden among cancer survivors: impact of age and comorbidity. J Am Board Fam Med 20:434-443.

198. Mejdahl MK, Andersen KG, Gartner R, Kroman N, Kehlet H (2013) Persistent pain and sensory disturbances after treatment for breast cancer: six year nationwide follow-up study. BMJ 346:f1865.

199. Miaskowski C, Cooper B, Paul SM, West C, Levine JD, Elboim C, Hamolsky D, Abrams G, Luce J, Dhruva A, Langford DJ, Merriman JD, Kober K, Baggott C, Leutwyler H, Aouizerat BE (2012) Identification of patient subgroups and risk factors for persistent breast pain following breast cancer surgery. J Pain 13:1172-1187.

200. Pettersson N, Olsson C, Tucker SL, Alsadius D, Wilderäng U, Johansson KA, Steineck G (2013) Urethral pain among prostate cancer survivors 1 to 14 years after radiation therapy. Int J Radiat Oncol Biol Phys 85:e29-37. 
201. Peuckmann V, Ekholm O, Rasmussen NK, Groenvold M, Christiansen P, Møller S, Eriksen J, Sjøgren $P$ (2009) Chronic pain and other sequelae in long-term breast cancer survivors: nationwide survey in Denmark. Eur J Pain 13:478-485.

202. Vistad I, Cvancarova M, Kristensen GB, Fossa SD (2011) A study of chronic pelvic pain after radiotherapy in survivors of locally advanced cervical cancer. J Cancer Surviv 5:208-216.

203. Akin S, Can G, Aydiner A, Ozdilli K, Durna Z (2010) Quality of life, symptom experience and distress of lung cancer patients undergoing chemotherapy. Eur J Oncol Nurs 14:400-409.

204. Bisht M, Bist SS, Dhamana DC, Saini S (2011) Study of pain management in advanced cancer patients in a tertiary care hospital in India. Trop Doct 41:31-32.

205. Bokhari FN, McMillan DE, McClement S, Daeninck PJ (2012) Pilot study of a survey to identify the prevalence of and risk factors for chronic neuropathic pain following breast cancer surgery. Oncol Nurs Forum 39:141-149.

206. Boonstra A, van Zadelhoff J, Timmer-Bonte A, Ottevanger PB, Beurskens CH, van Laarhoven HW (2013) Arthralgia during aromatase inhibitor treatment in early breast cancer patients: prevalence, impact, and recognition by healthcare providers. Cancer Nurs 36:52-59.

207. Brant JM, Beck SL, Dudley WN, Cobb P, Pepper G, Miaskowski C (2011) Symptom trajectories during chemotherapy in outpatients with lung cancer colorectal cancer, or lymphoma. Eur J Oncol Nurs 15:470-477.

208. Carlson LE, Waller A, Groff SL, Giese-Davis J, Bultz BD (2013) What goes up does not always come down: patterns of distress, physical and psychosocial morbidity in people with cancer over a one year period. Psychooncology 22:168-176.

209. Hayes SC, Rye S, Battistutta D, Newman B (2010) Prevalence of upper-body symptoms following breast cancer and its relationship with upper-body function and lymphedema. Lymphology 43:178-187.

210. Henry DH, Viswanathan HN, Elkin EP, Traina S, Wade S, Cella D (2008) Symptoms and treatment burden associated with cancer treatment: results from a cross-sectional national survey in the U.S. Support Care Cancer 16:791-801.

211. Karabulu N, Erci B, Ozer N, Ozdemir S (2010) Symptom clusters and experiences of patients with cancer. J Adv Nurs 66:1011-1021.

212. Kirchheiner K, Czajka A, Ponocny-Seliger E, Lütgendorf-Caucig C, Schmid MP, Komarek E, Pötter R, Dörr W (2013) Physical and psychosocial support requirements of 1,500 patients starting radiotherapy. Strahlenther Onkol 189:424-429.

213. Kurita GP, Tange UB, Farholt H, Sonne NM, Strömgren AS, Ankersen L, Kristensen L, Bendixen L, Grønvold M, Petersen MA, Nordly M, Christrup L, Niemann C, Sjøgren P (2013) Pain characteristics and management of inpatients admitted to a comprehensive cancer centre: a cross-sectional study. Acta Anaesthesiol Scand 57:518-525.

214. Lokker ME, Offerman MP, Van Der Velden LA, de Boer MF, Pruyn JF, Teunissen SC (2013) Symptoms of patients with incurable head and neck cancer: Prevalence and impact on daily functioning. Head and Neck 35:868-876.

215. Lovgren M, Tishelman C, Sprangers M, Koyi H, Hamberg K (2008) Symptoms and problems with functioning among women and men with inoperable lung cancer: a longitudinal study. Lung Cancer 60:113-124.

216. Oberguggenberger A, Hubalek M, Sztankay M, Meraner V, Beer B, Oberacher H, Giesinger J, Kemmler G, Egle D, Gamper EM, Sperner-Unterweger B, Holzner B (2011) Is the toxicity of adjuvant aromatase inhibitor therapy underestimated? Complementary information from patient-reported outcomes (PROs). Breast Cancer Res Treat 128:553-561.

217. Schultheis K, Hofheinz RD, Gencer D, Blunk JA, Benrath J (2013) Quality of life and symptom evaluation in daily oncology practice: a survey of 150 patients with advanced gastrointestinal tumours receiving palliative chemotherapy. Onkologie 36:33-37.

218. Spichiger E, Muller-Frohlich C, Denhaerynck K, Stoll H, Hantikainen V, Dodd M (2011) Prevalence of symptoms, with a focus on fatigue, and changes of symptoms over three months in outpatients receiving cancer chemotherapy. Swiss Med Wkly 141:w13303. 
219. Yamagishi A, Morita T, Miyashita M, Kimura F (2009) Symptom prevalence and longitudinal follow-up in cancer outpatients receiving chemotherapy. J Pain Symptom Manage 37: 823-830.

220. Bausewein C, Booth S, Gysels M, Kühnbach R, Haberland B, Higginson IJ (2010) Understanding breathlessness: cross-sectional comparison of symptom burden and palliative care needs in chronic obstructive pulmonary disease and cancer. J Palliat Med 13:1109-1118.

221. Black B, Herr K, Fine P, Sanders S, Tang X, Bergen-Jackson K, Titler M, Forcucci C (2011) The relationships among pain, nonpain symptoms, and quality of life measures in older adults with cancer receiving hospice care. Pain Med 12:880-889.

222. Bradley N, Davis L, Chow E (2005) Symptom distress in patients attending an outpatient palliative radiotherapy clinic. J Pain Symptom Manage 30:123-131.

223. Clark K, Smith J, Lovell M, Currow DC (2012) Longitudinal pain reports in a palliative care population. J Palliat Med 15:1335-1341.

224. Elmqvist MA, Jordhoy MS, Bjordal K, Kaasa S, Jannert M (2009) Health-related quality of life during the last three months of life in patients with advanced cancer. Support Care Cancer 17:191-198.

225. Jimenez A, Madero R, Alonso A, Martínez-Marín V, Vilches Y, Martínez B, Feliu M, Díaz L, Espinosa E, Feliu J (2011) Symptom clusters in advanced cancer. J Pain Symptom Manage 42:24-31.

226. Justo Roll I, Simms V, Harding R (2009) Multidimensional problems among advanced cancer patients in Cuba: awareness of diagnosis is associated with better patient status. J Pain Symptom Manage 37:325-330.

227. Kang JH, Kwon JH, Hui D, Yennurajalingam S, Bruera E (2013) Changes in symptom intensity among cancer patients receiving outpatient palliative care. J Pain Symptom Manag 46:652-660.

228. Lasheen W, Walsh D, Hauser K, Gutgsell T, Karafa MT (2009) Symptom variability during repeated measurement among hospice patients with advanced cancer. Am J Hosp Palliat Care 26:368-375.

229. Mystakidou K, Tsilika E, Parpa E, Pathiaki M, Patiraki E, Galanos A, Vlahos L (2007) Exploring the relationships between depression, hopelessness, cognitive status, pain, and spirituality in patients with advanced cancer. Arch Psychiatr Nurs 21:150-161.

230. Oi-Ling K, Man-Wah DT, Kam-Hung DN (2005) Symptom distress as rated by advanced cancer patients, caregivers and physicians in the last week of life. Palliat Med 19:228-233.

231. Saini T, Murtagh FEM, Dupont PJ, McKinnon PM, Hatfield P, Saunders Y (2006) Comparative pilot study of symptoms and quality of life in cancer patients and patients with end stage renal disease. Palliat Med 20:631-636.

232. Spichiger E, Muller-Frohlich C, Denhaerynck K, Stoll H, Hantikainen V, Dodd M (2011) Symptom prevalence and changes of symptoms over ten days in hospitalized patients with advanced cancer: a descriptive study. Eur J Oncol Nurs 15:95-102.

233. Wilson KG, Chochinov HM, Allard P, Chary S, Gagnon PR, Macmillan K, De Luca M, O'Shea F, Kuhl D, Fainsinger RL (2009) Prevalence and correlates of pain in the Canadian National Palliative Care Survey. Pain Res Manag 14:365-370.

234. Abu-Saad Huijer $H$, Abboud S (2012) Health-related quality of life among breast cancer patients in Lebanon. Eur J Oncol Nurs 16:491-497.

235. Brown JK, Cooley ME, Chernecky C, Sarna L (2011) A symptom cluster and sentinel symptom experienced by women with lung cancer. Oncol Nurs Forum 38:E425-35.

236. Holtan A, Aass N, Nordoy T, Haugen DF, Kaasa S, Mohr W, Kongsgaard UE (2007) Prevalence of pain in hospitalised cancer patients in Norway: a national survey. Palliat Med 21:7-13.

237. Hong SH, Roh SY, Kim SY, Shin SW, Kim CS, Choi JH, Kim SY, Yim CY, Sohn CH, Song HS, Hong YS (2011) Change in cancer pain management in Korea between 2001 and 2006: Results of two nationwide surveys. J Pain Symptom Manage 41:93-103. 
238. Kjaer TK, Johansen C, Ibfelt E, Christensen J, Rottmann N, Høybye MT, Ross L, Svendsen M, Dalton SO (2011) Impact of symptom burden on health related quality of life of cancer survivors in a Danish cancer rehabilitation program: a longitudinal study. Acta Oncol 50:223-232.

239. Kuo PY, Yen JTC, Parker GM, Chapman S, Kandikattu S, Sohanpal I, Barbachano Y, Williams JE (2011) The prevalence of pain in patients attending sarcoma outpatient clinics. Sarcoma: 1-6.

240. Manitta V, Zordan R, Cole-Sinclair M, Nandurkar H, Philip J (2011) The symptom burden of patients with hematological malignancy: a cross-sectional observational study. J Pain Symptom Manage 42:432-442.

241. Mercadante S, Roila F, Berretto O, Labianca R, Casilini S (2008) Prevalence and treatment of cancer pain in Italian oncological wards centres: a cross-sectional survey. Support Care Cancer 16:1203-1211.

242. Nuhu FT, Odejide OA, Adebayo KO, Yusuf AJ (2009) Psychological and physical effects of pain on cancer patients in Ibadan, Nigeria. Afr J Psychiatry 12:64-70.

243. Priscilla D, Hamidin A, Azhar MZ, Noorjan KO, Salmiah MS, Bahariah K (2011) Quality of life among patients with hematological cancer in a Malaysian hospital. Med J Malaysia 66: 117-120.

244. Reyes-Gibby CC, Ba Duc N, Phi Yen N, Hoai Nga N, Van Tran T, Guo H, Bhat S, Cleeland C (2006) Status of cancer pain in Hanoi, Vietnam: a hospital-wide survey in a tertiary cancer treatment center. J Pain Symptom Manage 31:431-439.

245. Salminen E, Clemens KE, Syrjanen K, Salmenoja H (2008) Needs of developing the skills of palliative care at the oncology ward: an audit of symptoms among 203 consecutive cancer patients in Finland. Support Care Cancer 16:3-8.

246. Williams JE, Yen JT, Parker G, Chapman S, Kandikattu S, Barbachano Y (2010) Prevalence of pain in head and neck cancer out-patients. J Laryngol Otol 124:767-773.

247. Yen JTC, Gubbay AN, Kandikattu S, Chapman S, Williams JE (2012) The prevalence and management of pain in gynaecological malignancy within the outpatient setting. Internet J Pain Symptom Contr Palliat Care 9:6.

248. Feyer P, Kleeberg UR, Steingraber M, Gunther W, Behrens M (2008) Frequency of side effects in outpatient cancer care and their influence on patient satisfaction: a prospective survey using the PASQOC questionnaire. Support Care Cancer 16:567-575.

249. O'Connor M, Weir J, Butcher I, Kleiboer A, Murray G, Sharma N, Thekkumpurath P, Walker J, Fallon M, Storey DJ, Sharpe M (2012) Pain in patients attending a specialist cancer service: prevalence and association with emotional distress. J Pain Symptom Manage 43:29-38.

250. Al Qadire M, Tubaishat A, Aljezawi MM (2013) Cancer pain in Jordan: prevalence and adequacy of treatment. Int J Palliat Nurs 19:125-130.

251. Johnsen AT, Petersen MA, Pedersen L, Groenvold M (2009) Symptoms and problems in a nationally representative sample of advanced cancer patients. Palliat Med 23:491-501.

252. Khan L, Kwong J, Nguyen J, Chow E, Zhang L, Culleton S, Zeng L, Jon F, Tsao M, Barnes E, Danjoux C, Sahgal A, Holden L (2012) Comparing baseline symptom severity and demographics over two time periods in an outpatient palliative radiotherapy clinic. Support Care Cancer 20:549-555.

253. Oechsle K, Goerth K, Bokemeyer C, Mehnert A (2013) Symptom burden in palliative care patients: Perspectives of patients, their family caregivers, and their attending physicians. Support Care Cancer 21:1955-1962.

254. Tishelman C, Petersson LM, Degner LF, Sprangers MA (2007) Symptom prevalence, intensity, and distress in patients with inoperable lung cancer in relation to time of death. J Clin Oncol 25:5381-5389.

255. Torvik K, Hølen J, Kaasa S, Kirkevold O, Holtan A, Kongsgaard U, Rustøen T (2008) Pain in elderly hospitalized cancer patients with bone metastases in Norway. Int $\mathrm{J}$ Palliat Nurs $14: 238-245$. 
256. Wang Y, Shen J, Xu Y (2011) Symptoms and quality of life of advanced cancer patients at home: a cross-sectional study in Shanghai, China. Support Care Cancer 19:789-797. 


\section{Appendices}

\section{Appendix 2.1 Search strategies}

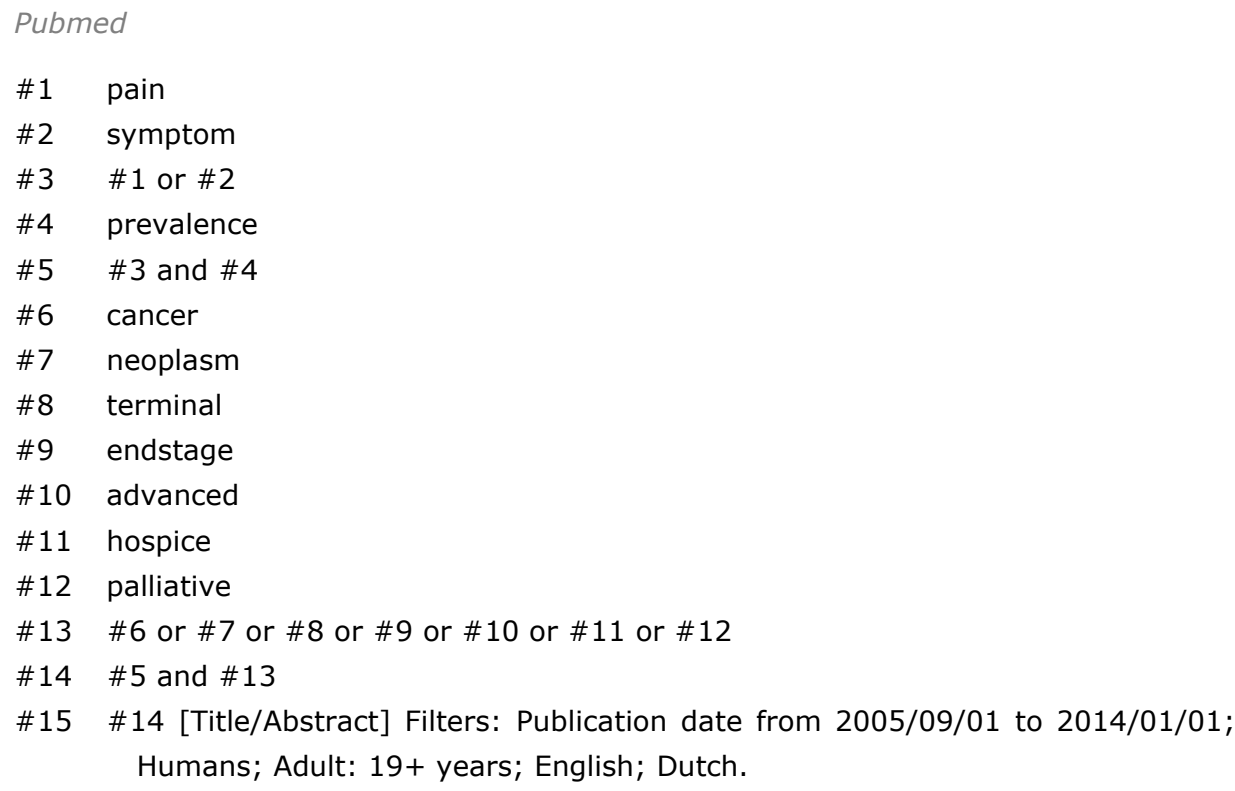

\section{Medline}

1. pain

2. symptom

3. 1 or 2

4. prevalence

5. 3 and 4

6. cancer

7. neoplasm

8. terminal

9. endstage

10. advanced

11. hospice

12. palliative

13. 6 or 7 or 8 or 9 or 10 or 11 or 12

14. 5 and 13

15. 5 and 13.ab,ti.

16. Limit 15 to [humans and $y r=" 2005-2015 "$ and "all adult [19 plus years]" and [dutch or english]] 


\section{Embase}

1. pain

2. symptom

3. 1 or 2

4. prevalence

5. 3 and 4

6. cancer

7. neoplasm

8. terminal

9. endstage

10. advanced

11. hospice

12. palliative

13. 6 or 7 or 8 or 9 or 10 or 11 or 12

14. 5 and 13

15. 5 and 13.ab,ti.

16. Limit 15 to [human and [dutch or english] and $y r=" 2005-2015 "$ and [adult $<18$ to 64 years $>$ or aged $<65+$ years]]

\section{Cinahl}

S1 pain

S2 symptom

$\mathrm{S} 3 \mathrm{~S} 1$ or $\mathrm{S} 2$

S4 prevalence

S5 S3 and S4

S6 cancer

S7 neoplasm

S8 terminal

S9 endstage

S10 advanced

S11 hospice

S12 palliative

$\mathrm{S} 13 \mathrm{~S} 6$ or $\mathrm{S} 7$ or $\mathrm{S} 8$ or $\mathrm{S} 9$ or $\mathrm{S} 10$ or $\mathrm{S} 11$ or $\mathrm{S} 12$

S14 S5 and S13

S15 AB S14 Limiters - Published Date: 20050901-20150101; Human; Age Groups: All Adult; Language: Dutch/Flemish, English 


\section{Cochrane}

\#1 pain

\#2 symptom

\#3 \#1 or \#2

\#4 prevalence

\#5 \#3 and \#4

\#6 cancer

\#7 neoplasm

\#8 terminal

$\# 9$ endstage

\#10 advanced

\#11 hospice

$\# 12$ palliative

$\# 13$ \#6 or \#7 or \#8 or \#9 or \#10 or \#11 or \#12

$\# 14 \quad \# 5$ and $\# 13$

\#15 \#5 and \#13.ti,ab. | Publication Year 2005-2014, in Trials. 


\section{Appendix 2.2 Distribution of methodological quality scores}

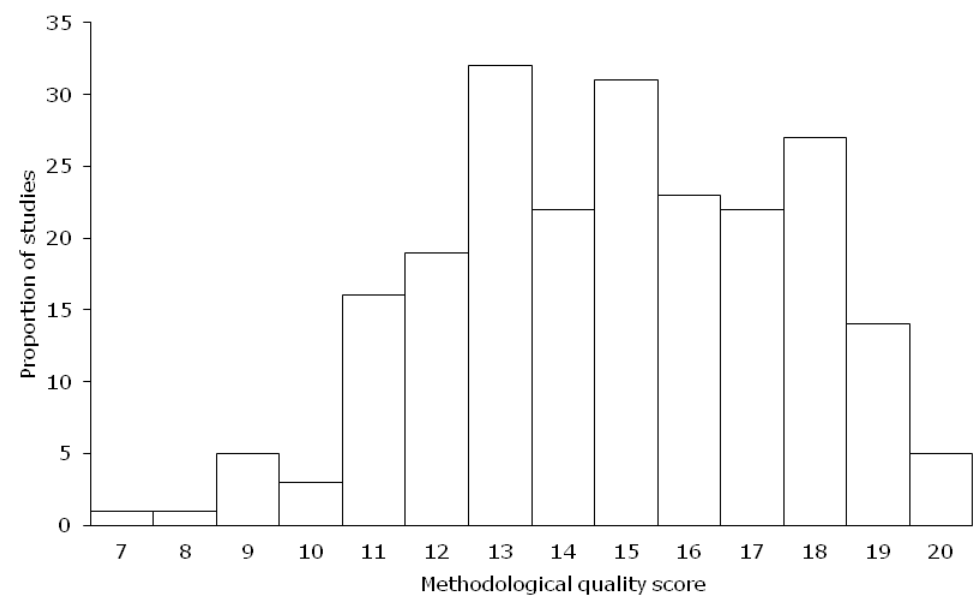

Appendix 2.3 Reasons for not reaching the quality score of 15 points

Response rate of less than $70 \%$ or not mentioned

$[5,83-176]$

Data collected by proxy or from medical records (retrospectively or prospectively) $[85,87,89,91,92,94,98,99,103-106,111,112,114,116,121,124-126,128-$ $130,137,141,143,144,148,150,152-155,161,163,164,166-170,176,177]$

Lack of description of the non-responders

$[5,83-86,88-98,100-102,104-111,113-136,139-180]$

Sample not representative

$[5,86,88,90,94-97,100-102,107-109,113,114,118-120,122,123,131-135$, $138-140,145,148,149,151,153,156-160,165,171-175,178,179]$ 
Appendix 2.4 Methodological quality assessment

\begin{tabular}{|c|c|c|c|c|c|c|c|c|c|c|c|c|}
\hline \multirow[t]{2}{*}{ Study } & \multicolumn{3}{|c|}{$\begin{array}{l}\text { Representativeness } \\
\text { of sample }\end{array}$} & \multicolumn{3}{|c|}{ Quality of data } & \multicolumn{4}{|c|}{$\begin{array}{l}\text { General description of } \\
\text { methods and results }\end{array}$} & \multirow{2}{*}{$\begin{array}{c}\text { Definition } \\
\text { of pain } \\
11 \\
\end{array}$} & \multirow[t]{2}{*}{$\begin{array}{l}\text { Total } \\
\text { score }\end{array}$} \\
\hline & 1 & 2 & 3 & 4 & 5 & 6 & 7 & 8 & 9 & 10 & & \\
\hline Abela, 2009 [83] & 2 & 0 & 0 & 1 & 2 & 3 & 2 & 0 & 2 & 1 & 1 & 14 \\
\hline Abu-Saad, 2012 [234] & 2 & 0 & 0 & 1 & 2 & 3 & 2 & 0 & 2 & 1 & 1 & 14 \\
\hline Abu-Saad, 2012 [84] & 2 & 2 & 1 & 2 & 2 & 3 & 2 & 1 & 2 & 1 & 1 & 19 \\
\hline Achterberg, 2009 [85] & 2 & 0 & 0 & 2 & 2 & 0 & 2 & 0 & 1 & 1 & 1 & 11 \\
\hline Akin, 2010 [203] & 0 & 2 & 1 & 2 & 2 & 3 & 2 & 1 & 2 & 1 & 1 & 17 \\
\hline Akin, 2013 [40] & 2 & 2 & 2 & 1 & 2 & 3 & 2 & 1 & 2 & 1 & 1 & 19 \\
\hline Al Qadire, 2013 [250] & 2 & 0 & 1 & 2 & 2 & 3 & 2 & 0 & 1 & 1 & 1 & 15 \\
\hline Alshemmari, 2010 [86] & 0 & 0 & 0 & 2 & 2 & 2 & 2 & 1 & 2 & 1 & 0 & 12 \\
\hline Alsirafy, 2010 [87] & 2 & 2 & 0 & 1 & 2 & 0 & 2 & 1 & 2 & 1 & 0 & 13 \\
\hline Andersen, 2012 [181] & 2 & 2 & 2 & 2 & 2 & 2 & 2 & 1 & 2 & 1 & 1 & 19 \\
\hline Andersen, 2013 [182] & 2 & 0 & 1 & 2 & 2 & 2 & 2 & 1 & 2 & 1 & 0 & 15 \\
\hline Aslan, 2011 [88] & 0 & 0 & 0 & 2 & 2 & 2 & 2 & 1 & 2 & 1 & 0 & 12 \\
\hline Bakitas, 2009 [30] & 2 & 2 & 0 & 1 & 2 & 3 & 2 & 1 & 2 & 1 & 1 & 17 \\
\hline Barbera, 2010 [89] & 2 & 0 & 0 & 2 & 2 & 0 & 2 & 1 & 2 & 1 & 1 & 13 \\
\hline Basen-Enquist, 2009 & 2 & 2 & 0 & 1 & 2 & 3 & 2 & 1 & 2 & 1 & 1 & 17 \\
\hline Bausewein, 2010 [220] & 2 & 0 & 0 & 2 & 2 & 3 & 2 & 1 & 2 & 1 & 1 & 16 \\
\hline Beck, $2005[50]$ & 2 & 0 & 0 & 1 & 2 & 3 & 2 & 1 & 2 & 1 & 1 & 15 \\
\hline Beck, 2009 [183] & 2 & 0 & 0 & 2 & 2 & 3 & 2 & 1 & 2 & 1 & 1 & 16 \\
\hline Bekelman, 2009 [90] & 0 & 0 & 0 & 2 & 2 & 3 & 2 & 1 & 2 & 1 & 1 & 14 \\
\hline Bergmann, 2011 [91] & 2 & 0 & 0 & 2 & 2 & 0 & 2 & 1 & 2 & 1 & 0 & 12 \\
\hline Bisht, 2011 [204] & 2 & 2 & 2 & 2 & 2 & 2 & 2 & 1 & 2 & 1 & 0 & 18 \\
\hline Black, 2011 [221] & 2 & 2 & 1 & 2 & 0 & 2 & 2 & 1 & 1 & 1 & 1 & 15 \\
\hline Bokhari, 2012 [205] & 2 & 0 & 0 & 2 & 2 & 3 & 2 & 1 & 2 & 1 & 1 & 16 \\
\hline Boonstra, 2013 [206] & 2 & 2 & 2 & 2 & 2 & 3 & 2 & 1 & 2 & 1 & 1 & 20 \\
\hline Borgsteede, 2007 [92] & 2 & 0 & 0 & 2 & 2 & 0 & 2 & 1 & 1 & 1 & 0 & 11 \\
\hline Bradley, 2005 [222] & 2 & 0 & 0 & 2 & 2 & 3 & 2 & 1 & 2 & 1 & 1 & 16 \\
\hline Brant, 2011 [207] & 2 & 0 & 0 & 2 & 2 & 2 & 2 & 1 & 2 & 1 & 1 & 15 \\
\hline Brant, 2011 [18] & 2 & 0 & 0 & 2 & 2 & 2 & 2 & 1 & 2 & 1 & 1 & 15 \\
\hline Breen, 2009 [43] & 2 & 2 & 1 & 1 & 2 & 3 & 2 & 1 & 2 & 1 & 1 & 18 \\
\hline Breivik, 2009 [5] & 0 & 0 & 0 & 2 & 2 & 2 & 0 & 0 & 2 & 1 & 1 & 10 \\
\hline Brown, 2013 [184] & 2 & 2 & 0 & 2 & 2 & 2 & 2 & 1 & 1 & 1 & 1 & 16 \\
\hline Brown, 2011 [235] & 2 & 0 & 0 & 2 & 2 & 3 & 2 & 1 & 2 & 1 & 1 & 16 \\
\hline Butt, 2008 [93] & 2 & 0 & 0 & 1 & 2 & 2 & 2 & 1 & 2 & 1 & 1 & 14 \\
\hline Camps, 2005 [94] & 0 & 0 & 0 & 1 & 2 & 0 & 2 & 1 & 2 & 1 & 0 & 9 \\
\hline Carlson, 2013 [208] & 2 & 2 & 1 & 2 & 2 & 3 & 2 & 0 & 2 & 1 & 1 & 18 \\
\hline Chen, 2006 [95] & 0 & 0 & 0 & 1 & 2 & 3 & 2 & 1 & 2 & 1 & 1 & 13 \\
\hline Cheng, 2005 [97] & 0 & 0 & 0 & 2 & 2 & 3 & 2 & 1 & 2 & 1 & 1 & 14 \\
\hline Cheng, 2009 [96] & 0 & 0 & 0 & 1 & 2 & 3 & 2 & 1 & 2 & 1 & 1 & 13 \\
\hline Cheung, 2009 [98] & 2 & 0 & 0 & 2 & 2 & 0 & 2 & 1 & 2 & 1 & 1 & 13 \\
\hline Choi, 2013 [99] & 2 & 2 & 0 & 1 & 2 & 0 & 2 & 1 & 2 & 1 & 0 & 13 \\
\hline Chow, 2008 [100] & 0 & 0 & 0 & 1 & 2 & 3 & 2 & 1 & 2 & 1 & 1 & 13 \\
\hline Clark, 2012 [223] & 2 & 2 & 2 & 2 & 2 & 3 & 2 & 1 & 2 & 1 & 1 & 20 \\
\hline Cohen, 2012 [101] & 0 & 0 & 0 & 2 & 2 & 3 & 2 & 1 & 1 & 1 & 1 & 13 \\
\hline Crew, 2007 [185] & 2 & 2 & 1 & 2 & 2 & 2 & 2 & 1 & 2 & 1 & 1 & 18 \\
\hline de Raaf, 2013 [102] & 0 & 0 & 0 & 1 & 2 & 3 & 2 & 1 & 2 & 1 & 1 & 13 \\
\hline De Santiago, 2012 [103] & 2 & 2 & 0 & 1 & 2 & 0 & 2 & 0 & 1 & 1 & 1 & 12 \\
\hline Delguado-Guay, 2009 [104] & 2 & 0 & 0 & 2 & 2 & 0 & 2 & 1 & 2 & 1 & 1 & 11 \\
\hline Deshields, 2011 [186] & 2 & 2 & 0 & 2 & 2 & 3 & 2 & 1 & 2 & 1 & 1 & 18 \\
\hline
\end{tabular}




\begin{tabular}{|c|c|c|c|c|c|c|c|c|c|c|c|c|}
\hline \multirow[t]{2}{*}{ Study } & \multicolumn{3}{|c|}{$\begin{array}{l}\text { Representativeness } \\
\text { of sample }\end{array}$} & \multicolumn{3}{|c|}{ Quality of data } & \multicolumn{4}{|c|}{$\begin{array}{l}\text { General description of } \\
\text { methods and results }\end{array}$} & \multirow{2}{*}{$\begin{array}{c}\text { Definition } \\
\text { of pain } \\
11\end{array}$} & \multirow[t]{2}{*}{$\begin{array}{l}\text { Total } \\
\text { score }\end{array}$} \\
\hline & 1 & 2 & 3 & 4 & 5 & 6 & 7 & 8 & 9 & 10 & & \\
\hline Dijkstra, 2007 [187] & 2 & 2 & 2 & 2 & 2 & 3 & 2 & 1 & 2 & 1 & 1 & 20 \\
\hline Dumitrescu, 2007 [105] & 2 & 0 & 0 & 2 & 2 & 0 & 2 & 1 & 2 & 1 & 0 & 12 \\
\hline Elmqvist, 2009 [224] & 0 & 1 & 0 & 2 & 2 & 3 & 2 & 1 & 2 & 1 & 1 & 15 \\
\hline Elsayem, 2010 [106] & 2 & 0 & 0 & 1 & 2 & 0 & 2 & 0 & 2 & 1 & 1 & 11 \\
\hline Fadol, 2008 [107] & 0 & 0 & 0 & 1 & 2 & 3 & 0 & 0 & 1 & 1 & 1 & 9 \\
\hline Fainsinger, 2005 [108] & 0 & 0 & 0 & 1 & 2 & 3 & 2 & 1 & 2 & 1 & 1 & 13 \\
\hline Feyer, 2008 [248] & 2 & 0 & 1 & 2 & 2 & 3 & 2 & 1 & 2 & 1 & 1 & 17 \\
\hline Finlay, 2009 [49] & 2 & 2 & 1 & 1 & 2 & 3 & 2 & 1 & 2 & 1 & 1 & 18 \\
\hline Fox, 2006 [109] & 0 & 0 & 0 & 2 & 2 & 3 & 2 & 1 & 2 & 1 & 1 & 14 \\
\hline Fraceschini, 2013 [110] & 2 & 0 & 0 & 2 & 2 & 3 & 2 & 0 & 1 & 1 & 1 & 14 \\
\hline Gahm, 2010 [188] & 2 & 2 & 2 & 2 & 2 & 2 & 2 & 1 & 2 & 1 & 0 & 18 \\
\hline Garabeli, 2012 [35] & 2 & 2 & 2 & 1 & 2 & 3 & 2 & 1 & 2 & 1 & 1 & 19 \\
\hline Garcia de Paredes, 2011 [111] & 2 & 0 & 0 & 2 & 2 & 0 & 2 & 1 & 2 & 1 & 0 & 12 \\
\hline Gärtner, 2009 [189] & 2 & 2 & 1 & 2 & 2 & 2 & 2 & 1 & 2 & 1 & 1 & 18 \\
\hline Georges, 2005 [112] & 2 & 1 & 0 & 1 & 2 & 0 & 0 & 1 & 2 & 1 & 1 & 11 \\
\hline Gerbershagen, 2008 [113] & 0 & 0 & 0 & 2 & 2 & 2 & 2 & 1 & 2 & 1 & 1 & 13 \\
\hline Ghosn, 2010 [114] & 0 & 0 & 0 & 1 & 2 & 0 & 2 & 1 & 1 & 1 & 1 & 9 \\
\hline Giesinger, $2011[25]$ & 2 & 0 & 0 & 1 & 2 & 3 & 2 & 1 & 2 & 1 & 1 & 15 \\
\hline Gomez-Batiste, 2010 [29] & 2 & 2 & 1 & 1 & 2 & 2 & 2 & 1 & 2 & 1 & 1 & 17 \\
\hline Gooneratne, 2007 [115] & 2 & 0 & 0 & 1 & 2 & 2 & 2 & 1 & 2 & 1 & 0 & 13 \\
\hline Gough, 2011 [116] & 2 & 0 & 0 & 2 & 2 & 0 & 2 & 1 & 2 & 1 & 0 & 12 \\
\hline Graves, 2007 [53] & 2 & 2 & 2 & 1 & 2 & 3 & 2 & 1 & 2 & 1 & 1 & 19 \\
\hline Green, 2011 [190] & 2 & 2 & 1 & 2 & 2 & 2 & 2 & 1 & 2 & 1 & 1 & 18 \\
\hline Grosen, 2013 [191] & 2 & 2 & 0 & 2 & 2 & 3 & 2 & 1 & 2 & 1 & 1 & 18 \\
\hline Guirimand, 2010 [46] & 2 & 0 & 0 & 1 & 2 & 3 & 2 & 1 & 2 & 1 & 1 & 15 \\
\hline Gwede, 2008 [58] & 2 & 0 & 0 & 1 & 2 & 3 & 2 & 1 & 2 & 1 & 1 & 15 \\
\hline Haifield-Wolfe, 2012 [178] & 0 & 0 & 1 & 2 & 2 & 3 & 0 & 1 & 2 & 1 & 1 & 13 \\
\hline Halawi, 2012 [117] & 2 & 0 & 0 & 2 & 2 & 2 & 2 & 1 & 2 & 1 & 0 & 14 \\
\hline Hamaker, 2011 [17] & 2 & 0 & 0 & 1 & 2 & 3 & 2 & 1 & 2 & 1 & 1 & 15 \\
\hline Harding, 2011 [118] & 0 & 0 & 0 & 2 & 2 & 3 & 2 & 1 & 2 & 1 & 1 & 14 \\
\hline Hayes, 2010 [209] & 2 & 1 & 1 & 2 & 2 & 3 & 2 & 1 & 2 & 1 & 1 & 18 \\
\hline Hansen, 2011 [192] & 2 & 2 & 1 & 2 & 2 & 2 & 2 & 1 & 2 & 1 & 0 & 17 \\
\hline Helzlsouer, 2012 [119] & 0 & 0 & 0 & 2 & 2 & 3 & 2 & 1 & 2 & 1 & 1 & 14 \\
\hline Henry, 2008 [210] & 2 & 0 & 0 & 2 & 2 & 3 & 2 & 1 & 2 & 1 & 1 & 16 \\
\hline Hickey, 2010 [120] & 0 & 0 & 0 & 1 & 2 & 3 & 2 & 1 & 2 & 1 & 1 & 13 \\
\hline Hickey, 2011 [193] & 2 & 1 & 0 & 2 & 2 & 3 & 2 & 1 & 2 & 1 & 1 & 17 \\
\hline Hirakawa, 2006 [121] & 2 & 0 & 0 & 2 & 2 & 0 & 2 & 1 & 2 & 1 & 1 & 13 \\
\hline Henningsohn, 2003 [180] & 2 & 1 & 1 & 1 & 2 & 2 & 2 & 0 & 1 & 1 & 1 & 14 \\
\hline Hoekstra, 2006 [44] & 0 & 2 & 1 & 1 & 2 & 2 & 2 & 1 & 2 & 1 & 1 & 15 \\
\hline Hoffman, 2007 [122] & 0 & 0 & 0 & 1 & 2 & 3 & 2 & 1 & 2 & 1 & 1 & 13 \\
\hline Hoimyr, 2011 [194] & 2 & 0 & 1 & 2 & 2 & 2 & 2 & 0 & 2 & 1 & 1 & 15 \\
\hline Holtan, 2007 [236] & 2 & 2 & 0 & 2 & 2 & 2 & 2 & 1 & 2 & 1 & 1 & 17 \\
\hline Homsi, 2006 [36] & 2 & 2 & 1 & 1 & 2 & 2 & 2 & 1 & 2 & 1 & 1 & 17 \\
\hline Hong, 2011 [237] & 2 & 0 & 0 & 2 & 2 & 3 & 2 & 1 & 2 & 1 & 1 & 16 \\
\hline Im, 2007 [123] & 0 & 0 & 0 & 1 & 2 & 3 & 2 & 1 & 2 & 1 & 1 & 13 \\
\hline Inoue, 2009 [124] & 2 & 0 & 0 & 2 & 2 & 0 & 2 & 1 & 2 & 1 & 0 & 12 \\
\hline Iritani, 2011 [125] & 2 & 0 & 0 & 1 & 2 & 0 & 2 & 1 & 2 & 1 & 0 & 11 \\
\hline Ishiyama, 2006 [195] & 2 & 0 & 1 & 2 & 2 & 2 & 2 & 1 & 2 & 1 & 1 & 16 \\
\hline Jimenez, 2011 [225] & 2 & 0 & 0 & 2 & 2 & 3 & 2 & 1 & 2 & 1 & 1 & 16 \\
\hline Johnson, 2009 [251] & 2 & 2 & 0 & 2 & 2 & 3 & 2 & 1 & 2 & 1 & 1 & 18 \\
\hline
\end{tabular}




\begin{tabular}{|c|c|c|c|c|c|c|c|c|c|c|c|c|}
\hline \multirow[t]{2}{*}{ Study } & \multicolumn{3}{|c|}{$\begin{array}{c}\text { Representativeness } \\
\text { of sample }\end{array}$} & \multicolumn{3}{|c|}{ Quality of data } & \multicolumn{4}{|c|}{$\begin{array}{l}\text { General description of } \\
\text { methods and results }\end{array}$} & \multirow{2}{*}{$\begin{array}{c}\text { Definition } \\
\text { of pain } \\
11\end{array}$} & \multirow[t]{2}{*}{$\begin{array}{l}\text { Total } \\
\text { score }\end{array}$} \\
\hline & 1 & 2 & 3 & 4 & 5 & 6 & 7 & 8 & 9 & 10 & & \\
\hline Johnson, 2005 [126] & 2 & 0 & 0 & 1 & 2 & 0 & 2 & 1 & 2 & 1 & 1 & 12 \\
\hline Justo Roll, 2009 [226] & 0 & 2 & 2 & 2 & 2 & 3 & 2 & 1 & 2 & 1 & 1 & 18 \\
\hline Kang, 2013 [227] & 2 & 0 & 0 & 2 & 2 & 3 & 2 & 1 & 2 & 1 & 1 & 16 \\
\hline Karabulu, 2010 [211] & 2 & 2 & 2 & 2 & 2 & 3 & 2 & 1 & 2 & 1 & 1 & 20 \\
\hline Kenne Sarenmalm, 2007 [23] & 2 & 2 & 1 & 1 & 2 & 3 & 2 & 1 & 2 & 1 & 1 & 18 \\
\hline Khan, 2012 [252] & 0 & 1 & 0 & 2 & 2 & 3 & 2 & 1 & 2 & 1 & 1 & 15 \\
\hline Kim, 2012 [127] & 2 & 0 & 0 & 2 & 2 & 2 & 2 & 1 & 2 & 1 & 0 & 14 \\
\hline Kirchheiner, 2013 [212] & 2 & 0 & 1 & 2 & 2 & 2 & 2 & 1 & 2 & 1 & 1 & 16 \\
\hline Kirkova, 2012 [56] & 2 & 0 & 2 & 1 & 2 & 2 & 2 & 1 & 2 & 1 & 0 & 15 \\
\hline Kjaer, 2011 [238] & 2 & 2 & 0 & 2 & 2 & 3 & 2 & 1 & 2 & 1 & 1 & 18 \\
\hline Kubrak, 2010 [57] & 2 & 1 & 1 & 1 & 2 & 3 & 2 & 1 & 2 & 1 & 1 & 17 \\
\hline Kuo, 2011 [239] & 2 & 2 & 0 & 2 & 2 & 3 & 2 & 1 & 2 & 1 & 1 & 18 \\
\hline Kurita, 2013 [213] & 2 & 2 & 1 & 2 & 2 & 3 & 2 & 1 & 2 & 1 & 1 & 19 \\
\hline Kwon, 2006 [55] & 2 & 0 & 0 & 1 & 2 & 3 & 2 & 1 & 2 & 1 & 1 & 15 \\
\hline Lal, 2012 [128] & 2 & 0 & 0 & 2 & 2 & 0 & 2 & 0 & 2 & 1 & 0 & 11 \\
\hline Lasheen, 2009 [228] & 2 & 1 & 0 & 2 & 2 & 2 & 2 & 1 & 2 & 1 & 1 & 16 \\
\hline Latvala, 2009 [32] & 2 & 2 & 2 & 1 & 2 & 3 & 2 & 1 & 2 & 1 & 1 & 19 \\
\hline Laugsand, 2010 [37] & 2 & 2 & 1 & 1 & 2 & 3 & 2 & 0 & 2 & 1 & 1 & 17 \\
\hline Lengacher, 2012 [60] & 2 & 2 & 2 & 1 & 2 & 3 & 2 & 1 & 2 & 1 & 1 & 19 \\
\hline Lesperance, 2008 [129] & 2 & 0 & 0 & 2 & 2 & 0 & 2 & 1 & 2 & 1 & 0 & 12 \\
\hline Li, $2011[196]$ & 2 & 0 & 0 & 2 & 2 & 2 & 2 & 1 & 2 & 1 & 1 & 15 \\
\hline Lin, 2011 [130] & 2 & 0 & 0 & 2 & 2 & 0 & 2 & 1 & 2 & 1 & 0 & 12 \\
\hline Liu, 2011 [131] & 0 & 0 & 0 & 1 & 2 & 3 & 2 & 1 & 2 & 1 & 1 & 13 \\
\hline Liu, 2013 [132] & 0 & 0 & 0 & 2 & 2 & 3 & 2 & 1 & 2 & 1 & 1 & 14 \\
\hline Lokker, 2013 [214] & 2 & 2 & 0 & 2 & 2 & 2 & 2 & 1 & 2 & 1 & 1 & 17 \\
\hline Lovgren, 2008 [215] & 2 & 2 & 0 & 2 & 2 & 3 & 2 & 1 & 2 & 1 & 1 & 18 \\
\hline Lukas, 2013 [133] & 0 & 0 & 0 & 1 & 2 & 2 & 2 & 0 & 2 & 1 & 1 & 11 \\
\hline Manitta, 2011 [240] & 2 & 2 & 2 & 2 & 2 & 3 & 2 & 1 & 2 & 1 & 1 & 20 \\
\hline Mao, 2007 [197] & 2 & 0 & 1 & 2 & 2 & 2 & 2 & 1 & 2 & 1 & 1 & 16 \\
\hline McPherson, 2008 [38] & 0 & 2 & 0 & 1 & 2 & 3 & 2 & 1 & 2 & 1 & 1 & 15 \\
\hline Meeske, 2007 [134] & 0 & 0 & 0 & 1 & 2 & 3 & 2 & 1 & 2 & 1 & 1 & 13 \\
\hline Mejdahl, 2013 [198] & 2 & 2 & 1 & 2 & 2 & 3 & 2 & 1 & 2 & 1 & 0 & 18 \\
\hline Mendoza, 2011 [135] & 0 & 0 & 0 & 1 & 2 & 3 & 2 & 1 & 2 & 1 & 1 & 13 \\
\hline Mercadante, 2013 [28] & 2 & 0 & 0 & 1 & 2 & 3 & 2 & 1 & 2 & 1 & 1 & 15 \\
\hline Mercadante, 2008 [241] & 2 & 0 & 0 & 2 & 2 & 2 & 2 & 1 & 2 & 1 & 1 & 15 \\
\hline Mercadante, 2010 [137] & 2 & 1 & 0 & 1 & 2 & 0 & 2 & 0 & 2 & 1 & 0 & 11 \\
\hline Mercandante, 2013 [136] & 2 & 0 & 0 & 1 & 2 & 0 & 2 & 1 & 2 & 1 & 0 & 11 \\
\hline Miaskowski, 2012 [199] & 0 & 1 & 1 & 2 & 2 & 3 & 2 & 1 & 2 & 1 & 1 & 16 \\
\hline Modonesi, 2005 [27] & 2 & 2 & 0 & 1 & 2 & 3 & 2 & 1 & 2 & 1 & 1 & 17 \\
\hline Morita, 2008 [48] & 2 & 1 & 2 & 1 & 2 & 3 & 2 & 1 & 2 & 1 & 1 & 18 \\
\hline Mota, 2012 [138] & 0 & 1 & 0 & 1 & 2 & 2 & 2 & 1 & 2 & 1 & 0 & 12 \\
\hline Mystakidou, 2007 [229] & 2 & 2 & 1 & 2 & 2 & 3 & 2 & 1 & 2 & 1 & 1 & 19 \\
\hline Nakaguchi, 2013 [39] & 2 & 1 & 1 & 1 & 2 & 3 & 2 & 1 & 2 & 1 & 1 & 17 \\
\hline Narducci, 2012 [42] & 2 & 0 & 2 & 1 & 2 & 3 & 2 & 1 & 2 & 1 & 1 & 17 \\
\hline Nuhu, 2009 [242] & 2 & 2 & 2 & 2 & 2 & 2 & 2 & 1 & 2 & 1 & 1 & 19 \\
\hline Oberguggenberger, 2011 [216] & 2 & 0 & 0 & 2 & 2 & 3 & 2 & 1 & 2 & 1 & 1 & 16 \\
\hline O'Connor, 2012 [249] & 2 & 2 & 1 & 2 & 2 & 3 & 2 & 1 & 2 & 1 & 1 & 19 \\
\hline Oechsle, 2012 [253] & 2 & 0 & 0 & 2 & 2 & 3 & 2 & 1 & 2 & 1 & 1 & 16 \\
\hline Oi-Ling, 2005 [230] & 2 & 1 & 0 & 2 & 2 & 2 & 2 & 1 & 2 & 1 & 1 & 16 \\
\hline O'Leary, 2009 [47] & 2 & 2 & 2 & 1 & 2 & 3 & 2 & 0 & 2 & 1 & 1 & 18 \\
\hline
\end{tabular}




\begin{tabular}{|c|c|c|c|c|c|c|c|c|c|c|c|c|}
\hline \multirow[t]{2}{*}{ Study } & \multicolumn{3}{|c|}{$\begin{array}{l}\text { Representativeness } \\
\text { of sample }\end{array}$} & \multicolumn{3}{|c|}{ Quality of data } & \multicolumn{4}{|c|}{$\begin{array}{l}\text { General description of } \\
\text { methods and results }\end{array}$} & \multirow{2}{*}{$\begin{array}{c}\text { Definition } \\
\text { of pain } \\
11\end{array}$} & \multirow[t]{2}{*}{$\begin{array}{l}\text { Total } \\
\text { score }\end{array}$} \\
\hline & 1 & 2 & 3 & 4 & 5 & 6 & 7 & 8 & 9 & 10 & & \\
\hline Omran, 2012 [139] & 0 & 0 & 0 & 2 & 2 & 3 & 2 & 1 & 2 & 1 & 1 & 14 \\
\hline Paiva, 2013 [31] & 2 & 0 & 0 & 1 & 2 & 3 & 2 & 1 & 2 & 1 & 1 & 15 \\
\hline Pantilat, 2012 [140] & 0 & 0 & 0 & 2 & 2 & 3 & 2 & 0 & 2 & 1 & 1 & 13 \\
\hline Park, 2006 [21] & 2 & 2 & 2 & 1 & 2 & 3 & 2 & 1 & 2 & 1 & 1 & 19 \\
\hline Parsons, 2008 [141] & 2 & 0 & 0 & 1 & 2 & 0 & 2 & 0 & 2 & 1 & 1 & 11 \\
\hline Pelayo-Alvarez, 2013 [142] & 2 & 0 & 0 & 1 & 2 & 3 & 2 & 0 & 2 & 1 & 1 & 14 \\
\hline Peng, 2006 [143] & 2 & 0 & 0 & 1 & 2 & 0 & 2 & 1 & 2 & 1 & 0 & 11 \\
\hline Peters, 2006 [20] & 2 & 0 & 0 & 1 & 2 & 3 & 2 & 1 & 2 & 1 & 1 & 15 \\
\hline Peuckman, 2009 [201] & 2 & 2 & 1 & 2 & 2 & 2 & 2 & 1 & 2 & 1 & 1 & 18 \\
\hline Porta-Sales, 2005 [144] & 2 & 0 & 0 & 1 & 2 & 0 & 2 & 0 & 2 & 1 & 0 & 10 \\
\hline Priscilla, 2011 [243] & 2 & 1 & 1 & 2 & 2 & 3 & 2 & 0 & 2 & 1 & 1 & 17 \\
\hline Price, 2013 [145] & 0 & 0 & 0 & 2 & 2 & 3 & 2 & 1 & 2 & 1 & 1 & 14 \\
\hline Pühse, 2012 [146] & 2 & 0 & 0 & 2 & 2 & 2 & 2 & 1 & 2 & 1 & 0 & 14 \\
\hline Rannestad, 2007 [147] & 2 & 0 & 0 & 2 & 2 & 2 & 2 & 1 & 2 & 1 & 0 & 14 \\
\hline Rausch, 2012 [24] & 2 & 0 & 2 & 1 & 2 & 3 & 2 & 1 & 2 & 1 & 1 & 17 \\
\hline Rayment, 2012 [148] & 0 & 0 & 0 & 1 & 2 & 0 & 2 & 1 & 0 & 1 & 0 & 7 \\
\hline Reed, 2012 [149] & 0 & 0 & 0 & 1 & 2 & 3 & 2 & 1 & 2 & 1 & 1 & 13 \\
\hline Reyes-Gibby, 2006 [177] & 2 & 0 & 1 & 2 & 2 & 0 & 2 & 0 & 2 & 1 & 0 & 12 \\
\hline Reyes-Gibby, 2012 [150] & 2 & 0 & 0 & 1 & 2 & 0 & 2 & 0 & 2 & 1 & 1 & 11 \\
\hline Reyes-Gibby, 2006 [244] & 2 & 0 & 1 & 2 & 2 & 3 & 2 & 1 & 2 & 1 & 1 & 17 \\
\hline Reyes-Gibby, 2007 [151] & 0 & 0 & 0 & 2 & 2 & 3 & 2 & 1 & 2 & 1 & 1 & 14 \\
\hline Riechelmann, 2007 [152] & 2 & 0 & 0 & 2 & 2 & 0 & 2 & 1 & 2 & 1 & 1 & 13 \\
\hline Saidi, 2008 [153] & 0 & 0 & 0 & 1 & 2 & 0 & 2 & 0 & 2 & 1 & 0 & 8 \\
\hline Saini, 2006 [231] & 2 & 0 & 0 & 2 & 2 & 3 & 2 & 1 & 2 & 1 & 1 & 16 \\
\hline Salamonde, 2006 [154] & 2 & 0 & 0 & 1 & 2 & 0 & 2 & 1 & 2 & 1 & 0 & 11 \\
\hline Salminen, 2008 [245] & 2 & 0 & 0 & 2 & 2 & 3 & 2 & 1 & 2 & 1 & 1 & 16 \\
\hline Sandgren, 2010 [155] & 2 & 0 & 0 & 2 & 2 & 0 & 2 & 0 & 2 & 1 & 1 & 12 \\
\hline Sarna, 2008 [156] & 0 & 0 & 0 & 2 & 2 & 3 & 2 & 1 & 2 & 1 & 1 & 14 \\
\hline Schrier, 2012 [157] & 0 & 0 & 0 & 1 & 2 & 3 & 2 & 1 & 2 & 1 & 1 & 13 \\
\hline Schultheis, 2013 [217] & 2 & 1 & 2 & 2 & 2 & 3 & 2 & 1 & 2 & 1 & 1 & 19 \\
\hline Semionov, 2012 [158] & 0 & 0 & 0 & 2 & 2 & 3 & 2 & 1 & 2 & 1 & 1 & 14 \\
\hline Sharma, 2012 [33] & 2 & 2 & 1 & 1 & 2 & 3 & 2 & 1 & 2 & 1 & 1 & 18 \\
\hline Sherman, 2007 [159] & 0 & 0 & 0 & 1 & 2 & 3 & 2 & 1 & 2 & 1 & 1 & 13 \\
\hline Shin, 2011 [19] & 2 & 0 & 0 & 1 & 2 & 3 & 2 & 1 & 2 & 1 & 1 & 15 \\
\hline Simone, 2012 [160] & 0 & 0 & 0 & 1 & 2 & 2 & 2 & 0 & 1 & 1 & 0 & 9 \\
\hline Skaug, 2007 [161] & 2 & 0 & 0 & 2 & 2 & 0 & 2 & 1 & 2 & 1 & 0 & 12 \\
\hline Smith, 2006 [162] & 2 & 0 & 0 & 2 & 2 & 0 & 2 & 1 & 2 & 1 & 0 & 12 \\
\hline Smith, 2006 [163] & 2 & 0 & 0 & 1 & 2 & 2 & 2 & 1 & 2 & 1 & 0 & 13 \\
\hline So, 2009 [179] & 0 & 0 & 1 & 1 & 2 & 3 & 2 & 1 & 2 & 1 & 1 & 14 \\
\hline Spichiger, 2011 [218] & 2 & 1 & 1 & 2 & 2 & 3 & 2 & 1 & 2 & 1 & 1 & 18 \\
\hline Spichiger, 2011 [232] & 2 & 1 & 0 & 2 & 2 & 3 & 2 & 1 & 2 & 1 & 1 & 17 \\
\hline Spoozak, 2013 [164] & 2 & 0 & 0 & 2 & 2 & 0 & 2 & 1 & 2 & 1 & 1 & 13 \\
\hline Steegers, 2008 [26] & 2 & 1 & 0 & 1 & 2 & 3 & 2 & 0 & 2 & 1 & 1 & 15 \\
\hline Steel, 2010 [165] & 0 & 0 & 0 & 1 & 2 & 3 & 2 & 0 & 2 & 1 & 1 & 12 \\
\hline Storey, 2012 [34] & 2 & 2 & 1 & 1 & 2 & 3 & 2 & 1 & 2 & 1 & 1 & 18 \\
\hline Stuver, 2012 [166] & 2 & 0 & 0 & 2 & 2 & 0 & 2 & 1 & 2 & 1 & 1 & 13 \\
\hline Teunissen, 2006 [41] & 2 & 1 & 1 & 1 & 2 & 2 & 2 & 1 & 2 & 1 & 1 & 16 \\
\hline Tishelman, 2007 [254] & 2 & 2 & 0 & 2 & 2 & 3 & 2 & 1 & 2 & 1 & 1 & 18 \\
\hline Torvik, 2008 [255] & 2 & 2 & 0 & 2 & 2 & 3 & 2 & 1 & 2 & 1 & 1 & 18 \\
\hline Torvinen, 2013 [16] & 2 & 0 & 0 & 1 & 2 & 3 & 2 & 1 & 2 & 1 & 1 & 15 \\
\hline
\end{tabular}




\begin{tabular}{|c|c|c|c|c|c|c|c|c|c|c|c|c|}
\hline \multirow[t]{2}{*}{ Study } & \multicolumn{3}{|c|}{$\begin{array}{l}\text { Representativeness } \\
\text { of sample }\end{array}$} & \multicolumn{3}{|c|}{ Quality of data } & \multicolumn{4}{|c|}{$\begin{array}{l}\text { General description of } \\
\text { methods and results }\end{array}$} & \multirow{2}{*}{$\begin{array}{c}\text { Definition } \\
\text { of pain } \\
11\end{array}$} & \multirow[t]{2}{*}{$\begin{array}{l}\text { Total } \\
\text { score }\end{array}$} \\
\hline & 1 & 2 & 3 & 4 & 5 & 6 & 7 & 8 & 9 & 10 & & \\
\hline Tsai, 2010 [167] & 2 & 0 & 0 & 1 & 2 & 0 & 2 & 1 & 2 & 1 & 1 & 12 \\
\hline Tsoussis, 2007 [168] & 2 & 0 & 0 & 1 & 2 & 0 & 0 & 1 & 2 & 1 & 1 & 10 \\
\hline van den Beuken, 2007 [15] & 2 & 2 & 1 & 2 & 2 & 3 & 2 & 1 & 2 & 1 & 1 & 19 \\
\hline Vaz, 2007 [22] & 2 & 1 & 2 & 1 & 2 & 2 & 2 & 1 & 2 & 1 & 1 & 17 \\
\hline Velloso, 2010 [52] & 2 & 1 & 0 & 1 & 2 & 3 & 2 & 0 & 2 & 1 & 1 & 15 \\
\hline Vergnenègre, 2013 [169] & 2 & 0 & 0 & 1 & 2 & 0 & 2 & 1 & 2 & 1 & 0 & 11 \\
\hline Vistad, 2011 [202] & 2 & 0 & 0 & 2 & 2 & 3 & 2 & 1 & 2 & 1 & 1 & 16 \\
\hline Waldenström, 2011 [59] & 2 & 0 & 1 & 1 & 2 & 3 & 2 & 1 & 2 & 1 & 0 & 15 \\
\hline Walsh, 2006 [170] & 2 & 0 & 0 & 2 & 2 & 0 & 2 & 1 & 2 & 1 & 0 & 12 \\
\hline Wang, 2010 [171] & 0 & 0 & 0 & 1 & 2 & 3 & 2 & 1 & 2 & 1 & 1 & 13 \\
\hline Wang, 2010 [172] & 0 & 0 & 0 & 1 & 2 & 3 & 2 & 1 & 2 & 1 & 1 & 13 \\
\hline Wang, 2011 [256] & 0 & 1 & 0 & 2 & 2 & 3 & 2 & 1 & 2 & 1 & 1 & 15 \\
\hline Watanabe, 2011 [173] & 0 & 0 & 0 & 1 & 2 & 3 & 2 & 1 & 2 & 1 & 1 & 13 \\
\hline Wilberg, 2012 [54] & 0 & 1 & 1 & 1 & 2 & 3 & 2 & 1 & 2 & 1 & 1 & 15 \\
\hline Williams, 2010 [246] & 2 & 1 & 0 & 2 & 2 & 3 & 2 & 1 & 2 & 1 & 1 & 17 \\
\hline Wilson, 2009 [233] & 2 & 0 & 0 & 2 & 2 & 2 & 2 & 1 & 2 & 1 & 1 & 15 \\
\hline Yalcin, 2005 [174] & 0 & 0 & 0 & 2 & 2 & 2 & 0 & 0 & 2 & 1 & 0 & 9 \\
\hline Yamagishi, 2009 [219] & 2 & 0 & 2 & 2 & 2 & 3 & 2 & 1 & 2 & 1 & 1 & 18 \\
\hline Yan, 2006 [175] & 0 & 0 & 0 & 1 & 2 & 3 & 2 & 1 & 2 & 1 & 1 & 13 \\
\hline Yen, 2012 [247] & 2 & 1 & 0 & 2 & 2 & 3 & 2 & 1 & 2 & 1 & 1 & 17 \\
\hline Yennurajalingam, 2012 [176] & 2 & 0 & 0 & 1 & 2 & 0 & 2 & 0 & 2 & 1 & 1 & 11 \\
\hline Yildirim, 2011 [45] & 2 & 0 & 2 & 1 & 2 & 3 & 2 & 1 & 2 & 1 & 1 & 17 \\
\hline Zucca, 2012 [51] & 2 & 1 & 0 & 1 & 2 & 3 & 2 & 1 & 2 & 1 & 1 & 16 \\
\hline
\end{tabular}




\title{
Co-creative development of an eHealth nursing intervention
}

\author{
self-management support for outpatients \\ with cancer pain
}

This chapter was published as:

Hochstenbach LM, Courtens AM, Zwakhalen SM,

Vermeulen J, van Kleef M, de Witte LP (2017)

Appl Nurs Res 36:1-8

DOI: 10.1016/j.apnr.2017.03.004 


\section{Abstract}

\section{Introduction}

Co-creative methods, having an iterative character and including different perspectives, allow for the development of complex nursing interventions. Information about the development process is essential in providing justification for the ultimate intervention and crucial in interpreting the outcomes of subsequent evaluations. This paper describes a co-creative method directed towards the development of an eHealth intervention delivered by registered nurses to support self-management in outpatients with cancer pain.

\section{Methods}

Intervention development was divided into three consecutive phases (exploration of context, specification of content, organisation of care). In each phase, researchers and technicians addressed five iterative steps: research, ideas, prototyping, evaluation, and documentation. Health professionals and patients were consulted during research and evaluation steps.

\section{Results}

Collaboration of researchers, health professionals, patients, and technicians was positive and valuable in optimising outcomes. The intervention includes a mobile application for patients and a web application for nurses. Patients are requested to monitor pain, adverse effects and medication intake, while being provided with graphical feedback, education and contact possibilities. Nurses monitor data, advise patients, and collaborate with the treating physician.

\section{Conclusions}

Integration of patient self-management and professional care by means of eHealth key into well-known barriers and seem promising in improving cancer pain follow-up. Nurses are able to make substantial contributions because of their expertise, focus on daily living, and their bridging function between patients and health professionals in different care settings. Insights from the intervention development as well as the intervention content give thought for applications in different patients and care settings. 


\section{Introduction}

Developing, piloting, evaluating, reporting, and implementing a complex intervention can be a challenging and lengthy process [1]. Although all these stages are regarded as equally important, the reporting of intervention development all too often receives only scant attention $[2,3]$. The steps that were taken, the methodologies that were applied, the collaboration of researchers and other experts, the involvement of health professionals and patients, the questions and problems that were identified, and the answers and solutions that were considered; all information that is essential in providing justification for the ultimate intervention and crucial in interpreting the outcomes of evaluations [4]. Lack of reporting also prevents others to reproduce and improve interventions based on new insights or to translate and transfer interventions to different patients and care settings. On that account, the present paper describes a co-creative method directed towards the development of an eHealth intervention delivered by registered nurses to support self-management in outpatients with cancer pain.

\section{Background}

As cancer pain represents one of the most prevalent and distressing symptoms $[5,6]$, adequate pain assessment and management are critical to patients' functioning and quality of life [7]. Regardless of available treatment though, pain in many patients is still insufficiently controlled. Inadequate cancer pain management in the outpatient setting can be attributed to barriers on different levels [8-10]. On the organisation level, fragmentation of care due to different health professionals in different healthcare settings complicates coordination and continuity of care [11]. Particularly in the outpatient setting, health professionals are unable to monitor pain and provide adequate follow-up. On the health professional level, pain is not structurally and thoroughly discussed during consultations, due to a lack of time and knowledge [12]. Consequently, health professionals are reluctant to prescribe opioids and only few patients are referred to pain or palliative care services. On the patient level, there is reservation to report pain because patients do not want to complain and keep the focus on the cure [8]. Insufficient knowledge causes misconceptions and fears about adverse effects, addiction, and risk of tolerance that, in turn, negatively interfere with patients' medication intake [13]. Much as advances are made regarding the effectiveness of cancer pain interventions, the optimal content and combination of components are still to be determined [14].

Recommendations to overcome barriers include a multidisciplinary approach that promotes collaboration between different health professionals and ongoing assessment 
of pain with regular follow-up appointments [15]. Moreover, patient education as well as pain and medication diaries are suggested to ensure realistic expectations and appropriate medication use [16]. In order to address these recommendations, active patient involvement seems a prerequisite. Because different patients require different support [17], multi-component interventions are proposed for self-management. Healthcare technology provides an excellent means for the integration of these different components, as it allows interventions to be tailored to the individual patient and the situation for which support is required. In addition, healthcare technology is particularly convenient for connecting patients at home with health professionals in primary or hospital care practice [18]. In this regard, remote self-monitoring offers both patients and health professionals more accurate and timely information to improve follow-up [19]. Healthcare technology has been successfully implemented before to support symptom control (McCann et al., 2009), to improve patient-health professional communication [20], and to allow greater access to healthcare services [21].

Although promising for multi-component interventions, healthcare technologies need embedding into routine clinical practice in order to be accepted and successfully implemented [22]. For this purpose, nurses can perform a coordinating role along the care process and across care settings [23]. With their expertise and focus on patients' daily living, nurses are able to make substantial contributions to day-to-day pain management in the outpatient setting [24]. The important role of nurses in delivering self-management interventions has been demonstrated with positive outcomes [25].

\section{Methods}

\section{Development approach}

Based on key principles of user centred design [26,27], intervention development was carried out by a multidisciplinary team in an iterative and incremental process. Health professionals and patients were actively involved; their context as well as their wishes and needs guided the process early and continuously. Intervention options were explained in easy-to-understand language and prototypes were used to support the creative process, elicit requirements, and visualise ideas and solutions. Integration of the intervention into routine clinical practice was organised in parallel and evaluations were performed in real life as much as possible.

\section{Development team}

Different perspectives were considered important to provide multiple views on problems and solutions. On that account, three researchers and three technicians with 
different expertise (cancer pain and palliative care, e-health and self-management, software development and design) collaborated in the translation of conceptual ideas into clinical practice. Ten health professionals working in primary and hospital care as well as five patients with current or past cancer pain were consulted during the development process. Decisions about the content and format of the intervention were based on their experiences and opinions, while remaining within practical and financial boundaries. Ethical principles that are outlined in the Dutch "Medical Research Involving Human Subjects Act" were followed throughout the development process [28].

Table 3.1 Conceptual framework of intervention components

\begin{tabular}{ll}
\hline Component & Tailored to the characteristics of outpatient with cancer pain \\
\hline Information [29] & $\begin{array}{l}\text { Patients need knowledge about cancer pain, its treatment, and the factors } \\
\text { that cause variations in pain levels including medication intake, adverse } \\
\text { effects, daily activities, psychological status, and support. } \\
\text { Skills important for patients include the capability to self-monitor pain } \\
\text { progress, use medication properly, contact health professionals when } \\
\text { needed, adjust behaviours, and cope with consequences of pain. } \\
\text { Insight into their own situation is a prerequisite to implement skills, } \\
\text { because self-monitored data enable patients to become aware of pain } \\
\text { trends and influential factors on the basis of which they can make decisions } \\
\text { and act accordingly. } \\
\text { Self-confidence, or self-efficacy, is critical in managing physical and } \\
\text { psychosocial consequences of pain. Interventions with a focus on self- } \\
\text { efficacy are believed to be advantageous, as patients high in self-efficacy } \\
\text { report lower levels of pain. } \\
\text { A supportive environment of formal and informal caregivers makes patients } \\
\text { feel they are not on their own and simultaneously allows them to practice } \\
\text { and gain confidence in their abilities to perform self-management and } \\
\text { better control their symptoms. }\end{array}$ \\
\hline $\begin{array}{l}\text { Supportive } \\
\text { environment [33] }\end{array}$
\end{tabular}

\section{Development process}

A review of the literature provided helpful guidance for identifying roles, tasks, and responsibilities of self-management by patients and self-management support by health professionals. Theories about self-management for chronic conditions in general $[17,29,34]$ and evidence about (educational) interventions for cancer pain specifically were taken into account $[14,35-37]$. To tailor the intervention to the characteristics of outpatients with cancer pain, the applicability of different components was screened and a selection was made. Table 3.1 outlines the conceptual framework with a description of the selected components, including information, skills, insight, selfefficacy, and supportive environment. 
The development process consisted of three consecutive phases: exploration of context, specification of content, and organisation of care. As presented in Figure 3.1, an iterative cycle consisting of five steps was addressed in each of these phases: research, ideas, prototyping, evaluation, and documentation. User and technical requirements were formulated, specified, and prioritised during the development process.

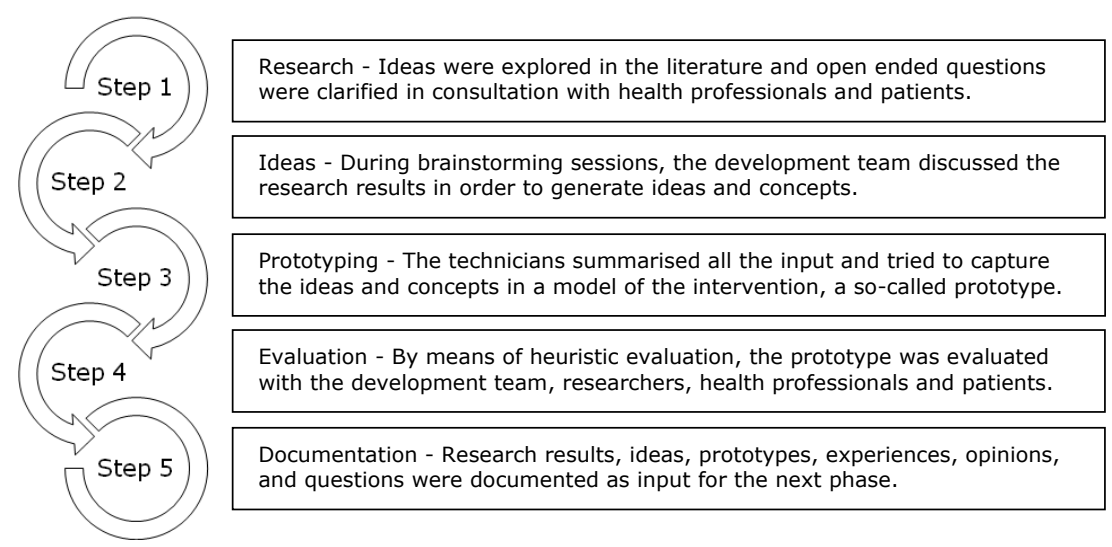

Figure 3.1 Iterative cycle of five steps that were performed in each of the three phases

\section{Phase 1 - Exploration of context}

Document analysis (guidelines, case reports) and semi-structured interviews with ten health professionals (two registered nurses specialised in pain and palliative care, a home care nurse, two oncologists, a pain specialist, a general practitioner, and three pharmacists) and two outpatients conveniently sampled by a pain specialist (a 64-year old male with squamous cell cancer and a 73-year old female with breast cancer) were performed to collect information about patient characteristics, usual care, and intervention needs (step 1). Information was discussed with the development team in two brainstorming sessions. Personas (fictitious characters that represent the patient population) and scenarios (activities, perceptions, and desires from these personas in daily life) were used to explore solutions (step 2). Paper drafts of the applications for patients and nurses were made (step 3) and evaluated during a development team meeting and separately with two researchers. Evaluations were observed and notes were taken by the main researcher (step 4). Data were documented and a first draft of the user requirements was made (step 5). 


\section{Phase 2 - Specification of content}

Document analysis (protocols for pain assessment, education materials) and three consultation sessions with a multidisciplinary palliative team provided input for the content of the intervention in terms of what to monitor, how to measure pain, how to assess medication use, and how to provide feedback (step 1). Ideas were discussed in two brainstorming sessions with the development team (step 2) and results were processed in a paper-based prototype for patients (step 3). This prototype was evaluated in three development team meetings. During these evaluations notes were taken by the main researcher (step 4). Data were processed and user requirements were formulated more precisely (step 5 ).

\section{Phase 3 - Organisation of care}

Semi-structured interviews from the first phase provided input for how care had to be organised for the embedding of the applications into routine clinical practice (step 1). During three brainstorming sessions, the development team considered division of roles, tasks, and responsibilities among the involved health professionals (step 2). Thoughts were summarised in a software-based prototype of the patient application and in an algorithm for the nurse application (step 3). Usability and desirability of the prototype were tested with three outpatients conveniently sampled by a pain specialist (a 59-year old male with prostate cancer, a 53-year old female with neurosarcoma, and a 60-year old female with former breast cancer). This individual 1-hour session at the hospital or at the patients' home consisted of tasks, a semi-structured interview, and a questionnaire. The thirteen tasks were scored on a 5-point scale, ranging from 1 (very easy to complete) to 5 (very difficult to complete), while thinking aloud. Interview questions addressed understanding and presentation of information. The questionnaire listed 118 words with positive and negative connotations of which patients were asked to select and explain all words they thought fit the application [38]. Evaluations were observed and audiotaped by the main researcher. Descriptive statistics were used to explore task performance. Interview notes were reviewed, initial reflections were added, and audiotapes were re-listened to uncover usability and desirability issues [39]. To examine external validity, all findings were discussed with the development team (step 4). Data were documented and together with two software engineers the final user requirements were translated into technical requirements (step 5). 


\section{Results}

\section{Development process}

\section{Phase 1 - Exploration of context (Month 1-3)}

This first phase focused on patient characteristics, usual care, and intervention needs. Guidelines and case reports uncovered a variety in pain treatments. Differences in medication names, dosages, and routes of administration as well as prescription changes at short notice, would require flexibility of the medication monitoring method. Health professionals emphasised the importance of measuring pain frequently and choosing a monitoring method that was applicable outside the research setting. Patients revealed that pain reference scores facilitated pain assessment, reminders were beneficial in taking medication (on time), and frequent communication with a nurse was appreciated. Both health professionals and patients acknowledged that the collaboration of different health professionals in the home setting deserved attention (steps 1-2). The sketches of the application for patients consisted of the following components: pain diaries, medication overview, trends and feedback, pain information, and text messages. For nurses the sketches included an application with pain diaries, medication intake, data summarised in graphs, and text messages (step 3). Important themes of the evaluation were frequency of self-monitoring, content of diaries and medication overviews, formulation of feedback, and follow-up by the nurse (steps 4-5).

\section{Phase 2 - Specification of content (Month 4-5)}

During the second phase, attention was directed to the content of application components. A short pain diary was designed based on present-day pain assessment. In the selection of questions, the multidisciplinary palliative team aimed at providing nurses with adequate information without burdening patients too much. The diary that was presented to patients twice daily used skip patterns, where affirmative answers on particular questions resulted in sub questions to obtain more information. Patients also needed to be able to score extra pain intensity optionally, to report (the effect of medication on) breakthrough pain and to provide a better reflection of pain over time. The numerical rating scale (NRS) was chosen to measure pain intensity, because of its usefulness, proven psychometric properties and sensitivity to change in patients with cancer [40]. Strategies that have proven to contribute to a better diary response were incorporated in the intervention, including a paper-copy manual, visual and sound reminders, contact, and feedback [41]. Pain medication was presented in a personalised day schedule with 'around the clock' medication per point in time and 'as needed' medication. A restricted 4-hour time frame was meant to motivate patients to take and register their pain medication in time. On time intake affects pain control; on 
time registration enables accurate feedback. Furthermore, medication icons were added to support patients visually. When providing feedback to support selfmanagement, different parameters in the moment and during longer periods, have to be combined. Therefore, automatically generated feedback to patients was restricted to a graph with pain intensity scores and medication intake moments, whereas the nurse should provide detailed textual feedback. Existing education about pain management was updated and divided into three sessions (steps 1-2). The paperbased prototype for patients consisted of an application with four components: diary, medication, knowledge, and contact (step 3). Important themes of the evaluation were patient expectations regarding responses and actions and, allied to that, roles, tasks, and responsibilities of involved health professionals (steps 4-5).

Table 3.3 Usability tasks and difficulty ratings

\begin{tabular}{lccc}
\hline Task & P1 & P2 & P3 \\
\hline 1. Look up the pain diary. & 2 & 1 & 1 \\
2. Look up where to get insight into your pain progress. & 2 & 1 & 3 \\
3. Look up your pain medication prescription. & 1 & 1 & 1 \\
4. Read up a message from the nurse. & 1 & 1 & 1 \\
5. Find information about pain. & 1 & 1 & 1 \\
6. Look up your pain medication for today. & 1 & 1 & 3 \\
7. Look up where to leave a message for the nurse. & 1 & 1 \\
8. Go from home to diary to medication to knowledge to contact. & 1 & 1 \\
9. Fill out the pain diary. & 2 & 3 & 3 \\
10. Register your medication. & 2 & 2 & 3 \\
11. Read up the information about causes of cancer pain. & 1 & 1 & 1 \\
12. Look up your pain progress. & 1 & 2 & 1 \\
13. Leave a message for the nurse. & 1 & 1 & 1 \\
\hline
\end{tabular}

Difficulty ratings ranged from 1 (very easy to complete) to 5 (very difficult to complete)

\section{Phase 3 - Organisation of care (Month 6-9)}

Integrating the applications in a structural organisation of care was the focus of the final phase. For obtaining an accurate overview of a patient's medication, the involvement of the pharmacist was considered. To facilitate interpretation of patients' data and to save nurses' time, supportive presentation of information within the nurse application was thought to be conditional. Together with the multidisciplinary palliative care team, consensus was reached about a decision support system that consisted of an algorithm of diary questions, answers, and coloured risk flags (Table 3.2). These flags turned red, yellow, and green depending on the presence and duration of diary answers. The development team defined the tasks and responsibilities of the nurse, treating physician, general practitioner, and pharmacist (steps 1-2). The software based prototype for patients included a mobile application with four components: diary (questions and graph), medication (overview and day schedule), knowledge (sessions 
and topics), and contact with the nurse (history and new text messages). An already existing web application for nurses was extended with a composite graph of pain and medication data and the possibility to enter medication (step 3). Three patients evaluated usability and desirability of the mobile application. After a few minutes of exploration, patients were able to navigate with little to no guidance and accomplished the tasks in $<15 \mathrm{~min}$. Task difficulty was rated as 'very easy' by most patients. Table 3.3 includes the tasks and corresponding difficulty ratings. As revealed during the interviews, usability issues concerned inconsistent terminology, ambiguous icons, small character sizes, unchangeable graphs; and absent read aloud functionalities. Discussion of the questionnaire words revealed that patients experienced the application as easy to use because of the few components and clear structure. Graphical feedback was thought to be stimulating and supportive, while the digital character of the application was believed to save time and effort. Patients felt that the application would help to adequately organise pain medication and control pain better. No negative formulated words were chosen (steps 4-5). Table 3.4 contains the final user requirements, as derived from the three phases.

Table 3.2 Algorithm of diary questions, answers, coloured risk flags, and follow-up questions

\begin{tabular}{|c|c|c|}
\hline Morning & Flag & Next \\
\hline \multicolumn{3}{|c|}{ Q1 Did you have a good night's sleep? } \\
\hline Yes & $\mathbf{\square}$ & Q2 \\
\hline No & - & Q1.1 \\
\hline
\end{tabular}

Q1.1 Did you experience any difficulties with falling asleep?

Yes

Q1.2

No in $<2$ morning diaries

Q1.2

No in $\geq 2$ morning diaries

Q1.2

Q1.2 Did you experience any difficulties with sleeping through the night?

Yes

No in $<2$ morning diaries

Q2

No in $\geq 2$ morning diaries

Q2

Q2

Evening Flag Next

Q1 How did you experience your pain today?

Very good or good

Q2

Not good, not bad or bad or very bad

Q1.1

Q1.1 Did the pain prevent you from position and behaviour; normal eating habits; contacts with others, other activities; none of these?

No

Yes to the same activity in $<2$ evening diaries

Yes to the same activity in $\geq 2$ evening diaries

Other activities

Q1.1.1 During which other activities did the pain bother you? 
Table 3.2 (continued)

\begin{tabular}{|c|c|c|}
\hline Morning and evening & Flag & Next \\
\hline \multicolumn{3}{|c|}{ Q2 How would you rate your pain at this moment? } \\
\hline NRS $0<4$ & $\square$ & Q3 \\
\hline NRS $\geq 4-10$ in $1<4$ diaries & 口 & Q3 \\
\hline NRS $\geq 4-10$ in $\geq 4$ diaries & $\mathbf{\square}$ & Q3 \\
\hline \multicolumn{3}{|c|}{ Q3 How many breakthrough pain attacks did you experience in the last 12 hours? } \\
\hline 0 & $\square$ & Q4 \\
\hline$\geq 1$ & - & Q3.1 \\
\hline \multicolumn{3}{|c|}{$\begin{array}{l}\text { Q3.1 How would you rate your pain when your pain was at its worst in the last } 12 \\
\text { hours? }\end{array}$} \\
\hline$<4$ & $\square$ & Q4 \\
\hline$\geq 4$ in $1<4$ diaries & 口 & Q4 \\
\hline$\geq 4$ in $\geq 4$ diaries & $\mathbf{\square}$ & Q4 \\
\hline \multicolumn{3}{|c|}{ Q4 Do you experience any symptoms other than pain at the moment? } \\
\hline No & $\square$ & Q5 \\
\hline Yes & & Q4.1 \\
\hline \multicolumn{3}{|c|}{$\begin{array}{l}\text { Q4.1 Which symptoms other than pain do you experience at the moment? Nausea, } \\
\text { vomiting, obstipation, tightness of the chest, problems with sleeping, scary } \\
\text { dreams, dry mouth, dizziness, drowsiness, sleepiness, other symptoms? }\end{array}$} \\
\hline Yes to the same symptom in $1<4$ diaries & $\square$ & Q5 \\
\hline Yes to the same symptom in $\geq 4$ diaries & $\square$ & Q5 \\
\hline Other symptoms & & Q4.1.1 \\
\hline \multicolumn{3}{|c|}{ Q4.1.1 Which other symptom that is not listed do you experience at the moment? } \\
\hline- & - & Q5 \\
\hline \multicolumn{3}{|c|}{ Q5 Has a physician changed your pain medication in the last 12 hours? } \\
\hline No & $\mathbf{\square}$ & Q6 \\
\hline Yes & $\mathbf{\square}$ & Q6 \\
\hline \multicolumn{3}{|c|}{ Q6 Are you satisfied with your pain relief at this moment? } \\
\hline Yes & $\square$ & - \\
\hline No & $\square$ & - \\
\hline
\end{tabular}

\section{Content of the intervention}

The development process resulted in a home visit, a mobile application for patients, a web application for nurses, and follow-up activities. Both applications are to be embedded in routine clinical practice. The mobile application runs on an iPad 2 with Internet connection; the web application is accessible from each computer with a browser. Patients and nurses need log in information to gain access to the applications. Monitored data are saved on secured servers that comply with present rules and regulations. 
Approval is sought from the treating physician and information is given to the general practitioner prior to the intervention. After contacting the pharmacist, the nurse enters pain medication details (name, route of administration, dosage, and timing) in the web application, while taking into account patients' daily routines. A second nurse performs a check and activation procedure, after which entered pain medication is visible in the mobile application.

Table 3.4 User requirements as derived from the three phases

Information

Patients require information about pain and pain management.

Information to be included: causes of pain, treatment of pain, recognition of symptoms that require action, and self-management methods to control pain.

Information needs to be presented dosed and in a logical sequence.

Skills

Patients need to receive a pain diary every morning and every evening.

Diaries have to ask for pain at this moment, pain attacks, adverse effects, satisfaction with pain

treatment, and interference of pain with activity or sleep.

Patients need to be able to register extra pain intensity scores at any moment.

Medication monitoring should fit the complexity of pharmacological pain treatment.

Patients have to monitor intake of 'around the clock' and 'as needed' medication.

'Around the clock' medication should be registered within a restricted time frame.

Medication overviews have to be entered and adjusted by a health professional.

Patients and nurses need to be able to interact via the application.

Insight

Patients should to be able to view pain intensity over time, also related to medication intake and daily routines, in order to see trends and patterns.

Automatically generated information about pain intensity and medication intake has to be depicted in a graph.

Nurses need to provide more detailed feedback in text messages.

Self-efficacy

The mobile application should be easy to use and easy to learn for a variety of patients independent of age, education level, or computers experience.

Patients should be able to practice with the application.

Patients need to receive feedback about pain self-management.

Supportive environment

Patients need to be reminded to complete diaries and take medication.

Nurses need to monitor pain diaries and medication intake every workday.

Supportive presentation of information and coloured risk flags needs to facilitate tasks.

Nurses should have access to all patient data to guarantee continuity of care.

Room for documentation needs to facilitate carry-over and follow-up of pain treatment.

The treating physician keeps responsibility for pain treatment.

Treating physicians need access to data of their own patients. 


\section{Home visit}

The intervention starts with a home visit, during which nurses perform a pain assessment, check pain medication, and provide information of which the content corresponds with the education within the application. Patients receive instructions about the iPad and the mobile application, after which they receive a paper-copy manual.

\section{Mobile application for patients}

Patients enter the application via a home screen. Every morning and evening they fill out a pain diary with questions about their pain, adverse effects, interference of pain with activity or sleep, and satisfaction with pain treatment. In between these diaries, registration of extra pain intensity scores is optional. Moreover, the application includes a personalised day schedule. In accordance with this schedule, patients are requested to register intake of 'around the clock' medication and 'as needed' medication in time. All pain intensity scores are presented in a graph together with the medication intake moments. The graphical information provides insight into pain patterns over time and the possible influence of medication intake and daily routines. Patients receive education about pain causes, pain treatment, recognition of symptoms that require action, and methods that patients themselves can implement to control pain. This education is divided into three sessions; each session consists of several topics. After completion of these sessions, those who want to know more can access additional information about pharmacological and alternative treatments. In case of questions, patients have the opportunity to send text messages to the nurse. Patients are reminded to complete diaries, take medication, read education materials, and check text messages from the nurse by visual and sound notifications.

\section{Web application for nurses}

The nurse monitors and analyses the patients' pain situation once every workday. In addition to the composition of the medication overview, the application for nurses includes completed pain diaries, information about scheduled and actual medication intake, composite graphs, and a text message function. The use of coloured flags supports nurses in their monitoring tasks. Red flags require immediate action, yellow flags ask to keep an eye, and green flags indicate that no action is needed. In case of red flags or incoming text messages, nurses receive email notifications. Nurses consult patients by text messages or phone.

\section{Follow-up activities by nurses}

When necessary, and also on a regular basis, nurses inform the treating physician about the patient's situation. In case of pain relief being inadequate, nurses consult 
the pain specialist or the multidisciplinary palliative team for advice. Advice is then reported to the treating physician who decides on follow-up, changes in prescriptions or other interventions. As a consequence, patients might eventually be invited to visit the outpatient clinic or, when necessary, a home visit by the nurse might be scheduled. Nurses have access to all patient data to facilitate patient handover and guarantee continuity of care.

\section{Discussion}

Assessment and management of cancer pain continue to be a common challenge in outpatient care. Actively involving patients by self-management support could provide answers to overcoming current barriers. The present paper describes a co-creative method directed towards the development of an eHealth intervention delivered by registered nurses to support self-management in outpatients with cancer pain. The development process, having an iterative character and including different perspectives, delivered promising results. The integration of patient self-management and professional care by means of healthcare technology facilitates partnership with shared responsibilities, offers valuable insights that complement usual care and accommodates subsequent consultations or referrals.

Intervention development was based on user centred design to ensure an intervention fit with patients' and nurses' wishes, needs, and daily practices and thereby to increase implementation success [42]. The collaboration of researchers, health professionals, patients, and technicians was positive though challenging at times due to differences in perspectives. Researchers usually work with a framework based on previous research and conceptual ideas. Health professionals and patients then introduce a more practical view on problems and solutions. In the end, the technical perspective brings in technological possibilities and restrictions. Taking all the perspectives into account, from research ideas to user requirements to technical functionalities, sometimes requires flexibility and concessions [43].

Intervention content was derived from self-management supporting components that were considered important for patients in general $[17,30,34]$ and that were selected specifically for outpatients with cancer pain. The present intervention provides patients with education to improve knowledge and understanding. Important skills for patients to implement, such as pain and medication monitoring, making appropriate decisions, and carrying out subsequent actions, are continuously encouraged by means of pain diaries, medication overviews, and graphical feedback. Being looked after by nurses needs to enable patients to practice their skills and to become more self-efficacious. Collaboration of nurses with the treating physician should further contribute to this supportive environment. Previously applied 
interventions focused mostly on information provision and skills instruction $[14,37,44]$. Even if monitoring was part, interventions often served pain management by health professionals, not self-management by patients [45-47].

Some limitations of the development process need to be addressed. First, the involvement of patients was restricted to the start of the first phase and the evaluation in the last phase. Ideally, patients would have been involved more frequently. Nevertheless, health professionals experienced in pain and palliative care and familiar with patient's home situation, articulated patients' ideas and experiences. Second, the development team was unable to implement all suggested changes. Patients, for one, preferred to monitor not just pain medication but also co-medication and medication for co-morbidities. However, practical and financial constraints required prioritising. After proven effective, the intervention could be optimised and serve more needs. Third, formative evaluations focused on the usability of the application for patients in terms of navigation, content, and satisfaction. Day-to-day feasibility and practical implications have yet to be explored, for which a small-scale study will be performed [48].

\section{Conclusion}

As advances in nursing practice and research are pursued, nurses are encouraged to adopt complex intervention thinking. A co-creative method, as implemented here, will help nurses to actually bring thoughts into action. An open and iterative process encourages thinking outside the box and considering less obvious solutions. At the same time there is room to involve health professionals and patients in order to create interventions that actually suit their daily routines both at home and in the clinical setting. Insights from the intervention development as well as the intervention content give thought for applications in different patients and care settings. 


\section{References}

1. Craig P, Dieppe P, Macintyre S, Michie S, Nazareth I, Petticrew M (2013) Developing and evaluating complex interventions: the new Medical Research Council guidance. Int J Nurs Stud 50:587-592.

2. van Hecke A, Verhaeghe S, Grypdonck M, Beele H, Flour M, Defloor T (2011) Systematic development and validation of a nursing intervention: the case of lifestyle adherence promotion in patients with leg ulcers. J Adv Nurs 67:662-676.

3. van Meijel B, Gamel C, van Swieten-Duijfjes B, Grypdonck MH (2004) The development of evidence-based nursing interventions: methodological considerations. J Avd Nurs 48:84-92.

4. Hoddinott P (2015) A new era for intervention development studies. Pilot Feasibility Stud 1: $1-4$.

5. Klepstad P, Kaasa S, Cherny N, Hanks G, de Conno F, Research Steering Committee of the EAPC (2005) Pain and pain treatments in European palliative care units. A cross sectional survey from the European Association for Palliative Care Research Network. Palliat Med 19:477-484.

6. Van den Beuken-van Everdingen MH, Hochstenbach LM, Joosten EA, Tjan-Heijnen VC, Janssen DJ (2016) Update on prevalence of pain in patients with cancer: Systematic review and meta-analysis. J Pain Symptom Manage 51(6):1070-1090.

7. Wool MS, Mor V (2005) A multidimensional model for understanding cancer pain. Cancer Invest 23:727-734.

8. Jacobsen R, Moldrup C, Christrup L, Sjogren P (2009) Patient-related barriers to cancer pain management: a systematic exploratory review. Scand J Caring Sci 23:190-208.

9. Luckett T, Davidson PM, Green A, Boyle F, Stubbs J, Lovell M (2013) Assessment and management of adult cancer pain: a systematic review and synthesis of recent qualitative studies aimed at developing insights for managing barriers and optimizing facilitators within a comprehensive framework of patient care. J Pain Symptom Manage 46:229-253.

10. Oldenmenger WH, Sillevis Smitt PA, van Dooren S, Stoter G, van der Rijt CC (2009) A systematic review on barriers hindering adequate cancer pain management and interventions to reduce them: a critical appraisal. Eur J Cancer 45:1370-1380.

11. Schumacher KL, Plano Clark VL, West CM, Dodd MJ, Rabow MW, Miaskowski C (2014) Pain medication management processes used by oncology outpatients and family caregivers part I: health systems contexts. J Pain Symptom Manage 48(5):770-783.

12. Kimberlin C, Brushwood D, Allen W, Radson E, Wilson D (2004) Cancer patient and caregiver experiences: communication and pain management issues. J Pain Symptom Manage 28: 566-578.

13. Miaskowski C, Dodd MJ, West C, Paul SM, Tripathy D, Koo P, Schumacher K (2001) Lack of adherence with the analgesic regimen: a significant barrier to effective cancer pain management. J Clin Oncol 19:4275-4279.

14. Koller A, Miaskowski C, De Geest S, Opitz O, Spichiger E (2012) A systematic evaluation of content, structure, and efficacy of interventions to improve patients' self-management of cancer pain. J Pain Symptom Manage 44:264-284.

15. Brink-Huis A, van Achterberg T, Schoonhoven L (2008) Pain management: a review of organisation models with integrated processes for the management of pain in adult cancer patients. J Clin Nurs 17:1986-2000.

16. Kwon JH (2014) Overcoming barriers in cancer pain management. J Clin Oncol 32:1727-1733.

17. Barlow J, Wright C, Sheasby J, Turner A, Hainsworth J (2002) Self-management approaches for people with chronic conditions: a review. Patient Educ Couns 48:177-187.

18. Dickinson R, Hall S, Sinclair JE, Bond C, Murchie P (2014) Using technology to deliver cancer follow-up: a systematic review. BMC Cancer 14:311.

19. Meystre S (2005) The current state of telemonitoring: a comment on the literature. Telemed J E Health 11:63-69. 
20. McCann L, Maguire R, Miller M, Kearney N (2009) Patients' perceptions and experiences of using a mobile phone-based advanced symptom management system (ASyMS) to monitor and manage chemotherapy related toxicity. Eur J Cancer Care 18:156-164.

21. Dy SM, Roy J, Ott GE, McHale M, Kennedy C, Kutner JS, Tien A (2011) Tell Us: a Web-based tool for improving communication among patients, families, and providers in hospice and palliative care through systematic data specification, collection, and use. J Pain Symptom Manage 42:526-534.

22. Hennemann-Krause L, Lopes AJ, Araujo JA, Petersen EM, Nunes RA (2015) The assessment of telemedicine to support outpatient palliative care in advanced cancer. Palliat Support Care 13:1025-1030.

23. Taylor J, Coates E, Brewster L, Mountain G, Wessels B, Hawley MS (2015) Examining the use of telehealth in community nursing: identifying the factors affecting frontline staff acceptance and telehealth adoption. J Adv Nurs 71:326-337.

24. Courtenay M, Carey N (2008) The impact and effectiveness of nurse-led care in the management of acute and chronic pain: a review of the literature. J Clin Nurs 17:2001-2013.

25. Vallerand AH, Musto S, Polomano RC (2011) Nursing's role in cancer pain management. Curr Pain Headache Rep 15:250-262.

26. Gulliksen J, Göransson B, Boivie I, Blomkvist S, Persson J, Cajander A (2003) Key principles for user-centered systems design. Behav Inform Technol 22:397-409.

27. van Gemert-Pijnen JE, Nijland N, van Limburg M, Ossebaard HC, Kelders SM, Eysenbach G, Seydel ER (2011) A holistic framework to improve the uptake and impact of eHealth technologies. J Med Internet Res 13:e111.

28. Central Committee on Research Involving Human Subjects (CCMO) (1998) Medical/scientific research and the WMO. Available from http://www.ccmo.nl/en/medical-scientific-researchand-the-wmo. Accessed September 9, 2016.

29. Lorig KR, Holman H (2003) Self-management education: history, definition, outcomes, and mechanisms. Ann Behav Med 26:1-7.

30. Holman H, Lorig K (2004) Patient self-management: a key to effectiveness and efficiency in care of chronic disease. Public Health Rep 119:239-243.

31. Wilde MH, Garvin S (2007) A concept analysis of self-monitoring. J Adv Nurs 57:339-350.

32. Porter LS, Keefe FJ, Garst J, McBride CM, Baucom D (2008) Self-efficacy for managing pain, symptoms, and function in patients with lung cancer and their informal caregivers: associations with symptoms and distress. Pain 137:306-315.

33. Bodenheimer T, Lorig K, Holman H, Grumbach K (2002) Patient self-management of chronic disease in primary care. JAMA 288:2469-2475.

34. Richard AA, Shea K (2011) Delineation of self-care and associated concepts. J Nurs Scholarsh 43:255-264.

35. Allard P, Maunsell E, Labbe J, Dorval M (2001) Educational interventions to improve cancer pain control: a systematic review. J Palliat Med 4:191-203.

36. Devine EC (2003) Meta-analysis of the effect of psychoeducational interventions on pain in adults with cancer. Oncol Nurs Forum 30:75-89.

37. Bennett MI, Bagnall AM, Jose Closs S (2009) How effective are patient-based educational interventions in the management of cancer pain? Systematic review and meta-analysis. Pain 143:192-199.

38. Benedek J, Miller T (2002) Measuring desirability: new methods for evaluating desirability in a usability lab setting. UPA Conf Proc.

39. Halcomb EJ, Davidson PM (2006) Is verbatim transcription of interview data always necessary? Appl Nurs Res 19:38-42.

40. Hjermstad MJ, Fayers PM, Haugen DF, Caraceni A, Hanks GW, Loge JH, Fainsinger R, Aass N, Kaasa S, European Palliative Care Research C (2011) Studies comparing Numerical Rating Scales, Verbal Rating Scales, and Visual Analogue Scales for assessment of pain intensity in adults: a systematic literature review. J Pain Symptom Manage 41:1073-1093. 
41. Morren M, van Dulmen S, Ouwerkerk J, Bensing J (2009) Compliance with momentary pain measurement using electronic diaries: a systematic review. Eur J Pain 13:354-365.

42. Shah SG, Robinson I (2007) Benefits of and barriers to involving users in medical device technology development and evaluation. Int J Technol Assess Health Care 23:131-137.

43. Vermeulen J, Verwey R, Hochstenbach LM, van der Weegen S, Man YP, de Witte LP (2014) Experiences of multidisciplinary team members during user-centered design of telecare products and services: a qualitative study. J Med Internet Res 16(5):e124.

44. Lovell M, Luckett T, Boyle F, Phillips J, Agar M, Davidson P (2014) Patient education, coaching, and self-management for cancer pain. J Clin Oncol 32:1712-1720.

45. Kim HS, Shin SJ, Kim SC, An S, Rha SY, Ahn JB, Cho BC, Choi HJ, Sohn JH, Kim HS, Chung HC, Kim JH, Roh JK, Lee S (2013) Randomized controlled trial of standardized education and telemonitoring for pain in outpatients with advanced solid tumors. Support Care Cancer 21:1751-1759.

46. Kroenke K, Theobald D, Wu J, Loza JK, Carpenter JS, Tu W (2010) The association of depression and pain with health-related quality of life, disability, and health care use in cancer patients. J Pain Symptom Manage 40:327-341.

47. Wilkie D, Berry D, Cain K, Huang HY, Mekwa J, Lewis F, Gallucci B, Lin YC, Chen AC, Ko NY (2010) Effects of coaching patients with lung cancer to report cancer pain. West J Nurs Res 32:23-46.

48. Hochstenbach LM, Zwakhalen SM, Courtens AM, van Kleef M, de Witte LP (2016) Feasibility of a mobile and web-based intervention to support self-management in outpatients with cancer pain. Eur J Oncol Nurs 23:97e105. 


\section{4}

Feasibility of a mobile and web-based

intervention to support self-management in outpatients with cancer pain

This chapter was published as:

Hochstenbach LM, Zwakhalen SM, Courtens AM, van Kleef M, de Witte LP (2016)

Eur J of Oncol Nurs 23:97e105

DOI: $10.1016 /$ j.ejon.2016.03.009 


\section{Abstract}

\section{Purpose}

Cancer pain is a prevalent and distressing symptom. To enhance self-management in outpatients, a multi-component intervention was developed, integrating patient selfmanagement and professional care through healthcare technology. This article describes feasibility of the intervention in everyday practice.

\section{Method}

Patients with moderate to severe cancer pain $(n=11)$ and registered nurses specialised in pain and palliative care $(n=3)$ participated in a 4-week study. The intervention involved daily monitoring, graphical feedback, education, and advice by means of a mobile application for patients and a web application for nurses. Learnability, usability, and desirability were measured in patients with a 20-item questionnaire (1-5 scale), higher scores indicating better feasibility. Patients' adherence was based on completion rates from server logs. Single semi-structured interviews with patients and a focus group interview with nurses provided insight into experiences.

\section{Results}

Questionnaire findings confirmed learnability (4.8), usability (4.8), and desirability (4.6) of the application for patients. Average completion rates were $76.8 \%$ for pain monitoring, $50.4 \%$ for medication monitoring, and $100 \%$ for education sessions. Interviews revealed that patients appreciated the simplicity of the mobile application and valued different components. Nurses agreed upon the added value and were mostly positive about the possibilities of the web application. Patients and nurses provided ideas for improvements relating to the content and technical performance of the intervention.

\section{Conclusions}

Study results confirm feasibility of the intervention in everyday practice. Provided that substantive and technical adjustments are made, the intervention enables patients with cancer pain to practice self-management and nurses to remotely support these patients. 


\section{Introduction}

Pain is a commonly experienced and inadequately controlled symptom in outpatients with cancer $[1,2]$. Several barriers on different levels contribute to difficulties in optimising outcomes. First, the organisation makes coordination and continuity of pain management to be challenging. Different health professionals in different health care settings are involved and close monitoring and follow-up of pain is difficult once patients are at home [3]. Second, pain is not structurally and thoroughly discussed by health professionals during consultations and the subjective experience of pain is difficult to measure objectively $[4,5]$. Health professionals are also careful to prescribe opioids and reluctant to refer patients to pain or palliative care services [6]. Third, patients struggle with misconceptions about pain medication, concerns about pain communication, and beliefs about the inevitability and uncontrollability of cancer pain [7]. These misconceptions, concerns, and beliefs influence adherence and prevent patients from taking their pain medication as prescribed [8]. At the same time, outpatients face more practical day-to-day challenges at home, such as coping with adverse effects and managing new or unusual pain [9]. Comparable to many prevalent chronic conditions, patients with cancer pain are therefore more and more encouraged to contribute actively to their own pain management and practice self-management $[10,11]$. Patients themselves do want to be more active in pain management [12].

Various valuable interventions have been developed and evaluated in order to improve pain control and support self-management [13-17]. Interventions directed at patients commonly address knowledge by sharing information about pain, pain medication, side effects, alternative methods to control pain, and when to get help. Some of the interventions also target problem-solving skills by providing instructions on how to assess pain, how to take medication, how to manage side effects, how to apply alternative methods, and how to communicate with health professionals. Because interventions are diverse and did not achieve desired effects on different outcome measures so far, questions remain about the optimal format as well as content and combination of intervention components $[18,19]$.

Awareness and measurement of symptom progress are considered essential for effective self-management [20]. Self-monitoring provides patients with insight into pain variations and how these variations possibly relate to variables such as adverse effects, medication intake, and daily activities. Self-monitored data could therefore support patients to make appropriate decisions, to take subsequent actions and to see the impact of these actions [21]. Daily diaries have been helpful in outpatients with cancer pain to heighten awareness, increase their sense of control, and improve communication with and assistance from health professionals $[22,23]$. As selfmonitoring enables actual implementation of knowledge and skills to their own 
situation, incorporation of a complementary self-monitoring component is expected to contribute positively to patients' self-management [24].

Health care technologies provide an excellent means for self-monitoring and selfmanagement. Technology based self-monitoring for instance provides direct access to supportively composed data for both patients and care professionals [25]. As a result, these technologies enable collaborative care as patients at home are connected with their health professionals in primary or secondary care. The availability of accurate and timely data facilitates feedback and communication, which advances follow-up and accommodates subsequent consultations or referrals [26]. Especially in cancer pain, frequent monitoring of symptom progress and medication intake is valuable, as variations are characteristic and the introduction of medication requires starting slowly and titrating based on effectiveness and side effects [27]. For outpatients facing cancer pain management, the combination of different self-management enhancing components by means of health care technology is innovative and could be promising in overcoming existing barriers.

The overall project concerns the development and evaluation of a technology based self-management support intervention that aims to improve pain control and quality of life in outpatients with moderate to severe cancer pain. As part of the overall project and in advance of the large-scale clinical evaluation [28], this smallscale evaluation was conducted to explore feasibility of the mobile application for patients, the web application for nurses, and the integration of both applications in routine clinical practice. The article summarises usability, learnability, and desirability as well as adherence and acceptance as evaluated by patients and nurses.

\section{Methods}

The present study is a one-group post-test only design that evaluates feasibility of a mobile and web-based self-management support intervention among patients and nurses using a combination of questionnaires, observations, and interviews. Ethical approval for this study was obtained from the Medical Ethical Committee AtriumOrbis-Zuyd (NL46552.096.12).

\section{Sample and setting}

Patients were recruited conveniently via the outpatient oncology clinic of one academic and one regional hospital in the south of the Netherlands. The inclusion and exclusion criteria are listed in Table 4.1. Based on these criteria, thirteen eligible patients were invited by their treating physician to participate in the study with a four-week followup. 
Patients received a folder before the start of the study, including an invitation, an information letter, and an informed consent form. After one week the researcher contacted patients by phone to provide more information and to ask for their willingness to participate. Participation was confirmed by returned signed informed consent form. After informed consent, the treating physician, and general practitioner were informed about the participation of patients.

Nurses were recruited conveniently via the palliative care consultation team that was linked to both hospitals. Most of these regional teams consist of health professionals from various disciplines and setting, including nurses from home, hospice or hospital care; general practitioners; elderly care physicians; and medical specialists; all with extra education and practice in palliative care. Their primary aim is to inform and advise other health professionals on questions regarding palliative care by phone or bedside consultation [29].

Table 4.1 Inclusion and exclusion criteria

Inclusion criteria

Diagnosis of cancer

Under (palliative) anti-tumour treatment in a day clinic or outpatient clinic, or having no treatment options available anymore

Moderate to severe cancer (treatment related) pain $\geq 4$ (NRS 0-10) for $>2$ weeks

Living at home

Exclusion criteria

Expected life expectancy $<3$ months

Chronic non-cancer pain

Known cognitive impairments

Participation in other studies that interfere with this study

Not being able to read and understand the Dutch language

Reduced vision

Non-accessible by phone 
Box 4.1 Usual care regarding cancer pain management in the outpatient clinic

\begin{abstract}
Outpatients with cancer pain enter the outpatient clinics involved in the study basically via three different routes: patients see their oncologist for follow-up and indicate having pain; patients are referred by their general practitioner with an increase in pain complaints; or patients contact the oncology department themselves. Patients are often treated for cancer pain by their oncologist. When pain proves to be difficult to treat, the oncologist might consult a pain specialist. During an outpatient consultation the pain specialist performs a pain assessment; checks pain medication and changes prescriptions when needed. Afterwards patients are seen again at the outpatient clinic or contacted by phone for a follow-up consultation. Depending on the type of medication that has been prescribed, the timing and frequency of these follow-up consultations differ: sometimes after four days, sometimes after a week, and when stabilised after two or three weeks. When pain control is adequate, followup is ended. When pain gets worse and treatment remains ineffective, patients might be admitted to the hospital. The general practitioner needs to be kept informed about the progress of pain treatment. Because multiple health professionals might be involved as well as different information systems, the pharmacist is often the health professional with the most current and accurate overview of a patient's pain medication.

Patients do often not receive information materials about pain and pain treatment. Usually patients are neither asked to monitor their pain scores, nor to register their medication intake on paper or to have frequent contact with a health professional about their pain.
\end{abstract}

\title{
Intervention
}

The intervention has been developed in an iterative co-creative development process with collaboration of researchers, technical experts, health professionals, and patients. As a result, the intervention consisted of a mobile application for patients that was connected to a web application for nurses. Both applications were to be embedded in routine clinical practice. More information about routine clinical practice with concern to cancer pain management can be found in Box 4.1.

At baseline, the nurse and the researcher visited patients at home. The nurse performed a pain assessment and checked pain medication. Patients were also provided with short oral education, of which the content was similar to the education within the application. The researcher explained to patients how to use the application, after which patients were given a paper-copy manual. The mobile application ran on an iPad 2 with Internet connection that was provided on loan during the study period. Patients were not restricted to using other applications than the application under study in order to make them feel comfortable using the iPad. 


\section{Application for the patient}

For each patient an account was created in the nurse application, which was then linked to the patient application. The home screen of the patient application contained four different components.

Diary: Patients registered their pain, adverse effects, interference of pain with activity or sleep, and satisfaction with pain treatment by use of a pain diary twicedaily. The diary in the morning was accessible between 7-12 am and asked for the past night; the diary in the evening was available between 6-12 pm and reviewed the past day. Diaries were based on present-day pain assessments and included a skip pattern (Table 4.2). In between these diaries, registration of extra pain intensity scores was optional in order to report (the effect of medication on) breakthrough pain and to provide a more accurate representation of pain over time. Pain intensity was measured with a numerical rating scale (NRS) numbered 0-10 with verbal anchors of ' 0 being no pain' and '10 being the worst pain imaginable' [30].

Medication: Based on an overview of the pharmacist, prescriptions were entered into the nurse application and activated to be visible in patient application. By doing so, patients were accommodated with a personalised medication day schedule for the registration of their 'around the clock' and 'as needed' pain medication. A restricted 4-hour time frame was introduced to motivate patients to take and register their pain medication in time. At the time of registration, pain intensity scores, and medication intake moments received an automatic time stamp. These registrations were continuously depicted in a graph that showed pain and the possible influence of medication intake and daily activities in order to support patients visually. To make sure the medication day schedule kept up to date, each diary contained the following question: 'Has a physician changed your medication?' In case of confirmation the nurse contacted the patient to ask for details in order to process updates.

Knowledge: Patients received education about causes of pain, treatment of pain, recognition of symptoms that require action, and methods that patients themselves can implement to control pain. This information to read was divided into three sessions; each session consisted of several topics (Table 4.3). Those who wanted to know more could access additional information about pharmacological and alternative treatments.

Contact: In case of questions, patients communicated with the nurse via text message functionality within the application. Nurses attempted to answer these messages within one workday. All communication remained accessible to enable patients to reread answers, advices or agreements on later moments in time. Patients were reminded to complete diaries, take medication, read education materials, and check text messages from the nurse by visual and sound notifications. 
Table 4.2 Diary questions

Morning

1. Did you have a good night's sleep?

Yes | No

1.1 Did you experience any difficulties with falling asleep?

Yes | No

1.2 Did you experience any difficulties with sleeping through the night? Yes | No

Evening

1. How did you experience your pain today?

Very good | Good | Not good / Not bad | Bad | Very bad

1.1 Did the pain prevent you from position and behavior; normal eating habits; contacts with others, other activities; none of the above?

From position and behavior | From normal eating habits | From contacts with others | From other activities | From none of the above

1.1.1 During which other activities did the pain bother you?

Morning and evening

2. How would you rate your pain at this moment?

$0|1| 2|3| 4|5| 6|7| 8|9| 10$

3. How many breakthrough pain attacks did you experience in the last 12 hours?

3.1 How would you rate your pain when your pain was at its worst in the last 12 hours?

$0|1| 2|3| 4|5| 6|7| 8|9| 10$

4. Do you experience any symptoms other than pain at the moment?

Yes | No

4.1 Which symptoms other than pain do you experience at the moment?

Nausea | Vomiting | Obstipation | Tightness of the chest | Problems with sleeping |

Scary dreams | Dry mouth | Dizziness | Drowsiness | Sleepiness | Other?

4.1.1 Which other symptom that is not listed do you experience at the moment?

$$
-
$$

5. Has a physician changed your pain medication in the last 12 hours?

Yes | No

6. Are you satisfied with your pain relief at this moment?

Yes | No

\section{Application for the nurse}

All monitored data were saved on secured servers that comply with present rules and regulations. The nurse monitored and analysed the patient's situation once every workday, taking into account completed pain diaries, scheduled and actual medication intake, and text messages. To facilitate interpretation of patients' data and to save nurses' time, information within the application was supportively presented by means of a weekly overview, a composite graph, and a decision support system of coloured risk flags. Based on an algorithm of diary questions and (the duration of) answers, different flags appeared: red flags required immediate action, yellow flags asked to keep an eye, and green flags indicated that no action was needed. In addition to sending text messages, nurses had the opportunity to consult patients by phone when 
more information was needed or patients specifically asked to do so. In case of pain relief being inadequate, the nurse consults the pain specialist or the palliative care consultation team for advice. Advices were reported to the treating physician who kept responsibility and decided on follow-up, changes in prescription, or other interventions. As a consequence, patients might eventually have been invited to visit the outpatient clinic or, when necessary, a home visit by the nurse might have been scheduled. Nurses had access to all patient data to facilitate patient handover and guarantee continuity of care.

Nurses took part in a 2-h instruction meeting about the nurse application prior to the study, after which they were provided with a paper-copy instruction manual. With approval of the management, nurses were allowed to spend on average 4-5 hours a week on monitoring and follow-up activities. Nurses were advised to log in once every workday and to pay attention to email notifications of red flags or incoming text messages. In case of emergency and when help is needed in the evening, at night, or during the weekend, patients were advised to notify their general practitioner or outof-hours GP service.

\section{Data collection}

\section{Learnability, usability, and desirability}

During a home visit after four weeks, patients received a 20 -item questionnaire to assess learnability ( 5 items), usability ( 6 items), and desirability ( 8 items). The questionnaire was constructed for this study, based on the content of the three categories [31]. Usability was defined as 'the extent to which the application could be used by outpatients with moderate to severe cancer pain to monitor their pain and medication intake effectively, efficiently, and satisfactorily in everyday practice'. Learnability involved 'the time and effort required for these patients to use the application'. Desirability was regarded as 'the extent to which the application was fun and engaging to use for these patients'. Patients rated each item on a 1-5 Likert scale (completely disagree - completely agree); higher scores indicated better learnability, usability, and desirability. The questionnaire contained a separate item to assess overall acceptance.

\section{Adherence to the application}

During the four-week follow-up, data from pain diaries (filled out or not, time of fill out, answers); medication intake (registered or not, time of registration); and knowledge sessions (opened or not, time of opening, how often opened) were logged on the server. These data were collected to assess patients' adherence to the application. 


\section{Experiences of patients}

During a home visit after four weeks, single semi-structured interviews (30-60 minutes) with all patients were held by the researcher in order to gain more insight into the experiences with the application. Topics discussed included: use and acceptance of the application, supportiveness of the application regarding selfmanagement, and technological functioning of the application. Interviews were taperecorded and concurrently notes were taken.

\section{Experiences of nurses}

At the end of the study period, a focus-group interview (90 minutes) with all nurses was held by the researcher about the following topics: use and acceptance of the application, supportiveness of the application in monitoring and advising patients, and technological functioning of the application. Interview notes were taken.

\section{Data analysis}

\section{Learnability, usability, desirability, and adherence to the application}

Mean scores were calculated for the total questionnaire as well as for the categories and items separately. Adherence to the application was based on completion rates as logged on the server; \% completed with concern to pain and adverse effect monitoring, medication monitoring, and education sessions. Composite pain intensity scores were calculated from an average of diary ratings across one day. Ratings were derived from the diary question "How would you rate your pain at this moment?"

\section{Experiences of patients and nurses}

After each interview notes were immediately reviewed and initial reflections were added. Then audiotapes of the semi-structured interviews were re-listened several times and notes were amended in order to ensure an accurate and thorough reflection of the interviews. All notes were discussed with the co-authors after which necessary changes were made. Notes were organised and summarised into predefined categories and illustrative quotes were added. No tape-recording of the focus group interview was available. A member check was performed to ensure that the notes properly reflected the interview [32]. 


\section{Results}

Thirteen patients provided written consent. Shortly after the initial home visit, two patients decided to withdraw. One patient (male, 71 years) doubted application use and the other patient (male, 79 years) reported being too ill.

Eleven patients ( 5 males, 6 females) eventually completed the study and were aged between 20-76 (M 53, SD 15) years. Patients were diagnosed with cancers of the head and neck $(n=4)$, breast $(n=2)$, central nervous system $(n=2)$, or other $(n=3)$. All patients were prescribed pain medication 'around the clock' and 'as needed', more specifically non-opioids and strong opioids $(n=5)$; along with adjuvant analgesics $(n=4)$; or adjuvant analgesics only $(n=2)$.

Three registered nurses specialised in pain and palliative care (1 male, 2 females) were aged between 50-54 (M 52, SD 2) years. Nurses had 10-15 (M 13, SD 3) years of experience in caring for outpatients with cancer pain while working within a palliative care consultation team.

\section{Learnability, usability, and desirability}

The overall mean score as well as the mean score of the categories and items separately are presented in Table 4.4. Scores suggested that patients learned quickly how to manage the application, could easily use the different components, and liked to work with the application. The item "I would recommend the application to other patients" gives an impression of the overall acceptance.

\section{Adherence to the application}

Average completion rates were $76.8 \%$ for pain and adverse effects monitoring, $50.4 \%$ for medication monitoring, and $100 \%$ for education sessions.

Patients completed, on average, 43 (SD 12.4) out of 56 diaries during the study period. Figure 4.1 shows composite pain scores as derived from the diaries. These representations are illustrative for the clinical course of pain as experienced by participating patients; some indicated extreme pain with significant fluctuations, others experienced a constant change in average pain, still others reported moderate and fairly stable levels of pain. Important to notice in terms of feasibility is that most patients kept monitoring regardless of how they felt. Reasons for not filling out diaries included not being in time given the time frame or not being in the mood for a day. Extra pain intensity scores, to show breakthrough pain or the effect of medication taken, had a mean frequency of 6.8 (SD 4.9) during the study period. Not reporting extra scores was related to the absence of breakthrough pain, the unwillingness to report all day, and the unawareness of the option to report extra scores. 
Table 4.4 Mean (SD) learnability, usability, and desirability scores

\begin{tabular}{ll}
\hline Learnability & $4.8(0.4)$ \\
\hline It was easy to learn how to use the application. $^{\text {I think the application was very complicated. }{ }^{\text {a }}}$ & $4.9(0.3)$ \\
I needed a lot of help to learn using the application. ${ }^{\text {a }}$ & $4.6(0.9)$ \\
I needed to learn a lot before I could use the application. ${ }^{\text {a }}$ & $4.9(0.3)$ \\
I am confident that I used the application in the right way. & $4.9(0.3)$ \\
\hline Usability & $4.4(1.2)$ \\
\hline I could easily report my pain and adverse effects with the application. & $4.8(0.5)$ \\
I could easily report my medication intake with the application. & $4.8(0.6)$ \\
I could easily recall my pain scores and medication intake with the application. & $4.8(0.6)$ \\
I understood the information about my pain scores and medication intake. & $4.5(0.9)$ \\
I could easily search for information about pain with the application. & $4.7(0.6)$ \\
I could easily leave a message for the nurse via the application. & $4.8(0.4)$ \\
\hline Desirability & $4.6(0.6)$ \\
\hline I liked using the application. & $4.6(0.4)$ \\
I liked using the pain diary. & $4.9(0.3)$ \\
I liked using the medication overview. & $4.7(0.6)$ \\
I liked using the knowledge sessions. & $4.6(0.7)$ \\
I liked using the contact function. & $4.1(0.7)$ \\
I liked the idea that the nurse monitors my pain, adverse effects, and medication use. & $4.8(1.0)$ \\
I liked the idea that my treating physician keeps track of my pain treatment. & $4.8(0.4)$ \\
I liked the idea that my pharmacist cooperates regarding my medication overview. & $4.7(0.4)$ \\
\hline I would recommend the application to other patients. & $4.8(0.4)$ \\
\hline Total & $4.7(0.3)$ \\
\hline
\end{tabular}

${ }^{\text {a }}$ Negatively-keyed items were reversed-scored before data analyses.

Monitoring of 'around the clock' medication ranged from $0.0 \%$ to $96.4 \%$. To illustrate, for patients who only had to change fentanyl patches once every three days, and forgot or were not able to register these changes in time, completion rates were low. 'As needed' medication was registered between 0 and 80 times. Some patients did not use 'as needed' medication, others were not aware of the option to report it.

All patients completed the education sessions; seven patients re-read some of the topics, more specifically the topics about what is pain, what causes pain in cancer, why is pain different every day, and non-opioids and opioids. 

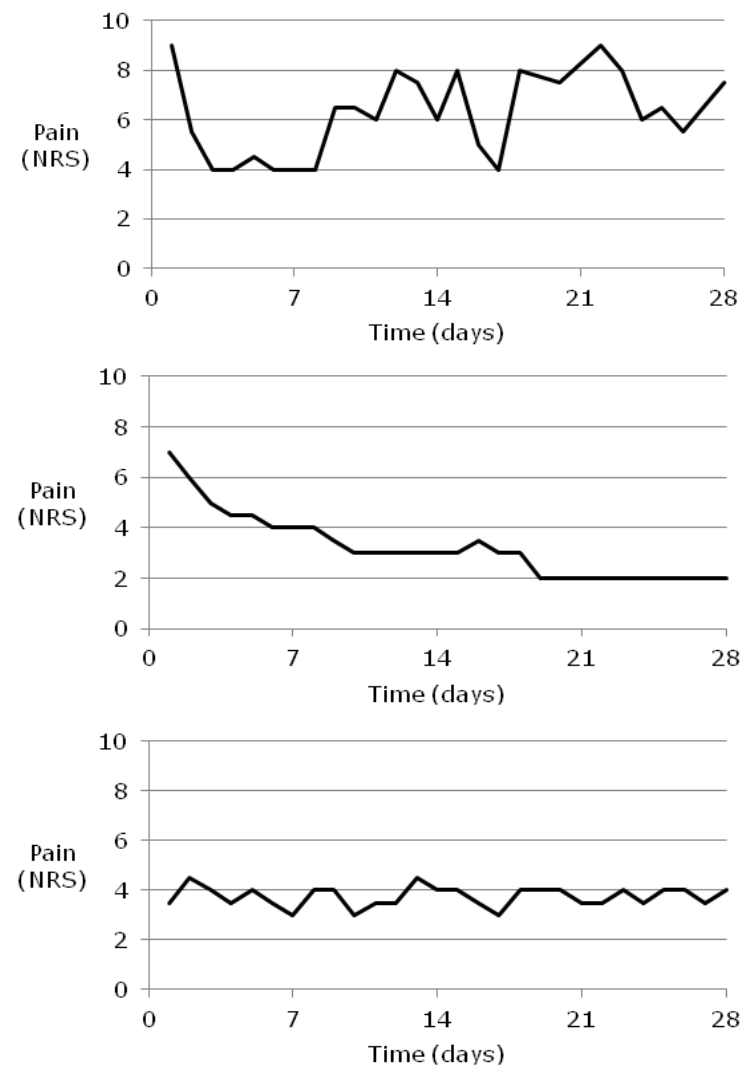

Figure 4.1 Average daily pain intensity scores of three patients to illustrate the clinical course of pain as experienced by participating patients

On average, patients and nurses interacted on 11 (SD 4.8) out of 28 days via text messages. Both patients and nurses started conversations with various content. Patients often elaborated on their diary answers; asked questions about side effects; and explained why they were not able to monitor. In turn, nurses mostly used these conversations to make agreements on what to monitor and when to have contact; to acquire more information if there was a need to do so based on diaries or medication intake; and to advise patients about prescribed pain medication. Aside from pain and pain medication, a patient's good day ("The sun is shining, I'm doing the laundry." and "Congratulations with your wife's birthday!") or a bad test result ("The scan was not that good today, on the liver a small spot was seen." and "Because of the results from last Monday, metastasis and surgery, I needed some distraction.") were also discussed. 


\section{Experiences of patients}

\section{Use and acceptance of the application}

Semi-structured interviews revealed that patients considered the application clear and simple. Navigating worked well and the application required limited effort and energy. Patients made most use of the diary and the medication overview and less use of the opportunity to reread education. Patients experienced comfort using the application and the iPad. Registering and monitoring with the application was seen as "fun to do" (P08) and as "a positive challenge" (P06), without making patients focused on their pain.

\section{"I concentrate on pain only when completing diaries and registering medication, that's all." (P05)}

Completing pain diaries twice-daily was feasible for patients. Diary questions were understandable and considered nearly complete; monitoring pain in different body locations was not possible and an open question to better describe pain and adverse effects was lacking. Two patients indicated that they got a little bit bored, because diary questions were the same every day. Others acknowledged that alike diaries were good, because variation would unnecessarily make things difficult. Medication overviews for 'around the clock' medication were clear. Registration of 'as needed' medication seemed less obvious. Almost all patients indicated that not incorporating co-medication and medication for comorbidities in the overview was a missed opportunity. All patients finished the education sessions. Information was partly new, dosed well and easy to understand.

"When the physician prescribes pain medication.. patients just take it.

I think it is interesting to learn, to know at least what's going on." (P12)

The home visit, with a pain assessment and instructions about the application, was highly appreciated. Some patients looked for information in the instructions once more, though most paper-copy manuals were returned unopened. Patients liked having seen faces and knowing how nurses respond.

"It has a reassuring effect, someone looking over your shoulder every day. It is meaningful and you really can't do anything wrong. " (P08) 


\section{Supportiveness of the application regarding self-management}

Patients emphasised the added value of the application in self-managing their pain and pain medication. The medication overview was supportive because registered medication was visible. Especially in cases where patients tended to forget what medication was taken. The 4-hour timeslot to encourage on time intake and registration was effective for some and less effective for others. Patients' experiences with the reminders were different as well. Some patients took medication based on the clock, for them sound and image reminders were useful. Others took medication based on their daily routines or pain experiences and found the reminders less useful. The graph provided insight into pain trends and activated patients to organise medication differently.

"Due to the medication overview and the graph, we concluded that the time between medication in the morning and the afternoon was too short and between the afternoon and evening was too long. To better control the pain we adapted the schedule, it worked!" (P04)

To get better insight into trends it would have been helpful if patients could review completed diaries and mediation overviews. Moreover, a wider graphical view would enable patients to compare days, weeks or even months.

"It is helpful when the physician calls. I look at the graph to get a good picture. It also gives justification that I'm not exaggerating my pain." (P06)

Asking patients for the most valuable component resulted in different answers. Contact with the nurse and the insight from the graph were often reported. Patients also mentioned the education sessions, sound reminders and the collaboration between nurses and treating physicians. One patient even concluded, "Not a single component, but the combination of components is valuable" (P08).

\section{Technological functioning of the application}

The most important technological problems experienced by patients had to do with not receiving a diary, not being able to register medication, not having an up-to-date graph, and not being able to access education; these problems were caused by connectivity and software issues. Because opportunities to register extra pain intensity scores or extra medications were not often used, these need to be made better visible or better explained in the instruction.

"This application makes remote health care personal, it breaks down barriers." (P05) 


\section{Experiences of nurses}

\section{Use and acceptance of the application}

The instruction meeting before the start of the study was clear and the timing was right. Nurses agreed on the abstractness at first, though their application became clearer over the course of the study. Sometimes diary answers were ambiguous. In case a patient had a difficult night's sleep, this could be caused by pain but also by many other factors. The application lacked room to write down the initial pain assessment; something that was necessary to actually facilitate patient handover and guarantee continuity of care.

\section{Supportiveness of the application in monitoring and advising}

Critical remarks were made regarding the identification of tasks and responsibilities. The application provided nurses with risk flags, yet how to act accordingly was up to the nurses based on their expertise and judgment. Especially diary answers or text messages that possibly, though not necessarily, related to cancer pain caused difficulties.

"At times I'm not sure. What is allowed? When do I intervene? Should I focus only on pain? Also when complaints are not caused by pain or pain medication, though influence pain?" (N01) "Important as well, what do patients wish for? What does the treating physician want? When do I interfere and take over care?" (N03)

As a consequence nurses acknowledged differences in their response to patients and situations. In particular, the one had telephone contact more often and the other visited patients at home more frequently. Based on their experiences during the study, however, nurses would prefer more uniformity for the sake of both clinical and research practice.

"There is need for a guideline on when, how and in what order, nothing conclusive, though some recommendations that provide guidance." (NO2)

Independency of patients was another somewhat related topic that was extensively discussed. On the one hand, advices from the nurse might have made patients more dependent than necessary; on the other hand, these advices might have ensured that patients could move on and made them in fact less dependent.

For nurses to perform their monitoring and advisory role well, collaboration with the treating physician, general practitioner, and pharmacist was crucial. Nurses emphasised the importance of communication and commitment of all parties involved in case of a large-scale evaluation in the future. 


\section{Satisfaction with the application}

Nurses were enthusiastic about the application and considered their new way of working as a real challenge. It brought about new tasks, different responsibilities and unknown technologies; something that needed a little time to get used to. The expectation that monitoring and advising would improve pain control in these patients showed nurses' trust in the intervention.

\section{Technological functioning of the application}

Nurses came up with some points for improvement that would have facilitated their tasks: graphs needed to contain more information to see trends and diary questions needed to be adapted ("Did you experience any difficulties with falling asleep caused by pain?"; "Did you experience any difficulties with sleeping through the night caused by pain?") or added ("Do you want the nurse to contact you based on the diary answers that you have given?").

\section{Discussion}

Small-scale feasibility evaluation in everyday life is a crucial first step in the development and testing of complex interventions before use in clinical and research practice [33]. The current study provides insight into the feasibility of a multicomponent technology supported self-management intervention delivered by nurses specialised in pain and palliative care to outpatients with cancer pain in everyday practice. Patients learned to use the application quickly, practiced tasks easily and liked to work with the application. Nurses had to get acquainted to their new way of working, though were positive about the possibilities of the application specifically and the idea of self-management support in general.

Different patients are in need of different support in self-managing their health $[34,35]$. Multi-component interventions are recommended $[27,36]$. Patients who practice effective self-management will select the type of support that fits with their wishes and needs at a given point in time and in a given situation [37]. Patients in this study valued and made use of different components, emphasising the need for a multi-component self-management approach: it better suits the reality of living with cancer pain. Aside from the multi-component nature, counseling of the nurses and the collaboration of nurses with treating physicians was well received by patients, which emphasises the need for embedding of self-management within routine multidisciplinary care practice [13]. When self-management is challenging and further complicated by comorbidities and polypharmacy, integration of patient selfmanagement and professional care is advisable. 
Although health professionals are often not educated to support patients in selfmanagement, nurses specialised in pain and palliative care are very well able to make substantial contributions based on their knowledge, expertise, and focus on patients' daily living [38]. The uptake of self-management and self-monitoring forms part of a process of change regarding roles and expectations $[39,40]$. In accepting the intervention, nurses gave up parts of their present role, previously delivered face to face, to remote health technology, but also to patients on which they had to rely on for information, and to treating physicians who kept responsibility for follow-up. Nurses' confidence and trust was instilled by training on technological aspects; by getting to know patients during home visits; and by making plain agreements with all those concerned.

Technical problems were taken into considerations during rework, as well as patients' and nurses' suggestions for improvement. As connectivity issues were mostly related to the software or patients' rural place of living, adjustments in synchronising data and local storage of data were the answer to most technical problems. These adjustments made the application for patients more stable and less dependent on the continuous availability of Internet. In response to patients' experiences, the look and feel of the application was optimised and the task to reply shortly to all text messages from patients was added to the nurse instructions. Patients' instructions were completed with the task to use the extra pain intensity score and to register PRN medication taken. Based on the experiences of nurses, arrangements were made on how to respond to patients and situations. Diary questions were adapted and room was created within the application to write down the initial pain assessment.

Because simplicity of the applications is highly important, also taking into account the target population, not all ideas could be incorporated. The addition of questions about pain in different body locations and other symptoms makes the diary long; the review of completed diaries and medication overviews makes the application more complex; the monitoring of medication for comorbidities would require nurses to have different knowledge and expertise. Not incorporating these changes might limit clinical use of the intervention, though for the intended aim of this project these improvements were thought to be less relevant. Nevertheless, with a broader rationale and a somewhat different patient population in the future, these functionalities are worth considering and relatively easy to incorporate.

Some limitations of this study need to be acknowledged. First, text messages to the nurses revealed that patients were not always able to register their medication intake. Reasons mentioned included the 4-hour timeslot, connectivity issues, not taking the iPad with them when they left home or simply just that they forgot to register. Consequently, percentages summarise medication monitoring, but not medication adherence. Second, the small convenience sample of patients could have introduced selection bias. The study was first and foremost conducted to explore feasibility of the intervention. Patients in poor health or experiencing extreme pain 
might therefore not have been included. However, with a small sample of patients who differed in demographic and clinical characteristics an attempt was made to get a fairly complete impression. Last, follow-up activities were not recorded. Data collection on the number of times nurses, consult patients by phone and collaborate with the treating physician, pain specialist, or the palliative care consultation team needs to be included in future evaluations.

\section{Conclusions}

The intervention under study provided patients with information and instructions; enabled them to monitor their pain and side effects as well as medication intake; allowed them with insight and feedback on their situation; and created a supportive and collaborative environment. Findings demonstrate that patients with moderate to severe cancer pain are well able to take up this intervention. The need for selfmanagement approaches to include multiple components is endorsed, as patients in this study valued and made use of different intervention components. Moreover, monitoring and advising by nurses as well as their collaboration with treating physicians impacted patient experiences positively, which emphasises the importance of involving nurses to deliver self-management support as well as integrating these interventions into routine clinical practice. Findings also revealed important information with regard to feasibility and technological functioning of the intervention as well as recruitment and methodological issues for research practice. Once again, small-scale evaluation in everyday life turned out to be extremely important; despite extensive evaluation by the development team unexpected issues and situations still occurred. Clinical effectiveness with regard to pain intensity and quality of life still needs to be evaluated [28], though the intervention is believed to impact both patient self-management as well as pain management by health professionals. 


\section{References}

1. Klepstad P, Kaasa S, Cherny N, Hanks G, de Conno F (2005) Pain and pain treatments in European palliative care units. A cross sectional survey from the European Association for Palliative Care Research Network. Palliat Med 19:477-484.

2. van den Beuken-van Everdingen $M H$, de Rijke JM, Kessels AG, Schouten HC, van Kleef M, Patijn J (2007) Prevalence of pain in patients with cancer: a systematic review of the past 40 years. Ann Oncol 18:1437-1449.

3. Schumacher KL, Clark VL, West CM, Dodd MJ, Rabow MW, Miaskowski C (2014) Pain medication management processes used by oncology outpatients and family caregivers part ii: home and lifestyle contexts. J Pain Symptom Manage 48:784-796.

4. Berry DL, Wilkie DJ, Thomas CR Jr, Fortner P (2003) Clinicians communicating with patients experiencing cancer pain. Cancer investigation 21:374-381.

5. Butow $P$, Sharpe $L$ (2013) The impact of communication on adherence in pain management. Pain 154:S101-107.

6. Kwon JH (2014) Overcoming barriers in cancer pain management. Journal of Clinical Oncology 32:1727-1733.

7. Jacobsen R, Liubarskiene Z, Moldrup C, Christrup L, Sjogren P, Samsanaviciene J (2009) Barriers to cancer pain management: a review of empirical research. Medicina (Kaunas) 45:427-433.

8. Miaskowski C, Dodd MJ, West C, Paul SM, Tripathy D, Koo P, Schumacher K (2001) Lack of adherence with the analgesic regimen: a significant barrier to effective cancer pain management. J Clin Oncol 19:4275-4279.

9. Schumacher KL, Koresawa S, West C, Hawkins C, Johnson C, Wais E, Dodd M, Paul SM, Tripathy D, Koo P, Miaskowski C (2002) Putting cancer pain management regimens into practice at home. J Pain Symptom Manage 23:369-382.

10. Bodenheimer T, Lorig K, Holman H, Grumbach K (2002) Patient self-management of chronic disease in primary care. Jama 288:2469-2475.

11. McCorkle R, Ercolano E, Lazenby M, Schulman-Green D, Schilling LS, Lorig K, Wagner EH (2011) Self-management: enabling and empowering patients living with cancer as a chronic illness. CA Cancer J Clin 61:50-62.

12. Kimberlin C, Brushwood D, Allen W, Radson E, Wilson D (2004) Cancer patient and caregiver experiences: communication and pain management issues. J Pain Symptom Manage 28 : 566-578.

13. Bennett MI, Bagnall AM, Jose Closs S (2009) How effective are patient-based educational interventions in the management of cancer pain? Systematic review and meta-analysis. Pain 143:192-199.

14. Cummings GG, Olivo SA, Biondo PD, Stiles CR, Yurtseven O, Fainsinger RL, Hagen NA (2011) Effectiveness of knowledge translation interventions to improve cancer pain management. J Pain Symptom Manage 41:915-939.

15. Jho HJ, Myung SK, Chang YJ, Kim DH, Ko DH (2013) Efficacy of pain education in cancer patients: a meta-analysis of randomized controlled trials. Support Care Cancer 21: 1963-1971.

16. Koller A, Miaskowski C, De Geest S, Opitz O, Spichiger E (2012) A systematic evaluation of content, structure, and efficacy of interventions to improve patients' self-management of cancer pain. J Pain Symptom Manage 44:264-284.

17. Oldenmenger WH, Sillevis Smitt PA, van Dooren S, Stoter G, van der Rijt CC (2009) A systematic review on barriers hindering adequate cancer pain management and interventions to reduce them: a critical appraisal. Eur J Cancer 45:1370-1380.

18. Adam R, Bond C, Murchie P (2014) Educational interventions for cancer pain. A systematic review of systematic reviews with nested narrative review of randomized controlled trials. Patient Educ Couns 98:269-282. 
19. Marie N, Luckett T, Davidson PM, Lovell M, Lal S (2013) Optimal patient education for cancer pain: a systematic review and theory-based meta-analysis. Support Care Cancer 21: 3529-3537.

20. Lorig KR, Holman H (2003) Self-management education: history, definition, outcomes, and mechanisms. Ann Behav Med 26:1-7.

21. Richard AA, Shea K (2011) Delineation of self-care and associated concepts. J Nurs Scholarsh 43:255-264.

22. Purtzer MA, Hermansen-Kobulnicky CJ (2013) 'Being a Part of Treatment': the meaning of self-monitoring for rural cancer patients. Cancer Nurs 36:93-103.

23. Schumacher KL, Koresawa S, West C, Dodd M, Paul SM, Tripathy D, Koo P, Miaskowski C (2002) The usefulness of a daily pain management diary for outpatients with cancer-related pain. Oncol Nurs Forum 29:1304-1313.

24. Wilde $\mathrm{MH}$, Garvin S (2007) A concept analysis of self-monitoring. J Adv Nurs 57:339-350.

25. Kuijpers W, Groen WG, Aaronson NK, van Harten WH (2013) A systematic review of webbased interventions for patient empowerment and physical activity in chronic diseases: relevance for cancer survivors. J Med Internet Res 15:e37.

26. Meystre S (2005) The current state of telemonitoring: a comment on the literature. Telemed J E Health 11:63-69.

27. Lovell MR, Luckett T, Boyle FM, Phillips, J, Agar M, Davidson PM (2014). Patient education, coaching, and self-management for cancer pain. J Clin Oncol 32:1712-1720.

28. Hochstenbach LM, Courtens AM, Zwakhalen SM, van Kleef M, de Witte LP (2015). Selfmanagement support intervention to control cancer pain in the outpatient setting: a randomized controlled trial study protocol. BMC Cancer 15:e416.

29. Kuin A, Courtens AM, Deliens L, Vernooij-Dassen MJ, van Zuylen L, van der Linden B, van der Wal G (2004) Palliative care consultation in the Netherlands: a nationwide evaluation study. J Pain Symptom Manage 27:53-60.

30. Hjermstad MJ, Fayers PM, Haugen DF, Caraceni A, Hanks GW, Loge JH, Fainsinger R, Aass N, Kaasa S, European Palliative Care Research Committee (2011) Studies comparing Numerical Rating Scales, Verbal Rating Scales, and Visual Analogue Scales for assessment of pain intensity in adults: a systematic literature review. J Pain Symptom Manage 41:1073-1093.

31. Petrie H, Bevan N (2009) The evaluation of accessibility, usability and user experience. From: The universal access handbook. London: Taylor and Francis.

32. Halcomb EJ, Davidson P (2006) Is verbatim transcription of interview data always necessary? Appl Nurs Res 19:38-42.

33. Craig P, Dieppe P, Macintyre S, Michie S, Nazareth I, Petticrew M (2013) Developing and evaluating complex interventions: the new Medical Research Council guidance. Int J Nurs Stud 50:587-592.

34. Trappenburg J, Jonkman N, Jaarsma T, van Os-Medendorp $H$, Kort $H$, de Wit $N$, Hoes $A$, Schuurmans M (2013) Self-management: one size does not fit all. Patient Educ Couns 92:134-137.

35. van Houtum L, Rijken M, Heijmans M, Groenewegen P (2013) Self-management support needs of patients with chronic illness: do needs for support differ according to the course of illness? Patient Educ Couns 93:626-632.

36. Kravitz RL, Tancredi DJ, Grennan T, Kalauokalani D, Street RL Jr, Slee CK, Wun T, Oliver JW, Lorig K, Franks P (2011) Cancer Health Empowerment for Living without Pain (Ca-HELP): effects of a tailored education and coaching intervention on pain and impairment. Pain 152:1572-1582.

37. Barlow J, Wright C, Sheasby J, Turner A, Hainsworth J (2002) Self-management approaches for people with chronic conditions: a review. Patient Educ Couns 48:177-187.

38. Courtenay M, Carey M (2008) The impact and effectiveness of nurse-led care in the management of acute and chronic pain: a review of the literature. J Clin Nurs 17:2001-2013. 
39. Segar J, Rogers A, Salisbury C, Thomas, C (2013) Roles and identities in transition: boundaries of work and inter-professional relationships at the interface between telehealth and primary care. Health Soc Care Community 21:606-613.

40. Taylor J, Coates E, Brewster L, Mountain G, Wessels B, Hawley MS (2014) Examining the use of telehealth in community nursing: identifying the factors affecting frontline staff acceptance and telehealth adoption. J Adv Nurs 71:326-337. 


\section{Self-management support intervention to control cancer pain in the outpatient setting}

a randomised controlled trial study protocol

This chapter was published as:

Hochstenbach LM, Courtens AM, Zwakhalen SM, van Kleef M, de Witte LP (2015) BMC Cancer 15:416

DOI: $10.1186 / \mathrm{s} 12885-015-1428-1$ 


\section{Abstract}

\section{Background}

Pain is a prevalent and distressing symptom in patients with cancer, having an enormous impact on functioning and quality of life. Fragmentation of care, inadequate pain communication, and reluctance towards pain medication contribute to difficulties in optimising outcomes. Integration of patient self-management and professional care by means of healthcare technology provides new opportunities in the outpatient setting.

\section{Methods}

This study protocol outlines a two-armed multicentre randomised controlled trial that compares a technology based multi-component self-management support intervention with care as usual and includes an effect, economic, and process evaluation. Patients will be recruited consecutively via the outpatient oncology clinics and inpatient oncology wards of one academic hospital and one regional hospital in the south of the Netherlands. Irrespective of the stage of disease, patients are eligible when they are diagnosed with cancer and have uncontrolled moderate to severe cancer (treatment) related pain defined as NRS $\geq 4$ for more than two weeks. Randomisation (1:1) will assign patients to either the intervention or control group; patients in the intervention group receive self-management support and patients in the control group receive care as usual. The intervention will be delivered by registered nurses specialised in pain and palliative care. Important components include monitoring of pain, adverse effects and medication as well as graphical feedback, education, and nurse support. Effect measurements for both groups will be carried out with questionnaires at baseline (T0), after 4 weeks (T1), and after 12 weeks (T2). Pain intensity and quality of life are the primary outcomes. Secondary outcomes include knowledge, self-efficacy, anxiety, depression, and pain medication use. The final questionnaire contains also questions for the economic evaluation that includes both cost-effectiveness and cost-utility analysis. Data for the process evaluation will be gathered continuously over the study period and focus on recruitment, reach, dose delivered, and dose received.

\section{Discussion}

The proposed study will provide insight into the effectiveness of the self-management support intervention delivered by nurses to outpatients with uncontrolled cancer pain. Study findings will be used to empower patients and health professionals to improve cancer pain control. 


\section{Background}

Pain continues to be a prevalent and distressing symptom described by patients during curative, palliative, and survivorship cancer care [1]. Each patient is unique and the process of controlling cancer pain evolves differently every time. At the inpatient or outpatient clinic, initial pain assessments and medication prescriptions are provided in consultation with a health professional. Once at home, patients and their caregivers face practical challenges and difficulties, because daily pain management requires more than simply following medication prescriptions [2]. Considering these challenges and difficulties, together with the barriers that have been identified in the outpatient setting [3-5], patients need to be supported in their cancer pain self-management [6].

Some arrangements are considered necessary for effective self-management. Patients require assistance in order to easily access information about pain and pain medication, about what is normal, and about when and how to get help [7]. Patients also need to be able to recognise and monitor pain and adverse effects in order to get insight into their own situation and feedback about how they are doing [8]. Patients will be motivated when they are supported by their health professional to have confidence and to undertake strategies to manage better [9]. On that account, researchers point at multi-component interventions that concentrate more intensively on self-efficacy [10]. Patients require different support in different situations when it comes to self-management [11]. Patients themselves will select the type of support needed in a given situation at a given point in time [12]. Being embedded in routine clinical practice, healthcare technology provides chances to integrate these different arrangements and contribute to patient self-management.

Providing patients with self-management support requires health professionals to accept a slightly different role and make a shift from clinical outcomes towards providing help with day-to-day problems [13]. By virtue of their expertise and focus on patients' daily living, nurses are able to make substantial contributions to pain selfmanagement [14]. Not being able to monitor pain has been identified as an important barrier to adequate pain management in the outpatient setting [15]. Ongoing review and management of symptoms can be difficult to achieve for health professionals when outpatient consultations take place occasionally whereas daily pain fluctuations are very common. Healthcare technology is promising in facilitating telemonitoring, enhancing symptom management and improving quality of life [16].

We previously developed a technology based multi-component self-management support intervention consisting of an iPad application for patients that is connected to a web application for nurses; both applications are embedded in routine clinical practice. Important components include monitoring of pain, adverse effects, and medication as well as graphical feedback, education, and nurse support. A small-scale evaluation confirmed feasibility of the intervention in everyday life. Even though patients and nurses had to get used to new tasks, responsibilities and technology, 
they were positive about the applications. Continuous monitoring in good and bad moments underscored clinical relevance and use in practice. Adjustments were made to overcome technical problems; suggestions for improvement gave input for the setup of the present large-scale evaluation.

\section{Methods}

\section{Design}

This study protocol outlines a two-armed multicentre randomised controlled trial that compares a self-management support intervention with care as usual and includes an effect, economic, and process evaluation. The study protocol was approved by the Medical Ethical Committee Atrium-Orbis-Zuyd, the Netherlands (NL46552.096.13). Registration of the study protocol was performed on December 29, 2014 (NCT02333968). A flowchart of the study design is presented in Figure 5.1.

\section{Eligibility}

Irrespective of the stage of disease, patients are eligible when they are diagnosed with cancer and cope with uncontrolled moderate to severe cancer (treatment) related pain. Moderate to severe pain is defined as an NRS score $\geq 4$. Pain should be present for more than two weeks and patients should live at home.

Patients will be excluded in case of an expected life prognosis $<3$ months, chronic non-cancer (treatment) related pain, known cognitive impairments, participation in studies that interfere with this study, insufficient reading skills and comprehension of the Dutch language, a reduced vision, and/or non-accessibility via telephone.

\section{Recruitment}

Patients will be recruited consecutively via the outpatient oncology clinics and inpatient oncology wards of one academic hospital and one regional hospital in the south of the Netherlands. When patients are considered eligible by the treating physician and are interested in participation, they will receive a patient information letter and an informed consent form. In the information letter detailed information is given about the intervention and study procedures. The fact that patients in the intervention group receive an intervention alongside the current care for their pain is emphasised. Patients will be asked to read the information carefully and to discuss participation with their partner, family, or friends. The contact details of the researcher are provided in the information letter and potential participants will be encouraged to contact the researcher or the independent physician in case of questions or doubts. Two weeks will be given to consider participation. Patients who 
decide to participate in the study are asked to return their informed consent. After informed consent, the treating physician and the general practitioner will be informed about the patient's participation.

\section{Randomisation and blinding}

Patients will be randomly allocated to the intervention or control group with an allocation ratio of $1: 1$. The randomisation, stratified per centre, is computer-generated and will be carried out by an independent research assistant; the allocation sequence is unknown to the treating physicians and nurses who recruit patients and to the researcher who includes patients. After informed consent, the independent research assistant will reveal the group allocation to the researcher who includes the patient. Blinding of patients, nurses, and treating physicians to group allocation is not possible due to the nature of the intervention. Data will be analysed after encryption, without recognition of original variables including name, centre, and group allocation. An independent research assistant will store the encryption key and reveal the original variables at the end of the study.

\section{Intervention}

Patients will receive the intervention alongside the pain treatment that is provided to them by their treating physician. The intervention will not interfere with, nor be a substitute for, their usual pain treatment as the treating physician remains responsible and decides on follow-up. The intervention has been designed in a co-creative process together with researchers, health professionals, patients, and technical experts. This process resulted in an intervention that integrates patient self-management and professional care by means of healthcare technology and consists of an iPad application for patients and a web-application for nurses. Both applications are embedded in routine clinical practice.

\section{Patient application}

Patients register their pain, adverse effects, interference of pain with activity or sleep, and satisfaction with treatment by use of a pain diary twice-daily and optional extra pain intensity scores within the iPad application. Moreover, patients are requested to register intake of 'around the clock' (ATC) and 'as needed' (PRN) medication in a personalised medication day schedule. Accordingly, registered pain intensity scores and medication intake moments are depicted in a graph. Besides, patients receive education about causes of pain, treatment of pain, recognition of symptoms that require action, and methods that patients themselves can implement to control pain. Patients are able to communicate with the nurse via text message functionality within the application in case of questions. 


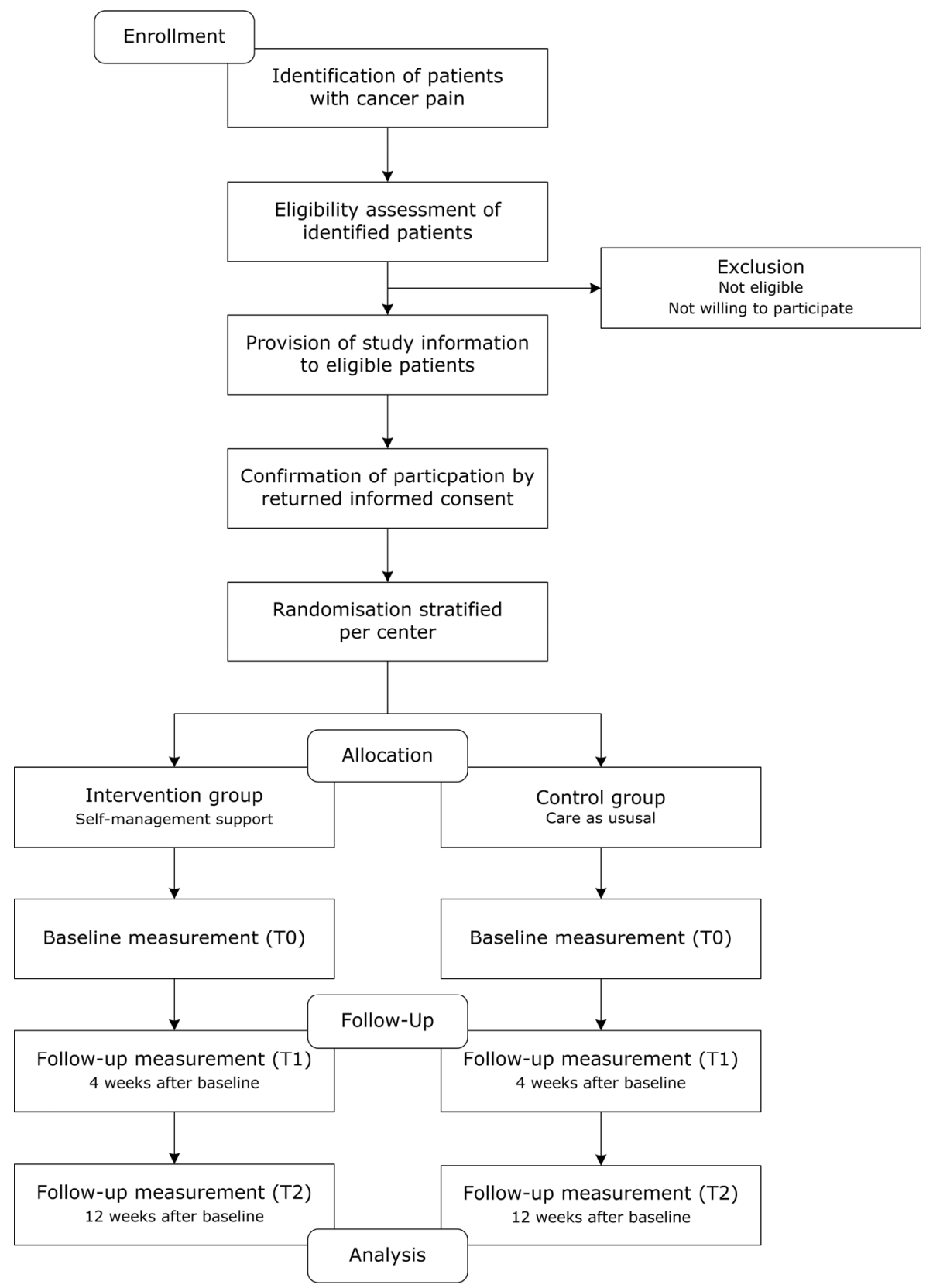

Figure 5.1 Flowchart of the study design 


\section{Nurse application}

Based on the web application, the nurse monitors and analyses the patient's situation once every workday, taking into account completed pain diaries, scheduled and actual medication intake, and text messages. A decision support system within the application, which consists of an algorithm with questions, answers, and coloured risk flags supports nurses in their monitoring tasks: red flags require immediate action, yellow flags ask to keep an eye, and green flags indicate everything is okay. In addition to sending text messages and consulting patients by phone, nurses have the opportunity to collaborate with the treating physician, pain specialist or the multidisciplinary palliative team when pain relief is inadequate.

In advance of the randomised controlled trial, nurses took part in a 2-h instruction meeting about the nurse application. These instructions are also summarised in an instruction manual.

\section{Procedure}

For each patient in the intervention group an account will be created in the nurse application, which will then be linked to the patient application. Accordingly, a medication overview will be obtained from the pharmacist. Pain medication from this overview will be entered into the nurse application and activated to be visible in the patient application. The nurse will process changes in pain medication during the study period alike.

At baseline, a home visit will be scheduled. The nurse carries out a pain assessment; checks pain medication; and provides patients with information about pain and pain management. The researcher explains how to use the patient application; information that is summarised in an instruction manual as well. In case of technical troubles with using the application during the study period, patients will be advised to contact a helpdesk. After twelve weeks the researcher will schedule another home visit to conduct a semi-structured interview to explore experiences of the patient.

\section{Care as usual}

Outpatients with cancer pain enter the outpatient clinics involved in the study basically via three different routes: patients see their oncologist for follow-up and indicate having pain; patients are referred by their general practitioner with an increase in pain complaints; or patients contact the oncology department themselves. Patients are often treated by their oncologist with regard to cancer pain. When the oncologist needs help, the pain specialist is consulted. During an outpatient consultation the pain specialist performs a pain assessment; checks pain medication and changes prescriptions when needed. Afterwards patients are seen again at the outpatient clinic 
or contacted by phone for a follow-up consultation. The timing and frequency of follow-up consultations differ and also depend on the type of medication that has been prescribed; sometimes after four days, sometimes after a week and when stabilised after two or three weeks. When pain is adequately treated, the consultation is closed. When pain gets worse and is difficult to treat, the patient is admitted to the hospital. Patients do often not receive information materials about pain and pain treatment. Usually patients are neither asked to monitor their pain scores, nor to register their medication intake on paper.

\section{Co-interventions}

For ethical and practical reasons, patients in both the intervention and control group are not restricted in the use of other methods to control pain. Because cointerventions might bias results and conclusions though, it is important to register these interventions and take them into account in the analyses. Therefore, all patients will be asked to report informational and practical sources or tools that supported them in coping with or controlling pain.

\section{Data collection and outcome measures}

Patients will be asked to complete postal questionnaires at three time points; namely at baseline (T0), after four weeks (T1), and after twelve weeks (T2). Measurements are selected based on their psychometric properties (validity, reliability), clinical utility, and appropriateness for the target setting and population. Patients in the intervention group will be interviewed after the study period as part of the process evaluation. A focus group interview will be held with the nurses.

Table 5.1 Outcome measures and time points of the effect evaluation

\begin{tabular}{|c|c|c|c|c|}
\hline \multirow{2}{*}{ Inclusion criteria } & \multirow{2}{*}{ Instrument or source } & \multicolumn{3}{|c|}{ Time points } \\
\hline & & T0 & $\mathrm{T} 1$ & $\mathrm{~T} 2$ \\
\hline \multicolumn{5}{|l|}{ Primary outcome measures } \\
\hline Pain intensity & BPI & $x$ & $x$ & $x$ \\
\hline Cancer related quality of life & EORTC-QLQ-C30 & $x$ & $x$ & $x$ \\
\hline \multicolumn{5}{|l|}{ Secondary outcome measures } \\
\hline Self-efficacy & CPSS-DLV & $x$ & $x$ & $x$ \\
\hline Knowledge & PKQ-DLV & $x$ & $x$ & $x$ \\
\hline Anxiety and depression & HADS & $x$ & $x$ & $x$ \\
\hline Pain medication use & Medication overview & $x$ & $x$ & $x$ \\
\hline \multicolumn{5}{|l|}{ Additional measures } \\
\hline Socio-demographic data & Questionnaire & $x$ & & \\
\hline Medical data & Medical record & $x$ & & \\
\hline Co-interventions & Questionnaire & & & $x$ \\
\hline
\end{tabular}

T0: Baseline, T1: 4 weeks, T2: 12 weeks 


\section{Effect evaluation}

\section{Primary outcome measures}

Primary outcomes include pain intensity and quality of life. Pain intensity will be measured with the Brief Pain Inventory (BPI), an instrument frequently used to assess pain in patients with cancer both within the clinical and research setting $[17,18]$. In addition to severity of pain over the past three days, the 14-item BPI asks for location of pain, pain medication and amount of pain relief in the past 24-h, and impact of pain on daily function over the past three days.

Quality of life will be measured with the EORTC Quality of Life Questionnaire (EORTC-QLQ-C30 version 3). This instrument is cancer specific, multi-dimensional and appropriate for self-administration. Five functional scales, three symptom scales, a global health and quality of life scale as well as single items for other symptoms are covered. The EORTC-QLQ-C30 has shown acceptable levels of reliability and validity [19]. Table 5.1 includes outcome measures and time points for the effect evaluation.

\section{Secondary outcome measures}

Secondary outcomes include self-efficacy, knowledge, anxiety, depression, and pain medication use. Self-efficacy will be measured with the Chronic Pain Self-efficacy Scale (CPSS-DLV) [20]. The Dutch language version of the CPSS has two subscales (pain and symptom management and physical functioning), each consisting of 10 items. Based on how secure they are to carry out a specific activity or to achieve a specific outcome, patients score these items on a 10-100 scale (10 representing very unsecure and 100 very secure). Reliability and validity have been demonstrated for different pain conditions.

Ferrell's Patient Pain Knowledge Questionnaire (PKQ-DLV) will be used to measure knowledge. The questionnaire includes eight items that will be transformed to a $0-100$ scale ( 0 is the lowest knowledge score; 100 is the highest knowledge score). The PKQDLV has an acceptable reliability and validity [21].

Anxiety and depression will be measured with the Hospital Anxiety and Depression Scale (HADS). The HADS showed good performance to assess symptom severity, anxiety disorders and depression in somatic, psychiatric, and primary care patients $[22,23]$.

Information about pain medication use will be derived from the medication overview of the pharmacist.

\section{Additional measures}

Relevant demographic and medical data will be collected at the first measurement and retrieved from the medical record. The final measurement will include a data sheet 
that inventories co-intervention use during the study period. These co-interventions include information about pain and pain treatment, advices on how to control pain, pain medication schemes, reminders to take medication, diaries to register pain scores or medication intake, contact with the physician, or nurse about pain or other selfreported resources.

\section{Process evaluation}

Process evaluation components that will be assessed include recruitment, reach, dose delivered (completeness) and dose received (exposure and satisfaction) [24]. The intervention will be evaluated qualitatively by means of semi-structured interviews with patients in the intervention group directly after the intervention period and with a focus group interview with nurses after the study period. Quantitative data will be collected continuously from plans, logbooks, log files, and checklists. Components, operationalisation, and methods of the process evaluation are summarised in Table 5.2 .

\section{Economic evaluation}

The economic evaluation will be performed from a societal perspective, which implies that all relevant medical and non-medical costs and effects are taken into account [25]. The economic evaluation will involve a combination of a cost-effectiveness analysis (CEA) and a cost-utility analysis (CUA). Compared to care as usual, the selfmanagement support intervention is expected to result in cost effective care with improvements in pain intensity and quality adjusted life years (QALYs).

The CEA includes intervention costs, healthcare costs, patient and family costs, and costs outside the health care sector. To limit the burden for patients, cost data are preferably collected by means of retrospective questionnaires that should not exceed a recall time frame of six months [26]. Therefore, a questionnaire will be included in the final measurement, retrospectively asking for costs made during the study period of three months. Existing questionnaires are combined to identify all relevant costs.

Within the CUA outcomes will be measured by means of the EuroQol (EQ-5D-5L), a self-administered questionnaire that consists of a descriptive system and a visual analogue scale (VAS) [27]. 
Table 5.2 Components, operationalisation and methods of the process evaluation

\begin{tabular}{|c|c|c|}
\hline Component and definition & Operationalisation & $\begin{array}{l}\text { Data collection } \\
\text { method }\end{array}$ \\
\hline \multicolumn{3}{|l|}{ Recruitment } \\
\hline $\begin{array}{l}\text { Procedures used to approach } \\
\text { patients, } \\
\text { at the individual and } \\
\text { organisational level }\end{array}$ & $\begin{array}{l}\text { Procedures applied within and outside } \\
\text { hospitals to recruit patients } \\
\text { Reasons for non-participation }\end{array}$ & $\begin{array}{l}\text { Recruitment plan } \\
\text { Recruitment } \\
\text { logbook }\end{array}$ \\
\hline \multicolumn{3}{|l|}{ Reach } \\
\hline $\begin{array}{l}\text { Proportion of the intended } \\
\text { population that participated in } \\
\text { the intervention }\end{array}$ & $\begin{array}{l}\text { Characteristics of patients } \\
\text { Number of patients that completed the } \\
\text { intervention or dropped out } \\
\text { Reasons for withdrawal }\end{array}$ & $\begin{array}{l}\text { Socio-demographic } \\
\text { questionnaire } \\
\text { Server log file } \\
\text { Enrolment logbook }\end{array}$ \\
\hline \multicolumn{3}{|l|}{ Dose delivered (completeness) } \\
\hline $\begin{array}{l}\text { Extent to which the intervention } \\
\text { is actually delivered to patients } \\
\text { and nurses }\end{array}$ & $\begin{array}{l}\text { Implementation of the home visit as } \\
\text { intended } \\
\text { Functioning of the patient and nurse } \\
\text { application as intended }\end{array}$ & $\begin{array}{l}\text { Checklist } \\
\text { Interviews patients } \\
\text { Interviews nurses } \\
\text { Server log file } \\
\text { Helpdesk logbook }\end{array}$ \\
\hline \multicolumn{3}{|l|}{ Dose received (exposure) } \\
\hline $\begin{array}{l}\text { Extent to which patients and } \\
\text { nurses received and used the } \\
\text { intervention }\end{array}$ & $\begin{array}{l}\text { Opinion about the ability of patients to } \\
\text { understand and implement the intervention } \\
\text { Patients' and nurses' adherence towards } \\
\text { the intervention } \\
\text { Number of actions nurses applied in } \\
\text { follow-up of monitored data }\end{array}$ & $\begin{array}{l}\text { Interviews patients } \\
\text { Interviews nurses } \\
\text { Server log file }\end{array}$ \\
\hline \multicolumn{3}{|l|}{ Dose received (satisfaction) } \\
\hline $\begin{array}{l}\text { Satisfaction of patients and } \\
\text { nurses with the intervention }\end{array}$ & $\begin{array}{l}\text { Experienced benefits, burden, and } \\
\text { supportiveness of the intervention by } \\
\text { patients and nurses } \\
\text { Overall opinion of patients and nurses } \\
\text { Facilitators and barriers in applying the } \\
\text { intervention }\end{array}$ & $\begin{array}{l}\text { Interviews patients } \\
\text { Interviews nurses }\end{array}$ \\
\hline
\end{tabular}

\section{Sample size and power calculation}

The power calculation is estimated by a two-tailed analysis, based on the assumption that alpha and beta equal 0.05 and 0.2 respectively. The mean pain intensity is expected to decrease 1.5 on a $0-10$ point-scale in the intervention group compared to the control group. To have adequate power to test the effect of the intervention on pain intensity, the sample size will equal 62.8 in both the intervention as well as control group. Taking into consideration $15 \%$ of non-response, a total of 73 patients per group will be needed. In addition, during the study period $20 \%$ of patients are expected to drop out because they are too ill or died (loss to follow-up). Therefore, 87 patients per group will be needed to have adequate power. 


\section{Planned analyses}

Quantitative data will be analysed using the Statistical Package for the Social Sciences (SPSS) version 21. A directed content analysis method will be followed to analyse data qualitatively.

\section{Analyses effect evaluation}

Intention to treat analyses and per protocol analyses will be conducted. Descriptive statistics and frequency distributions will be generated for demographic, disease, and pain related characteristics. Independent student $t$-tests and chi-square tests will be performed to determine comparability in baseline characteristics between patients randomised to the intervention and control group. To evaluate the effect of the intervention and changes over time, an analysis for longitudinal data will be conducted using repeated measures analysis of variance (ANOVA) or mixed regression models. The number of dropouts in this study, mainly by severe illness and death, will probably result in an unbalanced dataset. Mixed regression models offer an alternative for dealing with unbalanced data sets. Therefore, changes over time and differences between subgroups will be tested by using the Random Intercept Model.

\section{Analyses process evaluation}

Quantitative data will be analysed by means of descriptive statistics. The information that is collected during the semi-structured and focus group interviews as well as the notes of the nurses will be analysed qualitatively. Data will be summarised, coded and organised into categories. These categories reflect the emerging themes for patients and health professionals' experiences with the intervention.

\section{Analyses economic evaluation}

Within the context of the cost-effectiveness analysis, valuation of costs will be based on the Dutch manual for cost analysis in health care research [28]. Differences in costs and effects will be presented in an incremental cost-effectiveness ratio (ICER) and an incremental cost-utility ratio (ICUR). The ICER and ICUR represent the difference in mean costs of the intervention and control group in the numerator and the difference in mean effects of the intervention and control group in the denominator. 


\section{Discussion}

As actual cancer pain management is practiced particularly at home and outpatients face difficulties in putting prescriptions into practice [2], supporting self-management appears to be a promising solution. Healthcare technology provides opportunities to follow-up patients beyond the walls of the outpatient clinic. The RCT involves the evaluation of a technology based multi-component self-management support intervention that combines monitoring of pain, adverse effects, and medication with graphical feedback, education, and nurse support. Compared to care as usual, selfmanagement support is expected to result in better pain control and better quality of life.

The intervention is different from previous attempts in its multi-component and interactive approach. Complex interventions having several interacting components require good theoretical understanding and the use of different outcome measures to evaluate underlying mechanisms [29]. Quantitative and qualitative data collection will be combined and different outcomes related to cancer pain and self-management will be measured. While clinical effectiveness is of primary concern, the information from the process and cost evaluation will provide important in-depth insights into the success of the intervention in order to better interpret results and improve future implementation [30,31].

Recruitment of oncological patients in any study can be challenging. When the study involves symptom management, rather than disease treatment, recruitment even asks for more efforts [32]. Health professionals protect their patients because of high disease and symptom burden; patients most in need for these interventions often feel too ill or overwhelmed. Provision of information about the intervention and both advantages and disadvantages of study participation to health professionals and patients is believed to increase enrolment [33]. Departments of participating centres will be visited regularly and study information as well as number of inclusion updates will be disseminated repeatedly via commonly used communication channels. Moreover, shortly after they received the informed consent documents from their treating physician, patients will be called by the researcher in order to provide more information about the study and to answer questions. These contact moments with both health professionals as well as patients will reveal important information as regards the reasons for health professional not to recruit and for patients not to participate; information that will be used in future contacts to increase enrolment. Others lessons learned from previous research have been taken into account in the preparation of this RCT: the content and frequency of questionnaires have been minimised, flexibility will be offered in scheduling home visits, and a helpdesk will be available for technological support and assistance with filling out questionnaires [32-34]. 
Study outcomes will contribute to the understanding on interventions improving cancer pain in outpatients by means of self-management support. Evaluations will also provide important information as to whether a mixed population of cancer patients regarding age, socio-economic status, and complexity of disease and medication, is accepting healthcare technology. The intervention could be base for other cancer related health problems or for pain problems in other chronic diseased populations. 


\section{References}

1. van den Beuken-van Everdingen $M H$, de Rijke JM, Kessels AG, Schouten HC, van Kleef M, Patijn J (2007) Prevalence of pain in patients with cancer: a systematic review of the past 40 years. Ann Oncol 18(9):1437-1449.

2. Schumacher KL, Koresawa S, West C, Hawkins C, Johnson C, Wais E, Dodd M, Paul SM, Tripathy D, Koo P, Miaskowski C (2002) Putting cancer pain management regimens into practice at home. J Pain Symptom Manage 23(5):369-382.

3. Oldenmenger WH, Sillevis Smitt PA, van Dooren S, Stoter G, van der Rijt CC (2009) A systematic review on barriers hindering adequate cancer pain management and interventions to reduce them: a critical appraisal. Eur J Cancer 45(8):1370-1380.

4. Jacobsen R, Liubarskiene Z, Moldrup C, Christrup L, Sjogren P, Samsanaviciene J. (2009) Barriers to cancer pain management: a review of empirical research. Medicina (Kaunas) 45(6):427-433.

5. Luckett T, Davidson PM, Green A, Boyle F, Stubbs J, Lovell M (2013) Assessment and management of adult cancer pain: a systematic review and synthesis of recent qualitative studies aimed at developing insights for managing barriers and optimizing facilitators within a comprehensive framework of patient care. J Pain Symptom Manage 46(2):229-253.

6. McCorkle R, Ercolano E, Lazenby M, Schulman-Green D, Schilling LS, Lorig K, Wagner EH (2011) Self-management: enabling and empowering patients living with cancer as a chronic illness. CA Cancer J Clin 61(1):50-62.

7. Lorig KR, Holman H (2003) Self-management education: history, definition, outcomes, and mechanisms. Ann Behav Med 26(1):1-7.

8. Wilde $\mathrm{MH}$, Garvin S (2007) A concept analysis of self-monitoring. J Adv Nurs 57(3):339-350.

9. Bodenheimer T, Lorig K, Holman H, Grumbach K (2002) Patient self-management of chronic disease in primary care. JAMA 288(19):2469-2475.

10. Kravitz RL, Tancredi DJ, Grennan T, Kalauokalani D, Street Jr RL, Slee CK, Wun T, Oliver JW, Lorig K, Franks P (2011) Cancer Health Empowerment for Living without Pain (Ca-HELP): effects of a tailored education and coaching intervention on pain and impairment. Pain 152(7):1572-1582.

11. van Houtum L, Rijken M, Heijmans M, Groenewegen P (2013) Self-management support needs of patients with chronic illness: do needs for support differ according to the course of illness? Patient Educ Couns 93(3):626-632.

12. Barlow J, Wright C, Sheasby J, Turner A, Hainsworth J (2002) Self-management approaches for people with chronic conditions: a review. Patient Educ Couns 48(2):177-187.

13. Holman H, Lorig K (2004) Patient self-management: a key to effectiveness and efficiency in care of chronic disease. Public Health Rep 119(3):239-243.

14. Vallerand AH, Musto S, Polomano RC (2011) Nursing's role in cancer pain management. Curr Pain Headache Rep 15(4):250-262.

15. Schumacher KL, Clark VLP, West CM, Dodd MJ, Rabow MW, Miaskowski C (2014) Pain medication management processes used by oncology outpatients and family caregivers part I: health systems contexts. J Pain Symptom Manage 48(5):770-783.

16. Dickinson R, Hall S, Sinclair JE, Bond C, Murchie P (2014) Using technology to deliver cancer follow-up: a systematic review. BMC Cancer 14(1):311.

17. Cleeland CS, Ryan KM (1994) Pain assessment: global use of the Brief Pain Inventory. Ann Acad Med Singapore 23(2):129-138.

18. Jensen MP (2003) The validity and reliability of pain measures in adults with cancer. J Pain $4(1): 2-21$. 
19. Aaronson NK, Ahmedzai S, Bergman B, Bullinger M, Cull A, Duez NJ, Filiberti A, Flechtner $H_{\text {, }}$ Fleishman SB, de Haes JC, Kaasa S, Klee M, Osoba D, Razavi D, Rofe PB, Schraub S, Sneeuw K, Sullivan M, Takeda F (1993) The European Organization for Research and Treatment of Cancer QLQ-C30: a quality-of-life instrument for use in international clinical trials in oncology. J Natl Cancer Inst 85(5):365-376.

20. Anderson KO, Dowds BN, Pelletz RE, Edwards WT, Peeters-Asdourian C (1995) Development and initial validation of a scale to measure self-efficacy beliefs in patients with chronic pain. Pain 63(1):77-84.

21. de Wit R, van Dam F, Vielvoye-Kerkmeer A, Mattern C, Abu-Saad H (1999) The treatment of chronic cancer pain in a cancer hospital in the Netherlands. J Pain Symptom Manage 17: 333-350.

22. Bjelland I, Dahl AA, Haug TT, Neckelmann D (2002) The validity of the Hospital Anxiety and Depression Scale. An updated literature review. J Psychosom Res 52(2):69-77.

23. Spinhoven P, Ormel J, Sloekers PP, Kempen GI, Speckens AE, Van Hemert AM (1997) A validation study of the Hospital Anxiety and Depression Scale (HADS) in different groups of Dutch subjects. Psychol Med 27(2):363-370.

24. Saunders RP, Evans MH, Joshi P (2005) Developing a process-evaluation plan for assessing health promotion program implementation: a how-to guide. Health Promot Pract $6(2)$ : 134-147.

25. Russell LB, Gold MR, Siegel JE, Daniels N, Weinstein MC (1996) The role of cost-effectiveness analysis in health and medicine. JAMA 276(14):1172-1177.

26. van den Brink $M$, van den Hout WB, Stiggelbout AM, Putter $H$, van de Velde CJ, Kievit J (2005) Self-reports of health-care utilization: diary or questionnaire? Int J Technol Assess Health Care 21(3):298-304.

27. The EuroQoL Group. (2011) EQ-5D-5L User guide: basic information on how to use the EQ5D-5L Instrument. Available from: http://www.euroqol.org. Accessed January 12, 2015.

28. Oostenbrink J, Bouwmans C, Koopmanschap M, Rutten F (2004) Handleiding voor kostenonderzoek. Methoden en standaard kostprijzen voor economische evaluaties in de gezondheidszorg. Erasmus MC: Instituut voor Medical Technology Assessment.

29. Craig P, Dieppe P, Macintyre S, Michie S, Nazareth I, Petticrew M (2013) Developing and evaluating complex interventions: the new Medical Research Council guidance. Int J Nurs Stud 50(5):587-592.

30. Linnan L, Steckler A (2002) Process Evaluation for Public Health Interventions and Research. San Francisco, California: Jossey-Bass.

31. Oakley A, Strange V, Bonell C, Allen E, Stephenson J, Team RS (2006) Process evaluation in randomised controlled trials of complex interventions. BMJ 332(7538):413-416.

32. Ransom S, Azzarello LM, McMillan SC (2006) Methodological issues in the recruitment of cancer pain patients and their caregivers. Res Nurs Health 29(3):190-198.

33. Berger AM, Neumark DE, Chamberlain J (2007) Enhancing recruitment and retention in randomized clinical trials of cancer symptom management. Oncol Nurs Forum 34(2): E17-E22.

34. Koller A, Miaskowski C, De Geest S, Opitz O, Spichiger E (2013) Supporting self-management of pain in cancer patients: methods and lessons learned from a randomized controlled pilot study. Eur J Oncol Nurs 17(1):1-8. 


\section{Impact evaluation of an eHealth intervention to support self-management in outpatients with cancer pain}

Hochstenbach LM, Zwakhalen SM, Courtens AM, van den Beuken-Everdingen $M H$, van Kleef $M$, de Witte $L P$ Submitted 


\section{Abstract}

\section{Purpose}

Appropriate support is important to optimally involve outpatients with cancer in pain and medication self-management. An eHealth intervention, including a home visit, a mobile application for patients, a web application for nurses, and follow-up activities, was evaluated on process and effects.

\section{Methods}

Outpatients and nurses participated in a multicentre (randomised controlled) trial. The intervention combined pain, adverse effects, and medication monitoring with feedback, education, and nurse support. Process data (recruitment, reach, dose delivered, exposure, satisfaction) were gathered continuously over the study period; effect data (pain, quality of life) were collected at baseline, after 4 weeks, and after 12 weeks. Qualitative data were analysed thematically and quantitative data with descriptive statistics.

\section{Results}

Recruitment proved to be extremely difficult, for which the study protocol was amended twice. Of the 66 patients included, 32 patients completed the study. The intervention was mostly delivered as planned, exposure was considerable, and satisfaction was high. Patients felt encouraged in performing self-management; nurses felt assisted in providing self-management support. An indication of possible effects was seen in the intervention group for pain and quality of life.

\section{Conclusions}

Because of low inclusion numbers, possible selection bias, and high dropout rates, two amendments were needed and a shift of focus was required. Process outcomes showed added value of the eHealth intervention. Effect outcomes did not yet allow conclusions on clinical effectiveness. Future research and clinical practice need to consider different research designs, embedding in usual care, and opportunities for a tailor-made approach. 


\section{Introduction}

Cancer pain management is increasingly practiced on an outpatient basis, for which patients and health professionals need to collaborate [1-3]. Patients are encouraged to become actively involved and practice self-management [4]. In order to do so, patients need to be aware of pain and related symptoms, take pain medication as prescribed, be informed about pain, take action, and ask for help [5,6]. Health professionals are challenged to take a broader perspective and support these patients in their day-to-day self-management [7]. Self-management support in this case involves the systematic provision of education and supportive interventions to increase patients' skills and confidence in managing cancer pain, including regular assessments, goal setting, and problem-solving support [8].

eHealth offers promising opportunities for self-management and self-management support in facilitating communication, sharing information, tailoring advice, and improving follow-up [9]. As part of the current project an eHealth intervention was developed to support self-management, including a home visit, a mobile application for patients, a web application for nurses, and follow-up activities [10]. Monitoring of pain, adverse effects, and use of medication with feedback, education, and nurse support were taken together in a multi-component intervention.

A small-scale study previously performed to explore the feasibility of the intervention as well as its technological functioning in everyday practice showed promising results [11]. Patients learned to use the application quickly, practiced tasks easily, and enjoyed to work with the application. Although nurses had to get acquainted to remotely monitoring and advising patients about pain, they were mostly positive about the possibilities of the intervention specifically and the idea of selfmanagement support in general. Following patients' and nurses' ideas for improvement, rework was performed to improve the technological performance, to adapt the content, and to optimise the look and feel of both applications.

The present study was conducted to evaluate the impact of the intervention on process outcomes (recruitment, reach, dose delivered, exposure, and satisfaction) and effect outcomes (pain and quality of life). Moreover, this article provides insight into lessons learned for similar research with comparable interventions or patients.

\section{Methods}

\section{Design}

Three different phases were completed during the course of the study. The study started as a two-armed multicentre randomised controlled study that compared selfmanagement support with care as usual in two centres [12]. In order to speed up the 
recruitment, the study was extended as a two-armed multicentre randomised controlled study in four centres. Because of persisting difficulties regarding low inclusion numbers, possible selection bias, and high dropout rates, the study continued as a one-armed multicentre non-randomised intervention study that focused on the impact of self-management support. The three phases are referred to as:

- Phase 1a: Two centres, two arms, randomisation (February 2014- August 2014)

- Phase 1b: Four centres, two arms, randomisation (September 2014 - March 2015)

- Phase 2: Four centres, one arm, no randomisation (April 2015 - August 2015)

The original study protocol and the two amendments were discussed with and approved by the Medical Ethical Committee Atrium-Orbis-Zuyd, the Netherlands as well as the local authorities of the participating centres.

\section{Sample and setting}

\section{Patients}

Via the outpatient clinics and inpatient oncology wards of one academic centre, two regional hospitals and one radiotherapy clinic, patients were recruited consecutively and invited to participate in the study by the treating physician. Table 6.1 shows the inclusion and exclusion criteria. An informed consent procedure was followed and two weeks were given to consider participation.

Table 6.1 Inclusion and exclusion criteria of patients

\begin{tabular}{l}
\hline Inclusion criteria \\
Diagnosis of cancer \\
Undergoing (palliative) anti-tumour treatment in an outpatient clinic or having no treatment \\
options anymore \\
Moderate to severe cancer pain defined as $\geq 4$ on a NRS (scale $0-10$ ) $>2$ weeks \\
Living at home \\
Exclusion criteria \\
Life expectancy $<3$ months \\
Chronic non-cancer pain \\
Known cognitive impairments \\
Participation in other studies that interfere with this study \\
Not being able to read and understand the Dutch language \\
Reduced vision \\
Non-accessible by phone
\end{tabular}




\section{Nurses}

Four experienced registered nurses with extra education in oncology and pain were recruited conveniently via the four participating centres. Nurses received a $2-h$ instruction meeting, after which a paper-copy instruction manual was provided. With approval of the management, nurses were allowed to spend on average 4-5 hours a week on monitoring and follow-up activities.

\section{Intervention}

The intervention, including a home visit, a mobile application for patients, a web application for nurses, and follow-up activities, is illustrated in Figure 6.1. The intervention was restricted to pain and adverse effects of pain medication; patients were advised to contact their treating physician or general practitioner with other requests for help. Patients received an iPad 2 with Internet connection on loan during the study period, a paper-copy manual, and contact details of the help desk in case of technical problems. The 12-week intervention was provided alongside usual care.

\section{Care as usual}

As treating physician, the oncologist mostly takes care of pain experienced by his or her patients. When pain proves to be difficult to treat, the oncologist might consult a pain specialist for advice. The general practitioner needs to be kept informed, but is actually involved only in the palliative phase. Patients do often not receive information materials about pain and pain treatment; they are usually not asked to monitor pain intensity or medication intake; nor do they have frequent contact with a health professional about their pain.

\section{Data collection and outcomes measures}

Data were collected at the level of the patient, the nurse, and the organisation. Data collection remained unchanged during the course of the study, in all three phases.

\section{Process evaluation}

Quantitative data were collected continuously from logbooks, log files, and checklists. The intervention was evaluated qualitatively by semi-structured interviews with patients after the intervention (T2) and with a focus group interview with nurses after the study. The following process evaluation components [13] were studied: 
- Recruitment includes the procedures that were applied and the reasons to refrain from recruitment and participation;

- Reach involves the flow of patients through the study, reasons for dropout, and patient as well as nurse characteristics;

- Dose delivered relates to the implementation of the home visit, the functioning of both applications, and the follow-up activities performed by nurses as planned;

- Exposure includes the actual content of the home visit, adherence to the applications, and challenges experienced during follow-up;

- Satisfaction involves the advantages, disadvantages and supportiveness of the home visit, both applications, and follow-up activities.

\section{Effect evaluation}

Effect data were collected at baseline (T0), after 4 weeks (T1), and 12 weeks (T2) by using postal questionnaires. Primary outcomes included pain intensity as measured with the Brief Pain Inventory (BPI) and quality of life inventoried with the EORTC Quality of Life Questionnaire (EORTC-QLQ-C30 version 3) [14,15]. The Chronic Pain Self-efficacy Scale (CPSS-DLV), Ferrell's Pain Knowledge Questionnaire (PKQ-DLV), and the Hospital Anxiety and Depression Scale (HADS-DLV) were used to assess the secondary outcomes self-efficacy, knowledge, anxiety and depression [16-18]. Relevant demographic and medical data were collected at baseline and retrieved from medical records.

\section{Analysis}

\section{Process evaluation}

Quantitative data were analysed by means of descriptive statistics. Semi-structured and focus group interviews were analysed qualitatively [19]. Audiotapes were transcribed ad verbatim. Transcriptions were coded and data were organised into categories using NVivo version 11 . For each category data were summarised and illustrative quotes were added.

\section{Effect evaluation}

Descriptive statistics and frequency distributions were calculated for the demographic and clinical characteristics in the intervention and control group as well as for the effect outcomes in the intervention group using SPSS version 22. 


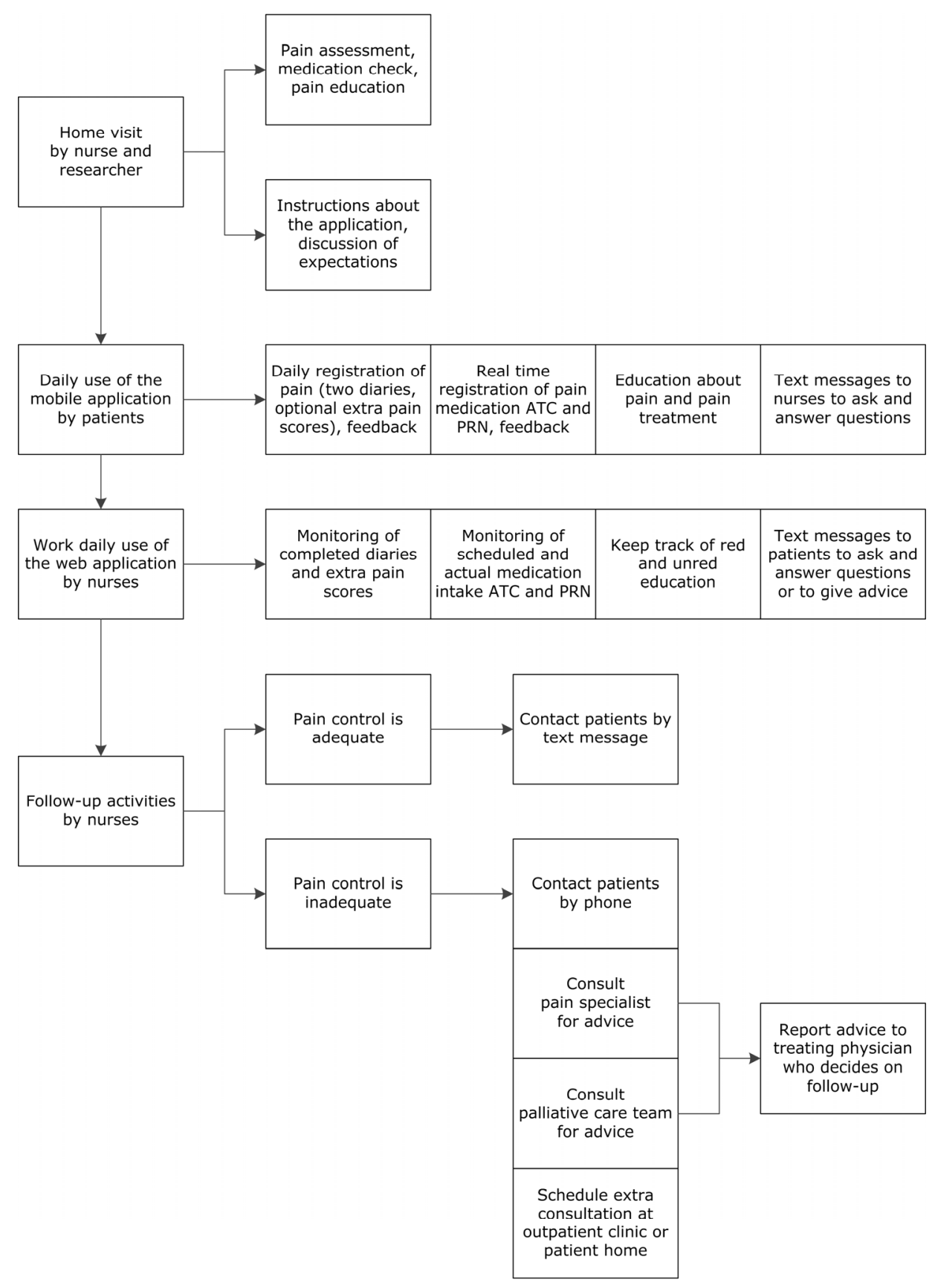

Figure 6.1 The eHealth intervention 


\section{Results}

The results are divided in three separate sections. First, the process evaluation regarding the study will be presented including recruitment and reach (intervention and control group). Second, the process evaluation with respect to the intervention will be discussed in terms of dose delivered, exposure, and satisfaction (intervention group). Third, an indication of effects for pain and quality of life will be given.

\section{Process evaluation - Study}

\section{Recruitment}

According to the recruitment plan, patients were selected and invited via outpatient oncology clinics or inpatient oncology wards of initially two and later four centres. Because the intervention was performed as part of the medical treatment contract, treating physicians were designated to recruit patients but sometimes delegated these tasks to the nursing staff. In addition, one centre worked with standard psychosocial screening questionnaires including a pain item based on which eligibility of patients was checked; another centre owned a trial agency for recruitment purposes. Printed folders with informed consent documents were available at the reception desks and in the consultation rooms; cards with eligibility criteria were distributed. Invited patient were usually reported which allowed the researcher to contact these patients to provide more information. The study was brought and kept to the attention by regular visits to the centres to provide study information, tailor recruitment procedures, and address possible doubts about the intervention. Updates about inclusion numbers per centre were disseminated via a monthly email. Regional associations of general practitioners and pharmacists were informed by visits or newsletter calls to further promote enrolment.

Despite all efforts, inclusion rates continued to lag behind. Recruitment logs showed that from each 100 outpatients with cancer pain that visited one of the centres, roughly half were invited into the study and about a quarter decided to participate. The most important reason for treating physicians not to recruit was not being eligible; the most frequent mentioned reason for patients not to participate was being too ill.

\section{Reach}

The flow of patients throughout the study is shown in Figure 6.2. Of all patients, 54 out of $66(81.8 \%)$ actually started with the study. Four weeks after the start 47 patients $(71.2 \%)$ continued participation; after twelve weeks 32 patients (48.5\%) finished the entire study period. Reasons for dropout were being too ill $(n=5)$; hospital 
admission $(n=5)$; too much focus on pain because of the intervention $(n=3)$; death $(n=12)$; or various $(n=9)$.

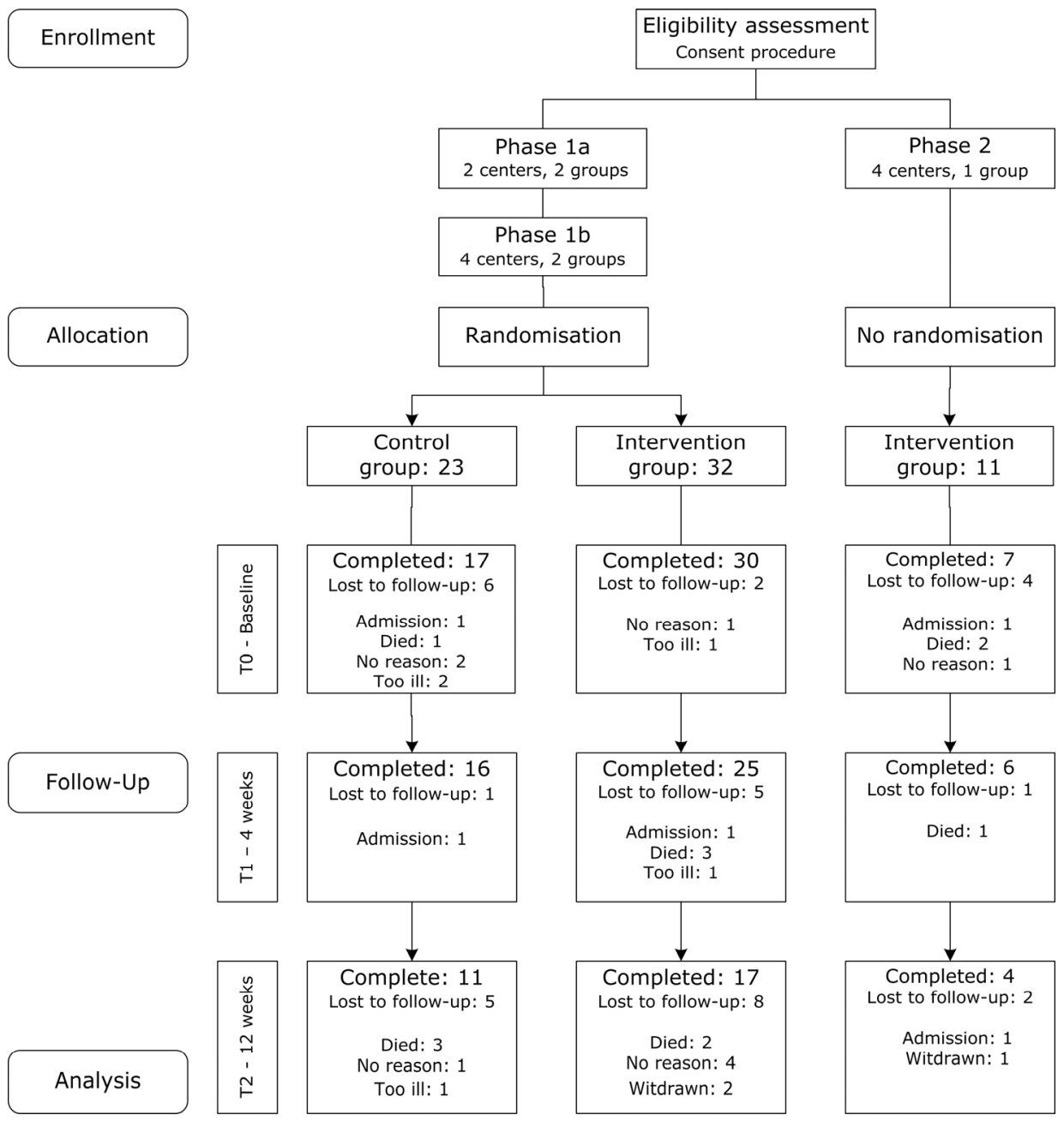

Figure 6.2 Flow of patients through the study

Table 6.2 shows the baseline characteristics for patients in each group. Patients (32 males, 22 females) were aged 24-77 (M 62.4, SD 10.0) years and all Dutch. Nurses ( 2 males, 2 females) were aged 47-57 (M 53.0, SD 4.4) years and had 12-22 ( $M$ 17, SD 6) years of experience while working as palliative consultant in a palliative care consultation team, as nurse practitioner oncology in the hospital, or as pain specialist at a home care organisation. 
Table 6.2 Baseline characteristics of patients in the control and intervention group. Values are numbers (percentages) unless stated otherwise.

\begin{tabular}{|c|c|c|c|}
\hline & \multicolumn{2}{|c|}{ Phase $1 \mathrm{a}$ and $1 \mathrm{~b}$} & \multirow{2}{*}{$\begin{array}{c}\text { Phase } 2 \\
\text { Intervention } \\
\mathrm{N}=7\end{array}$} \\
\hline & $\begin{array}{l}\text { Control } \\
\mathrm{N}=17\end{array}$ & $\begin{array}{c}\text { Intervention } \\
\qquad \mathrm{N}=30\end{array}$ & \\
\hline \multicolumn{4}{|l|}{ Sociodemographic characteristics } \\
\hline \multicolumn{4}{|l|}{ Gender } \\
\hline Male & $13(76.5)$ & $15(50.0)$ & $4(57.1)$ \\
\hline Female & $4(23.5)$ & $15(50.0)$ & $3(42.9)$ \\
\hline \multicolumn{4}{|l|}{ Age } \\
\hline Mean in years (SD) & $65.5(6.6)$ & $60.3(11.3)$ & $64.0(10.1)$ \\
\hline Range in years & $51-73$ & $24-77$ & $51-77$ \\
\hline \multicolumn{4}{|l|}{ Marital status } \\
\hline Married & $11(64.7)$ & $22(73.3)$ & $6(85.7)$ \\
\hline Unmarried & $4(23.5)$ & $7(23.4)$ & $0(0.0)$ \\
\hline Widowed & $2(11.8)$ & $1(3.3)$ & $1(14.3)$ \\
\hline \multicolumn{4}{|l|}{ Level of education } \\
\hline Low & $10(58.8)$ & $14(46.6)$ & $4(57.1)$ \\
\hline Middle & $4(23.5)$ & $11(36.7)$ & $2(28.6)$ \\
\hline High & $3(17.6)$ & $5(16.7)$ & $1(14.3)$ \\
\hline \multicolumn{4}{|l|}{ Medical characteristics } \\
\hline \multicolumn{4}{|l|}{ Diagnosis } \\
\hline Breast & $2(11.8)$ & $8(26.7)$ & $1(14.3)$ \\
\hline Digestive organs & $3(17.6)$ & $9(30.0)$ & $1(14.3)$ \\
\hline Female genital organs & $1(5.9)$ & $1(3.3)$ & $0(0.0)$ \\
\hline Head and neck & $1(5.9)$ & $1(3.3)$ & $0(0.0)$ \\
\hline Lower respiratory system & $2(11.8)$ & $5(16.7)$ & $0(0.0)$ \\
\hline Lymphatic-Haematological & $2(11.8)$ & $4(13.3)$ & $3(42.9)$ \\
\hline Male genital organs & $5(29.4)$ & $2(6.7)$ & $2(28.6)$ \\
\hline Unknown primary site & $1(5.9)$ & $0(0.0)$ & $0(0.0)$ \\
\hline \multicolumn{4}{|l|}{ Time since diagnosis } \\
\hline Mean in years (SD) & $4.2(4.7)$ & $3.6(5.4)$ & $3.4(2.8)$ \\
\hline Range in years & $0.2-16.2$ & $0.1-20.2$ & $0.3-7.0$ \\
\hline \multicolumn{4}{|l|}{ Disease stage* } \\
\hline Group 1 & $2(11.8)$ & $1(3.3)$ & $0(0.0)$ \\
\hline Group 2 & $1(5.9)$ & $4(13.3)$ & $1(14.3)$ \\
\hline Group 3 & $14(82.4)$ & $25(83.3)$ & $6(85.7)$ \\
\hline \multicolumn{4}{|l|}{ Treatment modalities } \\
\hline Surgery & $5(29.4)$ & $5(16.7)$ & $1(14.3)$ \\
\hline Radiotherapy & $9(52.9)$ & $15(50.0)$ & $4(57.1)$ \\
\hline Chemotherapy & $12(70.6)$ & $26(86.7)$ & $5(71.4)$ \\
\hline Other & $6(35.5)$ & $10(33.3)$ & $3(42.9)$ \\
\hline None & $1(5.9)$ & $1(3.3)$ & $0(0.0)$ \\
\hline \multicolumn{4}{|l|}{ Technology experience } \\
\hline \multicolumn{4}{|l|}{ Use of tablet $\mathrm{pc}$} \\
\hline Never or sometimes & $12(70.6)$ & $15(50.0)$ & $3(42.9)$ \\
\hline Regularly or daily & $5(29.4)$ & $15(50.0)$ & $4(57.1)$ \\
\hline
\end{tabular}

* Group 1: Finished anti-tumour therapy with curative intent; group 2: Receiving anti-tumour therapy with curative intent; group 3: Receiving anti-tumour treatment with palliative intent 


\section{Process evaluation - Intervention}

\section{Dose delivered}

Home visit | At baseline each patient was seen by one of the nurses together with the main researcher. Because of practical reasons, this introduction took not only place at home $(n=25)$; but also at the hospital prior to or after a scheduled appointment $(n=7)$; or both at home by the main researcher and at the hospital by the nurse $(n=5)$. The visits lasted approximately 60-90 minutes, depending on nurse's prior knowledge of the patient and a patient's skilfulness with the application.

"Sometimes information was very limited. Only an address, medication details were lacking, the diagnosis was unknown. Then the home visit lasted longer." (N1)

Application patient | In general, the application worked as intended. Occasionally, some time was needed to refresh. In a few cases the application was stalling; experienced users got a little frustrated and inexperienced users got a bit unsecure. Still patients found their way easily; some tried it again at a later moment in time, others considered it done. Most patients mentioned the visual and sound notifications as a reminder to complete diaries, take medication, read education materials, and check text messages.

For 95\%, it was fine. Sometimes it was a bit slow. Then you press, then you press again, then you press a bit harder, and then you press with two fingers.." (P112)

Application nurse | Although a 2-h instruction meeting enabled nurses to make a good start, learning only took place afterwards by actually using the application. Log in did not cause any problems; completed pain diaries, scheduled and actual pain medication intake, and incoming text messages were visible; email notifications and risk flags worked well. The main researcher was easily approachable for practical questions; a helpdesk was available for technical assistance. Complaints that were reported: technical flaws made the application slow at times; entering medication details proved to be a laborious task; and there was still no specific format to include the initial pain assessment.

"I'm the digital illiterate of the department, but overall, everything went well. And if not, I contacted the researcher or relied upon kind and helpful colleague nurses." (N2)

Follow-up activities I Nurses had the opportunity to initiate some sequential activities (Figure 6.1). The sequence of activities turned out to be applied not that strictly. Whereas one nurse visited patients at home sometimes (in line with her 
regular home care work), this was no option for the others who contacted the general practitioner in these situations (in accordance with their regular hospital work). One of the nurses saw patients more often at the outpatient clinic, where patients received usual care. The pain specialist was consulted several times; none of the patients was discussed with the palliative care team.

"Sometimes I thought, I maybe felt the necessity, for a home visit. With the idea, that if I could just see someone, personally, it would.. On the other hand, you should not hold on to the illusion that you can solve all problems." (N2)

\section{Exposure}

Home visit | Pain assessment and pain education were not fully standardised; some variation was seen in the extent to which nurses focused on medical background, medication use, and education topics. The same researcher explained the application to all patients and discussed expectations; a checklist was used to ensure every patient received the same instructions. In some cases input from the informal caregiver was necessary as they took care of pain medication.

"It requires some effort from patients. Don't underestimate that! Maybe, the home visit needs to include information about self-management as well. What is it? What to do as a patient?" (N1)

Application patients | Based on the log files, average completion rates were $78.8 \%$ for pain and adverse effects monitoring, $68.5 \%$ for medication monitoring, and $100 \%$ for education during the 12-week study period. Patients on average filled out one or both diaries on 74 (SD 12) out of 84 days and monitored 'around the clock' medication on 71 (SD 14) days. Extra pain intensity scores were given by 16 patients with a mean frequency of 20 (SD 37). 'As needed' medication was registered by 14 patients for on average 55 (SD 46) times. Monitoring of extra pain intensity scores and 'as needed' medication intake was not applicable or noteworthy for some and not the first thing to think about when being in worse pain for others. Patients looked into the graph regularly, but acknowledged to gain insight only in case of pain fluctuations. All patients completed the education sessions; ten patients viewed some of the topics once again, more specifically the topics about what is pain, what causes pain in cancer, and why do some experience more pain than others. Where some red the sessions carefully and considered it "interesting" (P303), others scanned the information quickly and "preferred not to know" (P413). On average, patients and nurses interacted on 27 (SD 8) out of 84 days via text messages, that were sent especially in case of questions or to indicate why diaries were missed and that medication was not registered yet taken. 
"I take oxynorm 2 to 3 times a day. I sleep badly and I snore, which is unpleasant for my husband. I am often confused and I can't do shoppings on my own. I think this is all caused by my pain medication. Could you provide me with some answers?" (P103)

Application nurses | Usually, nurses logged in twice a day at fixed times: early in the morning and late in the afternoon. In case of email notifications during the day, two nurses logged in more frequently. When patients were stable, monitoring took about 10 minutes each time. When patients needed follow-up, monitoring lasted longer. Nurses considered monitoring via the application very similar to performing a regular pain assessment.

"When pain was the case, I first studied pain intensity and potential causes of pain. Then I checked whether pain medication was taken. And I looked for trends over the previous days." (N4)

Follow-up activities | When patients were stable and days had passed without any contact, nurses sent a text message along the lines of "I see everything is well. If something is wrong, you know where to find me" (N1). Delineation was experienced as a true challenge. Patients for instance asked questions about constipation and sleeping difficulties. In order to assess the connection with pain or pain medication, more in-depth questioning was needed. The diary asked patients for these symptoms as potential side effects of pain medication, which might have created the expectation that broader support was provided by nurses.

"The challenge is to read between the lines, to look not only for pain intensity scores, but also for additions and text messages. Whether you are always able to filter out the right information.. I'm not sure." (N3)

\section{Satisfaction}

Home visit | Although quite intensive in terms of time and content, nurses considered the introduction extremely important in their collaboration with patients along the study period. Preferences regarding the location varied and were also related to how nurses were used to work. Nurses in favour of the introduction at home emphasised receiving more information about the home setting; nurses in favour of the introduction at the hospital stressed the efficiency. Nurses appreciated the room they got for pain assessment, which could then be tailored to each new patient and situation, in order to get a complete picture. 
"I noticed that the information I told about pain gradually became more concise. Whether I told the story from a-z or from a-k, eventually it made no difference for further follow-up. I guess too much information does not sink in." (N3)

Application patient I Patients generally were enthusiastic about the intervention and recognised added value in different components. Most of all, patients appreciated the involvement of the nurse. Whether the intervention truly supported them in pain self-management, provided mixed answers. At the same time, asking patients about the helpfulness of the intervention in being aware of pain, taking medication in time, gaining insight, learning about pain treatment, or discussing pain with their treating physician often resulted in more confirmatory answers. In this context, it is important to clearly discuss expectations at the start and emphasise that the intervention is a means to an end and not an end in itself are important.

"So you think it is too stressful or you don't feel like it for a day, no problem! How small or big do you make it? Off course we want information as complete as possible, but if it not works out for once, that's fine. As such, you can add some nuance." (N2)

Application nurse | The intervention or something alike was considered important to future care for cancer pain but only if "monitoring and follow-up is done by someone with know-how, who has the ability and the courage to act without actually seeing patients." (N2) Basically, the application offered sufficient support and trust to do so. Occasionally monitoring and follow-up felt as quite a responsibility. When patients reported significant pain day in day out or in case patients had a lot of symptoms and indicated no need for contact, nurses were not always sure what to do.

"There are still some obstacles and difficulties, but I believe that patients are provided with a certain feeling of reassurance in terms of 1) someone is keeping an eye; 2) someone is easy accessible; and 3) something is being done each time." (N1)

Follow-up activities I Nurses summarised with "a meaningful intervention" (N4) and "a positive experience" (N3). Difficulties in the implementation of follow-up activities included patients who did not respond to text messages that were sent by the nurse to obtain more information and general practitioners who were not well informed about the intervention, which complicated collaboration. However, implementation of such an intervention without their involvement was regarded both inconceivable and undesirable.

"You can come up with beautiful interventions, but the way it is used - both by patients and health professionals - makes or breaks its success. Integration into patient health records would help considerably." (N3) 


\section{Effect evaluation}

Table 6.3 shows the outcomes of the effect evaluation for all patients in the intervention group. Pain intensity in the intervention group declined at 4 weeks, but slightly increased again at 12 weeks. Quality of life was higher at 4 weeks and again at 12 weeks. Although noticeable for all primary and secondary outcomes at one or both moments in time, these changes are just an indication of possible effects of the intervention.

Outcomes of the control group are not presented to avoid conclusions that are unjustified based on the sample size (low inclusion numbers, high dropout rates) and protocol amendments (one group, no randomisation). For the same reasons, statistical testing of differences between groups and over time is not reported.

Table 6.3 Effect outcomes for all patients in the intervention group. Values are scores (SD).

\begin{tabular}{lccc}
\hline Outcome & $\begin{array}{c}\mathrm{T} 0 \\
\mathrm{~N}=21\end{array}$ & $\begin{array}{c}\mathrm{T} 1 \\
\mathrm{~N}=21\end{array}$ & $\begin{array}{c}\mathrm{T} 2 \\
\mathrm{~N}=21\end{array}$ \\
\hline $\begin{array}{l}\text { Pain** } \\
\quad \text { Pain now }\end{array}$ & $4.4(3.0)$ & $3.0(2.0)$ & $3.4(2.1)$ \\
$\quad$ Pain severity & $4.7(2.5)$ & $3.3(1.8)$ & $3.6(1.9)$ \\
$\quad$ Pain interference & $4.5(2.6)^{*}$ & $3.4(2.1)$ & $4.1(2.2)$ \\
Quality of life*** & & & \\
$\quad$ Sum score & $60.9(18.0)^{*}$ & $63.9(15.8)$ & $65.2(16.3)$ \\
Self-efficacy*** & $50.1(16.1)^{*}$ & $54.0(14.4)^{*}$ & $54.7(14.3)$ \\
$\quad \begin{array}{l}\text { Pain self-efficacy } \\
\text { Functional self-efficacy }\end{array}$ & $43.0(19.9)^{*}$ & $46.8(22.0)^{*}$ & $48.8(22.7)$ \\
Knowledge*** & & & \\
$\quad$ Sum score & $59.5(14.3)$ & $57.0(10.9)$ & $60.0(14.5)$ \\
Anxiety and depression** & & & \\
$\quad$ Anxiety & $5.5(4.0)$ & $6.0(4.2)$ & $5.0(3.5)$ \\
$\quad$ Depression & $5.3(5.0)$ & $5.3(3.9)$ & $5.0(3.2)$ \\
\hline
\end{tabular}

$* \mathrm{~N}=20 ; * *$ Higher scores indicate worse outcomes; ***Higher scores indicate better outcomes

\section{Discussion}

Evaluation of a multi-component eHealth intervention in a diverse group of patients that experience complex cancer pain is challenging [20]. For that reason, lessons learned from previous research were taken into account in the preparation and implementation of the current study [21,22]. Yet, what started as a multicentre randomised controlled trial was finalised as a multicentre non-randomised intervention study. Because of low inclusion numbers, possible selection bias, and high dropout rates, two amendments were needed and a shift of focus was required. As a consequence, process outcomes received more attention and effect outcomes were mainly descriptive in nature. 
For patients, different components of self-management support were important [23]. These differences appear to be related to the individual challenges faced by each patient. For some it's uncontrolled pain; for others it's unpleasant side effects; for still others it's tapering off medication; and there are patients who just feel comfortable having close contact with a nurse who looks over their shoulder. Moreover, asking patients for the supportiveness of the intervention to practice self-management resulted in mixed answers; asking patients for the supportiveness of the intervention to perform different behaviours that may be considered self-management led to more confirmatory answers. For effect evaluation purposes, not only clinical outcomes such as pain and quality of life are therefore interesting, but also more intermediate nonclinical outcomes such as self-efficacy and goal attainment [24-26].

For nurses, monitoring via the application was very similar to performing regular pain assessments, with the only major difference that nurses needed to act without actually seeing patients. The application initially offered enough information to do so and when needed the follow-up activities provided opportunities to find out more by texting, calling or seeing patients. In line with this, the home visit at baseline was very much appreciated. The introduction not only served a good pain assessment and proper start of the intervention; it enabled establishing contact, making plain agreements about what to expect from each other, and thereby creating a relationship of trust. Nurses emphasised that monitoring of these patients can only be done by experienced nurses with extra education in oncology and pain. Embedding the intervention into care as usual, involvement of treating physicians and general practitioners, and integration of the web application into electronic patient records are important and need further attention [27].

The explanation for not succeeding in the implementation of the planned protocol is probably based on a combination of factors. First, the research design led to several questions and discussions. There is no clear consensus about the most appropriate methodology for the evaluation of eHealth $[28,29]$. Randomised controlled trials are lengthy processes in a controlled set-up with a few fixed conditions; eHealth interventions go through quick developments, have a dynamic character, and offer different interactive and tailor made components [30,31]. Given that alternatives are available, the research questions needs to be decisive in choosing the right research design [32]. In this case, the process evaluation was exceptionally valuable and informative about the course of the study and the use of the intervention [33].

Second, the ease and pace of patient recruitment and inclusion are often overestimated. Department visits revealed that the staff was reluctant to recruit; contact with patients gave insights into doubts to participate. The type of intervention being an eHealth application for symptom management $[21,22]$ and the type of study being a randomised controlled trial with a care as usual control group might have affected decisions of treating physicians and patients whether or not to get involved 
[34]. Similar experiences for patient recruitment and attrition were reported by other cancer pain self-management initiatives [20].

Third, the intervention needs to fit patients' needs. Do these patients actually need self-management support? Do patients want to make use of eHealth in this respect? Does the intervention include the right components to do so? Intervention development and feasibility testing especially focused on these needs [11]. Nevertheless, patients and nurses recommended a more flexible and less rigid set-up for the intervention in order to be worthwhile for more patients, including pain monitoring less frequently, medication overviews as a reminder, information when there is a need to know, contact with the nurse only in case of questions. Selfmanagement support requires a tailor-made approach time and again [35].

\section{Conclusion}

Because of low inclusion numbers, possible selection bias, and high dropout rates, two amendments were needed and a shift of focus was required. Based on process outcomes, patients and nurses were satisfied and the eHealth intervention demonstrated added value alongside usual care for outpatient cancer pain management. Dose delivered was successful with exception of the home visit that varied in location and duration; technological flaws in both applications; and the follow-up activities by nurses that occurred less frequent and less structured then planned. Exposure showed considerable completion rates for the application of patients and confirmed the importance of giving room to nurses in carrying out the home visit at the start and selecting follow-up activities later on. Because of the intervention, patients felt encouraged in different tasks and skills that are part of selfmanagement and nurses felt assisted in monitoring and follow-up activities that are conditional to self-management support. Notwithstanding these positive findings, no conclusions can be drawn yet regarding clinical effectiveness of the intervention based on effect outcomes, due to inadequate recruitment and problematic reach. Future research and clinical practice need to consider different research designs, optimal embedding of the intervention in usual care, and further opportunities to offer a tailormade approach. 


\section{References}

1. McCorkle R, Ercolano E, Lazenby M, Schulman-Green D, Schilling LS, Lorig K, Wagner EH (2011) Self-management: enabling and empowering patients living with cancer as a chronic illness. CA Cancer J Clin 61:50-62.

2. Bodenheimer T, Lorig K, Holman H, Grumbach K (2002) Patient self-management of chronic disease in primary care. JAMA 288:2469-2475.

3. Te Boveldt N, Vernooij-Dassen M, Leppink I, Samwel H, Vissers K, Engels Y (2014) Patient empowerment in cancer pain management: an integrative literature review. Psychooncology 23:1203-1211.

4. Koller A, Miaskowski C, De Geest S, Opitz O, Spichiger E (2012) A systematic evaluation of content, structure, and efficacy of interventions to improve patients' self-management of cancer pain. J Pain Symptom Manage 44:264-284.

5. Barlow J, Wright C, Sheasby J, Turner A, Hainsworth J (2002) Self-management approaches for people with chronic conditions: a review. Patient Educ Couns 48:177-187.

6. Schumacher KL, Koresawa S, West C, Hawkins C, Johnson C, Wais E, Dodd M, Paul SM, Tripathy D, Koo P, Miaskowski C (2002) Putting cancer pain management regimens into practice at home. J Pain Symptom Manage 23:369-382.

7. Coleman MT, Newton KS (2005) Supporting self-management in patients with chronic illness. Am Fam Physician 72(8):1503-1510.

8. Adams K, Corrigan JM, eds. Institute of Medicine (2003) Priority areas for national action: Transforming healthcare quality. Washington DC: National Academies Press.

9. Murray E (2012) Web-based interventions for behavior change and self-management: potential, pitfalls, and progress. Med $2.01(2): \mathrm{e} 3$.

10. Hochstenbach LM, Courtens AM, Zwakhalen SM, Vermeulen J, van Kleef M, de Witte LP. Cancer pain self-management support: development of a technology based and nurse led intervention. Appl Nurs Res 36:1-8.

11. Hochstenbach LM, Zwakhalen SM, Courtens AM, van Kleef M, de Witte LP (2016) Feasibility of a mobile and web-based intervention to support self-management in outpatients with cancer pain. Eur J Oncol Nurs 23:97-105

12. Hochstenbach LM, Courtens AM, Zwakhalen SM, van Kleef M, de Witte LP (2015) Selfmanagement support intervention to control cancer pain in the outpatient setting: a randomized controlled trial study protocol. BMC Cancer 15, e416

13. Saunders RP, Evans $M H$, Joshi $P$ (2005) Developing a process-evaluation plan for assessing health promotion program implementation: a how-to guide. Health Promot Pract 6(2): 134-147.

14. Jensen MP (2003) The validity and reliability of pain measures in adults with cancer. J Pain $4(1): 2-21$.

15. Aaronson NK, Ahmedzai S, Bergman B, Bullinger M, Cull A, Duez NJ, Filiberti A, Flechtner $H$, Fleishman SB, de Haes JC, Kaasa S, Klee M, Osoba D, Razavi D, Rofe PB, Schraub S, Sneeuw K, Sullivan M, Takeda F (1993) The European Organization for Research and Treatment of Cancer QLQ-C30: a quality-of-life instrument for use in international clinical trials in oncology. J Natl Cancer Inst 85(5):365-376.

16. Anderson KO, Dowds BN, Pelletz RE, Edwards WT, Peeters-Asdourian C (1995) Development and initial validation of a scale to measure self-efficacy beliefs in patients with chronic pain. Pain 63(1):77-84.

17. de Wit R, van Dam F, Vielvoye-Kerkmeer A, Mattern C, Abu-Saad H (1999) The treatment of chronic cancer pain in a cancer hospital in the Netherlands. J Pain Symptom Manage 17: 333-350.

18. Bjelland I, Dahl AA, Haug TT, Neckelmann D (2002) The validity of the Hospital Anxiety and Depression Scale. An updated literature review. J Psychosom Res 52(2):69-77 
19. Hsieh HF, Shannon SE (2005) Three approaches to qualitative content analysis. Qual Health Res 15:1277-1288.

20. Koller A, Miaskowski C, De Geest S, Opitz O, Spichiger E (2013) Supporting self-management of pain in cancer patients: methods and lessons learned from a randomized controlled pilot study. Eur J Oncol Nurs 17(1):1-8.

21. Ransom S, Azzarello LM, McMillan SC (2006) Methodological issues in the recruitment of cancer pain patients and their caregivers. Res Nurs Health 29(3):190-198.

22. Berger AM, Neumark DE, Chamberlain J (2007) Enhancing recruitment and retention in randomized clinical trials of cancer symptom management. Oncol Nurs Forum 34(2):E17-22.

23. van Houtum L, Rijken M, Heijmans M, Groenewegen P (2013) Self-management support needs of patients with chronic illness: do needs for support differ according to the course of illness? Patient Educ Couns 93(3):626-632.

24. Clark N (2003) Management of chronic disease by patients. Annu Rev Public Health 24(1):289-313.

25. Ryan P, Sawin KJ (2009) The individual and family self-management theory: background and perspectives on context, process, and outcomes. Nurs Outlook: 57(4):217-225.

26. Miller WR, Lasiter S, Ellis RB, Buelow JM (2015) Chronic disease self-management: a hybrid concept analysis. Nurse Outlook 63(2):154-161.

27. Taylor S, Allsop MJ, Bekker HL, Bennet MI, Bewick BM (2016) Identifying professionals' needs in integrating electronic pain monitoring in community palliative care services: an interview study. Palliat Med:1-10

28. Baker TB, Gustafson DH, Shah D (2014) How can research keep up with eHealth? Ten strategies for increasing the timeliness and usefulness of eHealth research. J Med Internet Res 16(2):e36.

29. Mohr DC, Schueller SM, Riley WT, Brown CH, Cuijpers P, Duan N, Kwasny MJ, Stiles-Shields C, Cheung K (2015) Trials of intervention principles: evaluation methods for evolving behavioral intervention technologies. J Med Internet Res 17(7):e166.

30. Riley WT, Glasgow RE, Etheredge L, Abernethy AP (2013) Rapid, responsive, relevant (R3) research: a call for a rapid learning health research enterprise. Clin and Transl Med 2:10.

31. Patrick K, Heckler EB, Estrin D, Mohr D, Riper H, Crane D, Godino J, Riley WT (2016) The pace of technologic change implications for digital health behavior intervention research. Am J Prev Med 51(5):816-824.

32. Liu JL \& Wyatt JC (2011) The case for randomized controlled trials to assess the impact of clinical information systems. J Am Med Inform Assoc 18(2):173-180.

33. Oakley A, Strange V, Bonell C, Allen E, Stephenson J, Team RS (2006) Process evaluation in randomised controlled trials of complex interventions. BMJ 332(7538):413-416.

34. Thomson BT, Schoenfeld (2007) Usual care as the control group in clinical trials of nonpharmacologic interventions. Proc Am Thorac Soc 4:577-582.

35. Trappenburg J, Jonkman $N$, Jaarsma $T$, van Os-Medendorp $H$, Kort $H$, de Wit $N$, Hoes $A$, Schuurmans M (2013) Self-management: one size does not fit all. Patient Educ Couns 92, 134-137. 



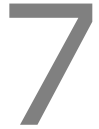

General discussion 



\section{General discussion}

The main objective of this thesis was to develop and evaluate an eHealth intervention for outpatients with moderate to severe cancer pain. The aim of the intervention was to support self-management in order to improve pain control and quality of life. Several steps were taken to realise the main objective.

Based on a systematic literature review and meta-analysis, an update was provided on the current status regarding pain prevalence in cancer. In an iterative and co-creative process, a multi-component eHealth intervention was developed with a special focus on needs and wishes of patients and health professionals. After internal testing, various aspects of feasibility were tested in a small-scale study in real life. Eventually, a multicentre randomised controlled trial (RCT) was set up to evaluate the intervention on clinical and cost effectiveness. Alongside the trial, a process evaluation was performed.

This final chapter provides a reflection on the main findings as well as some methodological and theoretical considerations. Moreover, implications for research, practice, and policy are discussed. The chapter ends with some concluding remarks.

\section{Main findings}

\section{Pain is still prevalent among patients with cancer}

Because of more attention for pain in patients with cancer, a better understanding of mechanisms underlying cancer pain, and developments in pharmacological and nonpharmacological treatment, a decrease in pain prevalence was expected compared to previous research [1]. Based on 122 articles that were published in the last 10 years, the number of patients that experience cancer pain still appears to be considerable. Pooled prevalence rates are $39.5 \%$ for patients after curative treatment, $55.0 \%$ for patients during anti-cancer treatment, $66.4 \%$ for patients with advanced disease, and $50.7 \%$ for studies that included all patients, irrespective of their disease stage. Moderate to severe pain is reported by $38.0 \%$ of patients [2]. Different organisational, professional and patient related barriers are associated with these prevalence rates [3-5]. Interventions will have to address barriers on all three levels in order to actually improve cancer pain management [6]. As a response and in line with healthcare developments, self-management support and eHealth could be meaningful for outpatients with cancer pain. 


\section{Development needs to focus on patients and health professionals}

Intervention development was performed according to key principles of user centred design (UCD) [7]. A multidisciplinary team was composed; a co-creative and iterative process was initiated; researchers and technicians collaborated to concretise conceptual ideas; patients and health professionals were consulted to gain input and evaluate output; prototypes were used to visualise solutions; and user and technical requirements were formulated, specified, and prioritised. This process resulted in a multi-component eHealth intervention that consisted of a home visit, a mobile application for patients, a web application for nurses, and several follow-up activities [8]. Looking back, the development worked out well and the outcomes are positive. Yet, there have been challenges along the process. Co-creation is extremely valuable, but difficult at times because all those involved have other interests and speak different languages [9]. Searching for commonalities requires time and effort. Iterations are necessary for continuous adjustments and improvements, but sometimes seem very open and endless. In hindsight, future project management could have been more structured and coordinated.

\section{The eHealth intervention proved feasibility in everyday practice}

Feasibility evaluation is a crucial step before use of a complex intervention in clinical and research practice [10]. In a small-scale study, thirteen patients and three nurses made use of the intervention with a four-week follow-up [11]. Findings demonstrated that patients learned to use the application quickly, practiced tasks easily, and liked to work with the application. Average completion rates were $76.8 \%$ for pain monitoring, $50.4 \%$ for medication monitoring, and $100 \%$ for education sessions. Reasons for nonadherence were either intervention related (connectivity issues, preset time frames) or patient related (forgetting to monitor, not being in the mood). Important to notice in terms of feasibility was that patients kept monitoring regardless of low or high pain levels. Nurses were positive about the intervention possibilities, though had to get acquainted to a new way of working. They had to rely on eHealth rather than face to face, on patients who had to provide them with the right information, and on treating physicians who had to consider their advises. Mixed data collection methods that covered various aspects of feasibility led to insights that were not expected explicitly on forehand and deserved further attention in following research activities.

\section{Self-management (support) was impacted by the intervention}

A two-armed multicentre RCT was set up to compare self-management support with care as usual and included an effect, cost, and process evaluation [12]. Because of low inclusion numbers, possible selection bias, and high dropout rates, two amendments were needed and a shift of focus was required. As a consequence, process outcomes 
were more valuable and received most attention. Data were collected from 66 outpatients with moderate to severe cancer pain and four registered nurses specialised in pain and palliative care. Recruitment proved very difficult and reach was quite problematic, presumably due to different factors including the recruitment strategy, the research design, the type of intervention, and the patient sample. Eventually 21 patients, who were randomly and non-randomly assigned to the intervention group, completed the 12-week study period. For them, the intervention was mostly delivered as planned, exposure was considerable, and satisfaction was high. The eHealth intervention provided a valuable combination of components for self-management by patients and self-management support by nurses. The importance of embedding the intervention in daily care practices was clearly highlighted. At the same time, the importance of opportunities to tailor the intervention based on what patients want, the situation needs and nurses prefer, was confirmed once again. Embedding and tailoring both deserves further attention in future research and clinical practice. Due to the small sample size (low inclusion numbers, high dropout rates) and protocol amendments (one group, no randomisation), statistical testing of differences between groups and over time would be inaccurate. Therefore, the study allows no conclusions on clinical effectiveness of the intervention. Yet, an indication of possible effects was seen in the intervention group for primary (pain and quality of life) and secondary (self-efficacy, knowledge, and anxiety and depression) outcomes.

\section{Methodological considerations}

This section addresses some methodological strengths and limitations of the studies performed in this thesis and focuses on the following issues: the measurements and assessment of cancer pain; the focus on patients and their needs and wishes; and the evaluation of eHealth interventions.

\section{Measurement and assessment of cancer pain}

The assessment of pain and the cut-off values for the categorisation of pain intensity are topic of ongoing discussions. Studies report on different definitions of mild, moderate and severe pain or give no definition at all. The most used cut-off values are mild (NRS 1-3), moderate (NRS 4-6), and severe (7-10) [13]. In this project, these cut-off values were applied to make comparisons in the systematic review and metaanalysis and to draw conclusions in the feasibility and impact evaluation. Moreover these values are integrated in the intervention. During the home visit, pain education was provided in which an NRS 4 was explained as a value indicative for nurses to act upon. The application for patients included a graph with a dashed line on NRS 4 to provide patients insight into how their own pain related to what is treated as 
acceptable pain. The algorithm that raised coloured flags in the application for nurses was based on an NRS 4. Taking other cut-off values might have resulted in interpreting, intervening, and concluding differently. In contrast to these general and fixed cut-off values, however, the subjectivity of the pain experience might even better be captured in individual and flexible cut-off values that are considered acceptable by patients themselves.

At the same time, it is questionable whether a single measure is appropriate for pain measurement. Patients often find it hard to express their pain in a figure, especially without regularly doing this and not being able to use their own pain as a reference. The revised Dutch clinical practice guideline on cancer pain includes clear recommendations to assess pain as a multidimensional symptom and to make use of scales to assess the influence of pain on daily functioning [14]. By doing so, pain becomes more concrete and it is easier for patients to reflect upon. Pain also becomes less medical and more linked to daily life [15], which probably opens up opportunities for patient self-management. The eHealth intervention, more specifically the application for patients, includes these ideas as well and asks patients for pain interference: in the morning patients are asked about the impact of pain on their sleep and in the evening patients can describe the impact of the pain on their daily activities. For the assessment and management of cancer pain in general, goal setting in terms of being able to go out for a walk again could be much more valuable to patients then getting pain from an NRS 7 to an NRS 4 .

The intervention focused specifically on cancer pain. Pain assessment asked patients for pain and adverse effects of pain medication. This delineation appeared to be a true challenge for nurses. To focus only on pain, while pain never stood alone, felt inadequate. To let patients decide whether their symptoms are linked to pain or pain medication, while in-depth questioning was needed, felt unrealistic. To conclude that symptoms are not pain or pain medication related and refer patients, while some nurse advice could have been beneficial, felt inaccurate. Delineation is also associated with expectations of patients [16]. What do patients expect from the intervention? What do and don't they tell? In what situations do they rely on the nurse? When do they contact the treating physician or general practitioner instead? Special attention was paid to these expectations during the instructions as part of the home visit. Yet, it's questionable how patients make sense of this. Nurses suggested that the idea that there was an iPad, and a nurse, might have created unintended expectations and thereby obligations. For patients, pain is one of the many symptoms they have to manage together with the questions and uncertainties that their situation brings along. Compared to the intervention, face-to-face contact creates more room for a broader perspective and these types of interventions need to complement rather then replace face-to-face contact $[17,18]$. 


\section{Focus on patients and their wishes and needs}

Patient involvement in intervention development is extremely important for a close fit between patient needs and intervention possibilities [19]. This may even apply the most when the intervention targets patients you rather want to burden the least. UCD principles give direction without shutting out possibilities. Intervention development needs to be performed by a multidisciplinary team in an incremental and iterative process that is customised to a particular organisation or project and with a strong focus on the user and usability [7]. As continuous involvement is intensive and requires quite some efforts from patients, an optimal format was searched for in this project. Individual patients were asked only once (each time other patients were invited) and when needed the most (at the start to gain input; and at the end to evaluate output). Apart from that, health professionals experienced in pain and palliative care and familiar with the patients' home situation, articulated patients ideas and experiences. Overall, this format for involvement of patients in the development process as well as their representation by health professionals was satisfactory. Optionally, more patients could be consulted. More mixed contributions would have offered a more comprehensive reflection of the diversity in patients' wishes and needs, as experienced during the evaluations. Moreover, patients could be involved more frequently. Not only at the start and the end, but also in between, larger patient involvement would have been meaningful for adjustments to the intervention.

Although patient and nurse perspectives were clearly included in the intervention development process, evaluations showed that patients have unique needs and nurses have their own preferences. Patients, for example, had different opinions regarding the frequency of monitoring. On days with many pain fluctuations, frequent monitoring was considered useful. When pain levels were stable, monitoring sometimes caused an unnecessary focus on pain. Nurses, for instance, struggled with the follow-up activities. At times they felt they could have done more, which caused some friction between what research allowed and what practice needed. Aside from this, situations sometimes required a different approach than what the protocol prescribed. Patients and nurses recommended a more flexible and less rigid set-up for the intervention (pain monitoring less frequently, medication overviews as a reminder, information when there is a need to know, contact with the nurse in case of questions), in order to be worthwhile for more patients. Self-management support requires a tailor-made approach time and again $[20,21]$. A modular setup within the intervention, including for instance a pain module, a fatigue module, and a nausea module, provides patients with opportunities to make self-management and self-management support as small or as big as needed and preferred. 


\section{Evaluation of eHealth interventions}

Recruitment of oncological patients in any study can be challenging and even asks for more efforts when the study involves symptom management rather than disease treatment $[22,23]$. During the RCT, recruitment was inadequate and reluctance was seen. Recruitment logs showed that from each 100 patients screened, roughly half were invited into the study and about a quarter decided to participate. Department visits revealed that patients were considered ineligible for different reasons. Treating physicians and nursing staff decided, without consultation, that patients were too ill; had already a lot on their minds; or experienced pain but not that badly or not due to cancer. They were also concerned that some patients were unable to use an iPad or understand the purpose of the intervention. Yet, another reason for treating physicians and nurses not to ask patients had to do with the research design and, more specifically, with the control group. Requesting their patients to fill out questionnaires and offering nothing in return evoked resistance. Patients struggled with randomisation as well. Telephone contact with invited patients revealed that on the one hand patients were very willing to do something about their pain, but didn't want to be assigned to the control group (they choose not to participate); and on the other patients wanted to be of significance to future patients by filling out questionnaires, but were not interested in the intervention group (they also choose not to participate). Based on all these assumptions, a selection of 'better' patients might have been made, with possible consequences for (generalisability of) process and effect outcomes. However, considering the high dropout rates due to illness, hospital admission or death, selection bias was probably not much of an issue.

The RCT is considered the ultimate research design for the evaluation of interventions, as the impact is estimated by direct comparison with a randomly allocated control group through which outcome differences can only be attributed to the intervention [24]. Because of these features, however, the RCT might be less appropriate for the evaluation of eHealth [25]. First, evaluation with an RCT is usually a lengthy process. As technological developments and advances progress quickly, interventions are often not innovative and the results not relevant anymore when the evaluation comes to an end [26]. Research therefore needs to focus not only on a particular intervention with a specific technology, but should also address the theories that underlie the intervention and technology [27]. To clarify, in this project there was interest in both the impact of the applications as well as the appropriateness of the conceptual framework for self-management and self-management support. Second, evaluation with an RCT typically has a protocolled and standardised setup. Adjustments in the design or intervention are not desirable during the course of an $\mathrm{RCT}$, because all these variations make direct comparison between the intervention and control group hardly possible. Complex eHealth interventions best achieve their potential when adjustments are allowed, tailored to the needs and wishes of patients 
and to daily practices at home and the hospital. For these reasons, alternatives are listed with shorter studies, smaller samples, and continuously improved interventions [25]. Adaptive designs such as Multiphase Optimisation Strategies (MOST) and Sequential Multiple Assignment Research Trials (SMART) are valuable for research questions that involve combinations or sequences of intervention components [28]. In MOST different intervention components are selected (screening phase), fine tuned (refining phase), and evaluated (confirmation phase). SMART includes multiple stages in which patients are randomly allocated to different intervention options in each next phase based on their responsiveness in the previous phase. In addition, with the evaluation of eHealth interventions large databases with rich information are created. Big data provide new opportunities for research purposes [27]. In this project the back-office of the applications contains data to answer important research questions, for instance about the course of pain or about the correlation between side effects and pain medication intake, without active data collection by means of questionnaires, observations or interviews.

\section{Theoretical considerations}

In this section some theoretical consideration will be discussed in relation to the interpretation of the results. The following issues that were present to a greater or lesser extent during the entire project will be mentioned: the definition of selfmanagement, intervention components to support self-management, and the operationalisation of self-management in terms of outcomes measures.

\section{The definition of self-management}

Self-management is mostly defined as "a person's ability to manage the symptoms and the consequences of living with a chronic condition, including treatment, physical, social, and lifestyle changes" [29]. The application of this definition to the situation of cancer pain results in several tasks and skills. Patients who experience pain are encouraged, among other things, to be aware of their continuous and average pain and to take 'around the clock' medication on time; to anticipate on breakthrough pain and take 'as needed' medication in time; to take co-medication in case of side effects from pain medication such as nausea and constipation; to be informed for a better understanding of pain; to bring pain out into the open; to ask for support from informal caregivers; to contact formal caregivers in case of help requests; to share their ideas and bring in their 'hands on expertise'; to discover what makes the pain better or worse; to be in control. Just like cancer pain, self-management is different for every individual patient, depending on what is needed and what is someone 
capable of and willing to do. The issue is not so much 'whether' but more 'how' patients perform self-management [30].

\section{Intervention components of self-management support}

In general, best practice is to develop interventions systematically, using appropriate theory and the best available evidence [10]. At the time of intervention development no theoretical framework about self-management support for cancer pain was available. Theories about self-management for chronic conditions [29,31,32] and evidence about interventions for cancer pain [33-36] were considered, components were screened to the characteristics of outpatients with cancer pain and a selection was made. Three tasks (medical management, role management, and emotional management) and six skills (problem solving, decision making, resource utilisation, formation of a patient-provider partnership, action planning, and self-tailoring) are linked to self-management $[31,37]$. How to optimally support these tasks and skills? Looking at components important to patients with chronic conditions in general and translating these to the situation of patients with cancer pain, as described above, we selected the following five components: information, skills, insight, self-efficacy, and a supportive environment [30,31,38-40]. The involvement of patients and health professionals during intervention development provided good opportunities both to verify as well as to shape and give meaning to these components. The present intervention provides patients with information to improve knowledge and understanding. Important skills for patients to implement, such as pain and medication monitoring, making appropriate decisions, and carrying out subsequent actions, are continuously encouraged by means of pain diaries, medication overviews, and insight via graphical feedback. Being looked after by nurses needs to enable patients to practice their skills and to become more self-efficacious. Collaboration of nurses with the treating physician should further contribute to this supportive environment.

\section{The operationalisation of self-management}

Self-management is not an endpoint or outcome, but a process that affects and results in particular outcomes [41]. What outcome measures are adequate? What is benefit in this case? Self-management finds meaning in behaviours that improve outcomes such as clinical measures or quality of life [42,43]. However, the appropriateness of clinical outcomes for the evaluation of these types of interventions is an element of discussion. Clinical outcomes might be more significant for health professionals, but less relevant for patients. To illustrate, pain and quality of life were the primary effect outcomes for the RCT. Patients assigned to the intervention group sometimes revealed different goals and for them other outcomes counted. For some 
acceptable pain levels were most important ("I want to get rid of the pain"), for others it was less impact from side effects ("I prefer pain over being sleepy and drowsy"), and for still others it was phasing out medication ("I don't want to take that stuff anymore") or feeling reassured and being more in control ("I can't do this on my own"). So by the measurement of only pain and quality of life, actual outcomes are easily missed. Both outcomes are difficult to capture in any event due to their multifaceted and subjective nature [44]. Assessing pain related knowledge and pain self-efficacy were added as secondary effect outcomes. Moreover, openly asking patients for the benefits they experienced from the intervention, as part of the process evaluation, was useful and gave new insights. Goal attainment of individual goals that patients set together with the nurse could be informative in future studies.

\section{Implications}

Interventions to better control cancer pain continue to be a matter of concern. This section addresses implications of this thesis for future research, clinical practice, and policymaking.

\section{Future research}

The findings of this thesis have important implications for future research. The development of an intervention that provides effective solutions for existing health problems definitely requires patient involvement. Continuous involvement is intensive and requires quite some efforts from patients. An optimal and reasonable format needs to be searched for with regard to timing, frequency, and role. Considering the participation ladder, there are different methods to include patient perspectives in research: informing, consulting, engaging, co-designing and co-producing [45].

The eHealth intervention offers many opportunities for further development for which a modular setup needs to be considered and feasibility testing needs to be included. Patients' wish list for improvements included the possibility of monitoring symptoms other than pain and of medication other than pain medication. In terms of refinements, the intervention could support self-management more tailored by different frequencies of monitoring, variation in diary questions, education based on diary answers, and adaptive time slots. In terms of context, different health professionals might be able to fulfil the role of the registered nurse in other settings, for instance a pharmacist or practice nurse. Extra education in pain and palliative care would be a prerequisite.

There seems to be a mismatch between RCT characteristics (lengthy process, fixed procedures) and features of complex eHealth interventions (quick advancements, multiple components, tailor-made approaches) [25-27]. The research question needs 
to guide the selection of an appropriate research design; practical and ethical aspects need to be taken into account in parallel [46]. Although considered a valid design for effect evaluation, the RCT has it's limits and alternatives are available. In case the RCT turns out to be the preferred option, thought needs to be given to the recruitment strategy and an appealing control group. To speed up inclusion rates and prevent a selection of 'better patients', recruitment is best performed by someone not directly involved in patient care. The control group could either be included simultaneously by a care as usual plus or waiting list control group, or involved at an earlier or later stage.

For evaluation purposes, appropriate outcomes measures need to be selected. To prove the added value of interventions to support self-management, clinical measures or quality of life are often used. Self-efficacy receives more and more attention. Researchers and health professionals though might aspire different goals and outcomes then patients do. The actual impact of the intervention is easily missed in that case. Intervention development and feasibility testing together with patients can provide useful input for the selection of appropriate outcome measures. By an extensive process evaluation, insight can be gathered into outcomes that are not expected on beforehand.

\section{Clinical practice}

This thesis adds that there is still much to gain in the management of pain in outpatients with cancer. Because of the enormous impact on quality of life, pain needs to be discussed systematically in each consultation. Asking patients how they are doing is important, but how they experience pain, what the daily impact is of pain and what they want to change or accomplish with pain treatment offers more valuable information. On this basis, appropriate follow-up is possible and tailor made support can be offered.

Although pain is prevalent in all stages of the disease, pain is often only assessed and treated in patients with advanced cancer. During the evaluations, patients with uncontrolled pain revealed previous insecurities and unawareness regarding pain and wished they would have known what they know today. Active patient involvement and appropriate support in earlier stages is recommended. By doing so, patients better know what to expect and what they can do themselves. Self-management support through the eHealth intervention could be a meaningful means to an end.

Implementation of eHealth is stimulated, opportunities for blended care arise, and patients face new applications. Some patients are very interested and skilled in the use of digital means; others are not that enthusiastic and lack experience. Because of these differences, it's extremely important to keep interventions basically simple, to provide clear instructions at the start, and to establish a help desk. Off course, not all 
will follow eHealth trends in the end. Yet, when some patients do and benefit, it might be worthwhile and possibly result in more time and attention for other patients.

\section{Policymaking}

The revised Dutch clinical practice guideline on cancer pain (2015) is updated with a module about self-management that provides an answer on the key question "How do health professionals enable patients to manage their cancer pain independently?" [14]. Recommendations include inviting patients to take control, informing them and teaching them skills that are necessary to take control, making plain agreements with all involved health professionals and pointing a first contact, writing everything down in the patient health record, and periodic following-up self-management. eHealth is only mentioned once, as important to future care without any further information, examples or recommendations. Although relatively new with limited evidence for patients with cancer (pain), eHealth seems to be promising in overcoming current barriers. For that reason, health professionals should be further encouraged to support self-management and look for eHealth applications that facilitate this process. More attention for this topic is in any case needed in medical, nursing, and professional training to create awareness and trust.

For innovations to become usual care and reimbursed, effectiveness and costeffectiveness need to be proven. This is a challenge for eHealth because of short-term and long-term as well as direct and indirect effects that are not easy to capture. The Dutch government acknowledges a lack of eHealth implementation [47]; the Dutch Cancer Society calls for better care for patients who experience early and late effects [48]. Health insurance companies need to revise agreements on financial reimbursements to stimulate implementation of eHealth applications and to improve care for patients with cancer.

\section{General conclusion}

Pain continues to be prevalent and distressing in patients with cancer. Active patient involvement is required to improve outcomes, for which support necessarily needs to be arranged. eHealth offers an excellent means to provide self-management support. The process of development, feasibility, and evaluation as described in this thesis provided interesting insights and was especially informative in situations that did not turn out as planned. Although no final conclusions can be drawn regarding clinical effectiveness based on effect outcomes, process outcomes were positive and the intervention demonstrated added value alongside usual care for outpatient cancer pain management. The intervention encouraged patients in different tasks and skills that are part of self-management and assisted nurses in monitoring and follow-up activities 
that are conditional to self-management support. Many ideas and opportunities for improvement have been articulated, for which the intervention needs and deserves further exploration in order to enable future patients to actually take control over their cancer pain. 


\section{References}

1. van den Beuken-van Everdingen $M H$, de Rijke JM, Kessels AG, Schouten HC, van Kleef M, Patijn J (2007) Prevalence of pain in patients with cancer: a systematic review of the past 40 years. Ann Oncol 18:1437-1449.

2. Van den Beuken-van Everdingen MH, Hochstenbach LM, Joosten EA, Tjan-Heijnen VC, Janssen DJ. (2016) Update on prevalence of pain in patients with cancer: systematic review and metaanalysis. J Pain Symptom Manage 51(6):1070-1090.

3. Jacobsen R, Moldrup C, Christrup L, Sjogren P (2009) Patient-related barriers to cancer pain management: a systematic exploratory review. Scand J Caring Sci 23:190-208.

4. Luckett T, Davidson PM, Green A, Boyle F, Stubbs J, Lovell M (2013) Assessment and management of adult cancer pain: a systematic review and synthesis of recent qualitative studies aimed at developing insights for managing barriers and optimizing facilitators within a comprehensive framework of patient care. J Pain Symptom Manage 46:229-253.

5. Oldenmenger WH, Sillevis Smitt PA, van Dooren S, Stoter G, van der Rijt CC (2009) A systematic review on barriers hindering adequate cancer pain management and interventions to reduce them: a critical appraisal. Eur J Cancer 45:1370-1380.

6. Kwon JH (2014) Overcoming barriers in cancer pain management. J Clin Oncol 32:1727-1733.

7. Gulliksen J, Göransson B, Boivie I, Blomkvist S, Persson J, Cajander A (2003) Key principles for user-centered systems design. Behav Inform Technol 22:397-409.

8. Hochstenbach LM, Courtens AM, Zwakhalen SM, Vermeulen J, van Kleef M, de Witte LP. Cancer pain self-management support: development of a technology based and nurse led intervention. Applied Nursing Research. Accepted.

9. Vermeulen J, Verwey R, Hochstenbach LM, van der Weegen S, Man YP, de Witte LP (2014) Experiences of multidisciplinary team members during user-centered design of telecare products and services: a qualitative study. J Med Internet Res 16(5):e124.

10. Craig P, Dieppe P, Macintyre S, Michie S, Nazareth I, Petticrew M (2013) Developing and evaluating complex interventions: the new Medical Research Council guidance. Int J Nurs Stud 50:587-592.

11. Hochstenbach LM, Zwakhalen SM, Courtens AM, van Kleef M, de Witte LP. (2016). Feasibility of a mobile and web-based intervention to support self-management in outpatients with cancer pain. Eur J Oncol Nurs 23:97e105

12. Hochstenbach LM, Courtens AM, Zwakhalen SM, van Kleef M, de Witte LP (2015). Selfmanagement support intervention to control cancer pain in the outpatient setting: a randomized controlled trial study protocol. BMC Cancer 15:e416.

13. Serlin RC, Mendoza TR, Nakamura Y, Edwards KR, Cleeland CS (1995) When is cancer pain mild, moderate or severe? Grading pain intensity by its interference with function. Pain 61: 277-284.

14. Netherlands Comprehensive Cancer Organisation (IKNL) (2016) Pain: National guideline, version 2.1.

15. Te Boveldt N, Vernooij-Dassen M, Burger N, Ijseldijk M, Vissers K, Engels Y (2013) Pain and its interference with daily activities in medical oncology outpatients. Pain Physician 16(4): 379-389.

16. Taylor J, Coates E, Brewster L, Mountain G, Wessels B, Hawley MS (2014) Examining the use of telehealth in community nursing: identifying the factors affecting frontline staff acceptance and telehealth adoption. J Adv Nurs 71:326-337.

17. MacNeill V, Sanders C, Fitzpatrick R, Hendy J, Barlow J, Knapp M, Rogers A, Bardsley M, Newman SP (2014) Experiences of front-line health professionals in the delivery of telehealth: a qualitative study. Br J Gen Pract 64(624):e401-407.

18. Huygens MW, Vermeulen J, Swinkels IC, Friele RD, Schayck OC, de Witte LP (2016) Expectations and needs of patients with a chronic disease toward self-management and eHealth for self-management purposes. BMC Health Serv Res 16:232.

19. Shah SG, Robinson I (2007) Benefits of and barriers to involving users in medical device 
technology development and evaluation. Int J Technol Assess Health Care 23:131-137.

20. Trappenburg J, Jonkman N, Jaarsma T, van Os-Medendorp H, Kort H, de Wit N, Hoes A, Schuurmans M (2013) Self-management: one size does not fit all. Patient Educ Couns 92: 134-137.

21. van Houtum L, Rijken M, Heijmans M, Groenewegen P (2013) Self-management support needs of patients with chronic illness: do needs for support differ according to the course of illness? Patient Educ Couns 93:626-632.

22. Ransom S, Azzarello LM, McMillan SC (2006) Methodological issues in the recruitment of cancer pain patients and their caregivers. Res Nurs Health 29(3):190-198.

23. Berger AM, Neumark DE, Chamberlain J (2007) Enhancing recruitment and retention in randomized clinical trials of cancer symptom management. Oncol Nurs Forum. 34(2):E17-22.

24. Eccles M, Grimshaw J, Campbell M, Ramsay C (2003) Research designs for studies evaluating the effectiveness of change and improvements strategies. Qual Saf Health Care 12(1):47-52.

25. Riley WT, Glasgow RE, Etheredge L, Abernethy AP (2013) Rapid, responsive, relevant (R3) research: a call for a rapid learning health research enterprise. Clin Transl Med 10(1):10.

26. Patrick K, Hekler EB, Estrin D,3 Mohr DC,4 Riper H, Crane D, Godino J, Riley WT (2016) The pace of technologic change: implications for digital health behaviour intervention research. Am J Prev Med 51(5):816-824

27. Baker TB, Gustagson DH, Shah D (2014) How can research keep up with eHealth? Ten strategies for increasing the timeliness and usefulness of eHealth research. J Med Internet Res 16(2):e36.

28. Collins LM, Murphy SA, Strecher V (2007) The multiphase optimization strategy (MOST) and the sequential multiple assignment randomized trial (SMART): new methods for more potent eHealth interventions. Am J Prev Med 32(5):S112-118.

29. Barlow J, Wright C, Sheasby J, Turner A, Hainsworth J (2002) Self-management approaches for people with chronic conditions: a review. Patient Educ Couns 48:177-187.

30. Bodenheimer T, Lorig K, Holman H, Grumbach K (2002) Patient self-management of chronic disease in primary care. JAMA 288:2469-2475.

31. Lorig KR, Holman H (2003) Self-management education: history, definition, outcomes, and mechanisms. Ann Behav Med 26:1-7.

32. Richard AA, Shea K (2011) Delineation of self-care and associated concepts. J Nurs Scholarsh 43:255-264.

33. Allard P, Maunsell E, Labbe J, Dorval M (2001) Educational interventions to improve cancer pain control: a systematic review. J Palliat Med 4:191-203.

34. Devine EC (2003) Meta-analysis of the effect of psychoeducational interventions on pain in adults with cancer. Oncol Nurs Forum 30:75-89.

35. Bennett MI, Bagnall AM, Jose Closs S (2009) How effective are patient-based educational interventions in the management of cancer pain? Systematic review and meta-analysis. Pain 143:192-199.

36. Koller A, Miaskowski C, De Geest S, Opitz O, Spichiger E (2012) A systematic evaluation of content, structure, and efficacy of interventions to improve patients' self-management of cancer pain. J Pain Symptom Manage 44:264-284.

37. Corbin JM, Strauss A (1998) Unending work and care: managing chronic illness at home. Jossey-Bass; San Francisco, CA.

38. Holman H, Lorig K (2004) Patient self-management: a key to effectiveness and efficiency in care of chronic disease. Public Health Rep 119:239-243.

39. Wilde MH, Garvin S (2007) A concept analysis of self-monitoring. J Adv Nurs 57:339-350.

40. Porter LS, Keefe FJ, Garst J, McBride CM, Baucom D (2008) Self-efficacy for managing pain, symptoms, and function in patients with lung cancer and their informal caregivers: associations with symptoms and distress. Pain 137:306-315.

41. Miller WR, Lasiter S, Ellis RB, Buelow JM (2015) Chronic disease self-management: a hybrid concept analysis. Nurs Outlook 63(2):154-161. 
42. Clark N (2003) Management of chronic disease by patients. Annual Review of Public Health. 24(1):289-313.

43. Ryan $P$, Sawin $K$ (2009) The individual and family self-management theory: Background and perspectives on context, process, and outcomes. Nurs Outlook 57(4):217-225.

44. Youner J, McCue R, Mackey S (2010) Pain outcomes: a brief review of instruments and techniques. Curr Pain Headache Rep 13(1):39-43.

45. Dutch Cancer Society (KWF Kankerbestrijding) (2011) Patient participation. Available from www.kwf.nl/onderzoek/denk-mee-over-onderzoek/Pages/Achtergrondinformatiepatiëntenpartcipatie.aspx. Accessed December 20, 2016.

46. Liu JL, Wyatt JC (2011) The case for randomized controlled trials to assess the impact of clinical information systems. J Am Med Inform Assoc 18(2):173-180.

47. Krijgsman J, Swinkels I, van Lettow B, de Jong J, Out K, Friele R, van Gennip L (2016) eHealth-monitor 2016. Meer dan techniek. Nictiz, Den Haag. Nivel, Utrecht.

48. Dutch Cancer Society (2011) Nazorg bij kanker: De rol van de eerste lijn. KWF Kankerbestrijding, Amsterdam. 

Summary

Samenvatting

\section{Valorisation}





\section{Summary}

For many patients cancer pain is an important source of concern. Particularly in the outpatient setting, pain management is a major challenge. In response to and in line with developments in healthcare, supporting self-management and implementing eHealth could be meaningful for these patients as well. This project was initiated for the development and evaluation of an eHealth intervention for outpatients with moderate to severe cancer pain. The aim of the intervention was to support selfmanagement in order to improve pain control and quality of life. In that context a number of studies were conducted and are presented in this thesis.

\section{Chapter 1}

In this chapter the general introduction for this thesis is described. Background information regarding cancer pain is provided. Moreover, a description of regular care informs about the methods that are used to detect, assess, and treat pain complaints. It is well known that inadequate pain relief can be attributed to different barriers. Existing interventions and further recommendations are shared. In that context, the concepts 'self-management' and 'eHealth' are clarified. This chapter ends with the objectives and outline of this thesis.

\section{Chapter 2}

This chapter contains a systematic literature review with a meta-analysis that was conducted to determine the prevalence of cancer pain; the prevalence of moderate to severe cancer pain; and the determinants that are associated with cancer pain. A total of 122 articles were selected and categorised into groups based on disease stage: patients after finishing curative treatment (group 1); patients receiving anti-cancer treatment, with curative or palliative intention (group 2); patients with advanced, metastatic and/or terminal disease (group 3); all patients regardless of their disease stage (group 4).

Pain is prevalent in $39.5 \%$ of the patients in group 1 ; in $55.0 \%$ of the patients in group 2 ; in $66.4 \%$ of the patients in group 3; and in $50.7 \%$ of the patients in group 4 . Patients in group 3 experience significantly more pain compared to patients in group 1 and 2. Patients in group 2 experience significantly more pain compared to patients in group 1. Moderate to severe pain is prevalent in $27.6 \%$ of patients in group 1 ; in $32.4 \%$ of patients in group 2 ; in $51.9 \%$ of patients in group 3 ; and in $33.1 \%$ of the patients in group 4 . Patients in group 3 experience significantly more moderate to severe pain compared to patients in group 1 and 2 .

Studies from Asia show higher prevalence rates compared to studies from Europe. Patients with prostate cancer report less pain compared to patients with head-neck, 
lung-, and breast cancer. Patients with a limited performance status experience more pain compared to patients with a normal performance status. Recall periods of a month or a year result in higher pain prevalence rates compared to recall periods of a week or a point in time. Age, race or data collection method are not associated with pain prevalence. Cancer pain continues to be a significant problem.

\section{Chapter 3}

The match between wishes and needs of patients and health professionals is essential for successful eHealth interventions. Intervention development was carried out based on key principles of user centred design (UCD) and is reported on in this chapter. A multidisciplinary team was composed; a co-creative and iterative process was initiated; researchers and technicians collaborated to concretise conceptual ideas; patients and health professionals were consulted to gain input and evaluate output; prototypes were used to visualise solutions; and user and technical requirements were formulated, specified, and prioritised.

The outcome of this process is an intervention consisting of a home visit, a mobile application for patients, a web application for nurses, and follow-up activities. During the home visit the nurse performs a pain assessment, checks pain medication, and provides information about pain. The main researcher gives instructions about the application and discusses expectations. Throughout the intervention period, patients make use of the intervention on a daily basis. Pain is monitored every morning and evening by means of a diary; medication intake is registered with a personalised day schedule; a graph with pain intensity scores and mediation intakes provides insight; information about pain is presented in knowledge sessions; in case of questions or remarks there is contact with the nurse via text messages.

Nurses enter the web application every workday and take note of completed diaries, medication intakes, and text messages. The nurse informs the treating physician, when needed and on a regular basis. Nurses can rely upon advices of the pain specialist or multidisciplinary team. This advice is reported to the treating physician who decides on follow-up.

\section{Chapter 4}

Small-scale feasibility evaluation in everyday life is a crucial step in the development and testing of complex interventions and is dealt with in this chapter. In the current study, thirteen patients and three nurses made use of the intervention with a followup of 4 weeks.

Questionnaire findings show that patients learned to use the application quickly, practiced tasks easily, and liked to work with the application. Average completion rates, as recorded in server logs, were $76.8 \%$ for pain monitoring, $50.4 \%$ for 
medication monitoring, and $100 \%$ for education sessions. Important in terms of feasibility is that most patients kept monitoring regardless of low or high pain intensity scores. Interviews reveal that patients valued and made use of different intervention components. Some indicate that the diaries create some kind of awareness each time; others preferred the reminders in order to not forget their medication; still others were enthusiastic about the nurse who is always looking over their shoulder.

Nurses were positive about the intervention, though had to get used to a new way of working. They had to rely on eHealth rather than face to face, on patients who had to provide them with the right information, and on treating physicians who had to consider their advises. In general study results confirm feasibility of the intervention in every day practice. Provided that substantive and technical adjustments were made, the intervention had the potential to contribute to self-management (support) of cancer pain.

\section{Chapter 5}

This chapter describes the protocol of a large-scale randomised and controlled study to compare self-management support with care as usual. The study would include an effect, cost, and process evaluation and was initially planned and organised as follows:

'Recruitment of the necessary 174 patients is performed via outpatient oncology clinics and inpatients oncology wards of one academic and one regional hospital. Patients are eligible when they are diagnosed with cancer (all stages of the disease), have moderate to severe pain (NRS $\geq 4$ for $>2$ weeks), and a life expectancy of $>3$ months. Random allocation (1:1) assigns patients to either the intervention or control group. Patients in the intervention group will receive self-management support by means of the eHealth intervention; patients in the control group will receive care as usual. The intervention is delivered by registered nurses specialised in pain and palliative care.

Effect measurements for both groups will be carried out with questionnaires at baseline (T0), after 4 weeks (T1), and after 12 weeks (T2). Pain and quality of life are primary outcomes. Secondary outcomes are knowledge, self-efficacy, anxiety and depression, and medication use. The final questionnaire contains also questions for the cost evaluation. Data for the process evaluation will be gathered continuously in both groups during the study using logbooks, log files, and checklists. After the intervention, semi-structured interviews will be performed with patients in the intervention group and at the end of the study a focus group interview with nurses.' 


\section{Chapter 6}

This chapter presents the results of the randomised and controlled study and particularly provides insight into the course of the study and process outcomes. Eventually, three phases can be distinguished.

The study kicked off in two centres (phase 1a) and was then extended to four centres (phase 1b) with at random allocation to the intervention or control group. Because the intervention was performed as part of the medical treatment contract, treating physicians were designated to recruit patients. In practice recruitment was often delegated to the nursing staff. Printed folders and recruitment cards were offered; screening lists and a trial agency were used; presentations and recruitment updates were distributed. Despite all efforts, inclusion rates continued to lag behind. The most important reason for treating physicians not to recruit was 'not being eligible', the most frequent mentioned reason for patients not to participate was 'being too ill'. Different factors probably affected recruitment including the recruitment strategy, the research design, the type of intervention, and the patient sample.

Because of low inclusion numbers, possible selection bias, and high dropout rates the study was continued with allocation to the intervention group only (phase 2). A total of 66 patients gave informed consent and 54 patients actually started. Patients were on average 62.4 years, $59.3 \%$ was male and $83.3 \%$ received anti-tumour treatment with palliative intent. Ultimately, 47 patients filled out the in-between measurement and 32 patients completed the entire study period. Due to the final protocol amendment, the focus of the study shifted from a comparison between the eHealth intervention and care as usual to the impact of the eHealth intervention. As a consequence process outcomes were more valuable and received more attention.

Based on semi-structured interviews with 21 patients and a focus group interview with four nurses, experiences have been inventoried. Some variation was seen both in the implementation of the home visit as well as in the selection of follow-up activities, partly caused by the situation of patients and the work routines of nurses. Patients appreciated the introduction and nurses were positive about the pragmatic approach. Technical flaws made the applications slow or stalling at times. In general, patients were satisfied, which is reflected in the average completion rates of pain monitoring (78.8\%), medication monitoring (65.5\%), and education sessions (100\%). Patients differ in their answers as to what extent the intervention supported them in their selfmanagement, though confirm in many cases that the intervention helped them in increasing awareness, taking medication on time, getting insight, learning about pain and the treatment of pain, and discussing pain with their treating physician. Nurses underline that this or a similar intervention could complement usual care for outpatients with cancer pain. Notwithstanding these positive findings, no conclusions can be drawn yet regarding clinical effectiveness of the intervention based on effect outcomes, due to the small sample size and the protocol amendments. 


\section{Chapter 7}

Finally, the general discussion provides a reflection on the main findings and addresses some methodological considerations that focus on the measurement and assessment of cancer pain; the focus on patients and their needs and wishes; and the evaluation of eHealth interventions. Moreover, theoretical considerations are discussed in terms of the definition of self-management; intervention components of selfmanagement support; and the operationalisation of self-management. The chapter concludes with some implications for practice, research, and policy. 



\section{Samenvatting}

Pijn bij kanker is voor veel patiënten een belangrijke bron van zorgen. De behandeling van pijn vormt met name in de thuissetting een grote uitdaging. In reactie op en in lijn met ontwikkelingen in de gezondheidszorg kan het ondersteunen van zelfmanagement en de inzet van eHealth ook voor deze patiënten van betekenis zijn. Dit project gaat over het ontwikkelen en evalueren van een eHealth interventie voor oncologie patiënten met matige tot ernstige pijn. Het doel van de interventie is het ondersteunen van zelfmanagement om zo bij te dragen aan minder pijn en meer kwaliteit van leven. In dat kader zijn een aantal studies uitgevoerd die in dit proefschrift achtereenvolgens worden beschreven.

\section{Hoofdstuk 1}

In de algemene introductie wordt de aanleiding voor dit proefschrift geschetst. Achtergrond informatie wordt gegeven over pijn bij kanker. Dan volgt een beschrijving van de reguliere zorg waarbij stil wordt gestaan bij de manier waarop pijnklachten op dit moment worden gesignaleerd, beoordeeld en behandeld. Het is bekend dat inadequate pijnstilling kan worden toegeschreven aan verschillende barrières. Bestaande interventies en verdere aanbevelingen worden vervolgens gedeeld. In dat kader worden ook de concepten 'zelfmanagement' en 'eHealth' toegelicht. Dit hoofdstuk sluit af met de doelstelling en opzet van dit proefschrift.

\section{Hoofdstuk 2}

Dit hoofdstuk beschrijft de resultaten van een systematisch literatuur onderzoek met een meta analyse die werd uitgevoerd om vast te stellen hoe vaak pijn bij kanker voorkomt; hoe vaak pijn bij kanker door patiënten als matig tot ernstig wordt ervaren; en welke determinanten samenhangen met pijn bij kanker. In totaal werden 122 artikelen geselecteerd en ingedeeld op basis van het stadium van de ziekte: patiënten na curatieve behandeling (groep 1); patiënten tijdens anti-tumor behandeling (groep 2 ); patiënten met vergevorderde ziekte (groep 3); en alle patiënten onafhankelijk van het stadium van de ziekte (groep 4).

Pijn komt voor bij 39.5\% van de patiënten in groep 1; bij 55.0\% van de patiënten in groep 2 ; bij $66.4 \%$ van de patiënten in groep 3 ; bij $50.7 \%$ van de patiënten in groep 4. Patiënten in groep 3 hebben significant meer pijn dan patiënten in groep 1 en 2; patiënten in groep 2 hebben significant meer pijn dan patiënten in groep 1 . Pijn wordt als matig tot ernstig ervaren bij $27.6 \%$ van de patiënten in groep 1 ; bij $32.4 \%$ van de patiënten in groep 2; bij 51.9\% van de patiënten in groep 3; bij $33.1 \%$ van patiënten in groep 4 . Patiënten in groep 3 hebben significant meer matige tot ernstige pijn dan patiënten in groep 1 en 2 . 
Studies uit Azië laten hogere pijn prevalenties zien dan studies uit Europa. Patiënten met prostaatkanker hebben minder pijn dan patiënten met hoofd-hals-, long- of borstkanker. Patiënten met een beperkte functionele status hebben meer pijn dan patiënten met een normale functionele status. Bij een periode van een maand of een jaar wordt minder pijn gerapporteerd dan bij een week of een bepaald moment. Leeftijd, etniciteit en methode van data verzameling zijn niet geassocieerd met pijn prevalentie. Pijn bij kanker blijft een groot probleem.

\section{Hoofdstuk 3}

In dit hoofdstuk wordt de totstandkoming van de interventie besproken. De afstemming op wensen en behoeften van patiënten en zorgverleners is essentieel voor een succesvolle eHealth interventie. Interventie ontwikkeling werd daarom uitgevoerd volgens belangrijke principes van user centred design (UCD) en staat beschreven in dit hoofdstuk. Een multidisciplinair team werd samengesteld; een cocreatief en iteratief proces werd in gang gezet; onderzoekers en technici werkten samen om conceptuele ideeën te concretiseren; patiënten en zorgprofessionals werden geconsulteerd om input te geven en output te evalueren; prototypes werden gebruikt om oplossingen te visualiseren; en functionele en technische eisen werden geformuleerd, gespecificeerd en geprioriteerd.

De uitkomst van dit proces is een eHealth interventie bestaande uit een huisbezoek, een mobiele applicatie voor patiënten, een web applicatie voor verpleegkundigen en verschillende follow-up activiteiten. Bij het huisbezoek neemt de verpleegkundige een pijnanamnese af, checkt pijnmedicatie en verstrekt informatie over pijn. De onderzoeker geeft instructies over het gebruik van de applicatie en bespreekt verwachtingen. Tijdens de interventieperiode maken patiënten dagelijks gebruik van de applicatie. Pijn wordt 's ochtends en 's avonds geregistreerd in een dagboek; medicatie wordt bij inname afgevinkt in een gepersonaliseerd medicatie schema; een grafiek met pijncijfers en medicatie innames geeft inzicht; informatie over pijn wordt verstrekt in kennissessies; bij vragen of opmerkingen vindt contact met de verpleegkundige plaats via berichten.

Verpleegkundige bekijken de applicatie iedere werkdag en nemen hierbij kennis van ingevulde dagboeken, medicatie innames en tekstberichten. De verpleegkundige informeert de behandelend arts, indien nodig en met regelmaat. Voor advies kan de verpleegkundige een beroep doen op een pijnspecialist of multidisciplinair palliatief team. Dit advies wordt teruggekoppeld aan de behandelend arts die besluit over follow-up. 


\section{Hoofdstuk 4}

Het evalueren van de bruikbaarheid in de dagelijkse praktijk staat centraal in dit hoofdstuk. In deze kleinschalige studie hebben dertien patiënten en drie verpleegkundigen gebruik gemaakt van de eHealth interventie met een follow-up van 4 weken. Vragenlijsten laten zien dat patiënten de applicatie snel onder de knie hebben, taken met gemak uitvoeren en het prettig vinden om met de applicatie te werken. Het gemiddelde gebruik, zoals vastgelegd in de logbestanden, was $76.8 \%$ voor pijnmonitoring, $50.4 \%$ voor medicatiemonitoring en $100 \%$ voor de educatieve sessies. Belangrijk in termen van bruikbaarheid was het gegeven dat patiënten bleven monitoren ongeacht hoge of lage pijnscores. De interviews geven aan dat de mobiele applicatie duidelijk is, eenvoudig werkt en weinig energie vraagt. Patiënten zijn tevreden met en maken gebruik van verschillende componenten. Waar de een aangeeft dat het dagboek telkens zorgt voor een stukje bewustwording; vindt de ander de reminders prettig om medicatie zo niet te vergeten; en is een derde erg te spreken over de verpleegkundige die altijd over de schouder meekijkt. Verpleegkundigen waren overwegend positief over de web applicatie, maar moesten wel wennen aan deze nieuwe manier van werken. $\mathrm{Zij}$ moeten vertrouwen op eHealth in plaats van het face to face contact, op patiënten die hen voorzien van informatie, en op behandelend artsen die adviezen in overweging nemen. Over het algemeen bevestigt deze studie de haalbaarheid van de interventie in de dagelijkse praktijk. Mits een aantal technische en inhoudelijke verbeteringen worden doorgevoerd, kan deze interventie mogelijk bijdragen aan (de ondersteuning) van zelfmanagement van pijn bij kanker.

\section{Hoofdstuk 5}

Dit hoofdstuk beschrijft het protocol van de grootschalige gerandomiseerde en gecontroleerde studie, waarbij zelfmanagement ondersteuning met behulp van de eHealth interventie wordt vergeleken met reguliere zorg. De studie bevat een effect, kosten en procesevaluatie en ziet er bij aanvang als volgt uit:

Werving van de benodigde 174 patiënten vindt plaats via de poliklinieken en verpleegafdelingen van een academisch en een streekziekenhuis. Patiënten komen in aanmerking voor deelname aan de studie bij de diagnose kanker (alle stadia van de ziekte), matige tot ernstige pijn (NRS $\geq 4$ voor $>2$ weken) en een levensverwachting van $>3$ maanden. Op basis van het toeval vindt toewijzing (1:1) plaats aan de interventie- of controlegroep. Patiënten in de interventiegroep maken gebruik van zelfmanagement ondersteuning middels de eHealth interventie; patiënten in de controlegroep krijgen reguliere zorg. De interventie wordt begeleid door geregistreerde verpleegkundigen met kennis en expertise op het gebied van pijn en palliatieve zorg. Metingen voor de effectevaluatie vinden plaats in beide groepen met 
vragenlijsten op baseline (T0), na 4 weken (T1) en na 12 weken (T2). Pijn en kwaliteit van leven zijn de primaire uitkomsten. Secundaire uitkomsten zijn kennis, selfefficacy, angst en depressie, en pijnmedicatie gebruik. De laatste vragenlijst bevat eveneens vragen voor de kostenevaluatie. Data voor de procesevaluatie worden tijdens de gehele studie in beide groepen verzameld aan de hand van logboeken, logbestanden en checklists. Na afloop van de interventie vinden semigestructureerde interviews plaats met patiënten in de interventiegroep en aan het einde van de studie een focusgroep interview met verpleegkundige.

\section{Hoofdstuk 6}

Dit hoofdstuk gaat in op de resultaten van de grootschalige gerandomiseerde en gecontroleerde studie en geeft met name inzicht in het verloop en de procesuitkomsten. Uiteindelijk kunnen verschillende fases worden onderscheiden.

De studie begon in twee centra (fase 1a) en werd daarna uitgebreid naar vier centra (fase 1b) met at random toewijzing aan de interventiegroep of de controlegroep. Aangezien de interventie deel uitmaakt van de behandelingsovereenkomst, werden behandelend artsen in eerste instantie benaderd voor de werving. In de praktijk werd dit vaak overgedragen aan verpleegkundigen. Informatiemappen en jaszakkaartjes werden aangereikt; screeningslijsten en een trial bureau werden ingezet; presentaties en updates werden verspreid. Ondanks alle inspanningen, bleef de inclusie van patiënten moeizaam. Als belangrijkste reden voor artsen om niet te werven wordt genoemd 'voldoet niet aan de criteria' en voor patiënten om niet mee te doen 'voelt zich te ziek'. Andere factoren die mogelijk een rol hebben gespeeld zijn de wervingsstrategie, het onderzoeksdesign, het type interventie en de groep patiënten.

Door een lage instroom van patiënten, mogelijke selectie bias door zorgprofessionals en een hoge uitval van patiënten, werd de studie voortgezet met toewijzing aan enkel de interventiegroep (fase 2). In totaal gaven 66 patiënten toestemming voor deelname en zijn 54 patiënten daadwerkelijk gestart. Patiënten waren gemiddeld 62.4 jaar, $59.3 \%$ was man en $83.3 \%$ kreeg in opzet palliatieve antitumor therapie. Uiteindelijk hebben 47 patiënten de tussentijdse meting ingevuld en 32 patiënten hebben de volledige studieperiode doorlopen. Door de laatste wijziging in het protocol verschoof de focus van de studie van de vergelijking tussen de eHealth interventie en reguliere zorg naar met name de impact van de eHealth interventie. Hierdoor zijn proces uitkomsten belangrijker geworden en hebben meer aandacht gekregen. Aan de hand van semigestructureerde interviews met 21 patiënten en een focusgroep met 4 verpleegkundigen zijn ervaringen in kaart gebracht. Bij de invulling van het huisbezoek en ook bij de keuze voor follow-up activiteiten werd enige variatie gezien, mede veroorzaakt door de situatie van patiënten en de manier van werken van verpleegkundigen. Patiënten vonden de introductie prettig en verpleegkundigen waren 
positief over de pragmatische aanpak. De applicatie bleken een enkele keer traag of niet toegankelijk door technische issues. Over het algemeen waren patiënten tevreden, wat ook zichtbaar is in het gebruik van pijnmonitoring (78.8), medicatiemonitoring $(65.5 \%)$ en educatieve sessies (100\%). Patiënten zijn wisselend in hun reacties als het gaat om de mate waarin de interventie bijdraagt aan zelfmanagement, maar bevestigen in veel gevallen wel dat de interventie heeft geholpen bij een stukje bewustwording, het op tijd innemen van medicatie, het verkrijgen van inzicht, het leren over pijn en de behandeling van pijn of het bespreken van pijn met de behandelend arts. Verpleegkundigen onderstrepen dat deze of een soortgelijke interventie een goede aanvulling zou op de reguliere zorg voor patiënten met pijn bij kanker in de thuissituatie. Ondanks deze positieve bevindingen kunnen door de relatief kleine groep patiënten en de aanpassingen in het protocol geen conclusies worden getrokken over de effectiviteit van de interventie op basis van effect uitkomsten.

\section{Hoofdstuk 7}

Tot slot worden in de algemene discussie de belangrijkste bevindingen van dit proefschrift samengevat en komen enkele methodologische overwegingen aan bod over het meten en beoordelen van pijn bij kanker; de focus op patiënten en hun wensen en behoeften; en het evalueren van eHealth interventies. Daarnaast worden ook een aantal theoretische overwegingen besproken die betrekking hebben op de definitie van zelfmanagement; interventie componenten voor zelfmanagement ondersteuning; en het operationaliseren van zelfmanagement. Het hoofdstuk wordt afgesloten met aanbevelingen onderzoek, praktijk en beleid. 



\section{Valorisation}

Research becomes valuable once being communicated not only to the scientific community, but also to the general public. The results of this thesis have led to new insights about cancer pain management; the application of self-management support and eHealth in the outpatient setting; and methodologies for intervention development and evaluation. Eventually, it is not so much the effectiveness of the intervention that is important in the context of valorisation, but much more the process both before and during the randomised controlled trial. This chapter will focus on valorisation of new insights and possible valorisation activities.

\section{Innovation}

Intervention content was derived from self-management supporting components that were considered important for patients in general and that were selected specifically for outpatients with cancer pain. In a co-creative and iterative development process, researchers and technicians collaborated in the translation of conceptual ideas. Different health professionals and patients were consulted to gain input and evaluate output. Involvement of all these perspectives was considered important in order to make sure the intervention would be an optimal solution to an actual problem.

The present intervention provides patients with education to improve knowledge and understanding. Important skills for patients to implement, such as pain and medication monitoring, making appropriate decisions, and carrying out subsequent actions, are continuously encouraged by means of pain diaries, medication overviews, and graphical feedback. Being looked after by nurses needs to enable patients to practice their skills and to become more self-efficacious. Collaboration of nurses with the treating physician should further contribute to this supportive environment.

What makes the present intervention different from previously applied interventions for outpatient cancer pain management is the intervention being the result of a co-creative and iterative process in which health professionals and patients were involved as much as possible; having a multi-component nature that enables patients to select the support that is needed at a given point in time and in a given situation; making use of eHealth by which the availability of accurate and timely data facilitates communication and advance follow-up; and being integrated in clinical practice by means of including the nurse, treating physician, general practitioner, and pharmacist and arranging follow-up activities. 


\section{Relevance}

Results of this thesis can be of relevance to patients, health professionals, companies, health insurance companies, and researchers.

\section{Patients}

Oncology patients are no different from patients with other chronic conditions in their search to better manage and control their situation. In this respect, self-management of patients and self-management support of health professionals seem obvious in oncology practice too. Patients that were involved in the evaluations often received antitumor therapy with palliative intent and reported moderate to severe pain intensity scores. The intervention though might be valuable for more patients. Both patients and nurses acknowledged that the timing of the intervention needs reconsideration, as self-management support already in an earlier phase would have better prepared patients for what to expect and maybe even how to prevent. Moreover it is conceivable to implement the intervention for other symptoms in oncological patients or for pain in non-oncological patients.

\section{Health professionals}

Health professionals (oncologists, urologists, gynaecologists, pulmonologists, radiotherapists, general practitioners, consultants palliative care) experience difficulties with monitoring and follow-up of cancer pain once patients are at home. The intervention offers real time data that offer better insight into the situation of patients at home, the extent to which they comply with treatment recommendations, and the effect of treatment on pain and side effects. At the same time, collaboration and coordination among involved health professionals is facilitated. All data monitored by patients as well as medication changed by health professionals is visible to health professionals who have login information. Registered nurses specialised in pain and palliative care, who can consult the pain specialist or multidisciplinary palliative team, inform and advice the treating physician. By doing so, a knowledge transfer or learning effect regarding cancer pain management in treating physicians is aimed for as well. Different health professionals might be able to fulfil the role of the registered nurse in other settings, for instance a pharmacist or practice nurse. Extra education in pain and palliative care would then be a prerequisite.

\section{Companies}

For companies with an interest in eHealth and self-management support, the development process of the intervention can be of relevance. Steps that were taken, methodologies that were applied, the collaboration of researchers and technicians, and the involvement of health professionals and patients could inspire the development of 
similar interventions. As for the content, the translation of conceptual ideas into two applications that are embedded in daily clinical practice could be regarded as an example. Important with respect to this is the simplicity of such interventions; less is more. Patients clearly expressed that there was no need for bells and whistles. Pain is a serious matter and the intervention needs to be functional. Moreover, companies need to take care of clear instructions at the start and a helpdesk during implementation of the intervention. For pharmaceutical companies, the intervention offers opportunities in order to contribute to a better quality of care and quality of life of oncology patients from a social point of view.

\section{Health insurance companies}

Self-management and eHealth fit perfectly with challenges that are faced in terms of shifting tasks and roles to arrange an efficient organisation of care as well as social trends including participation and digitalisation. For health insurance companies this intervention is an example of introducing self-management and eHealth to improve quality of care and quality of life for a potentially large group of outpatients with considerable symptom burden. Although no conclusions can be drawn regarding clinical effectiveness, the eHealth intervention was well received and impacted outcomes. Implementing eHealth calls for a change of mindset. eHealth needs no longer to be seen as something extra or again another project, yet should be part of regular care for which a different organisation of care is necessary. Scaling-up eHealth requires integration of technologies and structural finance. In implementing and scaling-up eHealth health insurance companies play an important part by initiating subsequent steps and taking the actual measures, both at a national and regional level.

\section{Researchers}

Based on new insights about cancer pain management, the application of selfmanagement support and eHealth in the outpatient setting, and methodologies for intervention development and evaluation, this thesis provided answers to certain research questions, left others open, and resulted in new ones as well. More research is needed as regards the conceptual framework for self-management support in outpatients with cancer pain, the optimisation of the intervention with concern to specific components and opportunities to further tailor the intervention, evaluation of the approach in terms of effects and costs, and successful implementation strategies. 


\section{Activities}

The most obvious valorisation activity is to present research results to the research and professional community. Studies have been published in international and national peer reviewed journals. Moreover, results have been disseminated via posters, presentations, and workshops at international and national conferences on various topics (pain, oncology, eHealth, nursing). Based on this output, the project attracted the attention of different researchers and health professionals abroad working on the same topic. Following an exchange of experiences regarding eHealth interventions for symptom management in oncology, the intention has been expressed to explore future collaboration on this topic from an international perspective. The first steps for a joint proposal are being prepared.

Technological developments and advances progress quickly, while implementation in clinical practice and education stays behind. To prevent future health professionals to be educated with 'yesterday's knowledge' for 'tomorrow's healthcare', selfmanagement and eHealth are important to be included in training for various health professionals. To create and contribute to a good understanding and positive attitude, insights from this thesis are made available through lectures and tutorials by the centre of Expertise for Innovative Care and Technology (EIZT) of Zuyd University of Applied Sciences. In the context of follow-up or refresher training, results are presented during meetings of processional groups too.

In collaboration with IDEE and Sananet, the two companies that were involved in intervention development and evaluation, future steps - upon completion of the project - were discussed. Together with Sananet, project results have been presented in a meeting of OncoZON, an oncology network in the south-east of the Netherlands, to assess whether hospitals would be interested and under what conditions they would be willing to implement the intervention in their daily practices. Basic idea is to integrate the intervention in local care pathways and protocols as much as possible. Because the integration might look different in different hospitals, it would be interesting to share experiences in a community of practice and find out what works and what does not. By doing so optimal implementation strategies might be established for these types of interventions in these groups of patients. At the moment (June, 2017), follow-up meetings with separate hospitals are taking place. 


\section{Dankwoord}

\section{About the author \\ List of publications}





\section{Dankwoord}

Ik kan het bijna niet geloven, mijn proefschrift is af! Het was absoluut een bijzonder project en een leerzaam proces en ik zou het zonder twijfel weer doen. Vooral ook wetende dat ik kan rekenen op fijne collega's, geweldige vrienden en lieve familie. Zonder hopelijk iemand te vergeten, wil ik een aantal van jullie in het bijzonder bedanken.

Wat heb ik een fantastisch team en wat heb ik veel van en met jullie geleerd. Aan motivatie en inspiratie geen gebrek. Ik kreeg de kans om van dit project ook echt mijn eigen project te maken. Tijdens onze overleggen was de sfeer prettig en de communicatie open. Jullie hadden oor voor wat ik zei en vooral ook voor wat ik niet zei. Ik was meer dan mijn project en dat heb ik altijd ontzettend gewaardeerd. Jullie zijn heel verschillend en waren samen voor mij een perfect team.

Luc, ik bewonder je manier van begeleiden. Je kijkt en ziet wat nodig is, je zoekt de uitdaging altijd op en je hebt een verfrissende blik. Wat ik soms moeilijk maakte, maakte jij makkelijk met je parallellen over jurkjes, liefde en muziek. Je hebt zicht op de grote lijnen, maar ziet ook de punten en komma's. Dankjewel voor je kritische houding, je pragmatische aanpak en je enorme vertrouwen ("Gewoon doen!").

Annemie, jij opende deuren bij de poli's en op de afdelingen en bracht me in contact met de juiste mensen. Als alles goed ging, waren we samen blij ("Sjoen! Hoera! Sjiek!"). Als ik het even niet meer wist, dacht je mee. Als ik te veel of te snel wilde, gaf je advies. Alles onder het motto "Wij lijken wel een beetje op elkaar!" Jij was mijn PhD mama. Dankjewel voor je zorgzaamheid en je positiviteit.

Sandra, bij jou kon ik te pas en te onpas binnenlopen en dat heb ik dan ook met regelmaat gedaan. Het was fijn om even te sparren en snel te schakelen. Ik liep altijd weer vol goede moed naar buiten. Daardoor ging het schrijven me ook steeds makkelijker af: meer structuur, minder gedoe. Ook aan het einde van mijn PhD, hield jij me bij de les. Dankjewel voor je betrokkenheid, je rust en ook je gezelligheid.

Marieke, je bent van begin tot eind in steeds een ietwat andere rol nauw betrokken geweest. Je kent de praktijk als geen ander en weet precies wat er regionaal en landelijk speelt. Je kon daardoor altijd goed inschatten of ons plan kans van slagen had. Je houdt de vaart erin en bent recht door zee. Dat was precies wat ik af en toe even nodig had. Dankjewel voor je snelle feedback en motiverende woorden! 
Maarten, jij was vanaf een afstandje betrokken en bekeek het project met een doktersbril. Je probeerde linken te leggen met lopende initiatieven, je bracht de interventie onder de aandacht bij je collega's en je dacht mee over de opzet van het onderzoek. "Kan ik nog iets voor je doen?" was vaak de inhoud van je mailtjes. Dankjewel voor je interesse en hulp daar waar nodig.

De leden van de beoordelingscommissie (Prof. Trudy van der Weijden, Prof. Liesbeth Boersma, Dr. Wendy Oldenmenger, Prof. Dirk Ruwaard), dank voor het beoordelen van mijn proefschrift. Prof. Mawson, thank you for the assessment of my thesis. Dr. Rik Crutzen, Prof. Anne-Marie Dingemans, Dr. Asiong Jie en Prof. Onno van Schayck fijn dat jullie deel willen uitmaken van de promotiecommissie.

Zonder de bereidheid van patiënten en de inzet van zorgverleners, was dit alles nooit gelukt. Mijn dank is groot! En dat geldt voor de verpleegkundigen in het bijzonder. Paul, Eliane, Marij en Paul, samen met jullie op huisbezoek gaan was een van de leukste activiteiten. Wat een lol hebben we gehad! Jullie werk is heel bijzonder en ik heb 't steeds met veel aandacht en vol bewondering mogen aanschouwen.

Binnen de deelnemende ziekenhuizen (MUMC+, Zuyderland MC Heerlen en Sittard, MAASTRO clinic) mocht ik voor de werving van patiënten rekenen op velen. Marcus, Gerda, Asiong, Roel, John en Claudia, dankjewel! Ook mijn andere co-auteurs wil ik bedanken. Zowel het artikel over de review als het artikel over de interventie waren een hele klus, maar met resultaat, mede dankzij jullie.

We hebben steeds nauw samengewerkt met IDEE en Sananet. Freek, Ralf en Tim, jullie hebben me wegwijs gemaakt in de wereld van persona's en scenario's, prototypes en testen, en scrum en agile. Jan, Arjan en Aniek, jullie kennis en ervaring met vergelijkbare applicaties was ontzettend waardevol. Natuurlijk hoop ik dat het niet stopt na dit project. Dankjewel voor een fijne samenwerking!

In dit project waren papier en praktijk nooit hetzelfde. Dat heeft tot de nodige aanpassingen in het plan van aanpak geleid. Ik wil KWF Kankerbestrijding en de MECT-Z bedanken voor hun open en constructieve houding om zo het oorspronkelijke plan op bepaalde punten los te kunnen laten en verder te kunnen gaan met het meest optimale alternatief.

Christel, dankzij de HSRM begon ik dit project voorzien van de nodige bagage. Dankjewel voor alle tips en tissues! Marla, Christoph en Maike, met jullie was ik PhD representative bij CAPHRI. Interessant om een kijkje achter de schermen te krijgen in gesprek met Onno en Trudy; leuk om steeds samen met Hannerieke een nieuwe 
invulling te bedenken voor de PhD meetings; en fijn om elke maand samen met Tanja de PhD InfoMail met alle in's en out's te versturen. Dankjewel!

Ik ben nooit met tegenzin naar m'n werk gegaan en dat is mede dankzij de fijne collega's op HSR. Dankjewel voor alle collegialiteit op DUB30! De koffiepauzes en de lunchwandelingen met andere PhDs, vaak net iets te lang en iets te gezellig, waren een welkome afwisseling. Brigitte, Suus en Arnold, dank voor jullie administratieve en ICT ondersteuning. Marianne, dank voor het invoeren van de vragenlijsten. Fons, dank voor je hulp bij de STATA analyses. Tiny, dank voor de opmaak van het proefschrift.

Maike en Susan, met mijn kamergenootjes was het altijd "feest!". Op kamer 0.043 gebeurde een heleboel. We hebben hard gewerkt, elkaar met raad en daad bijgestaan en flink gelachen. Lief en leed werd gedeeld, mooie uitspraken kwamen op de deur en ieder klein en groot succes werd gevierd. We hadden onze uitjes in Maastricht, Breda en Koblenz. En nu is ook het einde van jullie PhD's in zicht. Tijd voor nieuw avontuur. Maike, fantastisch dat jij mijn paranimf bent!

Bart en Sanne, met jullie erbij waren de vrimibo's en etentjes compleet. Bart, of het nou een biertje is na een drukke werkweek, een fietstochtje door de Limburgse heuvels of $80 \mathrm{~km}$ wandelen, jij bent altijd overal voor in. Sanne, jij bent zo oprecht en opgewekt. Je enthousiasme werkt aanstekelijk. Met jou kon ik uren kletsen over alles wat belangrijk en onbelangrijk was. Ik ben blij dat jij mijn paranimf bent!

Joan, Sanne, Renée, Martine, Ilse en Sarah, wat was het fijn om vergelijkbaar onderzoek te doen, ervaringen te delen en om advies te kunnen vragen. Dat gebeurde tijdens werkdagen op kantoor, maar ook tijdens tripjes naar Lissabon (als technology ladies) en Porto (als Dutch lady researchers). Good times, good memories!

Mijn proefschrift was nog niet af, maar mijn volgende werkplek diende zich alweer aan. Marieke, dankjewel voor je vertrouwen en de ruimte die je me geeft! Alle EIZT en ZAP collega's, ik heb me vanaf het allereerste moment ontzettend op m'n plek gevoeld, dank daarvoor! Loek en Sandra, heel fijn om tijdens onze laatste PhD uurtjes samen op te trekken.

Niks zo fijn als je werk af en toe even je werk te laten en af te schakelen met lieve vriendinnen! Nina, Bjel, Olga, Veerle, Fleur, Rieky, Corine, Frederique, Veerle en Catelijne, dankjewel! Een avondje uit, een dagje op stap, een weekendje weg, met en zonder de mannen. Op en top quality time! Wat heeft dat alles mij veel energie gegeven. Ik ben blij met jullie! 
Dank aan mijn lieve familie en schoonfamilie. Nu ben ik echt klaar met "school" en ga ik aan het "werk". Pierre en Marie-José, Anique en Dennis, het is hartstikke fijn om al heel wat jaren onderdeel te zijn van jullie gezin. Het maakt niet uit wanneer of waarvoor, jullie staan altijd voor ons klaar. Dankjewel voor veel mooie momenten. Daan, Gijs en Juul, jullie zijn zo leuk!

Frank en Sanne, jullie bleven onverminderd geïnteresseerd vragen naar mijn proefschrift. Broertje, jij bent altijd druk met van alles en nog wat. Een projectje hier, een projectje daar. Stilzitten is niet echt aan ons besteed (en ik denk te weten waar dat vandaan komt). Sanne, je bent hartstikke lief, creatief en altijd attent. Frank boft met jou. En wij met jullie!

Papa en mama, zoveel liefde en zoveel dankbaarheid. Door jullie ben ik geworden wie ik ben. Niks was jullie ooit te veel. Jullie gaven me de juiste dingen mee, altijd met respect voor alles en iedereen. Jullie lieten me $\mathrm{m}^{\prime} \mathrm{n}$ eigen keuzes maken en hielden me met beide benen op de grond. Ik ben al heel wat jaartjes uitgevlogen, maar het voelt nog steeds als thuiskomen. Jullie zijn ontzettend trots, en stiekem ook heel blij dat het nu klaar is. En ik moet toegeven, ik ook. Ik hou van jullie!

Mijn allerliefste, je kent me door en door en geeft me de ruimte om mezelf te zijn. Jij haalt m'n onzekerheden weg en moedigt me aan om m'n kansen te grijpen. Je zet alles in perspectief en haalt de scherpe randjes ervan af. Je zegt me vaak dat goed ook goed genoeg is en laat me minder denken en meer doen. Samen genieten, beleven, lachen, huilen, dansen, kletsen en ons verwonderen. Met jou is alles mooier en door jou ben ik gelukkig. De rest bewaar ik voor onze grote dag. Love you! 


\section{About the author}

Laura Hochstenbach was born on June 7, 1987 in Venray, the Netherlands. In 2005, she completed the Gymnasium at Trevianium Scholengroep in Sittard and started her bachelor Health Sciences at Maastricht University. During the curriculum with a major in Health Care Studies and a minor in Mental Health, Laura was enrolled in the Honours programme. In 2008, she obtained her bachelor certificate by completing her bachelor thesis about malnutrition in hospitalised elderly. Laura successfully applied for the Health Sciences Research Master, with a specialisation in Social Sciences. In 2010, she finished her master thesis about shared decision making in gynaecological oncology for which she was awarded with the Catharina Pijls incentive prize.

After completing her studies Laura started working as a junior advisor at the Comprehensive Cancer Centre the Netherlands (IKNL). Within regional and national working groups, she participated in various projects on rehabilitation, survivorship and palliative care. In 2011, Laura started as a PhD student at the department of Health Services Research at Maastricht University. Her project focused on self-management support for outpatients with cancer pain and concerned the development and evaluation of an eHealth intervention. During her PhD, Laura was involved in educational activities and presented her research at various national and international conferences. She also acted as a CAPHRI PhD representative, being a contact for other PhDs, spreading relevant information, and organising meetings. In 2016, Laura started working as a researcher on eHealth related projects at the Centre of Expertise for Innovative Care and Technology (EIZT), Zuyd University of Applied Sciences. 



\section{List of publications}

\section{International journals}

Vermeulen J, Verwey R, Hochstenbach LM, van der Weegen S, Man YP, de Witte LP (2014) Experiences of multidisciplinary development team members during usercentred design of telecare product and services: a qualitative study. J Med Internet Res 16:e124.

Hochstenbach LM, Courtens AM, Zwakhalen SM, van Kleef M, de Witte LP (2015) Selfmanagement support intervention to control cancer pain in the outpatient setting: a randomised controlled trial study protocol. BMC Cancer 15:e416.

Hochstenbach LM, Zwakhalen SM, Courtens AM, van Kleef M, de Witte LP (2016) Feasibility of a mobile and web-based intervention to support self-management in outpatients with cancer pain. Eur J Oncol Nurs 23:97e105.

Van den Beuken-van Everdingen MH, Hochstenbach LM, Joosten EA, Tjan-Heijnen VC, Janssen DJ (2016) Update on prevalence of pain in patients with cancer: systematic review and meta-analysis. J Pain Symptom Manage 51:1070-1090.

Hochstenbach LM, Courtens AM, Zwakhalen SM, Vermeulen J, van Kleef M, de Witte LP (2017) Cancer pain self-management support: development of a technology based and nurse led intervention. Appl Nurs Res 36:1-8.

\section{National journals}

Verwey R, Hochstenbach L, Vermeulen J, van der Weegen S (2013) Technologie ondersteunt patiënt bij zelfmanagement. TvZ 6:14-17.

Hochstenbach L, Huygens M, Swinkels I, Verwey R, van der Weegen S, Willard (2017) Geleerde lessen uit eHealth onderzoek. ICT \& health 1:11-13.

\section{International conference contributions}

Hochstenbach LM, Courtens AM, Zwakhalen SM, Vermeulen J, van Kleef M, de Witte LP (May 7-10, 2014) Cancer pain in the outpatient setting: development of a technology supported self-management intervention. 7th world conference of the World Institute on Pain (WIP), Maastricht, The Netherlands (poster presentation). 
Hochstenbach LM, Zwakhalen SM, Courtens AM, van Kleef M, de Witte LP (October 611 , 2014) Cancer pain self-management in the outpatient setting: evaluation of a technology supported intervention in everyday practice. 15th world congress on pain of the International Association for the Study of Pain (IASP), Buenos Aires, Argentina (poster presentation).

Hochstenbach LM, Courtens AM, Zwakhalen SM, Vermeulen J, van Kleef M, de Witte LP (February 22-27, 2015) Technology assisted self-management support to improve cancer pain control. 7th international conference on eHealth, Telemedicine, and Social Medicine (eTELEMED), Lisbon, Portugal (oral presentation, full paper).

Hochstenbach LM, Courtens AM, Zwakhalen SM, van Kleef M, de Witte LP (June 14-16, 2016) Evaluation of an eHealth self-management support intervention delivered to outpatients with cancer pain. Annual conference of the European Health Management Association (EHMA), Porto, Portugal (oral presentation).

Hochstenbach LM, de Witte LP (February 8, 2017) Self-management support of cancer pain in outpatients: development and evaluation of an eHealth intervention. Seminar on the future of pain management in palliative care, Leeds, United Kingdom (oral presentation).

Hochstenbach LM (March 3-5, 2017) Using e-tools in everyday oncology practice: symptom monitoring. Update for practising oncologists of the European Society of Medical Oncology (ESMO), Lisbon, Portugal (invited speaker).

\section{National conference contributions}

Verwey R, Hochstenbach L (November 13, 2013) Innovatie met behulp van technologie: ICT bij de ondersteuning van zelfmanagement. TVZ congres, Ede, the Netherlands (invited speaker).

Hochstenbach LM, Courtens AM, Zwakhalen SM, van Kleef M, de Witte LP (January 31, 2014) Zelfmanagement ondersteuning van pijn bij kanker: interventie ontwikkeling en evaluatie. Symposium junior onderzoekers proactieve palliatieve zorg, Nijmegen, The Netherlands (oral presentation).

Hochstenbach LM (April 11, 2014) Telemonitoring van pijn bij kanker: zelfmanagement ondersteuning. Symposium Expertisecentrum Palliatieve Zorg Maastricht (EPZM), Maastricht, The Netherlands (invited speaker). 
Hochstenbach LM (October 3, 2014) Telemonitoring van pijn bij kanker: eHealth toegepast in de praktijk. Verpleegkundig oncologie symposium MUMC+, Maastricht, The Netherlands (invited speaker).

Hochstenbach LM, Courtens AM, Zwakhalen SM, van Kleef M, de Witte LP (June 23, 2016) Evaluation of an eHealth self-management support intervention delivered by nurses to outpatients with cancer pain. Wetenschappelijk symposium Zuyderland, Heerlen, The Netherlands (oral presentation). 